\title{
DEVELOPMENT AND CHARACTERIZATION OF CAST MODIFIED AL- SI-CU-MG ALLOYS FOR HEAT RESISTANT POWER TRAIN \\ APPLICATIONS
}

By

Sugrib Kumar Shaha

BSc. Bangladesh University of Engineering and Technology, 2006

MSc. International Islamic University Malaysia, 2010

\author{
A dissertation \\ presented to Ryerson University \\ in partial fulfillment of the \\ requirements for the degree of \\ Doctor of Philosophy \\ in the Program of \\ Mechanical Engineering
}

Toronto, Ontario, Canada, 2015

CSugrib Kumar Shaha, 2015 


\section{AUTHOR'S DECLARATION FOR ELECTRONIC SUBMISSION OF A DISSERTATION}

I hereby declare that I am the sole author of this dissertation. This is a true copy of the dissertation, including any required final revisions, as accepted by my examiners.

I authorize Ryerson University to lend this dissertation to other institutions or individuals for the purpose of scholarly research.

I further authorize Ryerson University to reproduce this dissertation by photocopying or by other means, in total or in part, at the request of other institutions or individuals for the purpose of scholarly research.

I understand that my dissertation may be made electronically available to the public. 


\begin{abstract}
Development and Characterization of Cast Modified Al-Si-Cu-Mg Alloys for Heat Resistant Power Train Applications
\end{abstract}

Doctor of Philosophy, 2015

Sugrib Kumar Shaha

Mechanical Engineering

Ryerson University

High temperature tensile, compression and low cycle fatigue tests were performed to assess the influence of micro-additions of $\mathrm{Ti}, \mathrm{V}$ and $\mathrm{Zr}$ on the $\mathrm{Al}-7 \mathrm{Si}-1 \mathrm{Cu}-0.5 \mathrm{Mg}$ (wt.\%) alloy in the ascast and heat treated conditions. A combination of electron microscopy and high temperature Xray diffraction was used to identify phases and temperature ranges of their thermal stability. The microstructure of the as-cast $\mathrm{Al}-7 \mathrm{Si}-1 \mathrm{Cu}-0.5 \mathrm{Mg}$ (wt.\%) base and modified alloys consisted of $\alpha$ $\mathrm{Al}$, eutectic $\mathrm{Si}$, and $\mathrm{Cu}$-, $\mathrm{Mg}$ - and Fe-based phases $\mathrm{Al}_{2.1} \mathrm{Cu}, \mathrm{Al}_{8.5} \mathrm{Si}_{2.4} \mathrm{Cu}, \mathrm{Al}_{7.2} \mathrm{Si}_{8.3} \mathrm{Cu}_{2} \mathrm{Mg}_{6.9}$ and $\mathrm{Al}_{14} \mathrm{Si}_{7.1} \mathrm{FeMg}_{3.3 .}$. In addition, the micro-sized $\mathrm{Ti} / \mathrm{V} / \mathrm{Zr}$-rich phases $\mathrm{Al}_{6.8} \mathrm{Si}_{1.4} \mathrm{Ti}$, $\mathrm{Al}_{21.4} \mathrm{Si}_{4.1} \mathrm{Ti}_{3.5} \mathrm{VZr}_{3.9}, \mathrm{Al}_{6.7} \mathrm{Si}_{1.2} \mathrm{TiZr}_{1.8}, \mathrm{Al}_{2.8} \mathrm{Si}_{3.8} \mathrm{~V}_{1.6} \mathrm{Zr}_{\mathrm{r}}$ and $\mathrm{Al}_{5.1} \mathrm{Si}_{35.4} \mathrm{Ti}_{1.6} \mathrm{Zr}_{5.7} \mathrm{Fe}$ were identified in the modified alloys. During solution treatment, $\mathrm{Cu}$ - and $\mathrm{Mg}$ - based phases were completely dissolved, while the eutectic silicon, Fe- and Ti-V-Zr-rich intermetallics partially dissolved. The TEM analysis confirmed the presence of nano-sized precipitates of $(\mathrm{AlSi})_{3}(\mathrm{TiVZr})$ with $\mathrm{D}_{23}$ tetragonal crystal structure. The tensile tests of the alloy in the as-cast state showed that with 
increasing testing temperature from $25^{\circ} \mathrm{C}$ to $400^{\circ} \mathrm{C}$ the yield strength and tensile strength of the studied alloy decreased from $161 \mathrm{MPa}$ to $84 \mathrm{MPa}$ and from $261 \mathrm{MPa}$ to $102 \mathrm{MPa}$, respectively. Accordingly, the T6 heat treated alloy modified with additions of a higher content of Ti-V-Zr achieved the highest tensile strength of $343 \mathrm{MPa}$ over the base alloy and alloys modified with additions of Ti, Ti-Zr and lower contents of Ti-V-Zr. The fatigue life of the studied alloy in the T6 condition was substantially longer than those of the reference alloys A356 and the same Al$7 \mathrm{Si}-1 \mathrm{Cu}-0.5 \mathrm{Mg}$ base alloy with lower additions of $\mathrm{V}, \mathrm{Zr}$ and $\mathrm{Ti}$ in the $\mathrm{T} 6$ condition. The fractography revealed tensile crack propagation through the eutectic Si and primary phases, exhibiting intergranular fracture along with some cleavage-like features of the plate-shaped Ti$\mathrm{V}-\mathrm{Zr}$-rich intermetallics with a presence of fatigue striations on the latter, indicating their ductile nature. It is believed that the intermetallic precipitates containing $\mathrm{Zr}, \mathrm{Ti}$ and $\mathrm{V}$ improve the fatigue life of the studied alloy in the T6 condition. 


\section{ACKNOWLEDGEMENTS}

By the grace of Almighty God, I have been endowed the strength to complete this work. I wish to express my deepest gratitude to my research supervisors, Dr. Frank Czerwinski, Dr. Daolun Chen, Dr. Jacob Friedman and Dr. Wojciech Kasprzak, for their guidance, support, providing me with every opportunity and believing in me in all aspects of my education. I am grateful to them for their constant support, guidance and inspiration throughout this work. The completion of this project would not have been possible without Dr. Frank Czerwinski and Dr. Jacob Friedman continued guidance and time to time feedback; of which I have gotten interest to this work. Their valuable leadership, backing, quick reaction, devotion to hard work, is an extra source of encouragement to me. While being the inspiration light for my path to graduation, they have not only taught me aspects of materials science, but have supported me, oriented me and often engaged me discussions that have led to further insights. I will be forever obliged to my all four supervisors for promoting me carefully with useful research discussions, teaching me how to detect and solve the research problems, maintain the quality of research work and performed continuous efforts to reach the final objective.

I am also grateful to my committee members Dr. S.D. Bhole, and Dr. Marcello Papini for their treasurable time in evaluating and consequently raising several valuable issues to further improve the quality of the work. Their beneficial criticism has significantly helped me to expand the quality of the appearance of this thesis.

I would like to thank the ecoENERGY Innovation Initiative ecoEII of Natural Resources Canada at CanmetMATERIALS, the Natural Sciences and Engineering Research Council of Canada (NSERC), Premier's Research Excellence Award (PREA), NSERC-DAS Award, 
Ryerson Research Chair Program for providing financial support and Resource for the Innovation of Engineered Materials (RIEM) academic access program. I would also thank the advanced casting research group of CanmetMATERIALS for their help in casting and heat treatment of alloys, and preparation of tensile test bars.

Many thanks go out to the staff at Ryerson University's Department of Mechanical and Industrial Engineering and School of Graduate Studies. My special thanks to Mr. Joseph Amankrah, for help in compression specimen preparation, to Mr. Chao Ma and Mr. Alan Machin, for their help to handling the testing equipment, Mr. Qiang Li, always his help in SEM/EDX, EBSD and XRD analysis. Many people helped me on many aspects that are indispensable; in particular, the great assistance by R. Churaman has been vital in completing this work. I am humbled by their considerable help that they rendered to solve many problems with my equipment. Their experience, assistance and polite behavior were often a source of hope at any critical times. I also would like to express my gratitude to all of my group members for their kindness throughout this work. At last not least, I would like to thank to Dr. Babak Shalchi Amirkhiz for helping in Transmission Electron Microscopy analysis. 


\section{DEDICATION}

This work is dedicated to my beloved wife, Dyuti Sarker, who always encourages me to concentrate my work. And also, to my parents, Subodh K Shaha and Archona Shaha, my fatherand mother-in-law, Prem Chand Sarker and Ratna Sarker, and the rest of my family, for their believing in me, inspiring me, and encouraging me. Also, all of my teachers especially Prof. A.S.W. Kurny, who are always help me to reach this point. 


\section{TABLE OF CONTENTS}

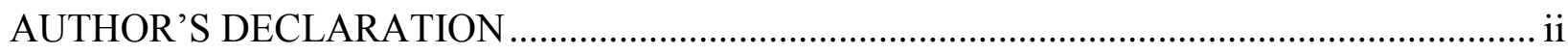

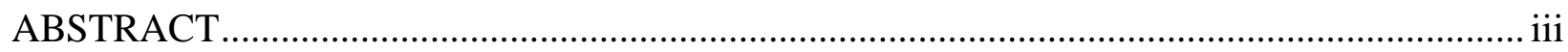

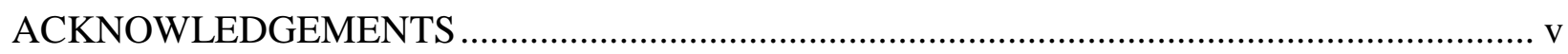

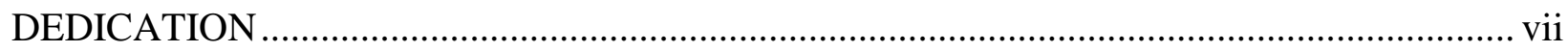

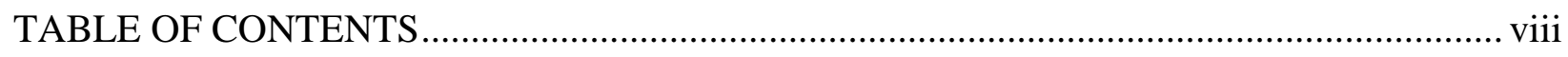

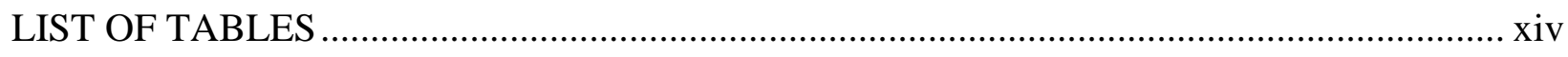

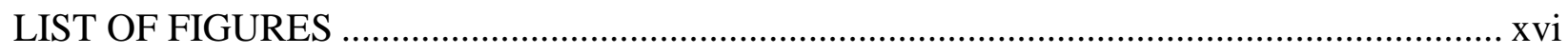

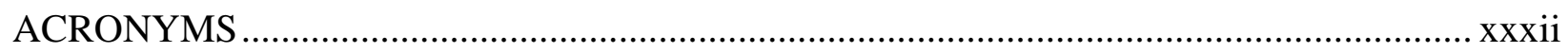

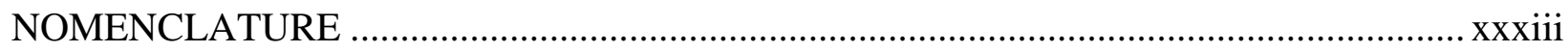

\section{CHAPTER 1}

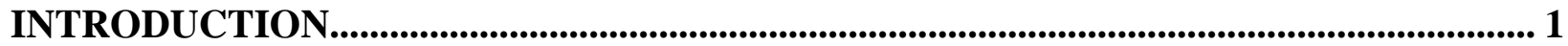

1.1 Background History and Motivation.................................................................... 1

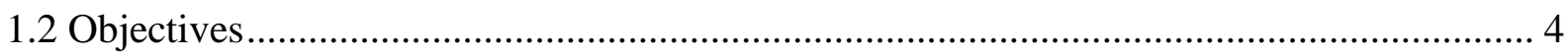

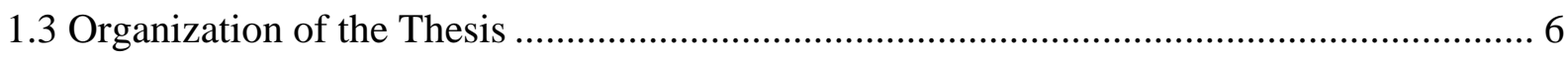

\section{CHAPTER 2}

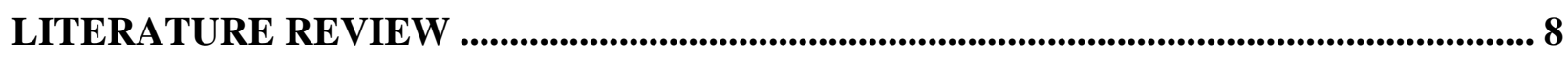

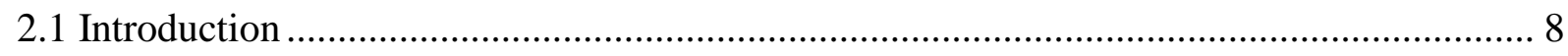

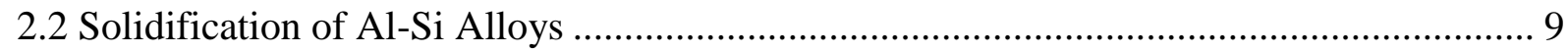

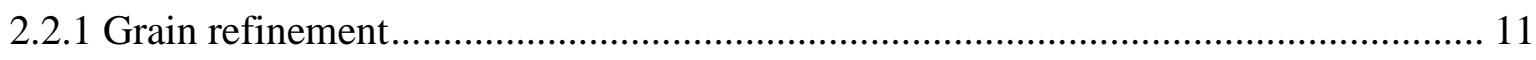

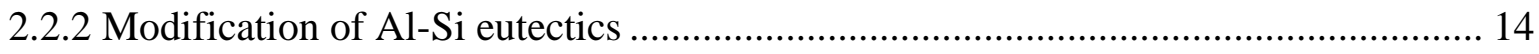

2.2.3 Formation of dispersoid phase .................................................................... 16

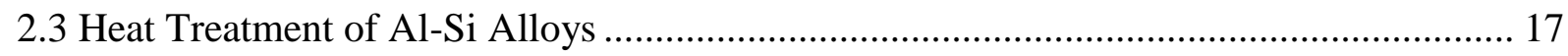




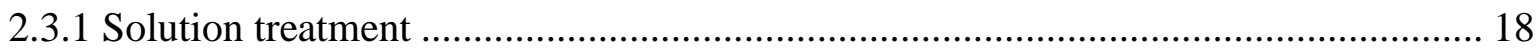

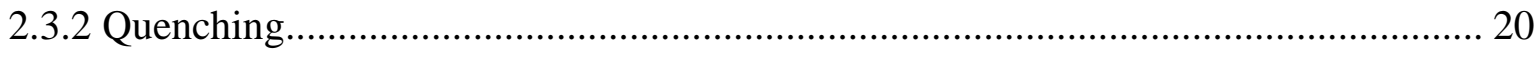

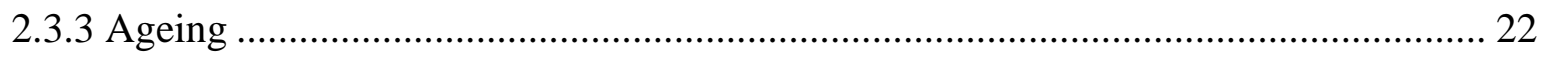

2.4 Strengthening Mechanism of Al Alloys............................................................. 27

2.4.1 Strengthening due to mechanical working ............................................... 27

2.4.2 Solid solution strengthening .................................................................... 28

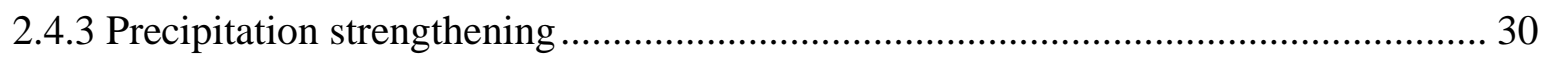

2.5 Recent Modification of Aluminum Alloys for High-Temperature Applications.............. 32

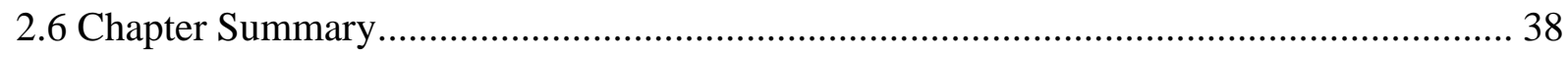

\section{CHAPTER 3}

MATERIALS AND EXPERIMENTAL PROCEDURE DETAILS ................................... 40

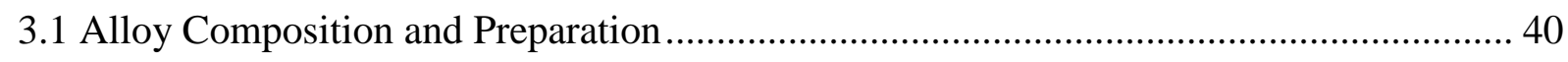

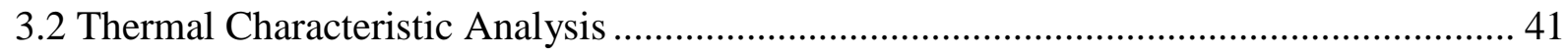

3.3 Heat Treatment of the Alloys ............................................................................. 43

3.4 Characterization of Microstructure ................................................................. 45

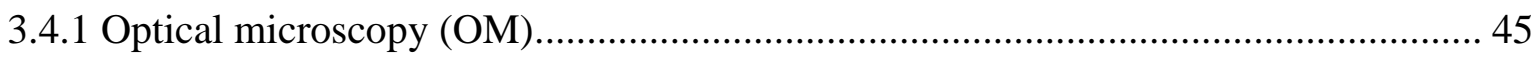

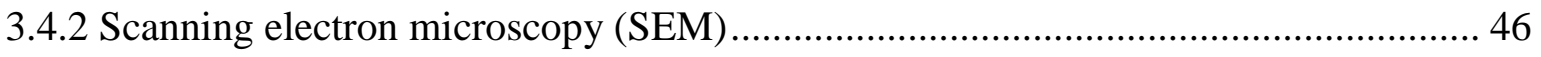

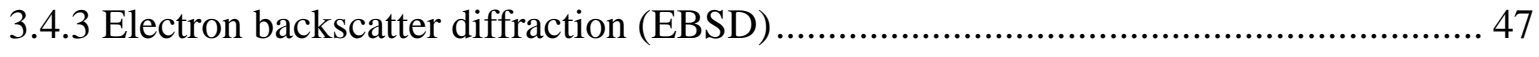

3.4.4 Transmission electron microscopy (TEM) .................................................. 47

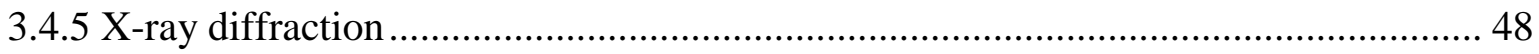

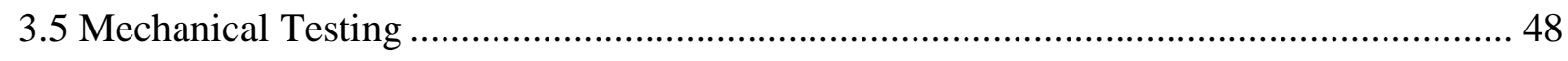

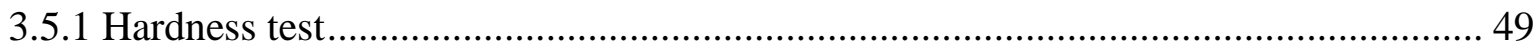

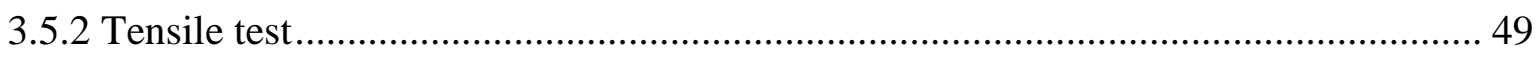

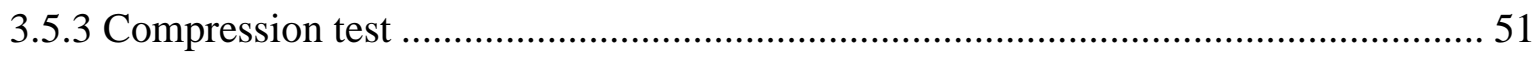




\section{CHAPTER 4}

\section{SOLIDIFICATION CHARACTERISTICS AND MICROSTRUCTURE OF THE}

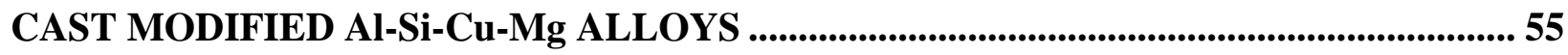

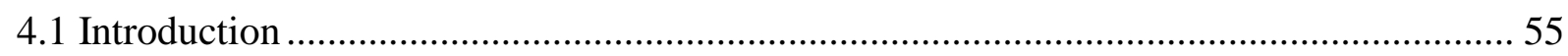

4.2 Solidification Characteristics of Alloys Containing Ti-V-Zr..................................... 57

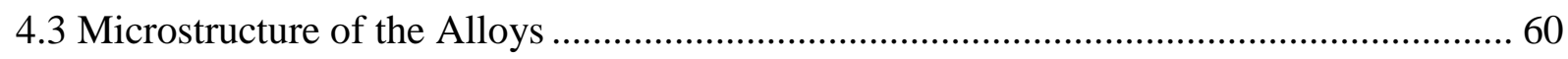

4.3.1 Effect of alloying elements on the microstructures ........................................ 60

4.3.2 Effect of solution treatment on the microstructure of alloy ............................... 67

4.3.3 Effect of cooling rate on the microstructure of alloy ....................................... 75

4.4 X-ray Diffraction Analysis of Alloy MA4 ....................................................... 78

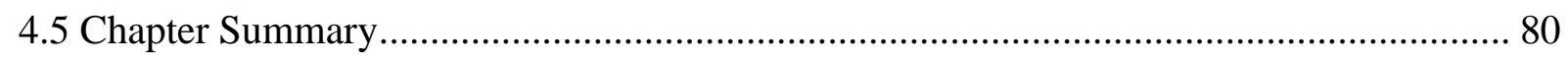

\section{CHAPTER 5}

\section{HEAT TREATMENT DEVELOPMENT FOR THE CAST MODIFIED Al-Si-Cu-}

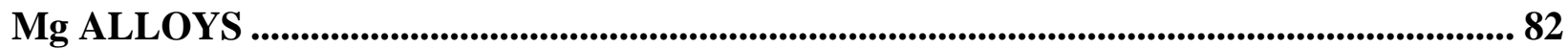

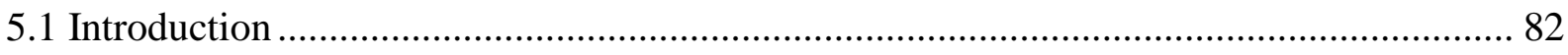

5.2 Alloy Characteristics in the As-Cast Condition ................................................. 83

5.3 Alloy Characteristics in the Heat Treated Condition ............................................. 84

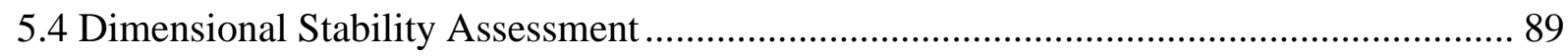

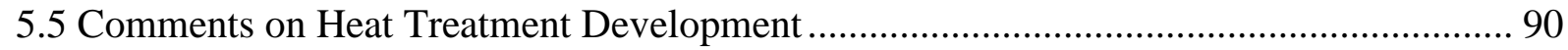

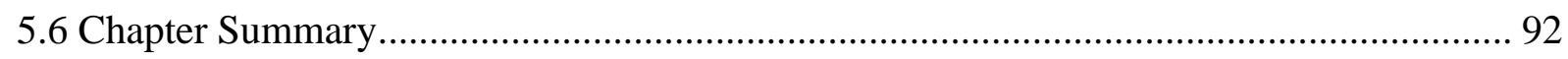




\section{CHAPTER 6}

\section{WORK HARDENING AND DISLOCATION SLIP DISTANCE DURING COMPRESSION DEFORMATION OF THE CAST MODIFIED Al-Si-Cu-Mg}

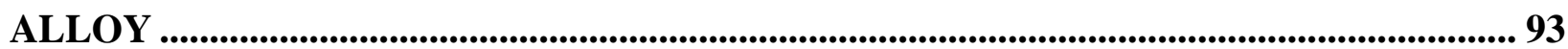

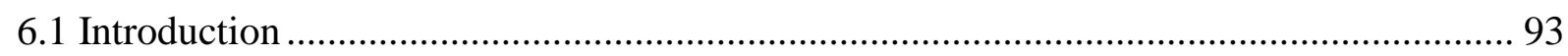

6.2 Alloy Microstructure after Compression Deformation .................................................. 95

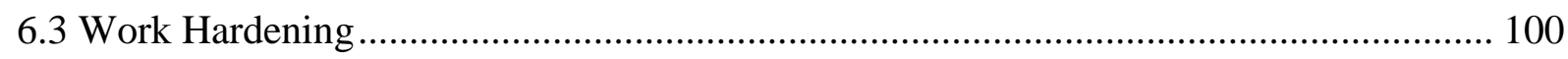

6.4 Effect of Precipitates on Flow Stress ……………….............................................. 102

6.5 Dislocation Slips Distance during Compression .............................................................. 109

6.5.1 Compression deformation at different temperature............................................... 109

6.5.2 Constitutive equation describing dislocation slips distance …................................ 113

6.5.3 Validation of the constitutive equation developed ................................................ 115

6.6 Chapter Summary ………………………………................................................ 120

\section{CHAPTER 7}

\section{COMPRESSIVE DEFORMATION BEHAVIOR OF THE CAST MODIFIED AI-}

Si-Cu-Mg ALLOYS ....................................................................................................................................... 121

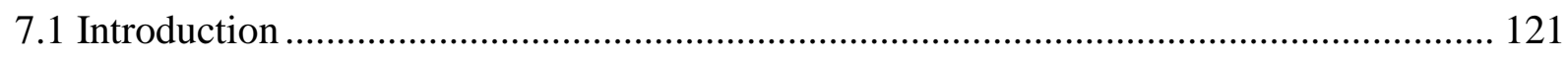

7.2 High Temperature Deformation Characteristics .......................................................... 122

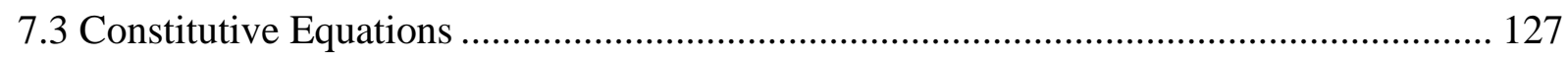

7.3.1 Activation energy of hot deformation ............................................................... 129

7.3.2 Zener-Hollomon parameter ............................................................................... 131

7.4 Microstructure Evolution during Deformation ......................................................... 132

7.4.1 Effect of temperature on precipitate cracking …………...................................... 134

7.4.2 Effect of temperature on precipitate rotation...................................................... 140 
7.5 Compression Characteristics and Activation Energy of Deformation

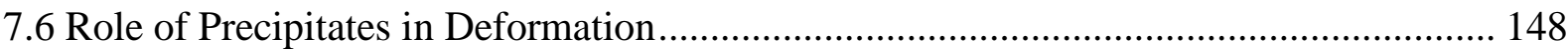

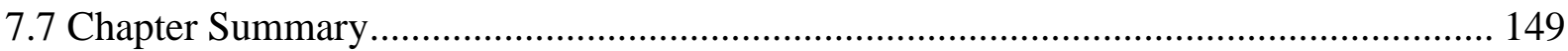

\section{CHAPTER 8}

\section{MONOTONIC AND CYCLIC DEFORMATION BEHAVIOR OF THE CAST}

MODIFIED Al-Si-Cu-Mg ALLOYS ................................................................................................. 151

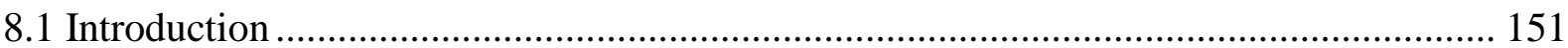

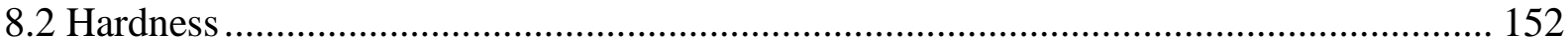

8.3 Tensile and Compressive Properties ........................................................................... 154

8.3.1 Influence of alloying elements on the tensile properties ...................................... 152

8.3.2 Influence of temperature on the alloy strength...................................................... 158

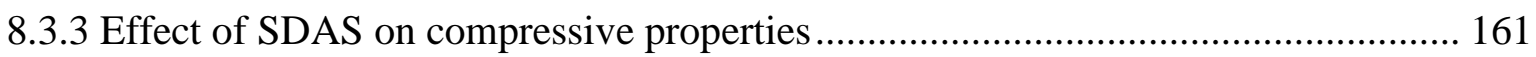

8.4 Low Cycle Fatigue Properties .................................................................................... 165

8.4.1 Influence of alloying elements on fatigue life ………........................................... 165

8.4.2 Influence of alloying elements on strain energy density ......................................... 172

8.4.3 Effect of SDAS on fatigue behavior of the alloy ..................................................... 177

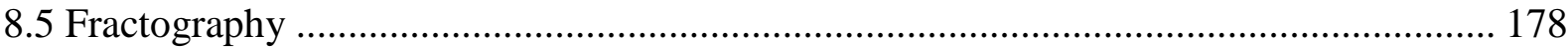

8.5.1 Fractography of the alloy during monotonic loading ........................................... 178

8.5.2 Fractography of the alloy during cyclic loading ...................................................... 181

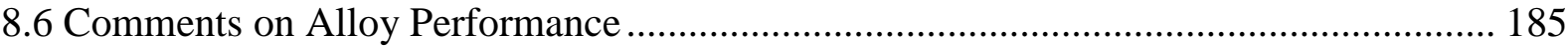

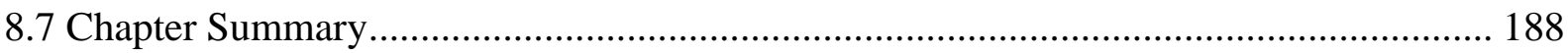

\section{CHAPTER 9}

CONCLUSIONS AND FUTURE WORK................................................................................... 190

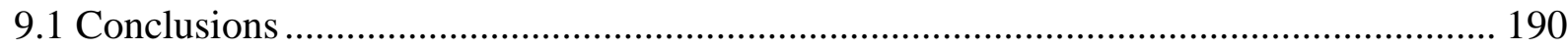


9.2 Recommendations for Future Work ............................................................... 193

9.3 Contribution of This Study........................................................................... 194

9.4 Publication Resulting from this Research ........................................................... 194

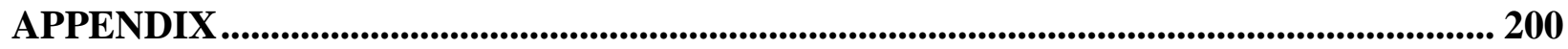

Appendix: A Microstructure of Master Alloys ....................................................... 200

Appendix: B Additional SEM Microstructures of the Studied Alloys ............................... 202

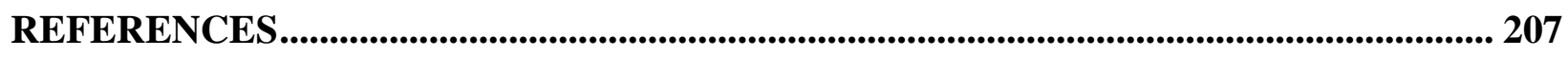




\section{LIST OF TABLES}

Table 3.1 Chemical composition of base alloy (BA) of Al-Si-Cu-Mg, and modified alloy (MA) with addition of $\mathrm{Ti} / \mathrm{V} / \mathrm{Zr}$ in base alloy in wt. \%

Table 3.2 Summary of alloy heat treatment parameters. .............................................. 44

Table 3.3 Tension and compression testing parameters …............................................ 50

Table 4.1 A comparision of phase transformation temperatures between the base alloy (BA) and modified alloy (MA4) during heating cycle (HC) and cooling cycle (CC).

Table 4.2 Summary of the phases present in the studied alloys identified using SEM/EDX

Table 4.3 The main intermetallic phases identified in the alloy MA3 in T6 conditions

Table 4.4 The major phases identified in the as-cast alloy MA4 and their response during T6 heat treatment process.

Table 4.5 Quantitative image analysis of the eutectic silicon and intermetallics present in the alloy MA4 at different SDAS 78

Table 6.1 Percentage of pores present in the studied alloy MA3 before and after compression. 96

Table 6.2 Material constants in Eq. (6.22) for different alloys

Table 7.1 Material constants of the hot deformed cast aluminum alloy, evaluated from the constitutive equation. 129

Table 7.2 The calculated Zener-Hollomon parameter of the MA1 and MA3 alloys at different strain rates and corresponding temperatures (DRV - dynamic 
recovery; DDRX - discontinuous dynamic recrystallization; CDRX -

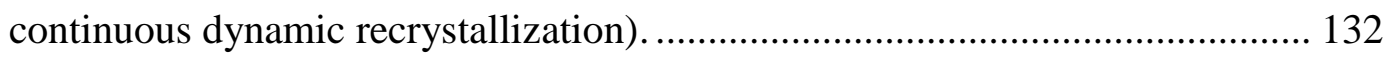

Table 8.1 Hardening parameters of the studied alloy MA4 during compression test......... 163 Table 8.2 Evaluated materials constants for LCF of the base and modified alloys of Al-Si-Cu-Mg alloy with addition of $\mathrm{Ti} / \mathrm{V} / \mathrm{Zr}$ in as-cast and $\mathrm{T} 6$ heat

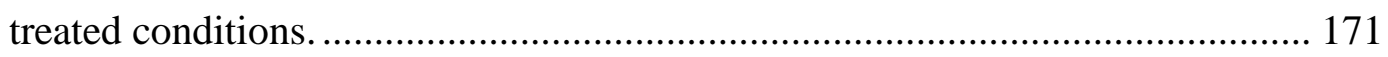

Table B1: The main phases and their chemistry in wt. $\%$ identified using SEM/EDX in the cast Al-Si-Cu-Mg modified alloy MA4.............................. 202 


\section{LIST OF FIGURES}

Fig. 1.1. The consumption of Aluminum alloys in pounds per light vehicle-history and forecast.

1

Fig. 2.1. Schematic of a binary phase diagram Al-B (2nd component) of the eutectic type: (a) Domains of wrought and cast alloys, (b) Al-Si alloy phase diagram (Al rich part) and typical microstructure of (c) hypoeutectic, (d) eutectic and (e) hypereutectic Al-Si alloys 10

Fig. 2.2. Schematic illustration shows the formation of dendrites to make grains. The dendrite stems within any one grain are all crystallographically associated to a common nucleus.

Fig. 2.3. Typical cooling-curves of an hypo Al-Si-Cu-Mg alloy, Cooling curve (top curve) and its derivative (bottom curve) obtained from the melt of Al-Si alloy.

Fig. 2.4. The growth mechanism of $\mathrm{Si}$ flakes on (111) surface by Ledge migration.

Fig. 2.5. The schematic illustration shows the location of twin planes and reentrant edge in a silicon crystal

Fig. 2.6. Al-Si binary phase diagram shows the shift of reaction point due to addition of modifier. 16

Fig.2.7. A graphic representation of the heat treatment processes for the Al alloys, (a) the heat treatment cycles and (b) microstructural changes. 18

Fig. 2.8. Schematic representation of temperature effects on factors that determine the heterogeneous precipitation rate during quenching. 21 
Fig.2.9. Comparison of the cooling rates of distilled water and normal "hard" water.

Fig. 2.10. A part of phase diagram of a heat treatable alloy system indicating the $\beta$ solvus and the GP zone solvus. Here, $\Delta \mathrm{T} 1$ is the range of solution heat treatment temperature, and $\Delta \mathrm{T} 2$ is the range of ageing heat treatment temperature.

Fig. 2.11. A typical sequence of phases found during age hardening of $\mathrm{Al}-\mathrm{Mg}-\mathrm{Si}$ alloys. Supersaturated solid solution (SSSS) decomposes as $\mathrm{Mg}$ and $\mathrm{Si}$ atoms are attracted first to themselves (cluster) then to each other to form precipitates GP(I), sometimes also called initial- $\beta^{\prime \prime}$. GP(I) zones either further evolve directly to a phase $\beta^{\prime \prime}$ and then to a number of other metastable phases labelled $\beta^{\prime}, B^{\prime}, \mathrm{U} 1, \mathrm{U} 2$ (another one, U3, has been postulated theoretically), or first form an intermediate phase called pre$\beta^{\prime}$

Fig. 2.12. A schematic illustration of different types of solid solution of (a) substitutional solid solution and (b) interstitial solid solution. 29

Fig. 2.13. A schematic illustration shows lattice strains imposed on host atoms due to solid solution along with the possible locations of alloying atoms relative to an edge dislocation, (a) tensile lattice strain and (b) compression lattice strain. 
Fig. 2.14. Mechanical properties of the $\mathrm{Al}-\mathrm{Si}-\mathrm{Cu}-\mathrm{Mg}$ alloy aged at $170^{\circ} \mathrm{C}$ (open symbols) and $210^{\circ} \mathrm{C}$ (solid symbols). a) Yield strength and b) UTS.

Fig. 2.15. A schematic illustration shows the interaction between the dislocation and precipitates during moving of dislocations (a) shearing or (b) bypassing, (c) Relationship between precipitate radius and strength of the particles to resist shearing or bypassing by dislocations. 32

Fig. 3.1. A schematic illustration of the casting process for the studied alloys, (a) copper wedge mold with automatic pouring and cooling control with circulating water, (b) position of thermocouples in the wedges during casting.

Fig. 3.2. An experimental setup for thermal analysis of the alloys during melting and solidification.

Fig. 3.3. A schematic representation of heat treatment cycles for the studied alloys, (a) single step solution treatment and (b) two-step solution treatment. 45

Fig. 3.4. Schematic diagram shows ion milling technique for thinning TEM samples of $3 \mathrm{~mm}$ disk. 48

Fig.3.5. Wedge casting and slices (base $60 \times 10 \mathrm{~mm}$ and height $120 \mathrm{~mm}$ ) used for ageing experiment and hardness measurements.

Fig. 3.6. Schematics showing sample extraction from the wedge cast and sample orientation during deformations and EBSD measurements. Note: LDTensile loading direction, SD-Solidification direction. 51

Fig. 3.7. Schematics showing sub-size rectangular sample for tensile and fatigue tests. All dimensions are in $\mathrm{mm}$. 51 
Fig. 3.8. Schematics showing sample extraction from the cast bar.

Fig. 3.9. A follow chart showing the experimental steps in this study 54

Fig. 4.1. Typical solidification behavior of $\mathrm{Al}-\mathrm{Si}-\mathrm{Cu}-\mathrm{Mg}$ alloy modified with addition of Ti-V-Zr at different cooling rates indicating the position of thermocouples in the wedge.

Fig. 4.2. A comparison of melting and solidification behavior of cast $\mathrm{Al}-\mathrm{Si}-\mathrm{Cu}-$ Mg alloy modified with $\mathrm{Ti}, \mathrm{V}$ and $\mathrm{Zr}$ and the base alloy, (a) cooling and heating curves, and (b) first derivatives of the cooling and heating curves. Note: HC-heating cycle, CC-cooling cycle. 59

Fig. 4.3. Typical LOM microstructure of the studied Al-Si-Cu-Mg alloy modified with addition of $\mathrm{Ti} / \mathrm{V} / \mathrm{Zr}$, (a) as-cast base alloy, T6 heat treated alloys (b) MA1, (c) MA2 (d) MA3, (e) as-cast MA4 and (f) T6 heat treated MA4 alloy. Note that numbered arrows correspond to phases are outlined in Table 4.2. 62

Fig. 4.4. Typical SEM microstructure of Al-Si-Cu-Mg alloy (MA4) modified with $\mathrm{Ti}, \mathrm{V}$ and $\mathrm{Zr}$, with conjunction of EDX line scans of as-cast alloy in unetched ( $a, c)$ and deep (b) etched condition. Note that numbered arrows correspond to phases are outlined in Table 4.2. 64

Fig. 4.5. Kikuchi pattern with solution of Ti-V-Zr-rich intermetallics (indicated in Fig.1 and listed in Table 4.2) of as-cast Al-Si-Cu-Mg alloy modified with Ti, V and Zr, (a) EBSP pattern of phase \#7, (b) EBSP pattern of phase \#8 and (c) EBSP pattern of phase \#9. 65

Fig. 4.6. Typical LOM (a) and SEM (b) microstructure with EDX line scan of the modified alloy MA3 T6 heat treated conditions having SDAS of xix 
approximately $25 \mu \mathrm{m}$. Note that numbered arrows correspond to phases outlined in Table 4.3.

Fig. 4.7. Microstructure of modified Al-Si-Cu-Mg alloy in 3D mode; (a) As-cast condition, (b) solution treatment at $485^{\circ} \mathrm{C}$ for $0.5 \mathrm{hr}$ and (c) solution treatment at $485^{\circ} \mathrm{C}$ for $4.5 \mathrm{~h}$. Note that with changing the solution treatment time eutectic silicon particles changes their plate-like shape to a round or spherical shape

Fig. 4.8. TEM observations of the secondary precipitates in T6 condition (modified alloy MA3) (a) Bright field TEM image and selected area diffraction pattern (SAD) taken from [0 $\left.\begin{array}{lll}0 & 1\end{array}\right]$ zone axis (inset) and (b) HAADF image of the precipitate structure in T6 heat treated condition (ST@ $910^{\circ} \mathrm{C}$ for $0.5 \mathrm{~h}+525^{\circ} \mathrm{C}$ for $4.5 \mathrm{~h}$ ) showing along with $\mathrm{EDX}$ elemental maps of nano-rod precipitates $(\mathrm{AlSi})_{3}(\mathrm{Ti}, \mathrm{V}, \mathrm{Zr})$.

Fig. 4.9. TEM observations of the secondary precipitates in $\mathrm{T} 6$ condition (modified alloy MA4) (a) Bright field TEM image and selected area diffraction pattern (SAD) taken from [0 001$]$ zone axis (inset) and (b) HAADF image of the precipitate structure in $\mathrm{T} 6$ heat treated condition (ST@ $510^{\circ} \mathrm{C}$ for $0.5 \mathrm{~h}+525^{\circ} \mathrm{C}$ for $4.5 \mathrm{~h}$ ) showing along with $\mathrm{EDX}$ elemental maps of nano-rod precipitates $(\mathrm{AlSi})_{3}(\mathrm{Ti}, \mathrm{V}, \mathrm{Zr})$. 72

Fig. 4.10. Typical LOM and SEM microstructure in backscattered imaging mode of $\mathrm{T} 6$ heat treated $\mathrm{Al}-\mathrm{Si}-\mathrm{Cu}-\mathrm{Mg}$ alloy with higher addition of $\mathrm{Ti}, \mathrm{V}$ and $\mathrm{Zr}$ (MA4), Note that numbered arrows correspond to phases outlined in

Table 4.2. 74 
Fig. 4.11 LOM microstructure of (a-d) as-cast and (e-h) T6 heat treated Al-Si-CuMg alloy modified with $\mathrm{Ti}, \mathrm{V}$ and $\mathrm{Zr}$ (MA4), with conjunction of casting wedge indication the position of corresponding microstructure. Note that numbered arrows correspond to phases are outlined in Table 4.4.

Fig. 4.12. $\mathrm{XRD}$ patterns showing the major phases present in the as-cast $\mathrm{Al}-\mathrm{Si}-\mathrm{Cu}-$ $\mathrm{Mg}$ alloy modified with $\mathrm{Ti}, \mathrm{V}$ and $\mathrm{Zr}$; (a) the diffraction patterns obtained from bulk materials and extracted intermetallics, and selected peaks at different temperatures in the range of 30 to $600^{\circ} \mathrm{C}$ (b) $\# 1$ as marked in (a) and (c) \#2 as marked in (a) obtained from heating cycle.

Fig. 5.1. Thermal analysis melting curves for the alloy in the following conditions: a) as-cast and b) T7 (H2) heat treated. Note that alloy in the T7 condition had incipient melting temperature $43{ }^{\circ} \mathrm{C}$ higher $\left(550{ }^{\circ} \mathrm{C}\right)$ than in the as-cast condition $\left(507{ }^{\circ} \mathrm{C}\right)$. Note that the transformation temperatures are indicated by arrows; \#1a, 1b: beginning of alloy melting; \#2: end of melting of $\mathrm{Cu}, \mathrm{Mg}$ based intermetallics; \#3: melting of Al-Si eutectic; \#4: end of alloy melting. 84

Fig. 5.2. The correlation between hardness, SDAS, solution treatment time and temperature for the alloy MA3 in (a) The as-cast, T6 (H2) and T7 (H3) conditions and (b) T6 at different solution treatment time and temperatures. 85

Fig. 5.3. The effect of solution treatment time and SDAS of 18 and $32.5 \mu \mathrm{m}$ on alloy strength development for 1-step (H2) and 2-steps (H4) solution treatment: (a) UTS (T6). (b) YS (T6). (c) E (T6). 88 
Fig. 5.4. The effect of solution treatment time and temperature on (a) yield strength (YS), (b) ultimate tensile strength (UTS) and (c) percentage of elongation (E) as function of time and temperature. Note: two steps heat treatment was considered as $525^{\circ} \mathrm{C}$. Increasing the solution treatment time and temperature, YS, UTS and E increased....................................... 89

Fig. 5.5. Dimensional analysis assessment of the alloy 2 -steps solution treated and aged at the following conditions: (a) T6 (AA $150{ }^{\circ} \mathrm{C} / 100 \mathrm{hrs}$ ) having $\mathrm{UTS}=300 \mathrm{MPa},(\mathrm{b}) \mathrm{T} 7-1\left(\mathrm{AA} 250^{\circ} \mathrm{C} / 1.5 \mathrm{hrs}\right)$ having UTS $=250 \mathrm{MPa}$ (c) T7-2 (AA $\left.250{ }^{\circ} \mathrm{C} / 16 \mathrm{hrs}\right)$ having UTS $=210 \mathrm{MPa}$. 90 Note that the ageing at $250{ }^{\circ} \mathrm{C}$ for 16 hours renders the most dimensionally stable condition without visible transformation peak.

Fig. 6.1. Typical true stress-strain curves of as-cast and T6 heat treated alloy MA3 obtained under uniaxial compression at a strain rate of $1 \times 10^{-3} \mathrm{~s}^{-1}$. 96

Fig. 6.2. Microstructure of the studied alloy MA3 in (a) as-cast condition before compression, (b) as-cast condition after compression, (c) after solution treated and compression, (d) T6 heat treated before compression and (e) T6 heat treated after compression, where SD stands for the solidification direction, and $\mathrm{CD}$ denotes the compression direction. The rectangles represent locations of magnified images shown in Fig. 6.3. 97

Fig. 6.3. Magnified view of the microstructure, in locations marked with boxes in Fig. 6.2, of the alloy examined: (a) as-cast before compression, (b) ascast after compression, (c) after solution treated and before compression, 
(d) after solution treated and compression, (e) T6 heat treated before compression, and (f) T6 heat treated after compression.

Note: 1- $\alpha$-Al, 2- eutectic silicon particles, 3-intermetallics, cracked present in the particles are indicated by white arrows.

Fig. 6.4. Quantitative image analysis of secondary phases present in the studied alloy after casting (AC), solutionizing (SSSS) and T6 treatment: (a) area percentage (volume fraction), (b) distribution of particle length and (c) distribution of particle width 101

Fig. 6.5. Work-hardening behavior under uniaxial compression: (a) Plot of the instantaneous work hardening rate of $\theta=d \sigma / d \varepsilon$ versus flow stress increments of $\sigma-\sigma_{y}$ for as-cast, solution treated (SSSS) and T6 heat treated alloy (b) typical work-hardening stages in fcc single crystal......

Fig. 6.6. Voce stress of super saturated solid solution (SSSS), as-cast (AC) and T6 heat treated alloy. 104

Fig. 6.7. Contribution of precipitates to alloy strengthening after T6 heat treatment: (a) plastic stress-strain comparison of model calculations (Equation 6.13) with the experimental curve; (b) calculated flow stress due to precipitation hardening caused by shearable and non-shearable precipitates.

Fig. 6.8. True stress-true strain curves of the $\mathrm{Al}-\mathrm{Si}-\mathrm{Cu}-\mathrm{Mg}$ alloy obtained during uniaxial compression, (b) at different temperatures and a strain rate of $10^{-3} \mathrm{~s}^{-1}$, and (c) at different strain rates and room temperature $\left(25^{\circ} \mathrm{C}\right)$. 110

Fig. 6.9. Influence of temperature on peak stresses of the studied alloy at different temperatures 
Fig. 6.10. (a) Parabolic strain hardening curves of the $\mathrm{Al}-\mathrm{Si}-\mathrm{Cu}-\mathrm{Mg}$ alloy during compression tested at different temperatures, and (b) the effect of temperature on the coefficient of parabolic strain hardening, $\chi$

Fig.6.11. (a) Log-log plot of stress vs strain rate to calculate the strain rate sensitivity and (b) linear fitting plot stress vs temperatures to find softening constant C. 116

Fig. 6.12. A comparison between the dislocation slip distances predicted from Eq. (6.22) and the experimental data for alloys of $\mathrm{Pb}-1.5 \% \mathrm{Sb}$ and $\mathrm{Pb}$ $10 \%$ Sn

Fig. 6.13. (a) A comparison of the dislocation slip distance predicted from Eq. (6.22) with the experimental data of the Al-Si-Cu-Mg alloy and other Al alloys available in the literature, (b) magnified view of slip distance up to $1 \mu \mathrm{m}$. 118

Fig.7. 1. Typical true stress strain behavior of the studied alloys of MA1 and MA3 under uniaxial compression (a) at different temperatures and constant strain rate of $10^{-2} \mathrm{~s}^{-1}$, and $(\mathrm{b}, \mathrm{c})$ at constant temperature of $200^{\circ} \mathrm{C}$ and different strain rates expressed in $\mathrm{s}^{-1}$. Note: Stage I: work hardening stage, Stage II: transition stage, Stage III: softening stage, Stage IV: steady stage. 123-124

Fig.7.2. Variation of peak stress with deformation temperature and strain rates of the studied alloys, (a) peak stress vs temperature plot for strain rates of $10^{-3} \mathrm{~s}^{-1}$ and $1 \mathrm{~s}^{-1}$; contour plot of peak stress corresponding to temperature and strain rate for, (b) MA1 alloy and (c) MA3 alloy, (d) 
peak stress increase calculated as a difference in peak stress between the MA3 and the MA1 alloy for different testing temperatures and strain rates of 1 and $10^{-3} \mathrm{~s}^{-1}$ $125-126$

Fig. 7.3. The relationship of peak stress, strain rate and temperature of the MA1 and MA3 alloys (a) $\ln (\hat{\varepsilon})$ versus $\ln (\sigma)$, and (b) $\ln (\dot{\varepsilon})$ versus $\sigma$. 128

Fig. 7.4. Plots of peak stress, strain rate and temperature of the alloys: (a) $\ln (\dot{\varepsilon})$ versus $\ln [\sinh (\alpha \sigma)]$ of the MA1 and MA3 alloys; (b) $\ln [\sinh (\alpha \sigma)]$ versus $1000 / \mathrm{T}$ of the base; (c) $\ln [\sinh (\alpha \sigma)]$ versus $1000 / \mathrm{T}$ of the modified alloy. Strain rates are expressed in $\mathrm{s}^{-1}$

Fig. 7.5. (a) Typical plot of $\ln Z$ vs. $\ln [\sinh (\alpha \sigma)]$ of Zener-Hollomon parameter and peak stress at different strain rates and temperatures of the MA1 and MA3 alloys, and (b) the relationship between Zener-Holomon parameter and strain rates at different temperatures.

Fig. 7.6. Microstructure of etched Al-Si-Cu-Mg alloy after hot deformation at a strain rate of $10^{-3} \mathrm{~s}^{-1}$ and different temperatures: (a) MA1 alloy deformed at $200^{\circ} \mathrm{C}$; (b) MA1 alloy deformed at $400^{\circ} \mathrm{C}$; (c) MA3 alloy defromed at $200^{\circ} \mathrm{C}$; (d) MA3 alloy deformed at $400^{\circ} \mathrm{C}$. The red and blue arrows indicate the recrystalized grains, and grain boundary without recrystalization, respectively.

Fig. 7.7. Precipitate particle cracking in the MA1 alloy after compression tests at strain rates of $1 \mathrm{~s}^{-1}$ and temperatures of (a) $200^{\circ} \mathrm{C}$ and (b) $400^{\circ} \mathrm{C}$, and strain of $10^{-3} \mathrm{~s}^{-1}$ and temperatures of (c) $200^{\circ} \mathrm{C}$ and (d) $400^{\circ} \mathrm{C}$. Note: $1-$ Al dendrite, 2 - eutectic Si phase, 3 - $\mathrm{Al}_{9} \mathrm{Mg}_{12} \mathrm{Si}_{6} \mathrm{Fe}$ related to $\pi$ - phase, 4 
- $\mathrm{Al}_{7.2} \mathrm{Si}_{8.3} \mathrm{Cu}_{2} \mathrm{Mg}_{6.9}$ related to $\mathrm{Q}-\mathrm{Al}_{5} \mathrm{Cu}_{2} \mathrm{Mg}_{8} \mathrm{Si}_{6}$ phase Composition of particles is given in Appendix B

Fig. 7.8. (a) SEM image showing particle cracking of the MA3 alloy after compression tests at strain rates of $1 \mathrm{~s}^{-1}$ and $200^{\circ} \mathrm{C}$ temperature (yellow arrows indicated the cracked in the particles). Optical microscopy images showing particle cracking of the MA3 alloy after compression tests at strain rates of $1 \mathrm{~s}^{-1}$ and temperaturesof (b) $200^{\circ} \mathrm{C}$ and (c) $400^{\circ} \mathrm{C}$, and strain of $10^{-3} \mathrm{~s}^{-1}$ and temperature of (d) $200^{\circ} \mathrm{C}$ and (e) $400^{\circ} \mathrm{C}$ temperature. Note: $5-\mathrm{Al}_{26} \mathrm{Si}_{5} \mathrm{Ti}_{4} \mathrm{VZr}_{4}$ phase. Composition of particles is given in Appendix B.

Fig. 7.9. A comparative distribution of quantitative image analysis of particles present in the studied alloys after hot compression at different temperatures with a strain rate of $1 \mathrm{~s}^{-1}$ for, (a) length of eutectic $\mathrm{Si}$ particle, (b) length of intermetallics particles, (c) width of eutectic Si particle and (d) width of intermetallics particles. Note: A - MA1 alloy deformed at $200^{\circ} \mathrm{C}, \mathrm{B}-\mathrm{MA} 1$ alloy deformed at $400^{\circ} \mathrm{C}, \mathrm{C}-\mathrm{MA} 3$ alloy deformed at $200^{\circ} \mathrm{C}$, and D - MA3 alloy deformed at $400^{\circ} \mathrm{C}$.

Fig. 7.10. Development of damage accumulation with temperature for studied alloys MA1 and MA3, (a) eutectic silicon particles and (b) intermetallics, where the strain rate is in $\mathrm{s}^{-1}$.

Fig. 7.11. The contour plot of damage accumulation during hot compression at different temperatures and strain rates for the studied alloys; (a) eutectic silicon particles and (b) intermetallics of MA1 alloy, and (c) eutectic 
silicon particles and (d) intermetallics of MA3 alloy where the strain rate is in $\mathrm{s}^{-1}$.

Fig. 7.12. A comparison of the morphological orientation distribution of particles present in the MA1 and MA3 alloys deformed at different temperatures and a constant strain rate of $1 \mathrm{~s}^{-1}$ for, (a) eutectic Si particles and (b) intermetallics particles. Note: A - base alloy deformed at $200^{\circ} \mathrm{C}, \mathrm{B}$ - base alloy deformed at $400^{\circ} \mathrm{C}, \mathrm{C}$ - modified alloy deformed at $200^{\circ} \mathrm{C}$, and D modified alloy deformed at $400^{\circ} \mathrm{C}$; i - loading axis, ii - major axis, and iii - particle orientation angle $(\theta)$.

Fig. 7.13. A schematic model depicting the successive steps of recrystallization of the MA1 (a-c) and MA3 (d-f) alloys during hot deformation. Note: 1 - Al matrix, 2a - eutectic silicon and $2 \mathrm{~b}$ - intermetallic particles analyzed under optical microscope; 3-precipitates present in the base alloy; 4 $\mathrm{Al}_{3} \mathrm{X}(\mathrm{X}=\mathrm{Ti}, \mathrm{V}, \mathrm{Zr})$ additional precipitates present in the modified alloy. The precipitates 3 and 4 were observed using transmission and scanning microscopy and their morphology and chemistry are given. Here, the presence of $\mathrm{Al}_{3} \mathrm{X}$ in the modified alloy increased the resistance of matrix preventing rotation of eutectic silicon. However, during deformation precipitates in both alloys experienced fracturing.

Fig. 8.1. The correlation between hardness and SDAS for as-cast and T6 heat treated $\mathrm{Al}-\mathrm{Si}-\mathrm{Cu}-\mathrm{Mg}$ alloy modified with $\mathrm{Ti}, \mathrm{V}$ and $\mathrm{Zr}$.. 153

Fig. 8.2. A comparison of the tensile property of the studied Al-Si-Cu-Mg alloys with addition of $\mathrm{Ti} / \mathrm{V} / \mathrm{Zr}$ obtained at room temperature, (a) yield strength 
(YS) and (b) ultimate tensile strength (UTS), (c) elongation and (d) quality index

Fig. 8.3. A comparison of the tensile property of the studied cast Al-Si-Cu-Mg alloy with literature data obtained at different temperatures, (a) yield strength (YS) and (b) ultimate tensile strength (UTS). Note: the testing temperature for the study of Mohamed et al., 2013 was $190^{\circ} \mathrm{C}$, instead of $200^{\circ} \mathrm{C}$ 159

Fig. 8.4. The correlation between compression properties, (a) ultimate compressive stress (UCS) and (b) \% of compressability, and SDAS for as-cast and $\mathrm{T} 6$ heat treated $\mathrm{Al}-\mathrm{Si}-\mathrm{Cu}-\mathrm{Mg}$ alloy modified with $\mathrm{Ti}, \mathrm{V}$ and $\mathrm{Zr}$. 162

Fig. 8.5. A plot of stress amplitude versus number of cycles for the studied alloys with the base alloy obtained from LCF testing. 166

Fig. 8.6. Fatigue life of the cast $\mathrm{Al}-\mathrm{Si}-\mathrm{Cu}-\mathrm{Mg}$ alloys with addition of $\mathrm{Ti} / \mathrm{V} / \mathrm{Zr}$ obtained at total strain amplitudes of $0.1-0.6 \%$ in comparison with base alloy 168

Fig. 8.7. Plot of fatigue tested data of $\mathrm{Al}-\mathrm{Si}-\mathrm{Cu}-\mathrm{Mg}$ alloy with addition of $\mathrm{Ti}, \mathrm{V}$ and $\mathrm{Zr}$ in $\mathrm{T} 6$ heat treated condition; (a) Basquin plot and (b) CoffinManson plot.

Fig. 8.8. Plot of the low cycle fatigue tests data of cast Al-Si-Cu-Mg alloy with addition of $\mathrm{Ti} / \mathrm{V} / \mathrm{Zr}$, (a) cyclic elastic strain energy density versus the number of cycles, (b) cyclic plastic strain energy density versus the number of cycles and (c) cyclic total strain energy density versus the number of cycles. $174-175$ 
Fig. 8.9. Plot of Halford-Marrow equation for the fatigue tested data of Al-Si-CuMg alloy with addition of $\mathrm{Ti}, \mathrm{V}$ and $\mathrm{Zr}$ in $\mathrm{T} 6$ heat treated condition. 176

Fig. 8.10. The correlation between fatigue life and SDAS for T6 heat treated Al-Si$\mathrm{Cu}-\mathrm{Mg}$ alloy modified with $\mathrm{Ti}, \mathrm{V}$ and $\mathrm{Zr}$ accompanied by reference data. 177

Fig. 8.11. Typical SEM microstructure with EDX spectrum showing the major intermetallics on the fracture surfaces obtained during tensile test of (a) base alloy and (b) alloy MA4 in as-cast condition.

Fig. 8.12. Typical SEM micrographs showing the types of fracture of the studied alloys occurred during tensile test of (a) as-cast base alloy, T6 heat treated alloys (b) MA1, (c) MA2 (d) MA3, (e) T6 heat treated MA4 alloy. Note: Red arrow-secondary cracks, Blue arrow-debonding of intermetallics/eutectic silicon and pink arrow- tear ridge.

Fig. 8.13. SEM images of fatigue fracture surfaces of the samples tested at a total strain amplitude of $0.2 \%$ showing an overall view and the corresponding fatigue crack initiation sites at higher magnifications for the studied alloys of (a-b) as-cast base alloy, T6 heat treated alloys (c-d) MA1, (e-f) MA2 (g-h) MA3, (i-j) T6 heat treated MA4 alloy. White and pink boxes are magnified in Fig. 8.14 and Fig. 8.15. Note: FCI-fatigue crack initiation zone, SB-slip band, OL-oxide layer.

Fig. 8.14. SEM images of fatigue fracture surfaces (corresponding enclosed by white boxes in Fig. 9) of the samples tested at a total strain amplitude of $0.2 \%$ showing the fatigue striation at the crack propagation zone in the matrix for the studied alloys of (a) as-cast base alloy, T6 heat treated alloys (b) MA1, (c) MA2 (d) MA3, (e) MA4 and (f) intermetallics of T6 xxix 
heat treated MA4 alloy. Note: FCG- fatigue crack growth/propagation, FS- fatigue striation, MC- Micro cliffs.

Fig. 8.15. SEM images of fatigue fracture surfaces (corresponding enclosed by pink boxes in Fig. 9) of the samples tested at a total strain amplitude of $0.2 \%$ showing tensile like fracture at the fast fracture zone in the matrix (a-e) and intermetallics (f) for the studied alloys of (a) as-cast base alloy and T6 heat treated alloys of (b) MA1, (c) MA2 (d) MA3 and (e-f) MA4. Note: Red arrow indicates secondary cracks in the matrix. 184

Fig. A1. Typical SEM microstructures with EDX spectrums of major phases of the master alloys used as a source of alloying elements; (a) Al-85\% V, (b) $\mathrm{Al}-10 \% \mathrm{Sr}$, (c) Al-6.1\% Ti, (d) Al-10\%Zr and (e) Al-35\% Si in wt $\%$.....200-201

Fig. B1. Typical SEM images showing morphology of extracted intermetallics in the cast $\mathrm{Al}-\mathrm{Si}-\mathrm{Cu}-\mathrm{Mg}$ modified alloy MA4. The above intermetallics composition is corresponding to the \#7 in Table B1.

Fig. B2. SEM micrographs with EDX spectrums in a magnified views correspondingly showing the tensile fracture surface of studied alloy MA4 in as-cast states obtained at different temperatures of (a) $25^{\circ} \mathrm{C}$, (b) $200^{\circ} \mathrm{C}$, (c) $300^{\circ} \mathrm{C}$ and (d) $400^{\circ} \mathrm{C}$. Note: the areas enclose by white and red lines show the surface pores and pullout of the precipitates, respectively. 203

Fig. B3. The corresponding SEM micrographs showing the matrix morphology of the tensile fracture surface of studied alloy MA4 in as-cast states obtained at different temperatures of (a) $25^{\circ} \mathrm{C}$, (b) $200^{\circ} \mathrm{C}$, (c) $300^{\circ} \mathrm{C}$ and (d) $400^{\circ} \mathrm{C}$ 204 
Fig. B4. SEM images of fatigue fracture surfaces of the samples tested at a total strain amplitude of (a) $0.2 \%$ and (b) $0.6 \%$ showing an overall view for as-cast $\mathrm{Al}-\mathrm{Si}-\mathrm{Cu}-\mathrm{Mg}$ modified alloy MA4 and the corresponding fatigue crack initiation sites at higher magnifications, where fatigue cracks initiate at a large surface pore and slip bands (c); clusters of near-surface pores and large surface inclusion (d). Here, yellow box and red arrows indicate the position of crack initiation sites while red dashed line separated the crack propagation area. The areas enclose by white line shows the surface pores. Note that increasing the strain amplitude crack propagation zone decreases. FCI-fatigue crack initiation, FCG-fatigue crack growth/propagation zone 205

Fig. B5. SEM images of fatigue fracture surfaces for as-cast $\mathrm{Al}-\mathrm{Si}-\mathrm{Cu}-\mathrm{Mg}$ modified alloy MA4 samples tested at total strain amplitude of $0.2 \%$ showing fatigue striation in matrix ( $a$ and $b$ ) (as indicated in Fig. 11a with i) and precipitates (c and d), (as pointed out in Fig. 14a with ii), (e) EDX analysis of intermetallic (typical \#7 as listed in Table 2) on the fracture surface and (f) final fracture of the alloy (as marked in Fig. 11a with iii). Note: the dotted lines in (e) show two sets of fatigue striations along the crack propagation direction which overlapped with each other as indicated by enclosed red box. 206 


\section{ACRONYMS}

$\begin{array}{cl}\text { CAFE } & \text { Corporate Average Fuel Efficiency } \\ \text { CAGR } & \text { Compound Annual Growth Rate } \\ \text { PDAS } & \text { Primary Dendrite Arms Spacing } \\ \text { AC } & \text { Secondary Dendrite Arms Spacing } \\ \text { GP } & \text { Guinier-Preston } \\ \text { YS } & \text { Yield strength } \\ \text { UTS } & \text { Ultimate tensile strength } \\ \text { SF } & \text { Sludge factor } \\ \text { ST } & \text { Solution treatment } \\ \text { AA } & \text { Artificial ageing } \\ \text { LCF } & \text { Low cycle fatigue }\end{array}$




\section{NOMENCLATURE}

\begin{tabular}{|c|c|}
\hline$\Delta T$ & Under cooling \\
\hline$\Delta C$ & Super-saturation \\
\hline$l$ & Length of eutectic Si particle \\
\hline$W$ & Width of eutectic Si particle \\
\hline$n$ & Total number of eutectic Si particle \\
\hline$A_{P}$ & Area of eutectic Si particle \\
\hline$G$ & Shear modulus \\
\hline$b$ & Burgers vector \\
\hline$\sigma_{T}$ & Total stress \\
\hline$\sigma_{i}$ & Intrinsic stress \\
\hline$\sigma_{s s}$ & Solid solution strengthening \\
\hline$\sigma_{e u}$ & Eutectic phase strengthening \\
\hline$\sigma_{\perp}$ & Dislocations strengthening \\
\hline$\sigma_{p}$ & Precipitates strengthening \\
\hline$\tau_{c r i c}$ & Critical resolved shear stress \\
\hline$\rho$ & Dislocation density \\
\hline$M$ & Taylor factor \\
\hline$L$ & Dislocation Slip Distance \\
\hline
\end{tabular}




\begin{tabular}{|c|c|}
\hline$\chi$ & Coefficient of parabolic strain hardening \\
\hline C & Softening constant \\
\hline$\sigma$ & Flow stress \\
\hline$\dot{\varepsilon}$ & Strain rate \\
\hline$Q$ & Activation energy of deformation \\
\hline$R$ & Universal gas constant \\
\hline$T$ & Testing temperature \\
\hline$Z$ & Zener-Hollomon parameter \\
\hline$Q_{\text {index }}$ & Quality index \\
\hline$\Delta W f^{\prime}$ & Plastic strain energy density coefficient \\
\hline$\gamma$ & Energy density coefficient exponent \\
\hline$\Delta W t$ & Strain energy density \\
\hline$\Delta W e$ & Elastic strain energy density \\
\hline$\Delta W p$ & Plastic strain energy density \\
\hline$\Delta \sigma$ & Total stress range at mid-life \\
\hline$\Delta \varepsilon p$ & Total plastic strain range \\
\hline$n_{l^{\prime}}$ & Cyclic strain hardening exponent \\
\hline$K^{\prime}$ & Cyclic strength coefficient \\
\hline \multicolumn{2}{|l|}{$\Delta \varepsilon_{t}$} \\
\hline 2 & Total elastic strain amplitude \\
\hline \multicolumn{2}{|l|}{$\Delta \varepsilon_{e}$} \\
\hline 2 & Elastic strain amplitude \\
\hline$\underline{\Delta \varepsilon_{p}}$ & \\
\hline 2 & The plastic strain amplitude \\
\hline
\end{tabular}




$\begin{array}{ll}E & \text { Young's modulus } \\ N_{f} & \text { Number of cycles to failure } \\ \sigma_{f}^{\prime} & \text { Fatigue strength coefficient } \\ b^{\prime} & \text { Fatigue strength exponent } \\ \varepsilon_{f}^{\prime} & \text { Fatigue ductility coefficient } \\ c & \text { Fatigue ductility exponent } \\ E_{l} & \text { \% of elongation }\end{array}$




\section{CHAPTER 1}

\section{INTRODUCTION}

\subsection{Background History and Motivation}

Over the past decade, the quantity of light metals used in motorized vehicles has continued to increase and is projected to grow further. A survey done by the Ducker Worldwide Company shows that the amount of aluminum and its alloys in North American vehicles has grown from about $80 \mathrm{lb}(37 \mathrm{~kg})$ in 1974 to $343 \mathrm{lb}(155 \mathrm{~kg})$ in 2012 and is projected to reach $550 \mathrm{lb}(250 \mathrm{~kg})$ by 2025 as seen in Fig. 1.1 [1]. More recent growth in the use of lightweight materials in automotive manufacturing has been in response to rising fuel costs as automakers look to provide consumers greater fuel efficiency and to meet more stringent Corporate Average Fuel Efficiency (CAFE) regulations to the equivalent of $54.5 \mathrm{mpg}$ for cars and light-duty trucks by 2025. The purpose of using light metals has been to reduce vehicle weight, increase fuel efficiency, improve vehicle performance, and enhance safety [1, 2, 3].

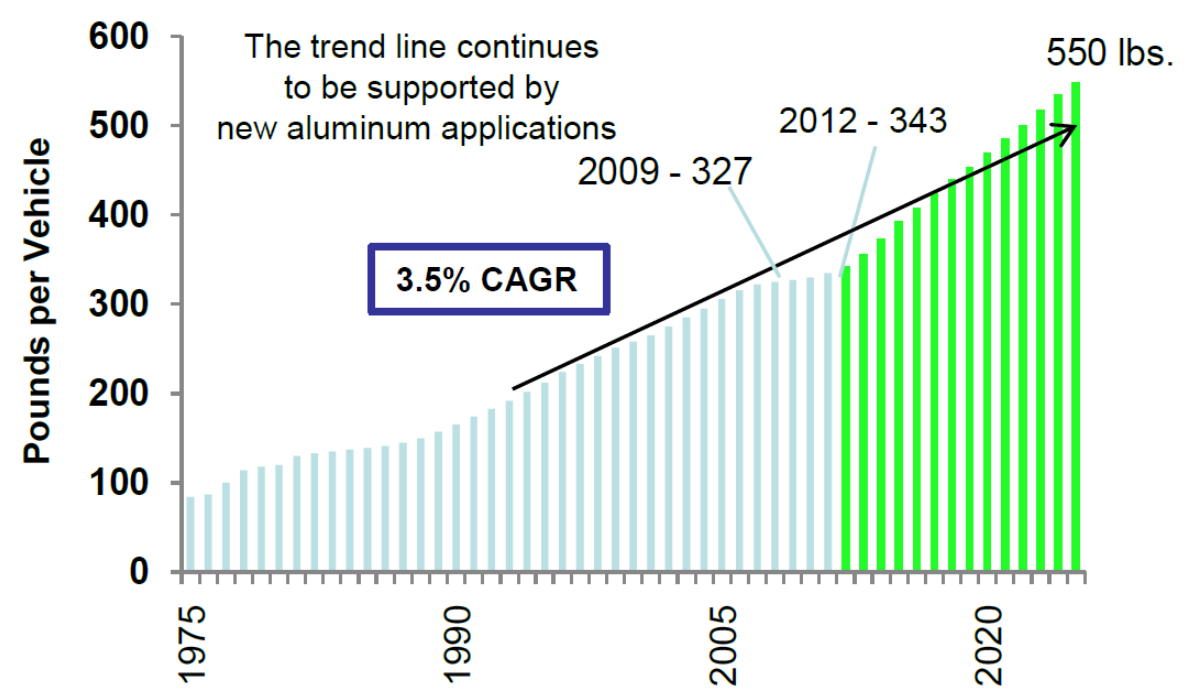

Fig. 1.1. The consumption of Aluminum alloys in pounds per light vehicle-history and forecast [1]. 
For light alloys, aluminum and magnesium alloys are the prominent candidates. Because of the anisotropic mechanical properties, poor formability, low corrosion and wear resistance of Mg alloys, only limited applications are seen currently in service $[4,5]$. However, aluminum alloys are becoming attractive structural materials in the automotive and aerospace industries due to their low density, high specific strength and stiffness, and good recyclability [6, 7]. New demands in the automotive industry for aluminum alloys suitable for high-temperature power train applications require the development of cast Al-Si alloys with enhanced high temperature performance. The alloys currently used are limited to an operating temperature of about $180^{\circ} \mathrm{C}$ [8]. Beyond this temperature, the mechanical properties deteriorate quickly owing to the coarsening of the precipitates. To meet the requirements of automotive engine parts, the Al-Si alloys can be modified by (1) changing the alloy composition and (2) post solidification treatment, i.e., heat treatment $[8,9]$.

In unmodified aluminum alloys the Si particles have plate/needle-like morphology, which act as crack initiators and have a negative impact on ductility [10]. By changing the morphology of the Si particles from a plate-like shape to a fibrous/spherical shape, the ductility of alloys could be improved and this modification could be done by (i) using a high cooling rate, (ii) adding a chemical modifier, (iii) exposing the casting to a high temperature for long periods, or (iv) by a combination of these processes [11]. Strontium and Sodium ( $\mathrm{Sr}, \mathrm{Na})$ are often used as chemical modifiers, and a small amount $(50-300 \mathrm{ppm})$ is often added $[12,13]$. The fibrous morphology obtained through $\mathrm{Sr}$ modification is much easier to fragment and spheroidize during solution treatment, and the solution treatment time can be shortened as well [10]. $\mathrm{Cu}$ and $\mathrm{Mg}$ can be added to increase the strength of the alloy, but this also leads to a reduction in ductility [14, 15]. The strength and ductility obtained are affected by factors such as if the $\mathrm{Cu}$ and $\mathrm{Mg}$ are present 
as coarse phases after solidification, as atoms in solid solution, as GP zones formed at room temperature, or as precipitates formed during artificial ageing [14]. The coarse phases which may form during solidification are the $\mathrm{Al}_{2} \mathrm{Cu}$ phase and the $Q-\mathrm{Al}_{5} \mathrm{Mg}_{8} \mathrm{Si}_{6} \mathrm{Cu}_{2}$ phase in $\mathrm{Al}-\mathrm{Si}-\mathrm{Cu}-$ $\mathrm{Mg}$ alloys $[16,17]$, while the $\pi-\mathrm{Al}_{8} \mathrm{Mg}_{3} \mathrm{FeSi}_{6}$ phase and the $\mathrm{Mg}_{2} \mathrm{Si}$ phase form in $\mathrm{Al}-\mathrm{Si}-\mathrm{Mg}$ alloys [18]. These coarse phases do not contribute to the strength, and their degree of influence on ductility depends on their distribution and size relative to the Si particles [18]. Additions of $\mathrm{Cu}$ and $\mathrm{Mg}$ also lead to the formation of bands of coarse Si particles and an increased risk of shrinkage porosity due to an increased solidification interval, which may decrease the elongation to fracture [15]. Iron is often regarded as an undesirable impurity as it forms long and brittle $\beta-\mathrm{Al}_{5} \mathrm{FeSi}$ plates that cause crack initiation. $\mathrm{Fe}$ is, however, needed to reduce die soldering in high pressure die casting (HPDC) [14]. However, the main challenge to wider applications of the $\mathrm{Al}$-alloys is their low strength at temperatures exceeding $180^{\circ} \mathrm{C}$. Above that temperature, the phases $\mathrm{Al}_{2} \mathrm{Cu}, \mathrm{Mg}_{2} \mathrm{Si}$ and/or $\mathrm{Al}_{2} \mathrm{CuMg}$, which maintain the strength of the alloy, usually coarsen or dissolve. This results in a reduced performance, consequently limiting their practical applications in engine blocks, cylinder heads or heat shields. [19, 20, 21, 22]. To maintain the alloy strength at high temperatures, a microstructure containing thermally stable and coarsening resistant phases that have lower diffusivity and inferior interfacial energy with the matrix is needed. It has been found that addition of transition metals in Al-alloys form thermally stable phases which improves the high temperature properties. Among the transition metals, $\mathrm{V}, \mathrm{Zr}$ and $\mathrm{Ti}$ have low diffusivity and solubility in $\mathrm{Al}$, forming thermally stable intermetallics and have been found to maintain their strength at temperatures up to $350^{\circ} \mathrm{C}[23$, 24]. Additions of transition metals, especially $\mathrm{Ti}, \mathrm{V}$ and $\mathrm{Zr}$, can modify the grain size as well as improve the elevated temperature properties by forming stable precipitates. The main reason to 
use these transition metals is the formation of coherent precipitates in the form of $\mathrm{Al}_{3} \mathrm{X}$ trialuminide phases of cubic $\mathrm{L}_{2}$ or $\mathrm{D}_{22}$ structures. Such phases can maintain their coherency with the matrix at elevated temperatures, thus strengthening the high temperature performance of materials. Another effect of adding these transition metals to the Al-alloys is to suppress discontinuous precipitation and accelerate homogeneous precipitation which reduces ageing time requirements of the heat treatment process $[23,24,25]$.

To achieve the desired properties, Al alloys need to go through long heat treatment processes which increases the consumption of energy, and results in an increase of production cost of $\mathrm{Al}$ alloy parts. As a result, manufacturing industries are now focusing on the heat treatment processes and elevated temperature properties to reduce the cost as well as to save energy without compromising the alloy properties. [2, 3]. Therefore, the objectives of this study are described in the following section.

\subsection{Objectives}

The research reported here in aimed to improve the high temperature properties of the Al-Si-Cu$\mathrm{Mg}$ alloy by introducing $\mathrm{Ti}, \mathrm{V}$ and $\mathrm{Zr}$ and to evaluate the properties in the as-cast (AC) and heat-treated (HT) conditions. The research was performed in three stages: (i) to study the effect of $\mathrm{Ti}, \mathrm{V}$ and $\mathrm{Zr}$ addition to the base alloy of $\mathrm{Al}-\mathrm{Si}-\mathrm{Cu}-\mathrm{Mg}$ during solidification, (ii) to identify a proper heat treatment procedure for the modified alloy, and (iii) to evaluate the changes in the microstructures and properties, such as mechanical, thermal, etc. of the modified alloys The following studies were conducted and the specific aims of each study are listed below: 


\section{Study 1: Solidification behavior}

The addition of an alloying element can change the solidification behavior of the alloy. The solidification rate changes the SDAS as well as the size and shape of the phases formed during solidification. The aim of this part of the work was:

i. to identify the effect of $\mathrm{Ti}, \mathrm{V}$ and $\mathrm{Zr}$ addition on solidification behavior of the modified alloys at different cooling rates.

ii. to correlate with the SDAS, size and shape of the phases formed at different solidification rates.

\section{Study 2: Heat treatment}

$\mathrm{T} 6$ and $\mathrm{T} 7$ are the most common heat treatment processes used in the aluminum alloy industry. In the present study $\mathrm{T} 6$ and $\mathrm{T} 7$ heat treatment were performed at different solution treatment times and temperatures, followed by peak ageing and over-ageing.

\section{Study 3: Characterization of alloys in terms of microstructure, mechanical and thermal properties}

The microstructures, mechanical and thermal properties of the modified alloys were evaluated in both the as-cast and heat-treated conditions.

i. The microstructural study was performed to evaluate the SDAS, morphology of the Si particles, intermetallics and the precipitates which are formed during ageing.

ii. Uniaxial tensile and compressive tests were performed to evaluate the strength and ductility of the alloy at room temperature as well as at elevated temperatures.

iii. Fatigue behavior of the modified alloys was evaluated as a function of SDAS, heat treatment processes and alloy chemistry. 


\section{Study 4: Constitutive model}

This part of the research was intended:

i. to establish a constitutive model to correlate the effect of precipitates on the deformation behavior.

ii. to explain the mechanical properties under different testing conditions, namely strain rates and test temperatures.

\subsection{Organization of the Thesis}

This thesis has been structured as follows:

Chapter-2 presents a literature survey on the cast alloys that contains a concise review of solidification behavior of $\mathrm{Al}-\mathrm{Si}$ alloys, criteria for developing high temperature aluminum alloys, strengthening mechanisms and heat treatment processes for Al-Si alloys, .

Chapter-3 presents the detailed experimental methodology to cast the alloys, to conduct the experiments, heat treatment processes with parameters, and material characterization in terms of microstructures and mechanical properties such as tensile and compressive strength and fatigue characteristics.

Chapter-4 examines the thermal analysis and microstructures of the alloys in the as-cast and T6 heat treated conditions.

Chapter-5 illustrates the effect of short term heat treatment processes and solidification rate on the microstructure and mechanical properties of the alloys.

Chapter-6 describes the influence of testing temperature and precipitates on the compression properties and dislocation slip distance change of the alloys.

Chapter-7 interprets the role of $\mathrm{Ti}, \mathrm{V}$ and $\mathrm{Zr}$ on the activation energy during hot deformation of the alloys. 
Chapter-8 reveals the role of $\mathrm{Ti}, \mathrm{V}$ and $\mathrm{Zr}$ on the high temperature tensile and low cycle fatigue properties of the alloys. The effect of T6 heat treatment and solidification rate in terms of SDAS on the alloy properties is also presented here.

Chapter-9 summarizes the outcomes from the study and makes concluding remarks as well as suggesting directions for the future work. 


\section{CHAPTER 2}

\section{Literature Review}

\subsection{Introduction}

The new CAFE benchmark aims to increase fuel economy to the equivalent of $54.5 \mathrm{mpg}$ for cars and light-duty trucks by 2025 . This effort will save U.S. consumers more than $\$ 1.7$ trillion at the gas pump and reduce oil consumption by 12 billion barrels every year [26]. The first step towards this goal has been the replacement of heavier metallic materials such as ferrous alloys with lighter materials such as Al alloys, plastics or their composites. Thus, Al alloys have become promising candidates as lightweight automotive materials $[27,28]$. In the family of cast Al-Si alloys, the Al-Si-Cu-Mg grades are commonly used in power train applications, due to their high strength to weight ratio, good thermal conductivity, excellent fluidity, hot tear resistance and feeding characteristics which allow casting intricate shapes such as engine blocks, cylinder heads or chassis components [29]. These alloys are most versatile materials, comprising $85 \%$ to $90 \%$ of the total aluminum cast parts produced in the automotive industry due to their excellent castability. They are therefore generally characterized in terms of solidification characteristics, castability, mechanical properties and other properties. In this

chapter the solidification behavior and post casting heat treatment of $\mathrm{Al}-\mathrm{Si}-\mathrm{Cu}-\mathrm{Mg}$, the effect of addition of transition metals for high temperature properties and recent research on these topics will be discussed. 


\subsection{Solidification of Al-Si Alloys}

One of the popular aluminum alloys used in automotive applications is the Al-Si alloy. This series of alloys can be classified as wrought and cast alloys based on the amount of silicon, as shown in Fig. 2.1a. Addition of $\mathrm{Si}$ increases the fluidity and decreases the solidification shrinkage, resulting in an improvement in castability [14]. Another advantage is that Si can be added without increasing the density of the alloy. While Si reduces the ductility, it increases the strength and stiffness of the cast aluminum alloys [30]. Based on the Si concentration present in the microstructures, the cast aluminum alloys can be referred to as hypoeutectic, eutectic or hypereutectic alloys as shown in Fig. 2.1b. The microstructure of the hypoeutectic alloys consists of $\alpha$-Al dendrites which solidify first, followed by the Al-Si eutectic structure in Fig. 2.1c. The distance between the secondary dendrite arms (SDAS), in Fig. 2.1c is related to the local solidification time of the alloy. Primary Si particles form first in hypereutectic alloys followed by the Al-Si eutectic, as shown in Fig. 2.1e. [31].

The solidification of the alloy is characterized by the changes of the enthalpy and Gibbs free energy which describe the chemical thermodynamics depending on the temperature, pressure and compositions of the alloys in the liquid state. The solidification rate in the Al-Si alloy system can be appraised by the enthalpy and heat capacity, which reflect the system's thermal state and heat energy requirements. At the same time the Gibbs Free Energy keeps the system in chemical equilibrium [32, 33, 34]. The solidification rate controls the fineness of the microstructure including the fraction, size and distribution of the phase constituents such as intermetallics, eutectic silicon etc. and the segregation of solute in the $\alpha$-Al matrix. As seen in Fig. 2.2 dendrite arms with smaller radius may re-melt into the molten liquid along with decreasing total interfacial energy. 

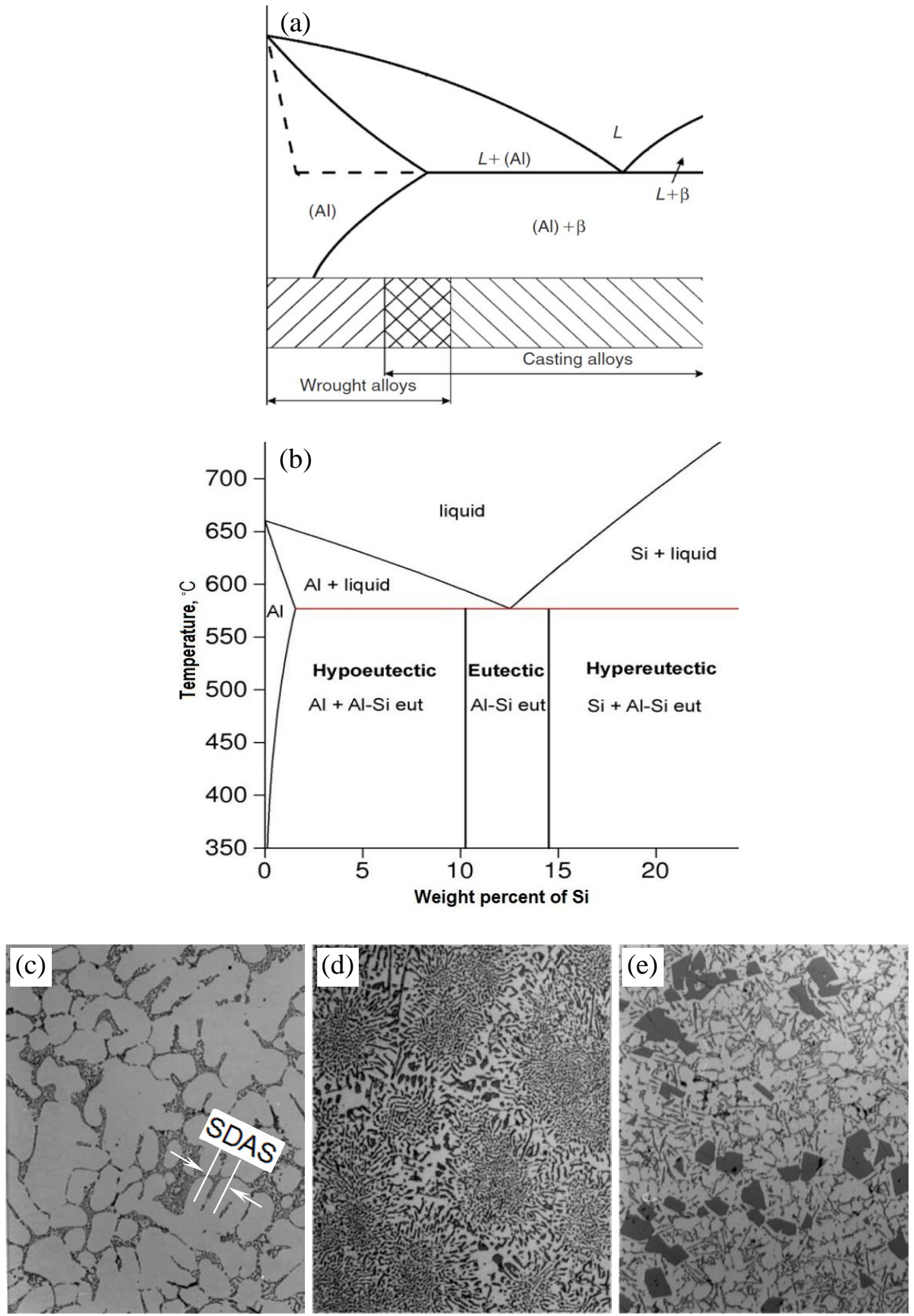

Fig. 2.1. Schematic of a binary phase diagram Al-B (2nd component) of the eutectic type: (a) domains of wrought and cast alloys [30], (b) Al-Si alloy phase diagram (Al rich part) and typical microstructure of (c) hypoeutectic, (d) eutectic and (e) hypereutectic Al-Si alloys [31]. 
The primary and secondary dendrites generally range from 10 to $150 \mu \mathrm{m}$ and are controlled mainly by the rate of solidification of the melt [35]. To achieve a maximum property of the alloy, the dendrite arm spacing size therefore must be minimized and distributed homogeneously. The details of solidification behavior of the alloys in terms of Gibbs Free Energy are given in $[32,33]$.

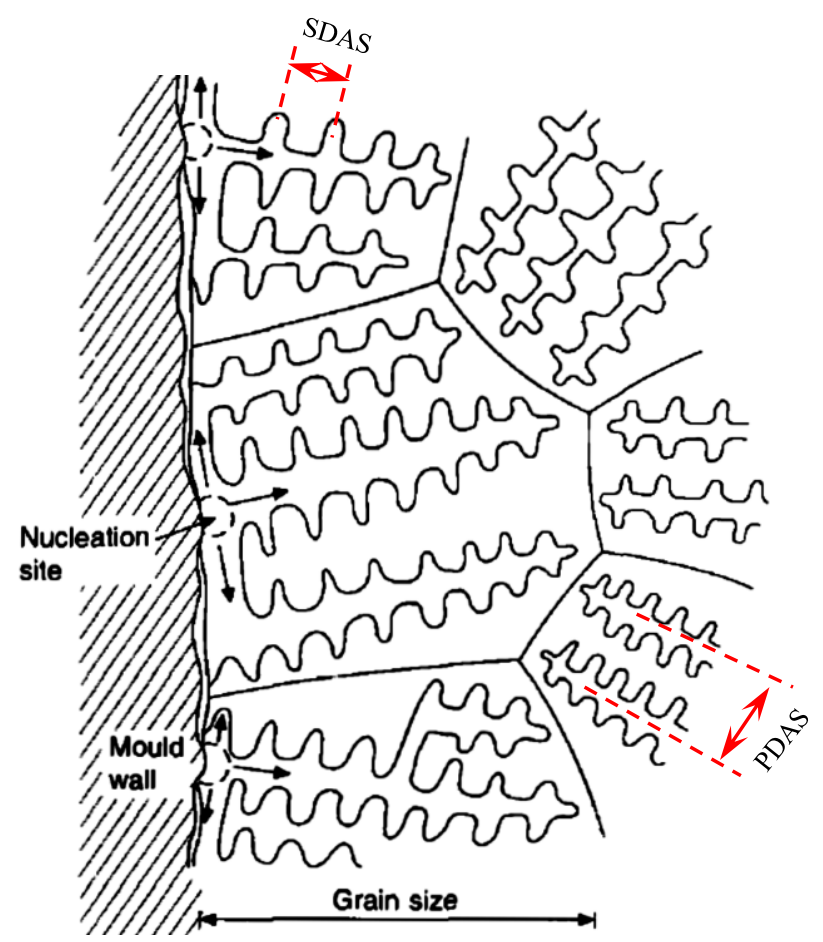

Fig. 2.2. Schematic illustration shows the formation of dendrites to make grains. The dendrite stems within any one grain are all crystallographically associated to a common nucleus [32].

\subsubsection{Grain refinement}

A fine grain size is often desired as it improves mechanical properties of the casting and at the same time has a constructive influence on castability. The most common way to accelerate the formation of fine grains is to add certain chemical agents that facilitate nucleation of new aluminum crystals. Most conveniently this is done by addition of specially prepared master alloys. Grain refinement is, however, the result of two separate processes: nucleation of new crystals from the melt, and subsequent growth of the new crystals into a limited size. Both these 
processes need a driving force that has to be supplied to the system via under-cooling $(\Delta \mathrm{T})$ and/or super-saturation $(\Delta \mathrm{C})$ in relation to the equilibrium conditions of the actual system (Fig. 2.3). If the cooling rate is very fast, the undercooling changes which enhances the degree of nucleation.

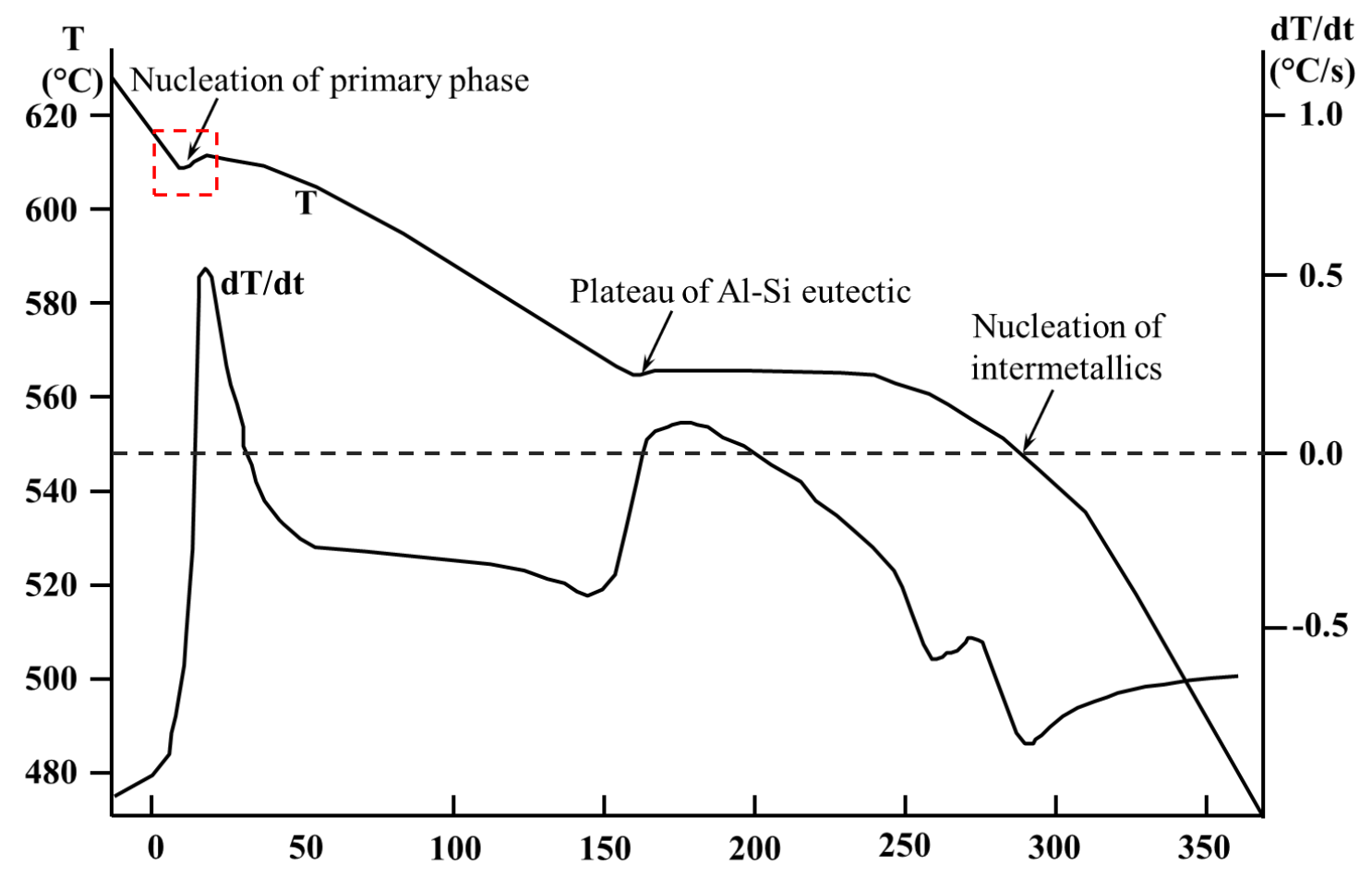

Fig. 2.3. Typical cooling-curves of an hypo Al-Si-Cu-Mg alloy, Cooling curve(top curve) and its derivative (bottom curve) obtained from the melt of Al-Si alloy.

In a real casting, this means that during the very first period of the solidification process, only those parts of the liquid metal in contact with mold walls are undercooled to such a degree that nucleation of new aluminum grains can occur. As soon as the first crystals have grown to a reasonable size, the recalescence brings the temperature of the whole interior liquid up to the actual growth temperature and no more aluminum crystals can form. The solidification therefore proceeds by growth of the originally nucleated crystals in a columnar, coarse-grained manner. To increase the alloy grain refinement, the liquid is constantly undercooled so that the new 
crystals formed in the liquid can grow at such a rate that they impinge upon each other and form a continuous dendritic network [36].

With the addition of a grain refiner, nucleation starts far above the equilibrium temperature, resulting in a longer range of nucleation time and more nucleuses. The grain refining inoculant used in aluminum foundry practice is usually master alloys such as Al-Ti. It was reported that Ti alone cannot effectively work as a grain refiner. Mohanty and Gruzleski [37] refined the Al-Si alloy by adding different inoculants of $\mathrm{TiB}_{2}, \mathrm{Al}-\mathrm{Ti}-\mathrm{Si}$ and $\mathrm{TiC}$. They concluded that $\mathrm{TiB}_{2}$ alone does not nucleate $\alpha$-Al, but rather is pushed into the interdendritic region by the primary phase. In the presence of solute $\mathrm{Ti}$ and $\mathrm{TiB}_{2}$, segregation of $\mathrm{Ti}$ and $\mathrm{Si}$ onto the particle/melt interface occurs, accompanied by the formation of a ternary aluminide (Al-Ti-Si) phase. This ternary aluminide acts as a nucleant for the $\alpha$-phase. A drastic reduction in the peritectic solidification temperature of the ternary system at higher $\mathrm{Si}$ contents appears to be the reason for the inefficient performance of Al-5Ti-1B master alloys. The nature of the solid substrates plays a very important role in the inhomegenous distribution of $\mathrm{Ti}$ in the bulk melt and the precipitation of the aluminide. The improved performance of Al-3Ti-3B is presumably due to excess $\mathrm{B}$ present in solution, which forms a B-rich layer at the $\mathrm{TiB} /$ melt interface. Upon cooling, this interfacial layer nucleates $\alpha$ - $\mathrm{Al}$ in a manner similar to that which occurs in the Al-B system, possibly via a eutectic reaction. $\mathrm{TiC}$ is not an effective nucleant since it decomposes in $\mathrm{Al}-\mathrm{Si}$ alloys. However, the effect of inoculant fades with time. Increasing the holding time to more than 20 min leads to decreased efficiency of the inoculant [38]. Other studies also reported that Al-Ti-B is one of the most effective grain refiners for the Al-Si alloys. However, the addition of carbides such as TiC, $\mathrm{SiC}$ etc. decomposed during melting and reduced the efficiency [39, 40, $41,42]$. 


\subsubsection{Modification of Al-Si eutectics}

$\mathrm{Si}$ exhibits the diamond-like face-centered cubic crystal structure where each $\mathrm{Si}$ atom is surrounded by four nearest neighbor atoms. There are several mechanisms of formation of eutectic silicon. The ledge process via migration is one of the common growth processes which is schematically shown in Fig. 2.4. When Si nucleates in to the Al-Si melt, it grows as flakes with atomically flat, (111) Si-oriented surfaces. The flakes are grown on the (111) surfaces by forming monoatomic ledges, which consequently migrate on the surface by integrating further atoms at the ledge [36].
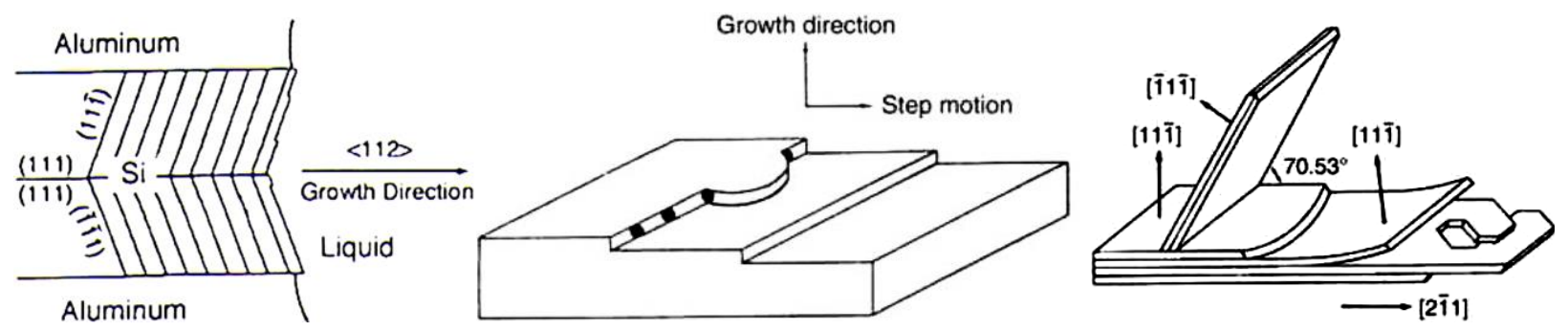

Fig. 2.4. The growth mechanism of Si flakes on (111) surface by Ledge migration [36, 43, 44].

Another growth mechanism, Twin Plane Re-entrant Edge (TPRE) is shown in Fig. 2.5. Here, the eutectic silicon growth in certain crystallographic directions is favored and some twin-planes forming re-entrant edges seem to be especially effective in promoting the growth. In directional solidification experiments it can be shown that the silicon crystals developed ahead of the Al phase, and the morphology of the silicon crystals look like plate/fan-shape, which are grown from a limited number of nucleation sites. Alloys containing these types of structures exhibit poor mechanical properties. Thus, the eutectic silicon was modified in two ways; (i) thermal treatment and (ii) chemical treatment which change the morphology of the eutectic silicon resulting in significant improvement of mechanical properties, especially ductility [36]. 


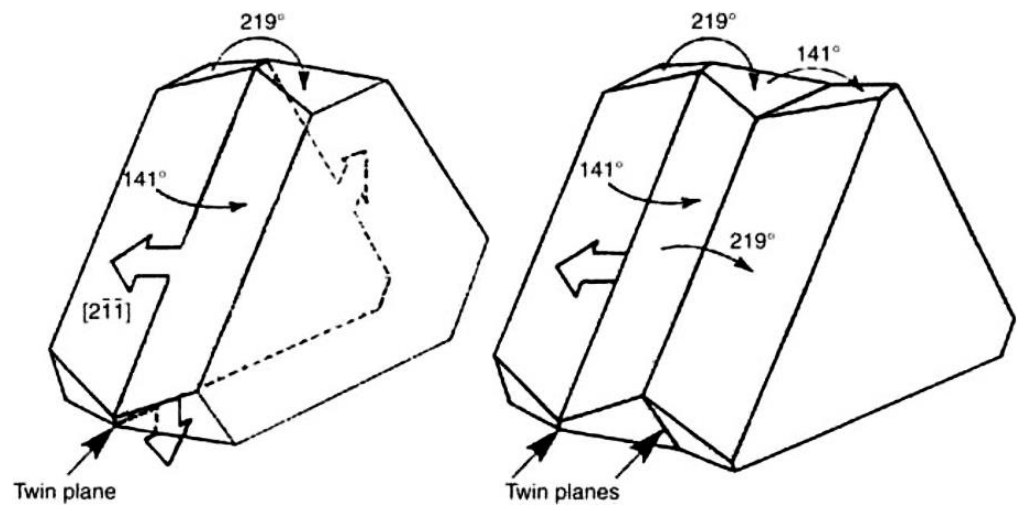

Fig. 2.5. The schematic illustration shows the location of twin planes and re-entrant edge in a silicon crystal [36].

Rapid solidification and heat treatment known as thermal modification can also modify the eutectic silicon. The basic mechanism of thermal modification of eutectic silicon is the fragmentation, rounding of sharp edges, spheroidization, coarsening of large and dissolution of small particles of eutectic silicon into the matrix. Many researchers investigated the effect of thermal treatment on spheroidization of eutectic silicon in the Al-Si alloy matrix $[45,46,47,48$, 49]. In addition, the eutectic silicon was also modified by addition of electropositive metals such as $\mathrm{Na}, \mathrm{Sr}, \mathrm{Ca}$ etc. The nucleation and the growth processes of the eutectic Si crystals are influenced by the addition and movement of the eutectic point to a higher silicon concentration and lower temperature, as seen in Fig. 2.6. This modifies the growth of the eutectic silicon to produce an irregular fibrous form rather than the usual flakes. The eutectic point has moved far enough to make the alloy form primary $\alpha$-Al, rather than primary Si. Depending on a hardsphere model, the mechanism of shape modification of the eutectic silicon by impurities has been explained by Lu and Hellawell $[44,50]$. They have reported that impurity atoms of the suitable size can force the formation of nucleation of twins and stacking faults at the solid-liquid (eutectic Si-melt) interface. These twins create sites for atom attachment at the interface, 
encouraging growth in a manner similar to that of an atomically rough interface. As a result, the morphology of the eutectic Si particles modifies from flakes to fibers.

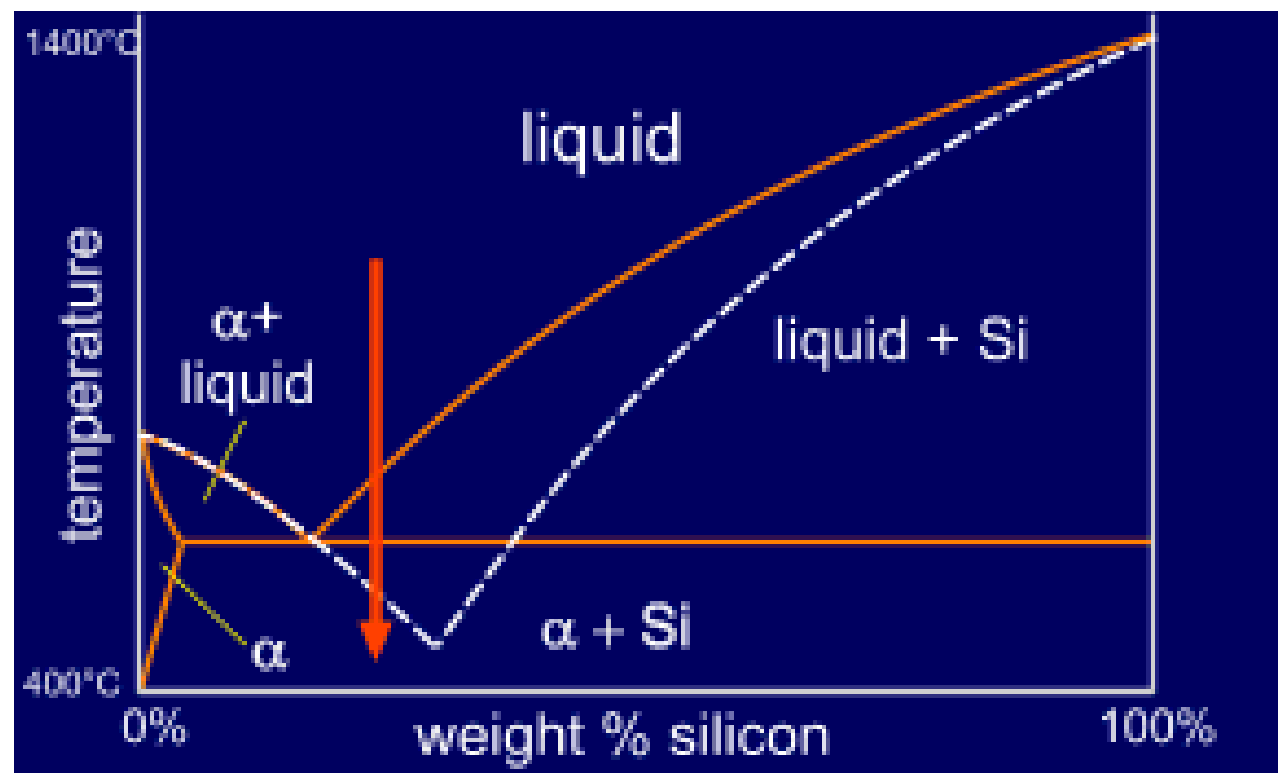

Fig. 2.6. Al-Si binary phase diagram shows the shift of reaction point due to addition of modifier [31].

$\mathrm{Na}$ has a higher vapor pressure than $\mathrm{Sr}$ and high affinity to oxygen, it readily burns off and its modification efficiency is lost within a rather short time. In contrast, $\mathrm{Sr}$ remains active for much longer periods of time and is easy to add to the melt as master alloy, which makes modifying properties much more controllable. Recent studies showed that the modification efficiency of $\mathrm{Na}$ and $\mathrm{Sr}$ is faded with increasing the number of re-melts. To improve the modification efficiency, the eutectic $\mathrm{Si}$ was modified using $\mathrm{Bi}, \mathrm{Sb}$ along with $\mathrm{Na}$ or $\mathrm{Sr}$, where the fading effect reduced significantly $[48,51]$.

\subsubsection{Formation of dispersoid phase}

Most commercial alloys are designed to have precipitates that control the grain structure. As mentioned earlier, aluminum combines with the transition metals, (chromium, manganese, 
zirconium, etc.), to form intermetallic phases with little or no solubility in the aluminum matrix. Because of their slow diffusivity in aluminum, these alloying additions form very small precipitates, less than one micron in size, either during solidification or during preheats. This fine distribution of precipitates called dispersoids delay or prevent static recrystallization during processing. Because they are strung out in the working direction, they also aid in retaining the elongated or "pancake"-shaped grains that develop during working. The mean free path of the dispersoids is greater in the working direction than in directions perpendicular to it. Thus, recrystallized grains can grow faster in the working direction. Such elongated grains impart anisotropic behavior to the material. The effectiveness of a particular dispersoid in controlling the grain structure depends on its size, spacing, and coherency [33].

\subsection{Heat Treatment of Al-Si Alloys}

Heat-treatment is one of the most important manufacturing processes where the microstructure can be changed to alter the mechanical properties of the alloys. The development of the mechanical properties of $\mathrm{Al}$ alloys due to heat treatment processes depends on the variation in solubility of the alloying elements with temperature. The most commonly used heat treatment processes for $\mathrm{Al}-\mathrm{Si}$ alloys in industries are $\mathrm{T} 6$ and $\mathrm{T} 7$ which are composed of solution treatment followed by ageing. Fig. 2.7 shows the major steps of the heat treatment which is generally used to improve the mechanical properties of aluminum alloys. As seen in Fig. 2.7a, at first the alloy is solution treated at a temperature just below the lowest melting temperature of the constituent phases for a long enough time to allow dissolving of the second phase. After that, the alloy is rapidly cooled to room temperature, a process known as quenching. Finally, the alloy is heated to a lower temperature to form fine precipitates. The microstructural changes of the alloys during heat treatment is illustrated in Fig 2.7b; from (1) atoms in solid solution at the solution 
treatment temperature, through (2) a supersaturated solid solution at room temperature after quench, to (3) precipitates formed at the artificial ageing temperature.

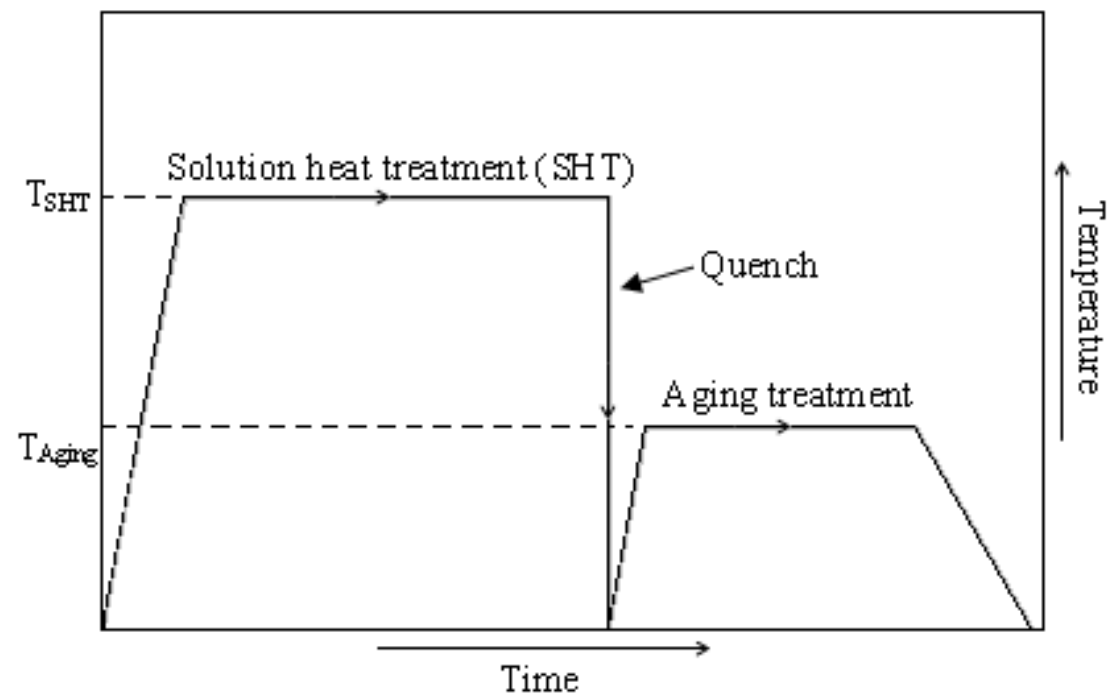

(a)

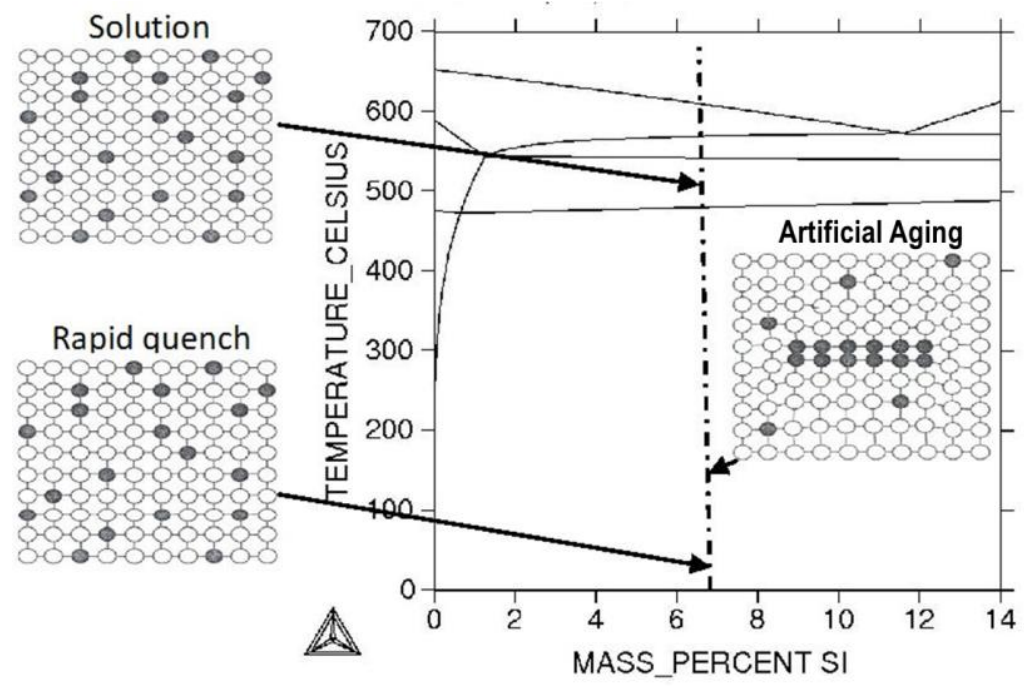

(b)

Fig.2.7. A graphic representation of the heat treatment processes for the Al alloys, (a) the heat treatment cycles and (b) microstructural changes [34].

\subsubsection{Solution treatment}

Solution heat treatment must be applied for a sufficient length of time to obtain a homogeneous supersaturated structure, followed by the application of quenching with the aim of maintaining 
the supersaturated structure at ambient temperature. In $\mathrm{Al}-\mathrm{Si}-\mathrm{Cu}-\mathrm{Mg}$ alloys, the solution treatment fulfils three roles: [34, 52].

a. Homogenization of the as-cast structure.

b. Dissolution of certain intermetallic phases such as $\mathrm{Al}_{2} \mathrm{Cu}$ and $\mathrm{Mg}_{2} \mathrm{Si}$.

c. Change of the morphology of eutectic silicon.

The microstructure segregation of alloying elements from dendritic solidification has a negative effect on mechanical properties. The time required for homogenization depends on the solution temperature and the size of SDAS. The alloying elements such as $\mathrm{Cu}$ and $\mathrm{Mg}$ display significant solid solubility in heat-treatable Al-Si alloys along the solidus line in the phase diagram. The solubility of alloying elements in the $\alpha$-Al matrix increases with increasing temperature.

Based on conventional solution treatment rules, the solution temperature of $\mathrm{Al}-\mathrm{Si}-\mathrm{Cu}-\mathrm{Mg}$ alloys is restricted to $495^{\circ} \mathrm{C}$, in order to avoid incipient melting of the copper-rich phase [34, 53, 54]. The time at the nominal solution treatment temperature must be long enough to homogenize the alloy and to ensure a satisfactory degree of precipitate solution. In alloys containing high levels of copper, complete dissolution of the $\mathrm{Al}_{2} \mathrm{Cu}$ phase is not usually possible. The solution time must then be chosen carefully to allow for the maximum dissolution of this intermetallic phase, bearing in mind that solution treating the alloy for long times is expensive and may not be necessary to obtain the required alloy strength. Moreover, the coarsening of the microstructural constituents and the possible formation of secondary porosity which result from prolonged annealing at such temperatures can have a deleterious effect on the mechanical properties $[34,55,56]$. The solution heat treatment of 319 alloys over a temperature range of $480^{\circ} \mathrm{C}$ to $540^{\circ} \mathrm{C}$, for solution times of up to 24 hours, showed that the best combination of tensile strength and ductility was obtained when the as-cast material was solution heat-treated 
at $515^{\circ} \mathrm{C}$ for 8 to 16 hours, followed by quenching in warm water at $60^{\circ} \mathrm{C}$ [34]. A two-step solution treatment, namely, conventional solution treatment followed by a high temperature solution treatment, is reported to reduce the amount of the copper-rich phase in 319 alloys significantly, thereby giving rise to better homogenization prior to ageing and thus also to improvements in the mechanical properties $[57,58,59]$. The holding time for the first stage and the solution temperature of the second stage are both significant parameters. Sokolowski et al. $[57,58]$ studied the improvement in 319 aluminum alloy casting durability by means of high

temperature solution treatment. Their results showed that a two-step solution treatment of $495^{\circ} \mathrm{C} / 2 \mathrm{~h}$ followed by $515^{\circ} \mathrm{C} / 4 \mathrm{~h}$ produced the optimum combination of strength and ductility compared to the traditional single-step solution treatment of $495^{\circ} \mathrm{C} / 8 \mathrm{~h}$.

\subsubsection{Quenching}

The precipitation occurring during quenching is dependent on the degree of solute supersaturation and the diffusion rate, as a function of temperature. As an alloy is quenched, there is greater super-saturation, which is a diffusion-controlled process. At lower temperatures, diffusion rate and super-saturation are lower, resulting in a lower precipitation rate. At intermediate temperatures, the amount of super-saturation is comparatively higher, as is the diffusion rate. Therefore the precipitation rate is the greatest at intermediate temperatures as shown in Fig. 2.8. The amount of precipitation occurring during quenching reduces the amount of precipitation reactions during ageing, resulting in lower mechanical properties such as tensile strength, yield strength, ductility, fracture toughness etc. There are three ways to prevent excessive precipitation during quenching; (i) the transfer time should be as low as possible, (ii) the quenchant properties must be fast enough to achieve the desired cooling rate, and (iii) the 
quench tank must have adequate thermal inertia so that the quenchant does not heat excessively, causing an interrupted quench [60].

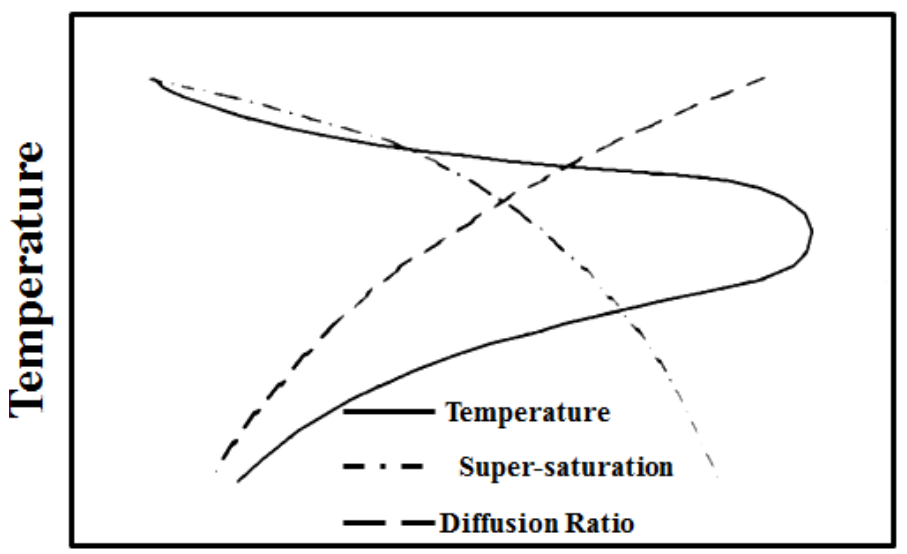

Fig. 2.8. Schematic representation of temperature effects on factors that determine the heterogeneous precipitation rate during quenching [60].

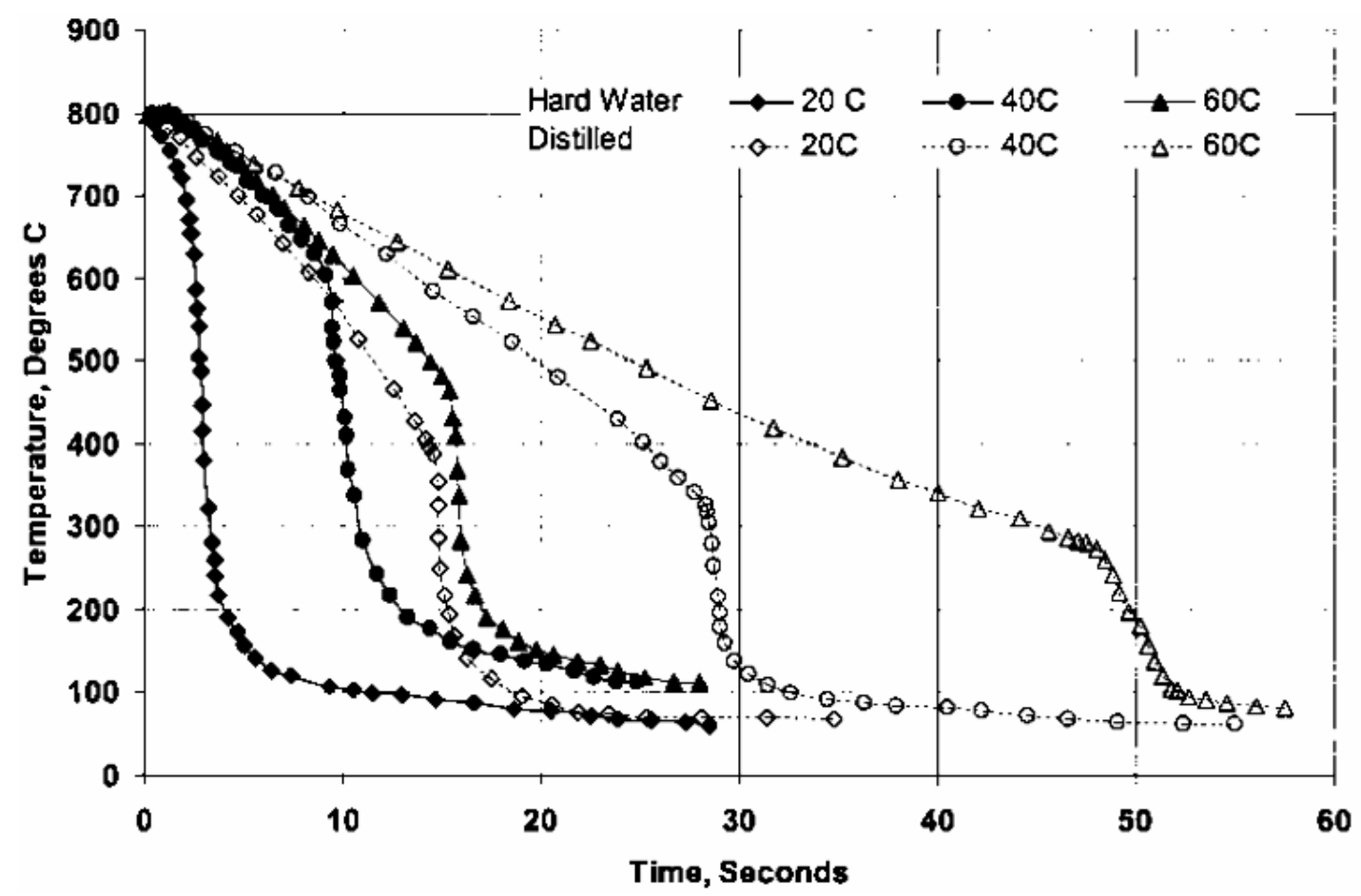

Fig.2.9. Comparison of the cooling rates of distilled water and normal "hard" water [60].

Cold water quenching is the most severe of commonly used quenchants. This study also showed that there was a marked difference between hard water and distilled water. Distilled water showed an extensive vapor blanket that extended to very low temperatures (Fig. 2.9). The 
cooling rate of water quenching is dependent on water temperature and agitation. Water temperature is the largest primary variable controlling the cooling rate. With increasing water temperature, the cooling rate decreases. The maximum cooling rate also decreases as the water temperature is increased. Also, the length of time and stability of the vapor barrier increases with increasing water temperature.

\subsubsection{Ageing}

The last stage of heat treatment is ageing. High strength is obtained by ageing for appropriate times at one or two intermediate temperatures to form a finely dispersed precipitate. This final step must be accomplished not only below the equilibrium solvus temperature, but also below a metastable miscibility gap called the Guinier-Preston (GP) zone solvus line (Fig. 2.10) in order to have uniform precipitation. As noted in Fig. 2.10 the temperature of the line increases with solute content. The critical temperature also increases with vacancy concentration $[34,60]$.

The supersaturation of vacancies allows diffusion and clustering of solute atoms to occur much faster than expected from equilibrium diffusion coefficients. In precipitation-hardening alloys, three types of interfaces may develop during nucleation and growth of strengthening precipitates: coherent, semicoherent, and incoherent interfaces. As a slight difference in lattice parameter may cause local elastic strains which maintain coherency, there was no significant difference in atomic positions across a coherent interface [43, 61].

When the coherency strains increased to the higher level during the ageing process, the coherent interface can be substituted by a periodic array of edge dislocations or structural ledges, which turn in to a semicoherent interface. Depending on the misfit between precipitates and the matrix and their interfacial energy, the coherent to semicoherent precipitates can be formed at different shapes, e.g., spheres, cubes, disks, and needles. The shape that forms usually 
reduces the total energy related to the formation of the precipitates. As the spherical particles exhibit lower surface area, there is smaller atomic misfit. At the same time, the shapes of disks or needles formed have a large atomic misfit in order to minimize the strain energy $[34,60]$.

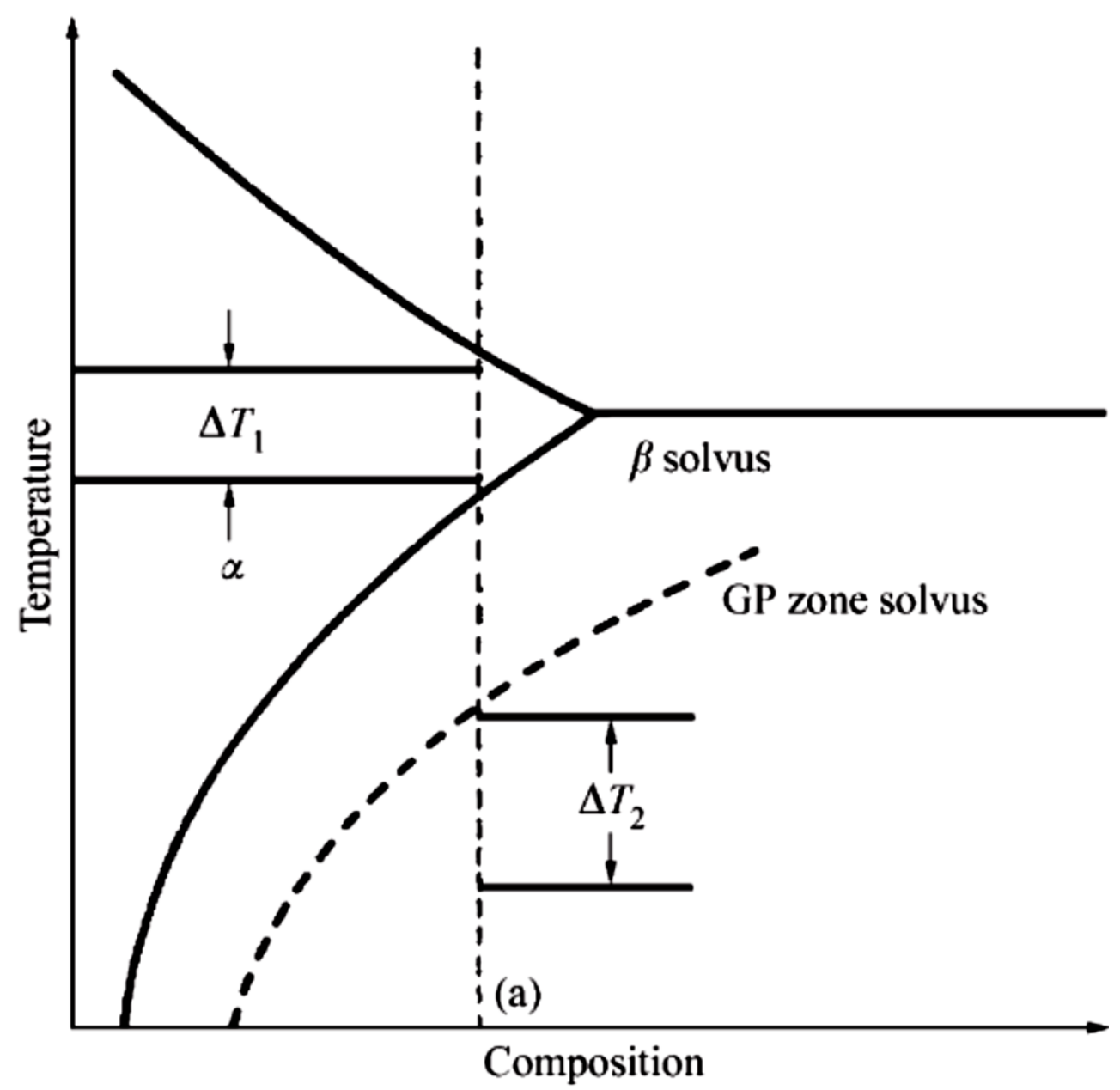

Fig. 2.10. A part of phase diagram of a heat treatable alloy system indicating the $\beta$ solvus and the GP zone solvus. Here, $\Delta \mathrm{T} 1$ is the range of solution heat treatment temperature, and $\Delta \mathrm{T} 2$ is the range of ageing heat treatment temperature [61].

The interface of incoherent precipitates has a degree of disorder comparable to that of a highangle grain boundary. The formation sequences of the precipitates are supersaturated solid solution, clusters of solute atoms, transition of precipitate and lastly equilibrium precipitate. [43, 61]. To achieve desired strengthening precipitates, more than one alloying element is added in to the aluminum matrix. The atomic size of the alloying elements also impacts the formation of 
the precipitates. If the first solute atomic size is larger than the solvent atom, the atomic size of the second solute should be smaller which minimizes the internal strain related to clustering of solute atoms. Thus, the critical size for precipitation decreases, and causes a uniform dispersion of strengthening precipitates. As strengthening is related to the volume fraction, shape and size of the participate particles, maximizing those elements which can be formed during the ageing sequence and can be incorporated into solution at the solutionizing stage optimize the alloy strength $[34,43]$.

Alfred Wilm in 1906 first developed the heat-treatable Al-alloy based on the Al-Cu alloy system. The results showed that the hardness of Al-alloys which contained $\mathrm{Mg}, \mathrm{Cu}$, and other trace elements such as $\mathrm{Fe}$, Si etc. increased with time at room temperature, which was later described as precipitation hardening. The typical precipitation sequence for the Al-Si-Cu alloy, such as 319 , is dependent on the formation of $\mathrm{Al}_{2} \mathrm{Cu}$ precipitates. The sequence of $\mathrm{Al}_{2} \mathrm{Cu}$ precipitation can be defined as follows $[34,57,58,59]$ :

$$
\mathrm{SSSS} \rightarrow \mathrm{GP} \text { Zones } \rightarrow \theta^{\prime \prime} \rightarrow \theta^{\prime} \rightarrow \theta\left(\mathrm{Al}_{2} \mathrm{Cu}\right)
$$

The solid solution decomposes first and forms a $\mathrm{Cu}$-cluster which leads to the formation of coherent, disk-shaped GP zones. With ageing at room temperature, the size of the GP zones increase homogeneously; these zones manifest as two-dimensional, $\mathrm{Cu}$-rich disks with diameters of about to 3-5 nm. With increasing the ageing temperature of $\mathrm{Al}-\mathrm{Cu}$ alloys above $100^{\circ} \mathrm{C}$ the GP zones dissolve and are replaced by the $\theta^{\prime \prime}$ precipitate. This precipitate obtained a three dimensional plate-like disk-shape having an ordered tetragonal arrangement of $\mathrm{Al}$ and $\mathrm{Cu}$ atoms. The $\theta^{\prime \prime}$ precipitates which are coherent with the matrix in binary $\mathrm{Al}-\mathrm{Cu}$ alloys are uniformly nucleated in the matrix. The high degree of coherency causes extensive coherencystrain fields to increase $[34,62]$ the peak strength of the materials. 
Increases in $\mathrm{Cu}$ content in $\mathrm{Al}$-alloys cause a reduction of ductility and change of morphology of the $\mathrm{Cu}$-rich phases $[34,61]$. The strength of the age-hardenable alloys is affected by the interaction between the dislocations and precipitates. The motion of dislocations hindered by the precipitates in age hardened alloys can be either the strain field around the GP zone caused by from their coherency with the matrix, or the zones and precipitates themselves, or both. During deformation of the alloy containing precipitates, the dislocations are cut through or go around forming loops around the precipitates, which will be discussed in a later section. Kasprzak et al. [63] investigated the dimensional changes occurring during the heat treatment of an automotive alloy by means of T6 and T7 tempers involving solution treatment, solutionizing followed by artificial ageing. They observed that increasing the solution temperature has the greatest influence in the dimensional change of samples due to dissolution of the $\mathrm{Al}-\mathrm{Cu}(\theta)$ eutectic phase. By increasing the ageing temperatures, however, expansion is produced as a result of the transformation of the metastable phases into equilibrium phases.

Mohammed et al. [34] and Shivkumar et al. [64] studied the parameters which control the mechanical properties of A356 alloy in the T6 heat treated condition. The improvement of the alloy strength has been considered to be due to the precipitation of minor phases from a supersaturated matrix. The sequence of precipitation in Al-Si-Mg alloys (Fig. 2.7) is similar to the $\mathrm{Al}-\mathrm{Cu}$ alloy system as described earlier. In this alloy, at first, GP zones with needle-like precipitates of about $10 \mathrm{~nm}$ long were formed from the supersaturated solid solution. After that, an intermediate homogeneous precipitate of $\beta^{\prime \prime}-\mathrm{Mg}_{2} \mathrm{Si}$ is formed followed by heterogeneous precipitates of $\beta^{\prime}-\mathrm{Mg}_{2} \mathrm{Si}$ and finally, the equilibrium precipitates of $\beta-\mathrm{Mg}_{2} \mathrm{Si}$ are formed. The ultimate alloy strength at peak-ageing is obtained before the precipitation of the incoherent $\beta$ platelets. Apelian et al. $[10,34]$ studied the ageing characteristics of Al-Si-Mg alloys and reported that the precipitation of very fine $\beta^{\prime}-\mathrm{Mg}_{2} \mathrm{Si}$ during ageing leads to a significant 
improvement in mechanical properties. Both ageing time and temperature controlled the final properties (Fig. 2.11). They also reported that increasing the ageing time of the alloy by a factor of two increases the ageing temperature by $10^{\circ} \mathrm{C}$. In the early stages of natural ageing, a higher concentration of quenched in vacancies increases the formation rate of solute clustering which causes a reduction of super-saturation of solute in the matrix. The solute clusters which act as successful nuclei for the formation of $\beta^{\prime \prime}$ during subsequent artificial ageing, show a uniform distribution in the matrix and cause a fine precipitate. A lower solute super-saturation is anticipated to diminish the kinetics of precipitation. The unstable clusters are dissolved by increasing the solute concentration during artificial ageing. At the same time, larger clusters that are stable eliminate solute by increasing the GP zones that work as nucleation sites for $\beta^{\prime \prime}$. Thus, the solute super-saturation is continued at a reasonably low level during artificial ageing and the density of the $\beta^{\prime \prime}$ is much lower than that produced in alloys without natural ageing.

As shown in Fig. 2.11 by Mohammad et al. [34], the precipitation sequence for $\mathrm{Al}-\mathrm{Si}-\mathrm{Cu}-\mathrm{Mg}$ alloys is similar, but more complex, as the $\mathrm{Q}^{\prime \prime}$ precipitates and the $\theta^{\prime}$ precipitates can be formed. $\mathrm{Cu}$ increases the fraction tendency of the $\beta^{\prime \prime}$ precipitates, but it also can form the $\mathrm{Q}^{\prime \prime}$ precipitates, which have a lower contribution to the alloy strength compared to the $\beta^{\prime \prime}$ precipitates. The $\beta^{\prime \prime}$ precipitates are more significant to improve the alloy strength than the $\mathrm{Q}^{\prime \prime}$ precipitates. For wrought alloys it was reported that the fraction of the $\mathrm{Q}^{\prime \prime}$ precipitates increases with natural ageing and artificial ageing time and temperature [34, 54, 53]. The Mg-to-Si ratio controls the formation of metastable Mg-rich precipitates. The kinetics of precipitation and the phase composition are changed by the excess of Si in solid solution. Similarly, stable phases are rich of $\mathrm{Mg}$ while metastable phases are enriched of $\mathrm{Si}[34,65,66,67,68]$. 


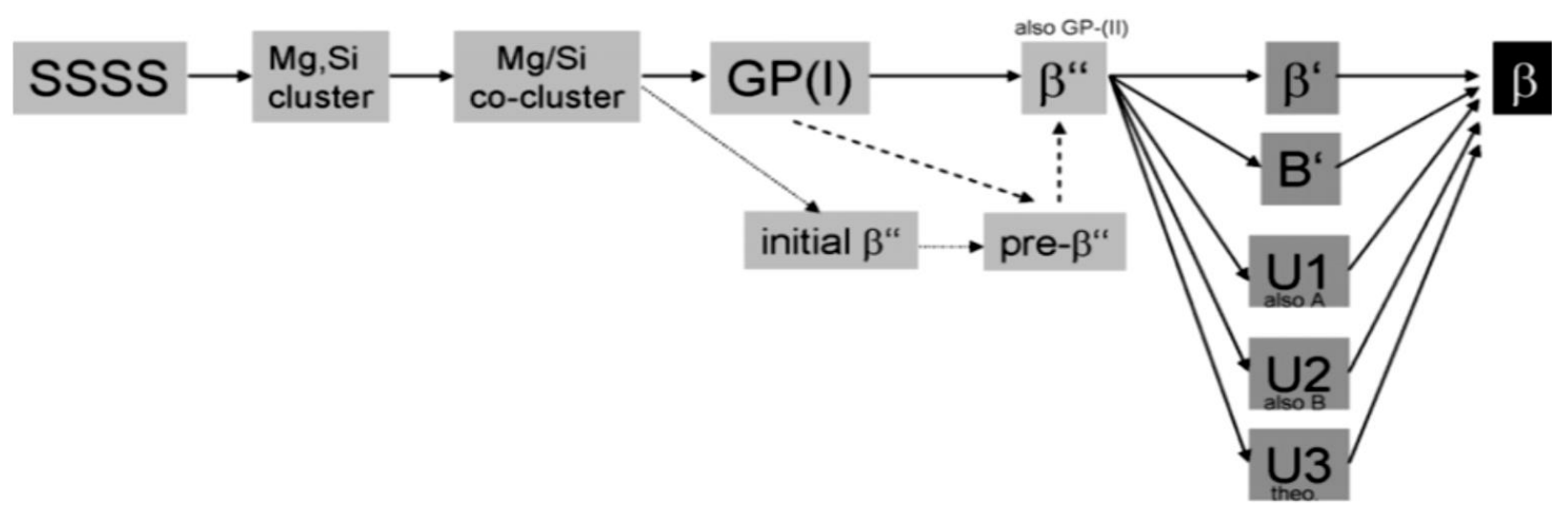

Fig. 2.11. A typical sequence of phases found during age hardening of Al-Mg-Si alloys [34].

"Supersaturated solid solution (SSSS) decomposes as Mg and Si atoms are attracted first to themselves (cluster) then to each other to form precipitates GP(I), sometimes also called initial-

$\beta^{\prime \prime}$. GP(I) zones either further evolve directly to a phase $\beta^{\prime \prime}$ and then to a number of other metastable phases labelled $\beta^{\prime}, B^{\prime}, \mathrm{U} 1, \mathrm{U} 2$ (another one, U3, has been postulated theoretically), or first form an intermediate phase called pre- $\beta^{\prime \prime \prime}$ [34].

\subsection{Strengthening Mechanism of Al Alloys}

Pure aluminum is soft and cannot meet the engineering requirements. In order to use aluminum as a structural material, it should be strengthened so that it can meet the requirements of the industry. There are three ways: mechanical working, solid solution strengthening, and precipitation strengthening to strengthen $\mathrm{Al}$ and its alloys. In the following sections different strengthening mechanisms will be discussed.

\subsubsection{Strengthening due to mechanical working}

Mechanical working or strain hardening is a process of making a metal harder and stronger through plastic deformation. The plastic deformation in crystalline materials is directly related to the generation, motion and storage of dislocations, which move at a stress far below that required to deform a defect-free crystal [69]. Increasing the density of dislocations in the material results in more interactions occurring and cause pinning or tangling which reduces the mobility of the dislocations and strengthens the material. Also, increasing the dislocation 
density increases the yield strength which results in a higher shear stress required to move the dislocations resulting in strengthening of the alloys. The most commonly used method to strengthen wrought $\mathrm{Al}$ alloys is to mechanically deform the alloys at elevated temperatures (hot/warm working) or at room temperature (cold working). Hot working of $\mathrm{Al}$ alloys is typically performed at above the recrystallization temperature while the warm working is executed between the room and recrystallization temperatures. Several methods are available for mechanical working of the as-cast alloys. The most frequently used method is rolling. Besides rolling there are other mechanical working methods to strengthen aluminum alloys. Other less commonly used mechanical working methods are forging, spinning, and drawing. The wrought alloys are commonly strengthened by mechanical working. However, the Al-Si cast alloy is the subject of the present study. Thus, further discussion will not be presented on this topic.

\subsubsection{Solid solution strengthening}

Another technique to strengthen the metals is alloying with impurity atoms that go into solid solution which is known as solid-solution strengthening. Increasing the concentration of the alloying elements in the base metal increases the tensile and yield strengths. Generally, there are two types of solid solutions; substitutional solid solution (Fig. 2.12a), such as Si in Al, and interstitial solid solution (Fig. 2.12b), such as Mn in Al. In substitutional solid solution, atoms of the solute metal $(\mathrm{Si})$ replace atoms of the solvent $(\mathrm{Al})$ metal in the crystal lattice. In contrast, the interstitial solution, the solute atoms are small enough to fit into interstices spaces between the solvent atoms in the crystal lattice. Since the solute and solvent atoms are different in sizes, they distorted the crystal lattice so that the movement of dislocations will be resisted by the solute atoms. To overcome this barrier higher stress levels or temperatures will be required to activate the sliding or climbing motion of dislocations [70]. 


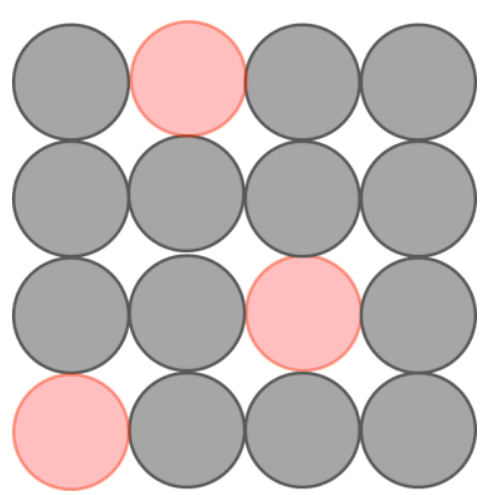

(a)

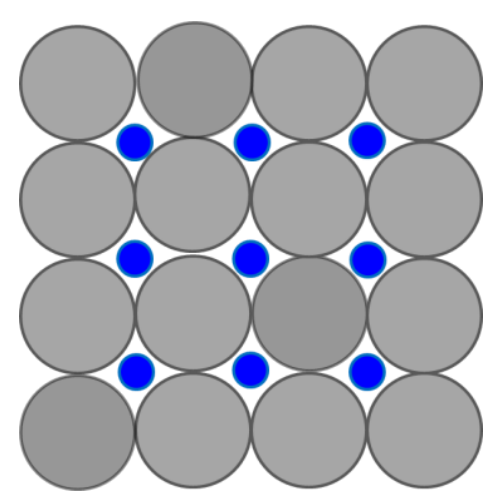

(b)

Fig. 2.12. A schematic illustration of different types of solid solution of (a) substitutional solid solution and (b) interstitial solid solution.

The alloys are stronger than pure metals because alloying elements' atoms that go into solid solution generally exert lattice strains on the surrounding atoms of the base metals. For example, an impurity atom that is smaller than a host atom for which it substitutes exerts tensile strains on the surrounding crystal lattice, as illustrated in Fig. 2.13a. Conversely, a larger substitutional atom levies compressive strains in its neighborhood (Fig.2.13b). These solute atoms tend to diffuse and segregate around dislocations to reduce the overall strain energy that is, to cancel some of the strain in the lattice surrounding a dislocation. To achieve this, the impure smaller atom is located where the tensile strain will partially abolish some of the dislocations' compressive strain. For the edge dislocation in Fig. 2.13a, this would be adjacent to the dislocation line and above the slip plane. A larger impurity atom would be situated as in Fig. 2.13b. The resistance to slip is higher when the impure atoms are present because the overall lattice strain must increase if a dislocation is torn away from them. Furthermore, the same lattice strain interactions (Fig 2.13) will exist between impurity atoms and dislocations that are in motion during plastic deformation [70]. 


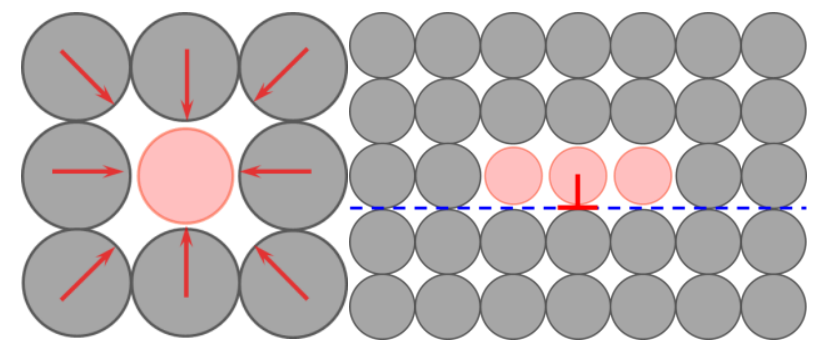

(a)

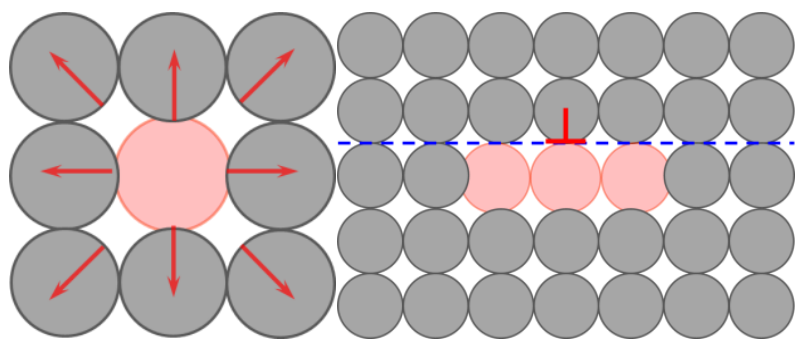

(b)

Fig. 2.13. A schematic illustration shows lattice strains imposed on host atoms due to solid solution along with the possible locations of alloying atoms relative to an edge dislocation, (a) tensile lattice strain and (b) compression lattice strain.

\subsubsection{Precipitation strengthening}

Precipitation hardening is commonly employed with high-strength Al alloys. Although a large number of these alloys have different proportions and combinations of alloying elements, the mechanism of hardening has perhaps been studied most extensively for the $\mathrm{Al}$-alloys containing $\mathrm{Cu}$ and $\mathrm{Mg}$. As discussed in an earlier section, the fine precipitates are formed during ageing, which resist the movement of dislocations and increase the strength of the materials. The important parameters of precipitation-hardened alloys are the strength, volume fraction and the dispersion of the precipitate phases and their mean size and the mean distance between them.

Precipitated particles can effectively hinder the dislocations motion in the $\alpha-\mathrm{Al}$ matrix. From the above discussion it is clear that the effect of hardening due to precipitates depends on two parameters: the size of the particle and the spacing between two particles. Sjölander and Seifeddine $[53,54]$ studied the ageing characteristics of Al-Si-Cu-Mg alloys. After solution treatment and naturally ageing at room temperature for 1 day prior to artificial ageing in a forced circulation air furnace at $170^{\circ} \mathrm{C}$ or $210^{\circ} \mathrm{C}$ for various times, they concluded that the peak yield strength decreases as the ageing temperature is increased (Fig. 2.14). The ageing response is weakly dependent on the coarseness of the microstructure when the solution treatment time is adjusted to achieve complete dissolution and homogenization. 

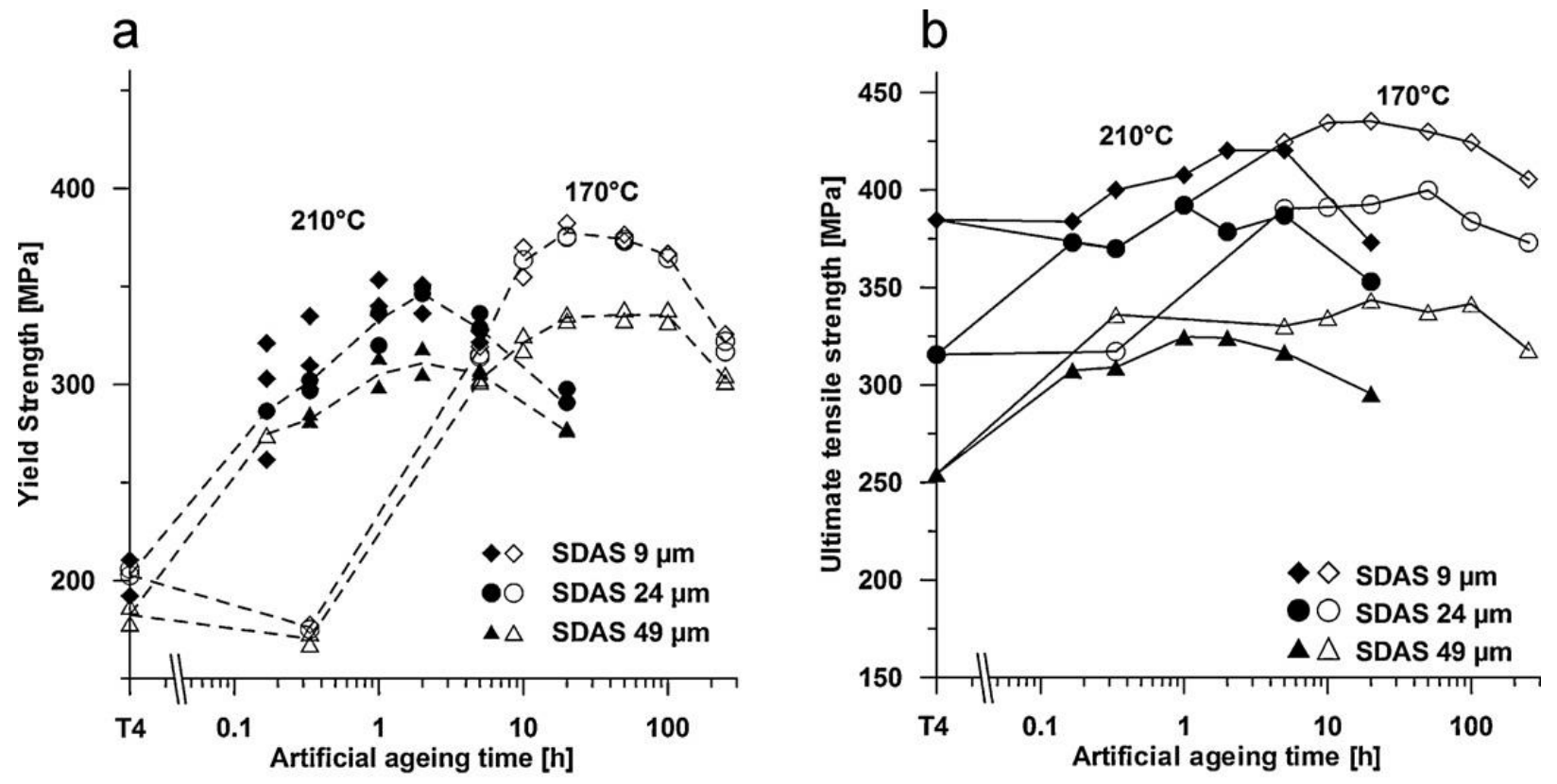

Fig. 2.14. The mechanical properties of the Al-Si-Cu-Mg alloy artificially aged at $170^{\circ} \mathrm{C}$ (open symbols) and $210^{\circ} \mathrm{C}$ (solid symbols). a) Yield strength and b) UTS [53, 54].

The strength is determined by the size and distribution of the precipitates and by the coherency of the precipitates with the matrix. The interaction with the dislocations can be described by the Friedel effect and by the Orowan mechanism (Fig. 2.15) [53]. Small and not too hard precipitates are generally sheared by the moving dislocations (Friedel effect), as shown in Fig. 2.15a. When the precipitates are larger and hard enough, the moving dislocations pass the precipitates by bowing (Fig. 2.15b). The precipitates' strength increases with increasing the size of the precipitates until it can be sheared by dislocations. With further increase of the size of precipitates, the shearing processes become difficult which leads to the more favorable condition for the dislocations to pass the precipitates via the Orowan mechanism, resulting a reduction in strength with further increase in precipitate size (Fig. 2.15c). When the fraction of precipitates shearing and bowing by the dislocations is equal, the alloys achieve peak strength. 

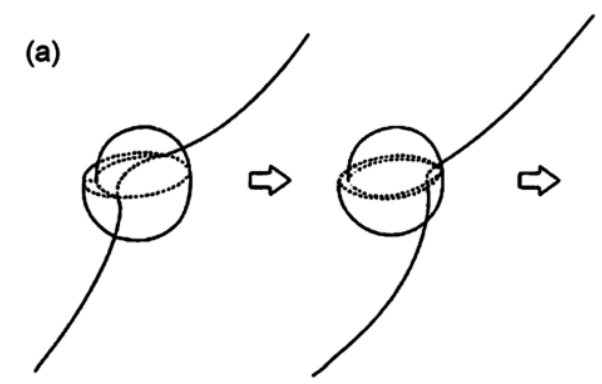

(b)

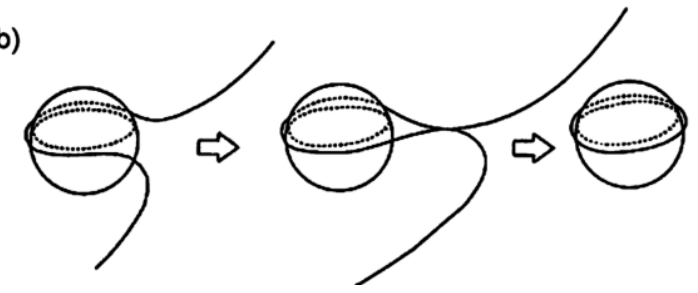

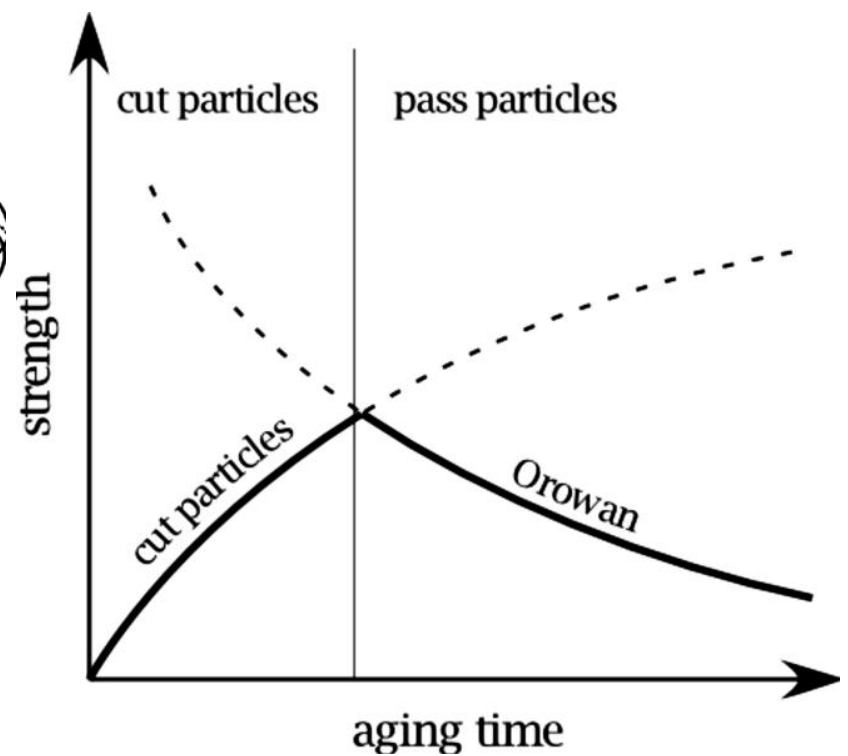

Fig. 2.15. A schematic illustration shows the interaction between the dislocation and precipitates during moving of dislocations(a) shearing or (b) bypassing, (c) Relationship between precipitate radius and strength of the particles to resist shearing or bypassing by dislocations [53].

\subsection{Recent Modification of Aluminum Alloys for High-Temperature Applications}

Although the Al-Si alloy system is not new, the modification of the alloys for high temperature application has been studied by many researchers $[46,63,71,72,73,74,75,76]$. According to Knipling [77], to develop a cast Al alloy for high-temperature application, the selected alloying elements should fulfil four criterions. They are (i) capable of forming thermal stable strengthening phases, (ii) show low solid solubility in the Al matrix, (iii) low diffusivity in Al matrix, and (iv) retain the ability for the alloy to be conventionally solidified.

As discussed earlier, the strengthening of the Al-alloys is generally achieved by precipitation which is a diffusion-controlled process. This phenomenon can be explained by Ostwald ripening which arises during the final stage of the heat treatment process known as ageing, and involves the dissolution of small precipitates with growth of larger precipitates. The kinetics of the ageing process is controlled by volume diffusion of solute atoms through the matrix from the 
shrinking precipitates to the growing ones. Lifshitz and Slyozov [78] and Wagner [79] (LSW) showed that the average precipitate size $\langle\Gamma\rangle$ increases with time $t$ according to [77]:

$$
\langle\Gamma(t)\rangle^{3}-\langle\Gamma(t=0)\rangle^{3}=\kappa t
$$

where the average precipitate radius at time $t$ is $\langle\Gamma(\mathrm{t})\rangle,\langle\Gamma(\mathrm{t}=0)\rangle$ is the average initial precipitate radius at the onset of coarsening, and $\kappa$ is the rate constant given by [80]. According to Eq. (2.2), to develop an alloy for high temperature application, it is necessary that the dispersion of precipitates resist coarsening during prolonged exposure at elevated service temperatures.

Several studies suggested that any alloy system must have the capability to form a fine dispersion secondary strengthening phase in the base matrix to achieve higher strength [22, 23 , $24,47,63,71,72,73,76]$. Fine [81] reported that the intermetallics formed in the Al-matrix with addition of other alloying elements such as $\mathrm{Cu}, \mathrm{Mg}$ etc. are the most favorable candidates for strengthening phases in ductile, thermally-stable dispersion-strengthened Al-based alloys [77]. While a number of possible Al-rich intermetallics can be used to strengthen $\mathrm{Al}$ [8, 77] which can form coherent or semi-coherent trialuminide compounds of the type $\mathrm{Al}_{3} \mathrm{M}$ (where $\mathrm{M}$ is an element of the transition metals) only a few have significant characteristics such as low density, high specific strength, good thermal stability, and excellent oxidation resistance. Those dispersed trialuminide precipitates formed the cubic $\mathrm{L}_{2}$ structure which is similar to the matrix and precipitated. As those phases are coherent or semi-coherent, it tends to maximize the strengthening efficacy of the dispersed phase. In addition, coherency reduces the surface energy per unit area of the hetero-phase interface, which increases the stability at high temperatures by minimizing the driving force for precipitate coarsening. 
A review of the published phase diagrams and crystallographic data [82, 83, 84] indicates that a number of alloying additions crystallize to form stable $\mathrm{Al}_{3} \mathrm{M}$-trialuminides. The highsymmetry cubic $\mathrm{L}_{2}$ and related tetragonal $\mathrm{D}_{22}$ and $\mathrm{D}_{23}$ structures are prevalent among the early transition elements. Among many ways of improving the high-temperature properties, alloying with transition metals to form thermally stable and coarsening-resistant precipitates was found to be very promising. To achieve this, different alloying elements such as $\mathrm{Ni}, \mathrm{Fe}, \mathrm{Cr}$, $\mathrm{Ti}, \mathrm{V}$ and $\mathrm{Zr}$ in cast Al-Si alloys were tested in the literature $[22,23,24,47,63,71,72,73,76]$. $[74,85,86,87,88,89,90,91]$. The most effective alloying element is Sc, forming a dispersoid strengthening phase which has crystal structure of $\mathrm{L}_{2}$, coherent with the Al-matrix and can improve the high temperature alloy performance [77, 85, 92]. However, the higher cost and difficulty of casting makes it unattractive and therefore other alloying elements need investigating. Other studies $[22,93,94]$ showed that addition of $\mathrm{Fe}, \mathrm{Cr}, \mathrm{Mn}$ and $\mathrm{Ni}$ also improved the high temperature alloy properties. The Fe-bearing intermetallic phases can nucleate and grow at temperatures higher than the $\alpha$-Al dendrites. These Fe-rich intermetallics, commonly known as sludge [94, 95], have higher specific density and tends to segregate at the bottom of the melts in the holding furnace resulting the changes of the chemical composition of the melts and increases the tendency of the alloy to die solder in HPDC by reducing Fe from the liquid metal. In addition, the sludge reduces the melts' fluidity and can be trapped and dragged into the castings. Since sludge are harder and brittle in nature [93, 94], they can also conciliation the machining operations with a considerable effect on the cutting tool life, and moreover degrade the mechanical properties of the cast products $[93,94]$.

The tendency of formation of primary Fe-rich particles in Al-Si-Cu alloys can be calculated by the sludge factor $(S F)$ equation, which represents the combined effects of $\mathrm{Fe}, \mathrm{Mn}$ and $\mathrm{Cr}$. The well-known empirical relation of $S F$ is expressed as [93, 94]: 


$$
\text { Sludgefactor }(S F)=(1 \times w t . \% F e)+(2 \times w t . \% M n)+(3 \times w t . \% C r)
$$

As shown in Eq. (2.3), the presence of $\mathrm{Fe}, \mathrm{Mn}$ and $\mathrm{Cr}$ increase the micro-segregation of the alloys which degrade the alloy performance. Recently, Mohamed et al. and others [22, 96] showed that additions of $\mathrm{Ni}$ in the $\mathrm{Al}-\mathrm{Si}-\mathrm{Cu}-\mathrm{Mg}$ alloy caused a reduction in alloy strength at room temperature mainly due to a decrease in the available $\mathrm{Cu}$ for precipitation strengthening through forming $\mathrm{Al}_{3} \mathrm{CuNi}$. In this alloy, an increase in content of the $\mathrm{Al}_{3} \mathrm{CuNi}$ and $\mathrm{Al}_{9} \mathrm{NiFe}$ phases was responsible for some reduction in ductility.

Westengen et al. [97] studied the effect of minor additions of transition elements on the recrystallization of commercial aluminum alloys, and reported that $\mathrm{Zr}$ works as inhibitor of recrystallization. The effect of $\mathrm{Zr}$ and $\mathrm{Ti}$ in wrought aluminum alloys was also investigated by other researchers $[25,98]$ and they found that the presence of $\mathrm{Si}, \mathrm{Zr}$ and Ti formed stable phases with $\mathrm{L1}_{2}, \mathrm{D}_{22}$ and $\mathrm{D}_{23}$ type structures which are stable at elevated temperatures. In another study it was reported that the yield strength (YS) and ultimate tensile strength (UTS) of $6111 \mathrm{Al}$ alloy can be significantly enhanced by modifying the alloy with a small amount of $\mathrm{Zr}$ and controlling a suitable heat treatment [99]. Age hardenability and the sequence of the precipitates was changed by the addition of $\mathrm{Zr}$ in $\mathrm{Al}-\mathrm{Mg}-\mathrm{Si}-\mathrm{Cu}$ alloy with $\mathrm{Sc}$, and it was reported that $\mathrm{Zr}$ can form very fine precipitates of $20-40 \mu \mathrm{m}$ in diameter in size which are fully coherent with the aluminum matrix, compared to Sc-containing precipitates [85, 92].

The influence of $\mathrm{Zr}$ and $\mathrm{Ti}$ additions in $\mathrm{Al}$ alloys was a subject of a number of studies with major conclusions that the morphology and type of phases formed during either casting or heat treatment control the high temperature properties [46, 73]. Mahmudi et al. [24] and Sepehrband et al. [23] modified the A319 Al-Si cast alloy with additions of $\mathrm{Zr}$ and improved its tensile strength and wear resistance. Research also showed that V could enhance the alloy performance 
by forming $\mathrm{Al}_{3} \mathrm{~V}$ or $\mathrm{Al}_{10} \mathrm{~V}$. [89]. Another study performed by $\mathrm{Gao}$ et al. [73, 91, 100] where the hyper-eutectic Al-Si cast alloy was modified by addition of $\mathrm{Zr}$ in different amounts. They reported that increasing the addition of $\mathrm{Zr}$ in $\mathrm{Al}-\mathrm{Si}$ alloys modified the morphology of the strengthening dispersoid phases which improved the alloy room temperature properties and high temperature properties up to $350^{\circ} \mathrm{C}$. Kasprzak et al. [72] introduced $\mathrm{Zr}$ and $\mathrm{V}$ to modify 356 cast aluminum alloy for the elevated temperature applications, and observed that the minor additions of $\mathrm{Zr}$ and $\mathrm{V}$ might not affect the grain refinement potency for the concentration up to $0.2 \mathrm{wt} . \%$. It should be noted that all the studies done to date, either introduce $\mathrm{Zr}$ or $\mathrm{Ti}$ or $\mathrm{V}$ individually, or in a combination of any two alloying elements in aluminum alloy, or involving the evaluation of the mechanical properties in terms of hardness and tensile strength in the ascast condition or heat-treated condition. No extensive study has been done with the addition of all three (Ti, $\mathrm{Zr}$ and $\mathrm{V}$ ) alloying elements together in a cast alloy to achieve potentially finer microstructures and coherent stable precipitates. Information about the compression and fatigue properties, and proper heat treatment processes for these modified alloys in the literature is also very limited. Recently, Elhadri et al. [101] and Kasprzak et al. [102] studied the room temperature tensile and fatigue properties of a modified alloy with addition of $\mathrm{Ti}, \mathrm{Zr}$ and $\mathrm{V}$ in a T6 heat treated condition and revealed that there were no significant changes between the base alloy and modified alloy with minor additions of $0.11 \mathrm{Ti}, 0.2 \mathrm{~V}$ and $0.25 \mathrm{Zr}$. Again, no high temperature properties and optimum heat treatment processes were reported.

Different techniques are being developed in order to produce a more uniform and efficient heat treatment through the use of fluidized beds and basketless heat treatment systems [47, 66]. This is accomplished by transforming the traditional batch process into a continuous process with more stringent control over heat profiles and temperature control. Rather than focusing on modifying the physical machinery, optimization of heat treatment cycles is being performed 
using the current technology by controlling casting conditions as well as heat treatment times and temperatures. The interactions of these processing parameters are complex, which change from composition to composition, and as such there is still a lot of trial and error required to optimize these treatments [103]. The information gathered from the tests is now frequently used to construct models which can accurately predict properties but still requires research in order to further understand the kinetics of the reactions based on time, temperature, and composition [104].

For the sake of improving energy efficiency, a number of researchers have attempted to study short heat treatment cycles. The possibility of reducing the duration of $\mathrm{T} 6$ heat treatment of a hyper-eutectic aluminum alloy by $68 \%$ without compromising hardness or tensile properties was achieved by increasing the solution treatment (ST) temperature and reducing the time of both the ST and ageing time. The choice of increasing the ST temperature was based upon thermal analysis of a particular alloy [105]. Another approach to reducing the heat treatment times rather than increasing temperatures while staying within a certain safety margin is to modify the conventional procedures. He et al. [106] modified the conventional T6 temper and utilized part of the solidification process to create what they called the T6' temper and the T6" temper. These processes attempt to quench the alloy during solidification or begin ST without complete solidification. Another group of researchers has determined a practical map for the effect of ST time on properties. They reported that the ST time could be reduced from 6 hours to 30 minutes for their particular alloy while maintaining $90 \%$ of the YS and maximum $95 \%$ of the UTS. This showed that there are various potential approaches involving the reduction of time (and energy) [107]. Haro et al. [108] performed a similar analysis but did not supply relative results to the typical treatment cycle. Extensive studies on the hardness curves and microstructure have also been performed by Tash et al. [109] on as-cast and heat-treated 356 
and 319 alloys and have supplied a very comprehensive summary of the different phases formed and optimal treatment times for these alloys. Lumley et al. [110] successfully showed applicability of low temperature solution treatment for HPDC parts having satisfactory strength without blistering typically observed when using conventional tempers. Since no such results were reported on the newly developed Al-Si cast alloys with additions of $\mathrm{Zr}$, Ti and $\mathrm{V}$, a detailed study is needed to optimize the heat-treatment procedure that can achieve elevated temperature properties of the alloy while shortening the processing time or temperature.

\subsection{Chapter Summary}

The Al-Si-Cu-Mg alloys possess good strength at room temperature. However, the changes in morphology of the strengthening phases, $\mathrm{Al}_{2} \mathrm{Cu}, \mathrm{Mg}_{2} \mathrm{Si}$ and/or $\mathrm{Al}_{2} \mathrm{CuMg}$ above approximately $170{ }^{\circ} \mathrm{C}$ result in diminution of high temperature performance, consequently limiting their applications. [19, 20, 21, 22]. To improve the high temperature properties, a continuous effort has been made to modify the alloy chemistry, e.g., with micro-additions of transition metals. Among transition metals, $\mathrm{V}, \mathrm{Zr}$ and $\mathrm{Ti}$ are considered to be more effective due to their low diffusivity and solubility in $\mathrm{Al}$, causing the formation of thermally stable intermetallics of primary and secondary types that allow maintaining the alloy strength at temperatures up to 350 ${ }^{\circ} \mathrm{C}[23,24]$.

Many researchers have investigated the effect of $\mathrm{V}, \mathrm{Zr}$ and $\mathrm{Ti}$ addition in $\mathrm{Al}-\mathrm{Si}-\mathrm{Cu}-\mathrm{Mg}$ alloys $[46,63,71,72,73,74,75,76]$. Although studies on strain-controlled low-cycle fatigue (LCF) provide important input into the design of engineering components [111], most of the literature data are focused on tensile properties and high-cycle fatigue (HCF) behavior of Al alloys for a particular secondary dendrite arm spacing (SDAS). Kasprzak et al. [102] and Elhadari et al. [101] studied the effect of micro-additions of $\mathrm{V}, \mathrm{Zr}$ and $\mathrm{Ti}$ in $\mathrm{Al}-\mathrm{Si}-\mathrm{Cu}-\mathrm{Mg}$ alloys for a SDAS of 
$25 \mu \mathrm{m}$. They reported that $\mathrm{V}, \mathrm{Zr}$ and $\mathrm{Ti}$ could improve the mechanical properties of the alloy at room temperature and high temperature as well. Another study showed that increasing the solidification rate improved tensile strength of the alloy modified with micro-additions of $\mathrm{V}, \mathrm{Zr}$ and Ti [63]. The study of the influence of rapid solidification (similar to high pressure die casting) on SDAS, compression and LCF fatigue resistance of cast Al-Si-Cu-Mg alloys for automotive power train applications, especially the $\mathrm{Al}-\mathrm{Si}-\mathrm{Cu}-\mathrm{Mg}$ alloys modified with additions of $\mathrm{Zr}$, Ti and $\mathrm{V}$ is not available in the literature. It is also not clear how the SDAS of the cast Al$\mathrm{Si}-\mathrm{Cu}-\mathrm{Mg}$ alloy influence the tension, compression and low cycle fatigue behavior. 


\section{CHAPTER 3}

\section{MATERIALS AND EXPERIMENTAL PROCEDURE DETAILS}

The Al-Si-Cu-Mg base alloy was modified with additions of Ti, V and Zr. After casting, the alloy was subjected to heat treatment processes. Then, the performance of the alloys was characterized in terms of mechanical properties, especially LCF and tensile testing, and correlated to the microstructure. The following sections will cover the casting and heat treatment processes as well as preparation of the materials, the detailed procedure of microstructural analysis, hardness, compression and tensile testing at room temperature and elevated temperatures and LCF of the alloys. All experimental data was carefully collected with the help of data acquisition instruments connected to the various testing systems.

\subsection{Alloy Composition and Preparation}

The experimental alloys were cast in CANMETMaterials, Hamilton, Canada. It was prepared in a $30 \mathrm{~kg}$ induction furnace by mixing commercial master alloys of (in wt. \%) Al-50\%Cu, Al$35 \% \mathrm{Si}, \mathrm{Al}-6.1 \% \mathrm{Ti}, \mathrm{Al}-85 \% \mathrm{~V}, \mathrm{Al}-10 \% \mathrm{Zr}, \mathrm{Al}-10 \% \mathrm{Sr}$ and the pure metals $\mathrm{Mg}$ and $\mathrm{Al}$, to achieve the targeted chemistry, as listed in Table 3.1. The alloy was melted at $760^{\circ} \mathrm{C}$ under a protective atmosphere. During addition of alloying elements the melt temperature was increased to 800$850^{\circ} \mathrm{C}$ to ensure their proper dissolution. The melt degassing was done using a graphite lance with a porous cake filter for improved Ar gas dispersion. An addition of $60 \mathrm{ppm} \mathrm{Sr}$ was used for the Al-Si eutectic modification as well as dispersion of potential porosity that could develop during the solidification process. In this study, five alloys were cast, including the Al-Si-Cu-Mg base alloy (BA). The alloys are designated as alloy modified with addition of Ti, Ti-Zr, Ti-V-Zr 
in lower content and Ti-V-Zr in higher content as MA1, MA2 MA3 and MA4, respectively. As shown in Fig. 3.1 (a), the alloy was cast at $740^{\circ} \mathrm{C}$ into the wedge-shaped mold with a copper insert, and cooled with flowing water at a temperature of $60^{\circ} \mathrm{C}$.

Table 3.1 Chemical composition of base alloy (BA) of Al-Si-Cu-Mg, and modified alloy (MA) with addition of Ti/V/Zr in base alloy in wt. \%.

\begin{tabular}{cccccc|ccccr}
\hline \multicolumn{7}{c|}{ Constant } & \multicolumn{5}{c}{ Variables } \\
\hline Sample ID & $\mathrm{Si}$ & $\mathrm{Cu}$ & $\mathrm{Mg}$ & $\mathrm{Fe}$ & $\mathrm{Sr}$ & $\mathrm{Ti}$ & $\mathrm{Zr}$ & $\mathrm{V}$ & $\mathrm{Mn}$ & $\mathrm{Al}$ \\
\hline BA & 7.10 & 1.0 & 0.50 & - & 0.008 & - & - & - & - & Bal. \\
\hline MA1 & 7.0 & 1.0 & 0.50 & 0.12 & 0.008 & 0.11 & - & - & - & Bal. \\
\hline MA2 & 7.0 & 1.0 & 0.50 & 0.12 & 0.008 & 0.11 & 0.2 & - & - & Bal. \\
\hline MA3 & 7.0 & 1.0 & 0.5 & 0.12 & 0.008 & 0.11 & 0.2 & 0.25 & - & Bal \\
\hline MA4 & 7.02 & 0.95 & 0.48 & 0.090 & 0.012 & 0.20 & 0.56 & 0.32 & 0.005 & Bal. \\
\hline
\end{tabular}

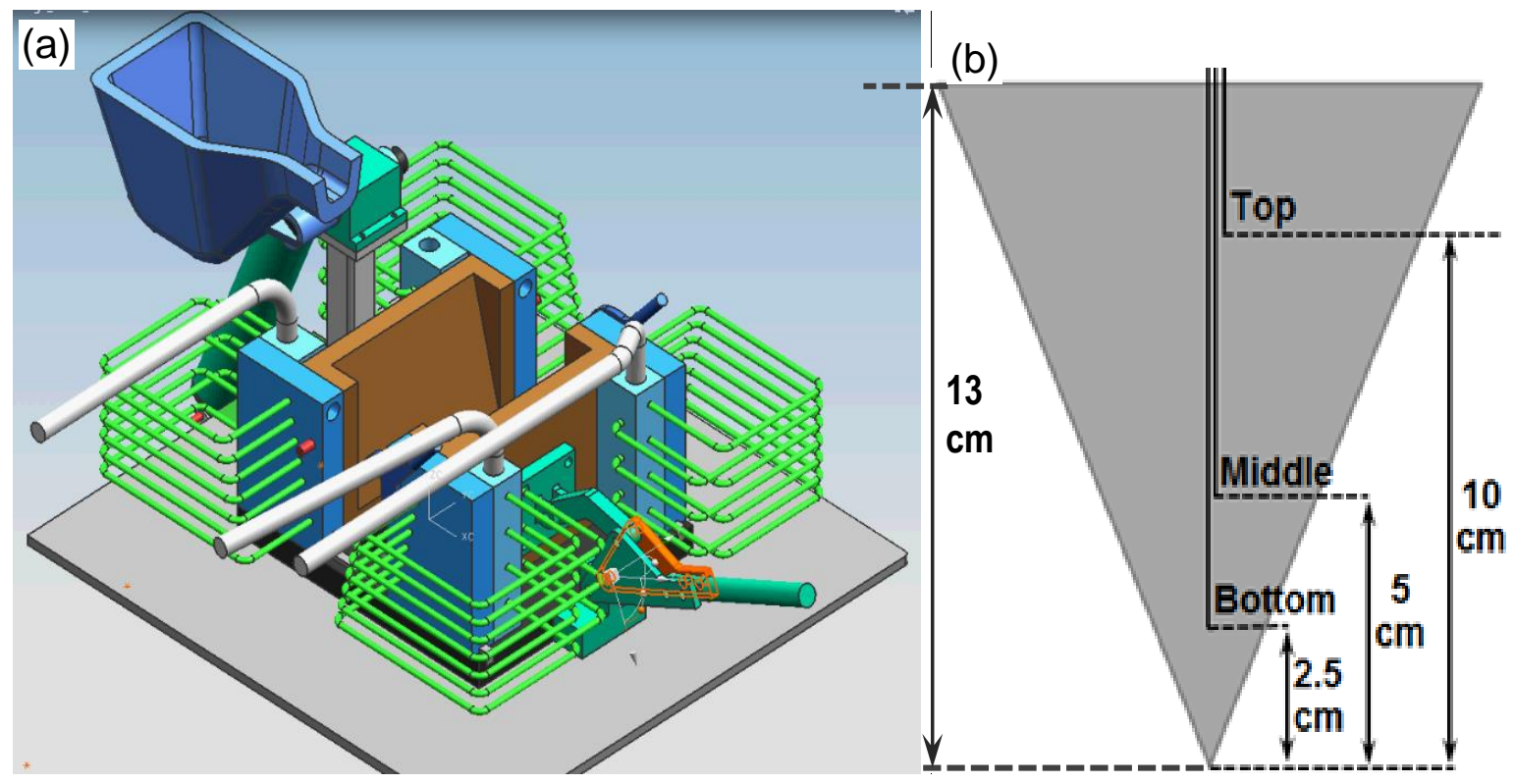

Fig. 3.1. A schematic illustration of the casting process for the studied alloys, (a) copper wedge mold with automatic pouring and cooling control with circulating water, (b) position of thermocouples in the wedges during casting.

\subsection{Thermal Characteristic Analysis}

For thermal analysis (TA), three chromel-alumel (K-type) thermocouples were embedded in the wedge mold (Fig. 3.1b). As illustrated in Fig. 3.1 (b), the positions of the thermocouples were 
2.5, 5.0 and $10.0 \mathrm{~cm}$ from the bottom and named bottom, middle and top, respectively. The data for TA was collected each $0.05 \mathrm{~s}$ using a high-speed National Instruments data acquisition system linked to computer. The cooling rates of the alloy were calculated from the slope of the cooling curves between the maximum temperature recorded in the mold and nucleation temperature of $\mathrm{Al}$ dendrite $\left(\mathrm{T}_{\mathrm{N}}^{\alpha-\mathrm{Al}}\right)$ as follows:

$$
\text { Cooling rate }=\frac{\left(\mathrm{T}_{\mathrm{P}}-\mathrm{T}_{\mathrm{N}}^{\alpha-\mathrm{Al}}\right)}{\mathrm{t}_{\mathrm{N}}}
$$

where $T_{P}$ and $T_{N}$ are the recorded maximum and nucleation temperatures, respectively; $t_{N}$ is the time recorded up to nucleation.

After casting, the alloy was re-melted in a graphite crucible as shown in Fig. 3.2. To determine reactions taking place during solidification and melting, the alloy MA1 and alloy MA4 (100 gm from each alloy) were poured into a graphite crucible and heated to $860^{\circ} \mathrm{C}$. To acquire equilibrium solidification conditions, the alloys were cooled at a rate of $0.15^{\circ} \mathrm{Cs}^{-1}$. After cooling to $200^{\circ} \mathrm{C}$, the alloys were heated again to $860^{\circ} \mathrm{C}$ at a rate of $0.2^{\circ} \mathrm{Cs}^{-1}$. To verify reproducibility, heating and cooling cycles were performed twice. Thermal analysis was carried out using a K-type thermocouple inserted into the crucible and linked to a computer via a MadgeTech QuadTemp2000 to record the temperature-time data (Fig. 3.2). The cooling curves along with their first derivatives were analyzed to determine reactions taking place during solidification and melting of the alloy.

Prior to performing the heat treatment, a single thermocouple thermal analysis was also carried out to determine the sequence of transformations during the alloy melting and solidification process [112]. During heating and cooling, the temperature versus time was measured, and the corresponding first derivative versus temperature curves was plotted. In addition to gaining fundamental knowledge of the alloy melting/solidification process, the 
selected data was used for the selection of solution treatment temperatures, namely the solidus temperature.

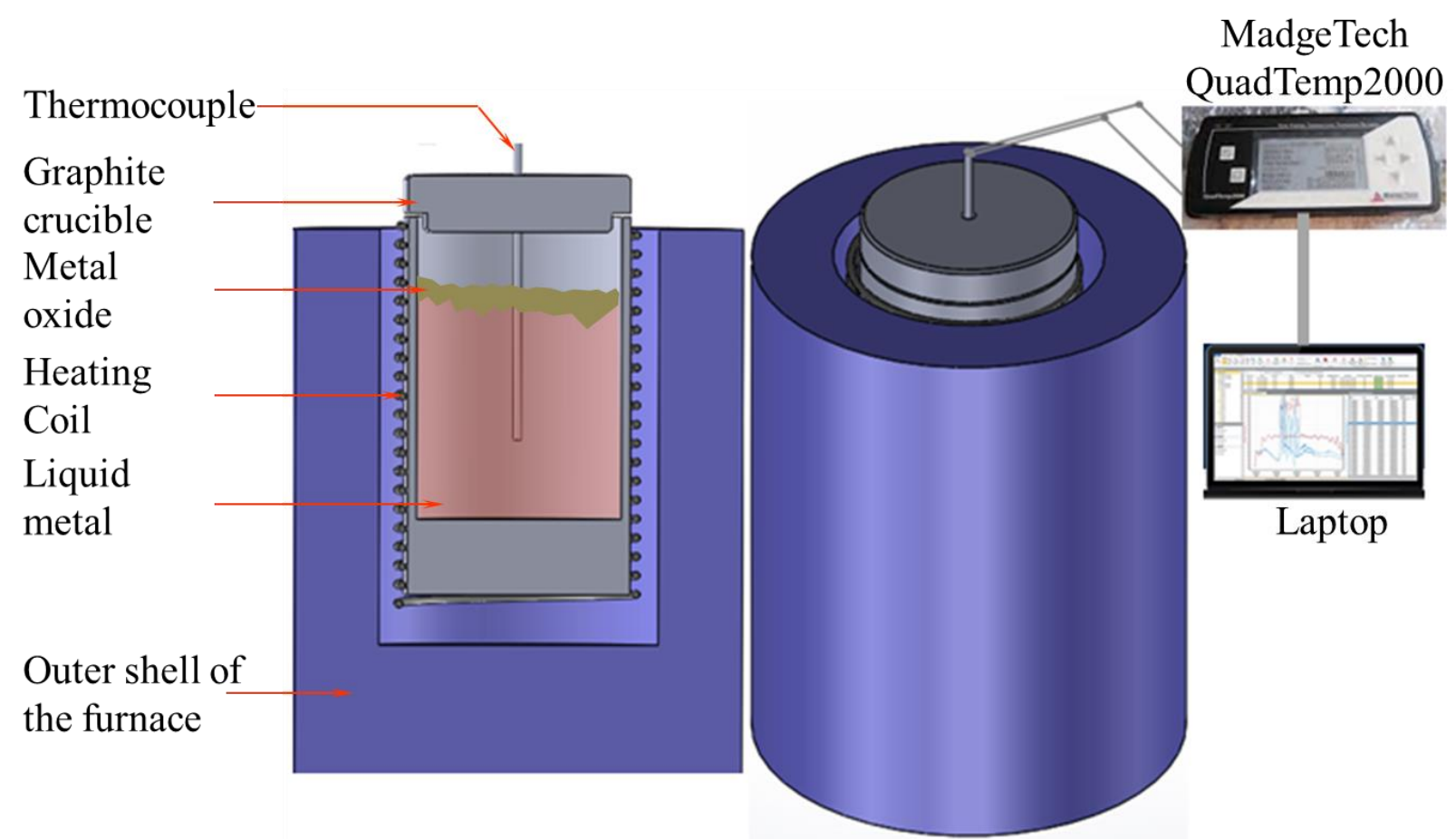

Fig. 3.2. An experimental setup for thermal analysis of the alloys during melting and solidification.

\subsection{Heat Treatment of the Alloys}

The heat treatment processes of the alloys are the combination of solution treatment and ageing processes. The alloy samples were initially solutionized followed by ageing at different times and temperatures. The solution treatment parameters were selected based on the thermal analysis data. The heat treatment was performed in two furnaces, an air circulating resistance furnace (LINDBERG HEVI-DUTY), with an accuracy of $\pm 5^{\circ} \mathrm{C}$ in Ryerson University and an air circulating resistance furnace (Blue $\mathrm{M}$, Park Thermal), with an accuracy of $\pm 3^{\circ} \mathrm{C}$ in CANMETMaterials, Hamilton, Canada. From the heating cycle, three different solution treatment temperatures were chosen; just below the solidus temperature, at the solidus temperature and a two-step solution treatment. As illustrated in Fig. 3.3a, the samples were 
heated up to the solutionizing temperature of $485^{\circ} \mathrm{C}$ or $510^{\circ} \mathrm{C}$ held for the desired time, followed by quenching in water during the single step solution treatment for alloy MA3. In contrast, the two step solution treatment consisted of solutionizing at the temperature of $510^{\circ} \mathrm{C}$ for $0.5 \mathrm{~h}$ to dissolve the lower melting point phases followed by an increment of $15^{\circ} \mathrm{C}$ to reach the temperature of $525^{\circ} \mathrm{C}$ for homogenization (Fig. 3.3b). After homogenizing for the desired time, the samples were quenched in water followed, by artificial ageing (AA). The isothermal holding time also was varied with possible values of $0.5,1.5,4.5$, and $9 \mathrm{~h}$. For peak ageing (T6) of alloy MA3, the solution-treated samples were aged at $150^{\circ} \mathrm{C}$ for $100 \mathrm{~h}$, while over ageing (T7) for alloy MA3 were done at $250^{\circ} \mathrm{C}$ for $16 \mathrm{~h}$. To examine ageing characteristics, the alloy MA4 was aged from $50^{\circ} \mathrm{C}$ to $500^{\circ} \mathrm{C}$ in a $50^{\circ} \mathrm{C}$ steps. For each ageing temperature step, ageing times were changed from 0.25 to $24 \mathrm{~h}$. The optimum ageing parameter for alloy MA4 was found out based on the hardness. Finally, the alloy MA4 aged at that temperature and performed rest of the mechanical test. The heat treatment processes are summarized in Table 3.2.

Table 3.2 Summary of alloy heat treatment parameters.

\begin{tabular}{|c|c|c|c|c|c|c|}
\hline Alloys & $\begin{array}{c}\text { Heat } \\
\text { treatment } \\
\text { ID }\end{array}$ & $\begin{array}{l}\text { ST temperature } \\
\left({ }^{0} \mathrm{C}\right)\end{array}$ & & $\begin{array}{l}\text { ST time } \\
\text { (h) }\end{array}$ & & $\begin{array}{c}\text { AA } \\
\text { condition }\end{array}$ \\
\hline MA3 & $\mathrm{H} 1$ & 485 & \multirow{4}{*}{0.5} & \multirow{4}{*}{$1.5 \quad 4.5$} & \multirow{4}{*}{9} & T6 \\
\hline MA3 & $\mathrm{H} 2$ & 510 & & & & T6 \\
\hline MA3 & $\mathrm{H} 3$ & 510 & & & & $\mathrm{~T} 7$ \\
\hline MA3 & $\mathrm{H} 4$ & 510 for $0.5 \mathrm{~h}+525$ & & & & T6 \\
\hline BA, MA1, MA2 and MA4 & H5 & 510 for $0.5 \mathrm{~h}+525$ & & 4.5 & & T6' \\
\hline
\end{tabular}




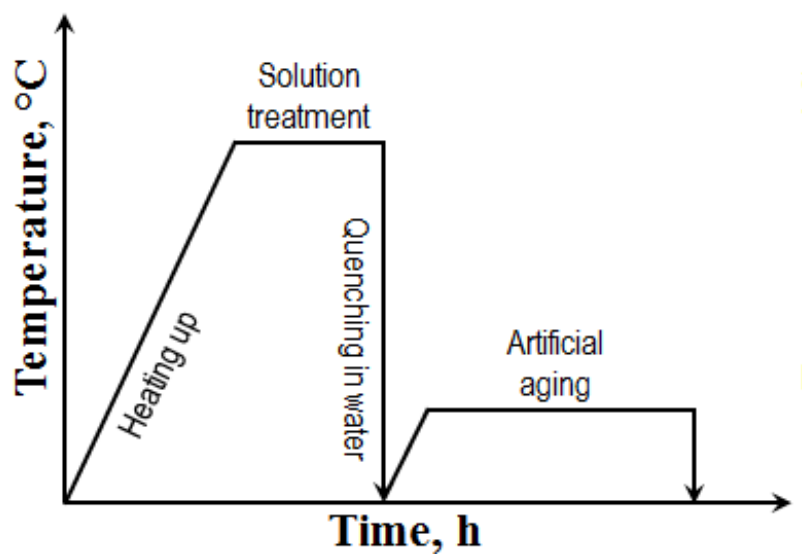

(a)

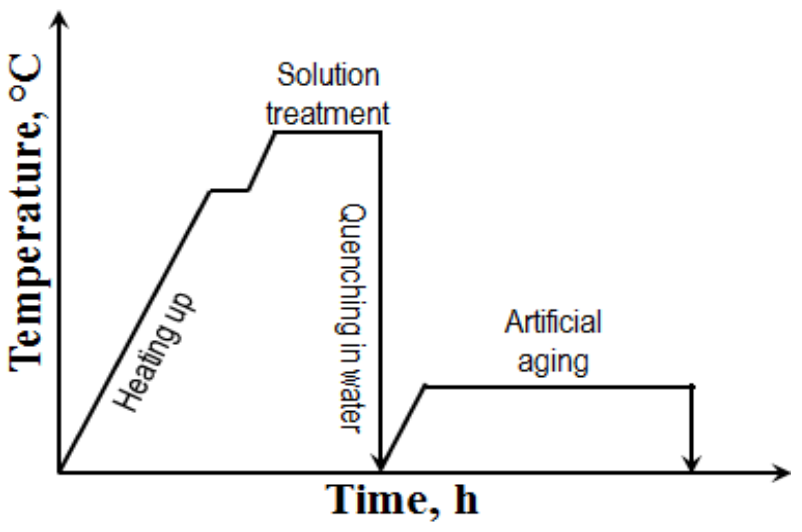

(b)

Fig. 3.3. A schematic representation of heat treatment cycles for the studied alloys, (a) single step solution treatment and (b) two-step solution treatment.

\subsection{Characterization of Microstructure}

\subsubsection{Optical microscopy (OM)}

For microstructural study, samples were collected from several positions in the wedge, each characterized by different solidification rates. The alloy samples were ground using SiC papers up to a grit number of 1200 , polished using first an $\mathrm{Al}_{2} \mathrm{O}_{3}$ slurry and then colloidal silica. The microstructure was examined in the unetched condition using a light optical microscope (OM) (Model: Nikon EPIPHOT200) equipped with a quantitative image analyzer (CLEMEX software). Average SDAS values were determined using the linear intercept technique, which involves measuring the distances between secondary dendrite arms along a line normal to the dendrite arms. The quantitative image analysis was also performed to measure the size of the particles. For each heat treatment parameter, at least ten (10) micrographs, each covering an area of $7350 \mu \mathrm{m}^{2}$, were analyzed and average values were taken with standard deviation. Length $(l)$, width $(W)$ in $\mu \mathrm{m}$, total particle number $(n)$, and particle area $\left(A_{P}\right)$ in $\mu \mathrm{m}^{2}$ were measured using OM. Circular equivalent diameter of the particles $D_{S i}$ was calculated using following equation [113]: 


$$
D_{S i}=\frac{1}{n} \sum_{1}^{n} \sqrt{\frac{4 A_{P}}{\pi}}
$$

To find out the degree of spheroidization, the roundness of the particles $R_{S i}$ was calculated using Eq. (3.3) [114]:

$$
R_{S i}=\frac{1}{n} \sum_{1}^{n}\left(\frac{\pi l^{2}}{4 A_{P}}\right)
$$

To analyze the cumulative volume percent of $\mathrm{Ti}, \mathrm{V}$, and $\mathrm{Zr}$ phases, SEM images at 200X magnification were analyzed using $\mathrm{OM}$. Here, Ti-V- Zr-containing phases were separated from other phases in color contrast, being brighter than other phases.

\subsubsection{Scanning electron microscopy (SEM)}

The microstructure was also examined using a scanning electron microscope (SEM), coupled with energy-dispersive X-ray spectroscopy (EDX) in the unetched and deep etched condition. To reveal the morphology of intermetallics and perform their chemical analysis, deep etching was employed by immersing the samples in $5 \% \mathrm{NaOH}$ solution. After $2 \mathrm{~h}$ the samples were taken out from the solution and rinsed with water. After that, the intermetallics were analyzed using a scanning electron microscope (SEM), coupled with energy-dispersive X-ray spectroscopy (EDX) in Back-scattered electron (BSE) mode and Secondary electron image (SEI) mode. 


\subsubsection{Electron backscatter diffraction (EBSD)}

The sample preparation is a crucial factor for the EBSD analysis. After polishing with $1 \mu \mathrm{m}$ diamond paste, samples were polished using colloidal silica for $30 \mathrm{~min}$ to remove the mechanical strain induced during polishing. After that, EBSD maps data were acquired in a scanning electron microscope (SEM) JEOL JSM 6380LV, with a fully automatic EBSD attachment, (AZtecHKL Technology), operating at an accelerating voltage, working distance and tilt angle of $20 \mathrm{kV}, 15 \mathrm{~mm}$ and $70^{\circ}$, respectively. For each condition, at least 30,000 data points were collected. The corresponding data processing was carried out using Matlab2012 with the help of the MTEX texture analysis tool. EBSD analysis was performed on the T6 heat treated samples in undeformed and deformed states.

\subsubsection{Transmission electron microscopy (TEM)}

A TEM is used in CANMETMaterials, Hamilton, Canada, to obtain information about the precipitates presents in the modified alloys. There are several ways to prepare the sample for TEM analysis. The sample preparation for this study was a two-step procedure which involved polishing and ion milling. First, the samples were cut into several strips. Then the samples were attached to the polishing disks with adhesive and reduced to a thickness between 0.3 to $0.5 \mathrm{~mm}$ by polishing with emery paper. A $3 \mathrm{~mm}$ disk sample was cut from the polished samples by punching using an ultra-sonic machine. Final thinning was performed by ion milling as shown in Fig 3.4. The materials from the samples were removed by sputtering with argon ions until a perforated hole size of $\sim 1 \mu \mathrm{m}$ appeared in the center of the disk. The sample disks were placed in the ion mill with the surface of the specimen at an angle of $15-25^{\circ}$ to the surface, which made a gradient of material removal leading to the lowest thickness at the center of the samples 
compared to the edge. After preparing the sample, structure analysis was performed using FEI Tecnai Osiris Transmission Electron Microscope in bright and dark field imageing mode.

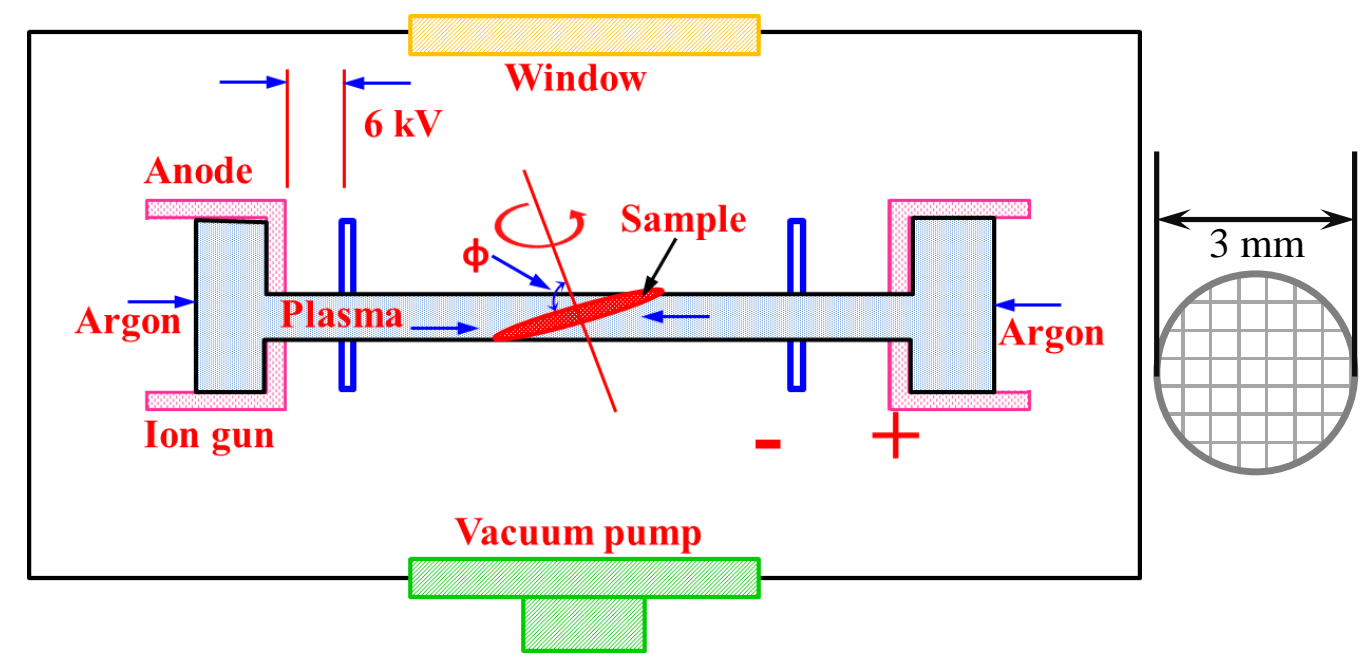

Fig. 3.4. Schematic diagram shows ion milling technique for thinning TEM samples of $3 \mathrm{~mm}$ disk.

\subsubsection{X-ray diffraction}

The X-ray diffraction experiment was performed using a PANalytical X-ray diffractometer (XRD) in the alloy bulk samples and precipitates as well. To improve analysis accuracy, the intermetallics were collected by a dissolution method explained in [115]. The phase formation was investigated in situ via high temperature X-ray diffraction (XRD) using $\mathrm{CuK}_{\alpha}$ radiation at $45 \mathrm{kV}$ and $40 \mathrm{~mA}$, with a step size of $0.05^{\circ}$ and duration of $2 \mathrm{~s}$ for each step. During heating, the XRD measurements were conducted at $30,200,300,400,500,550$ and $600^{\circ} \mathrm{C}$. Temperatures have been selected based on the thermal analysis which indicated the key transformation points.

\subsection{Mechanical Testing}

The alloy mechanical properties were evaluated in terms of hardness, monotonic tensile and compression and low cycle fatigue (LCF) tests. The test procedures are described as follows. 


\subsubsection{Hardness tests}

After casting, the wedges were sliced and hardness was measured as a function of the distance from the wedge base using a Rockwell hardness tester and F scale with a load of $60 \mathrm{~kg}$ and $1 / 16^{\prime \prime}$ steel ball indenter converted to B scale. Fig. 3.5 depicts the cast wedge slices showing the hardness indentations. Nine (9) measurements were done and the average value was plotted as function of solution treatment time and temperature.
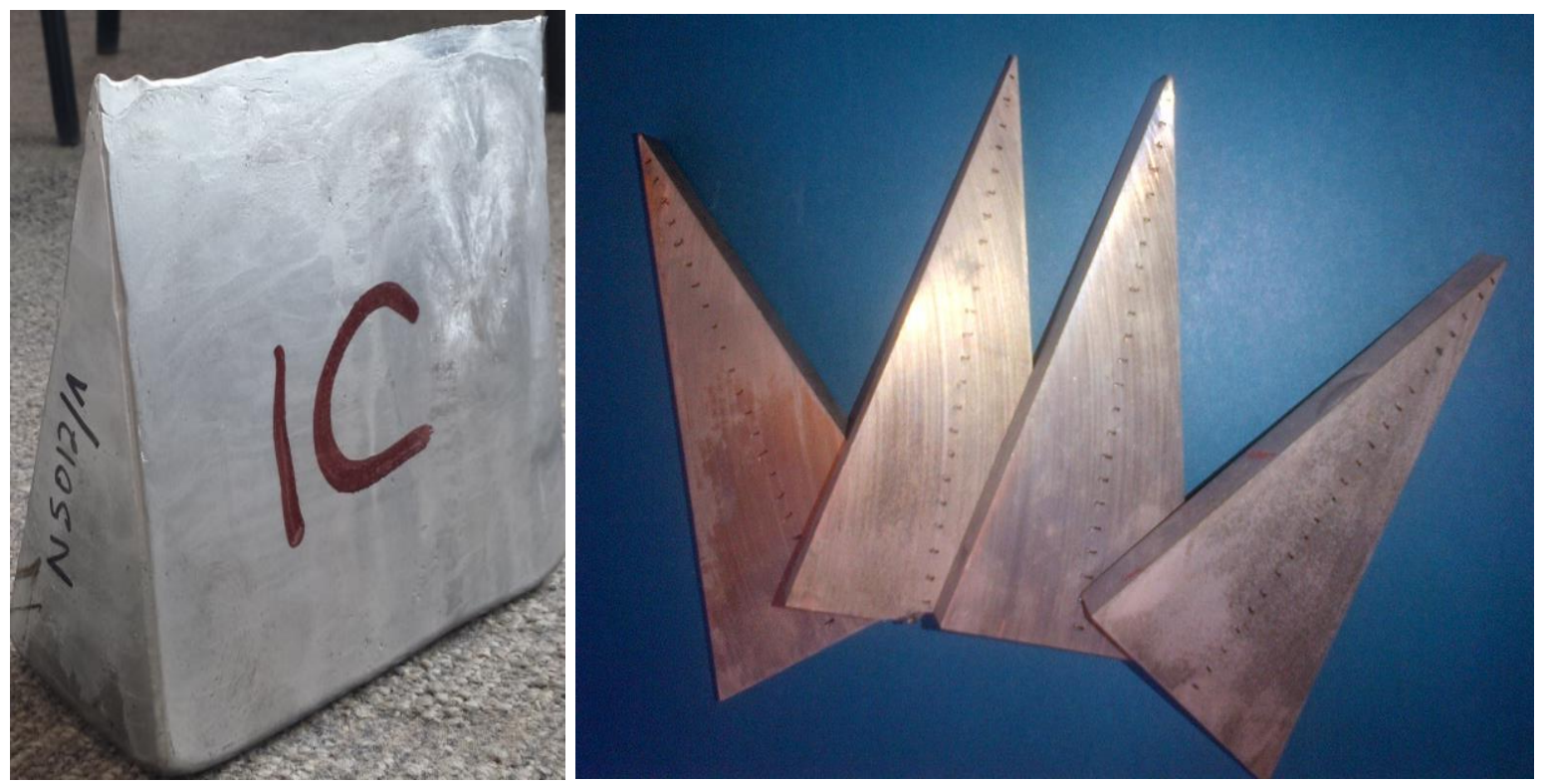

Fig.3.5. Wedge casting and slices (base 60x10 $\mathrm{mm}$ and height $120 \mathrm{~mm}$ ) used for ageing experiment and hardness measurements.

\subsubsection{Tensile tests}

The extraction of samples from the wedge having secondary dendrite arm spacing (SDAS) of 18, 25 and $30 \mu \mathrm{m}$ is illustrated in Fig. 3.6 [116]. The tensile testing was performed on sub-size rectangular bar samples (Fig. 3.7) with a gauge length of $25 \mathrm{~mm}$ (or parallel length of $32 \mathrm{~mm}$ ) and a cross-section of $6 \mathrm{~mm} \times 6 \mathrm{~mm}$ following the ASTM: E8M-11 standard at the temperatures of $25^{\circ} \mathrm{C}$ (room temperature), $200^{\circ} \mathrm{C}, 300^{\circ} \mathrm{C}$ and $400^{\circ} \mathrm{C}$ with a deviation of $\pm 5^{\circ} \mathrm{C}$ at a strain rate 
of $10^{-3} \mathrm{~s}^{-1}$ using a computerized United Tensile Testing machine (Model: STM, 50kN). The strain was measured by a clip-on $25 \mathrm{~mm}$ extensometer attached to the gauge length.

Table 3.3 Tension and compression testing parameters for the studied alloys

\begin{tabular}{ccc}
\hline $\begin{array}{c}\text { SDAS, } \\
\mu \mathrm{m}\end{array}$ & $\begin{array}{c}\text { Testing temperature, } \\
{ }^{\circ} \mathrm{C}\end{array}$ & $\begin{array}{c}\text { Strain Rate, } \\
\mathrm{S}^{-1}\end{array}$ \\
\hline 18 & 25 & $10^{-3}$ \\
\hline 25 & $25,200,300$ and 400 & $10^{0}, 10^{-1}, 10^{-2}$ and $10^{-3}$ \\
\hline 30 & 25 & $10^{-3}$ \\
\hline
\end{tabular}

For higher temperature tensile tests, each specimen was kept in the heating chamber of the testing machine for $10 \mathrm{~min}$ at the desired temperature. The temperature of the heating chamber was precisely measured in two ways; using a K-type thermocouple which was placed near the sample grip connected to a multi-meter, and the pre-assembled heating chamber thermocouple. After testing, the specimens were quenched in water to keep the same microstructure at testing temperature. As described in [117], after tensile testing, the calculated true-stress vs. true-strain graphs were plotted using collected raw data. From the graph, $0.2 \%$ offset was calculated and considered as the yield stress/strength (YS) of the materials while maximum stress was considered as ultimate tensile strength (UTS) will be reported in later Chapter 5. The YS and UTS value of the average of at least two samples was plotted with respect to the testing temperature will be stated in later Chapter 7 and Chapter 8 . 


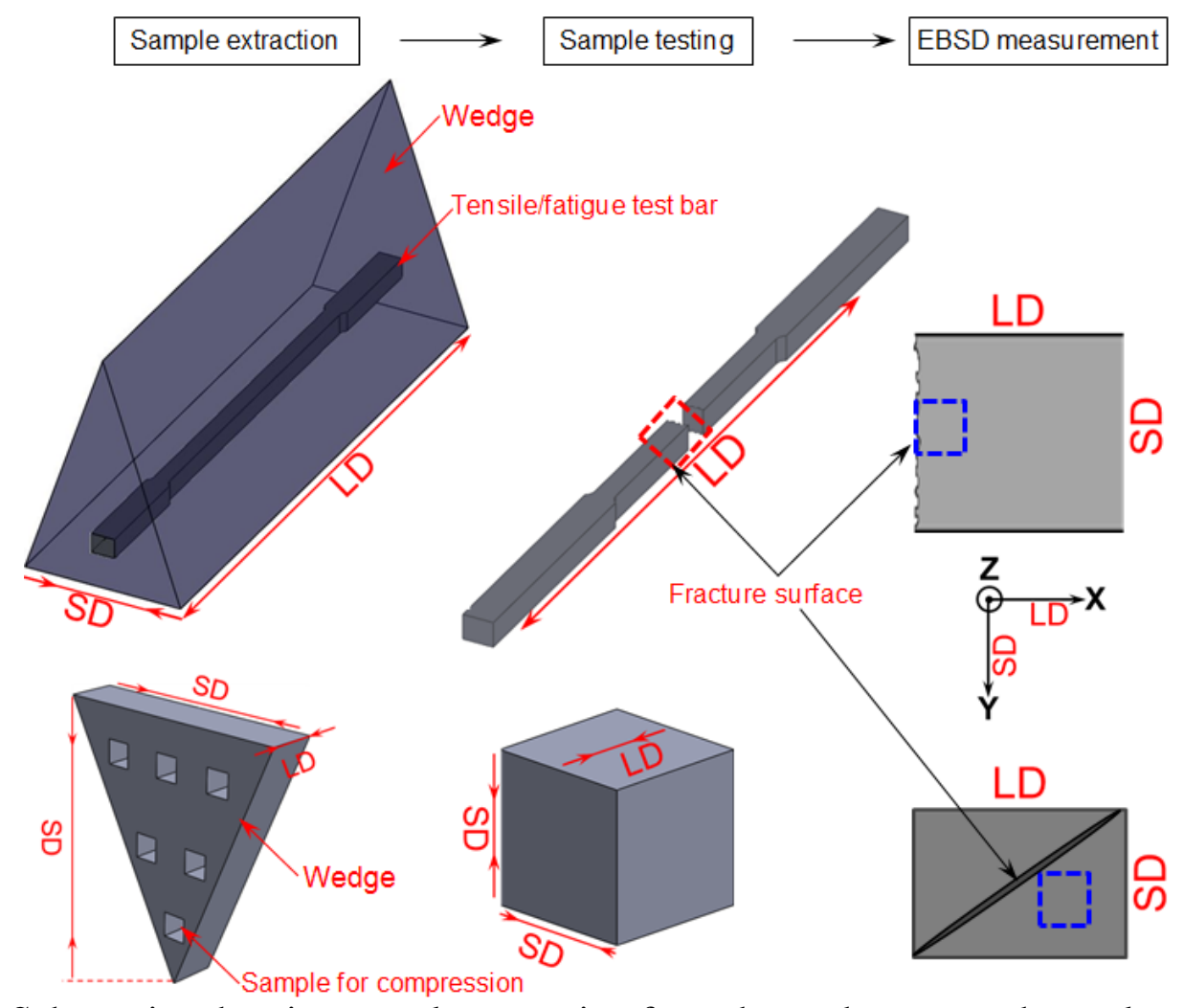

Fig. 3.6. Schematics showing sample extraction from the wedge cast and sample orientation during deformations and EBSD measurements. Note: LD-Tensile loading direction, SDSolidification direction.

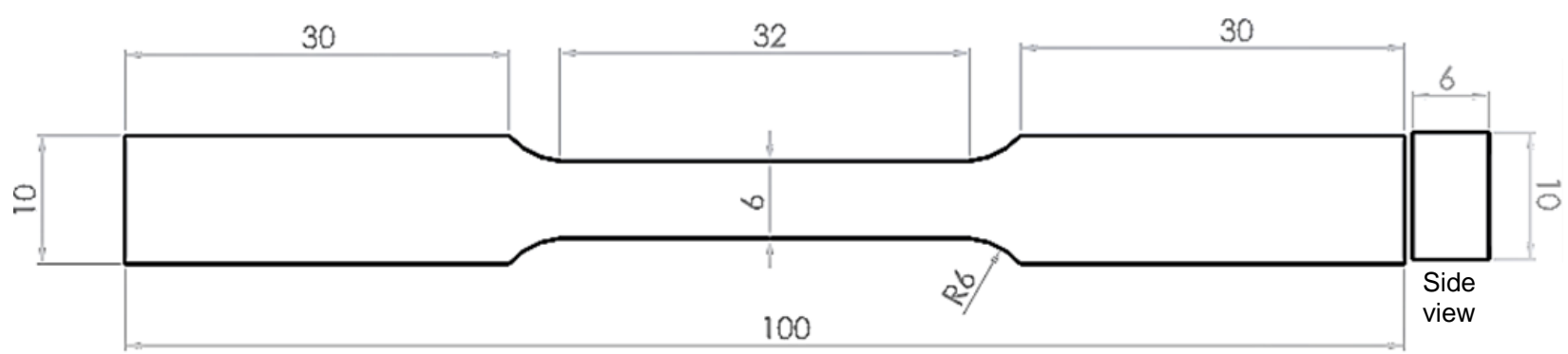

Fig. 3.7. Schematics showing sub-size rectangular sample for tensile and fatigue tests. Note: All dimensions are in $\mathrm{mm}$.

\subsubsection{Compression tests}

Two types of samples were prepared for compression tests. In the first group, for alloys MA1 to MA3 in the T6 state, the compression tested cylindrical samples of $8 \mathrm{~mm}$ in height and $5 \mathrm{~mm}$ in diameter were collected from the $20 \mathrm{~mm}$ cylindrical rod having SDAS of $\sim 25 \mu \mathrm{m}$ (Fig. 3.8). At the same time, the rectangular samples with a dimension of $7 \times 8 \times 9 \mathrm{~mm}$ for the alloy MA4 were 
collected from the wedge having secondary dendrite arm spacing (SDAS) of 18, 25 and $30 \mu \mathrm{m}$ as illustrated in Fig. 3.6 [116]. Compression tests were performed according to the ASTM-E9M standard at temperatures of 25 (room temperature), 200,300 and $400^{\circ} \mathrm{C}$, and strain rates of $10^{-3}$, $10^{-2}, 10^{-1}$ and $1 \mathrm{~s}^{-1}$. The testing equipment involved a computerized United tensile testing machine equipped with an environmental chamber having a temperature accuracy of $\pm 5^{\circ} \mathrm{C}$. The samples were held for $10 \mathrm{~min}$ before testing to allow a uniform distribution of temperature. Two samples were tested at each temperature followed by water quenching. After testing, the alloys were subjected to microstructural examination. The tested samples were cut into two halves. One was used for texture analysis and the other one for cutting the specimens for metallographic examinations. Following cutting along the loading axis, samples from each group were prepared as described above. The sample surfaces were examined in the as-polished state and also after etching with $5 \mathrm{ml} \mathrm{HF}, 20 \mathrm{ml} \mathrm{HCl}, 20 \mathrm{ml} \mathrm{HNO}_{3}$ and $60 \mathrm{ml} \mathrm{H}_{2} \mathrm{O}$. The microstructure was characterized as described in section 3.4.

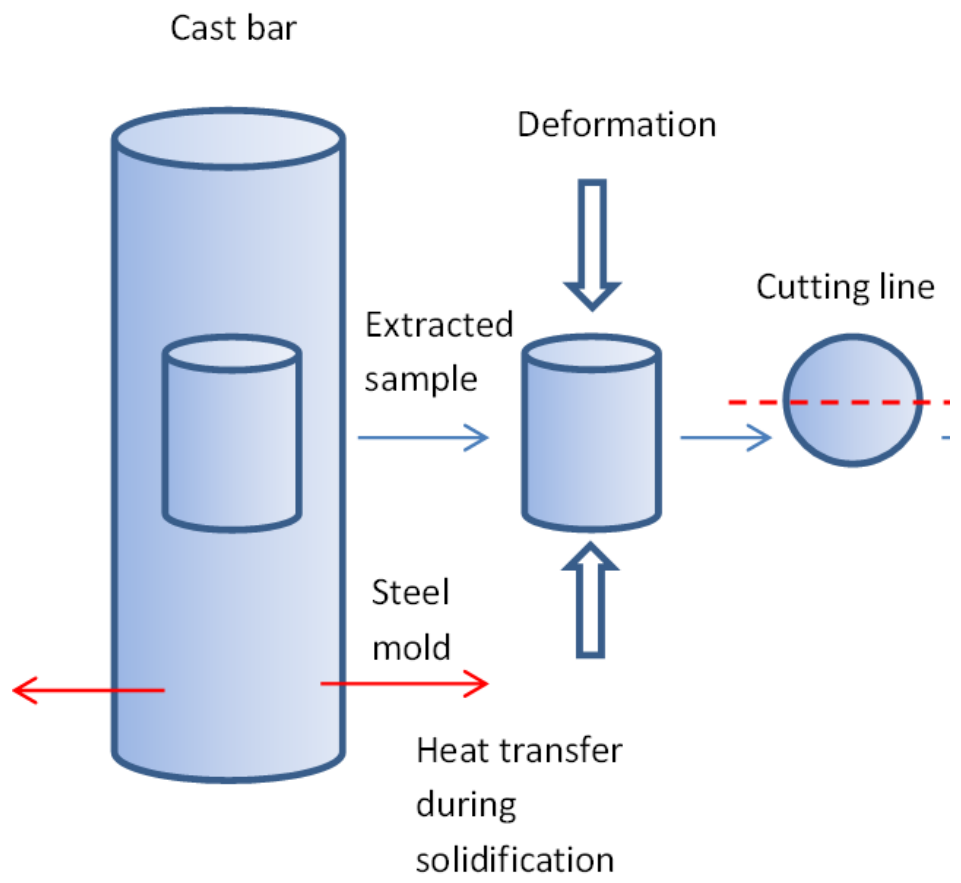

Fig. 3.8. Schematics showing sample extraction from the cast bar. 


\subsubsection{Fatigue tests}

For cyclic testing, a similar type of sub-size bar sample as shown in Fig. 3.7 was used. The samples were first polished by $\mathrm{SiC}$ sand paper up to 600 grade to remove the machining effect. The strain-controlled, pull-push type fatigue tests were conducted in accordance with the ASTM: E606 standard at room temperature with a $25 \mathrm{~mm}$ extensometer using a computerized Instron 8801 fatigue testing machine operated by Bulehill LCF2 software. Triangular waveform loading with a zero mean strain (i.e., a strain ratio of $\mathrm{R}_{\varepsilon}=-1$, completely reversed strain cycle) at a constant strain rate of $1 \times 10^{-2} \mathrm{~s}^{-1}$ was applied during cyclic deformation tests. The cyclic frequency was varied depending on the strain amplitude to maintain a fixed strain rate. The strain was also measured using a clip-on $25 \mathrm{~mm}$ extensometer attached to the gauge length. Low cycle fatigue tests were performed at total strain amplitudes of $0.1 \%, 0.2 \%, 0.3 \%, 0.4 \%$, $0.5 \%$ and $0.6 \%$ with at least two samples tested at each level of strain amplitude. If the sample survived 10,000 cycles, then the strain-controlled tests were transferred to load control at a frequency of $50 \mathrm{~Hz}$ using a sinusoidal waveform. The fatigue life was considered as the number of cycles to completely break apart of the samples.

The fracture surfaces of the tensile, compression and fatigue specimens were examined via scanning electron microscope (SEM) to identify fracture behavior during monotonic loading, and fatigue crack initiation sites and propagation characteristics. The following Fig. 3.9 represents the overall experimental work done for this study. 


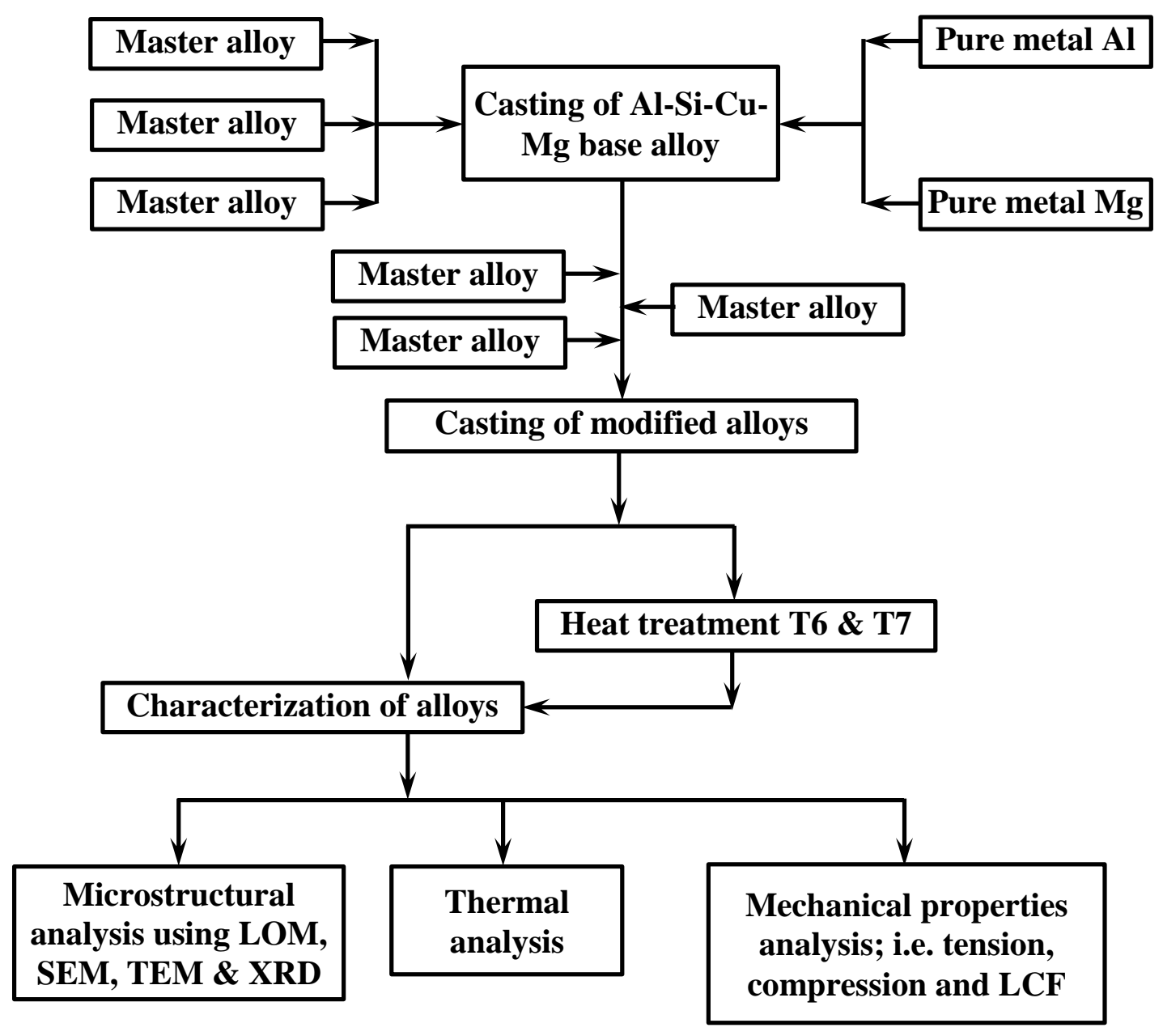

Fig. 3.9. A follow chart showing the experimental steps in this study. 


\section{CHAPTER 4}

\section{SOLIDIFICATION CHARACTERISTICS AND MICROSTRUCTURE OF THE CAST MODIFIED Al-Si-Cu-Mg ALLOYS}

\subsection{Introduction}

The application challenge of the Al-Si-Cu-Mg grades alloys is a demand to increase the service temperature to that of automotive engines, especially in the inter valve zone from $170^{\circ} \mathrm{C}$ to peak temperatures above $300^{\circ} \mathrm{C}$ in recently proposed designs [118]. Generally, Al-Si-Cu-Mg alloys possess a complex microstructure of $\alpha$-Al, eutectic silicon and intermetallics which control the mechanical properties. However, the strengthening phases such as $\mathrm{Al}_{2} \mathrm{Cu}, \mathrm{Mg}_{2} \mathrm{Si}$ and/or $\mathrm{Al}_{2} \mathrm{CuMg}$ within the $\mathrm{Al}-\mathrm{Si}-\mathrm{Cu}-\mathrm{Mg}$ alloy usually coarsen or even dissolve at temperatures above $170^{\circ} \mathrm{C}$, thus limiting their practical applications in engine blocks and cylinder heads $[19,22]$. To improve the alloy's high temperature properties, a continuous effort has been made to modify the alloy chemistry, e.g., with micro-additions of transition metals. Among transition metals, V, $\mathrm{Zr}$ and $\mathrm{Ti}$ are considered to be the most effective due to their low diffusivity and solubility in Al, causing the formation of thermally stable intermetallics, both primary and secondary phases allowing the alloys to maintain their strength at temperatures up to $350^{\circ} \mathrm{C}$ [23]. Although the effect of alloying elements such as $\mathrm{Ni}, \mathrm{Fe}, \mathrm{Cr}, \mathrm{Ti}, \mathrm{V}$ and $\mathrm{Zr}$ on the high temperature properties of the Al-Si cast alloy has been a subject of many studies $[46,63,71,72,73,74,75,76,102]$ most of them were focused on mechanical properties rather than on details of the microstructure development. According to recent findings [22, 96], additions of $\mathrm{Ti}-\mathrm{Zr}-\mathrm{Ni}$ in the Al-Si-Cu-Mg

\footnotetext{
${ }^{1}$ W. Kasprzak, D.L. Chen, and S.K. Shaha, J. Mater. Eng. Perform., Vol. 22(7), pp 1839-1847, 2013.

S.K. Shaha, F. Czerwinski, W. Kasprzak, J. Friedman and D.L. Chen, Thermochim. Acta, Vol. 595, pp 11-16, 2014.

S.K. Shaha, F. Czerwinski, W. Kasprzak, J. Friedman and D.L. Chen, Int. J. Fatigue, Vol. 70, pp 383-394, 2015.

S.K. Shaha, F. Czerwinski, W. Kasprzak, J. Friedman and D.L. Chen, COM 2015, Toronto, ON, Canada.
} 
alloy may form $\mathrm{Zr}$-Ni-rich intermetallics which improve mechanical properties. The transition metals-containing phases (TMCP) in the Al-Si-Cu-Mg alloy modified with micro additions of Ti-V-Zr were recently quantified by TEM techniques [102]. The effect of heat treatment on microstructural changes, which improves the alloy performance both at room and elevated temperatures, was also reported. Recent studies $[119,120,121,122]$ on thermal analysis of Al$\mathrm{Si}-\mathrm{Cu}$ alloys were performed by several authors. Most of the studies were focused on the behavior of eutectic silicon along with $\mathrm{Cu}-, \mathrm{Mg}$ - and Fe-containing phases. However, the specific temperatures of TMCP phase formation during solidification and their dissolution during heating are not yet determined. Also, to the authors' knowledge, there is no description of in-situ investigation of phase transformations, crystallographic structure and lattice parameters of the TMCP phases formed in the Al-Si-Cu-Mg cast alloy with additions of Ti-V$\mathrm{Zr}$.

At the same time, the Si-rich eutectic phase also has a great impact on mechanical properties. Most of the as-cast Al-Si alloys form a coarse flake-like eutectic phase during solidification which enhances the formation and propagation of cracks resulting a in reduction of mechanical properties [123]. Therefore, it is of interest to researchers to modify the morphology of the eutectic silicon from flake to fiber and/or spherical shapes which improve the mechanical properties. The basic mechanism of thermal modification of eutectic silicon is the fragmentation, rounding of sharp edges, spheroidization, coarsening of large and dissolution of small eutectic silicon phases to the matrix. Many researchers investigated the spheroidization of eutectic silicon in the Al-Si alloy matrix [45, 46, 47, 48, 49]. However, the spheroidization mechanism of eutectic silicon in $\mathrm{Al}-\mathrm{Si}-\mathrm{Cu}-\mathrm{Mg}$ alloys modified with $\mathrm{Ti}, \mathrm{V}$ and $\mathrm{Zr}$ is still unknown. There is not enough information in the literature about the formation of intermetallics of transition metals containing $\mathrm{Ti}, \mathrm{V}$, and $\mathrm{Zr}$ during casting and how it responds to the heat 
treatment process, i.e. solubility of these phases in the matrix is also not clear. So, in this chapter the thermal analysis during casting at higher solidification rates and re-melting of the Al-Si-Cu-Mg alloy modified with addition of $\mathrm{Ti}, \mathrm{V}$, and $\mathrm{Zr}$ will be described. Also, the effect of solution treatment on the phases, especially eutectic $\mathrm{Si}$ and $\mathrm{Ti}-\mathrm{V}-\mathrm{Zr}$-rich phases will be characterized in the as-cast and T6 heat treated state.

\subsection{Solidification Characteristics of Alloys Containing Ti-V-Zr}

Fig. 4.1 represents the experimental cooling curves obtained during rapid solidification; the alloy (MA4) experienced a cooling rate of $35.8^{\circ} \mathrm{C} / \mathrm{s}$ at the bottom of the mold. With increasing distance from the bottom to the top, the cooling rate decreased to 18.6 and $10.0{ }^{\circ} \mathrm{C} / \mathrm{s}$ for the center and top of the mold, respectively. It is also evident that the Temperature vs. Time curves showed visible temperature arrests due to phase reactions during solidification. These plateaus corresponded to the nucleation of the Al-network, Al-Si eutectic and intermetallics and were caused by latent heat release. The particular plateau shapes were influenced by the cooling rate and phase changes as well. As seen in Fig. 4.1, the plateau length (duration) decreased with increasing cooling rate. At the same time, the latent heat of eutectic Si was higher (approximately $1810 \mathrm{~kJ} / \mathrm{kg})$ than the Al-network formation $(\sim 395 \mathrm{~kJ} / \mathrm{kg})$ [124] which significantly increased the temperature of the melt during the solidification process, leading to longer cooling time. A similar phenomenon was reported by Kasprzak et al. [112] for an Al$20 \% \mathrm{Si}$ alloy casting in a copper mold where the cooling rate was $35^{\circ} \mathrm{C} / \mathrm{s}$.

The typical cooling and heating curves acquired during thermal analysis for the base alloy (BA) and modified alloy (MA4) are portrayed in Fig.4.2a. The first derivatives (dT/dt) vs. time were plotted in Fig.4.2b to determine precisely the phase transformation reaction. The locations of phase changes, marked on the curves, are listed in Table 4.1 along with the accompanying 
phase transformation reactions as reported in $[112,125]$. The results revealed that during solidification of the base alloy, the nucleation of the $\alpha$-Al dendritic network, eutectic $\mathrm{Si}$, $\mathrm{Mg}_{2} \mathrm{Si}_{/} \mathrm{Al}_{8} \mathrm{Mg}_{3} \mathrm{FeSi}_{6}$ and $\mathrm{Al}_{2} \mathrm{Cu} / \mathrm{Al}_{5} \mathrm{Mg}_{8} \mathrm{Cu}_{2} \mathrm{Si}_{6}$ started at $612,570,535$ and $505^{\circ} \mathrm{C}$, respectively.

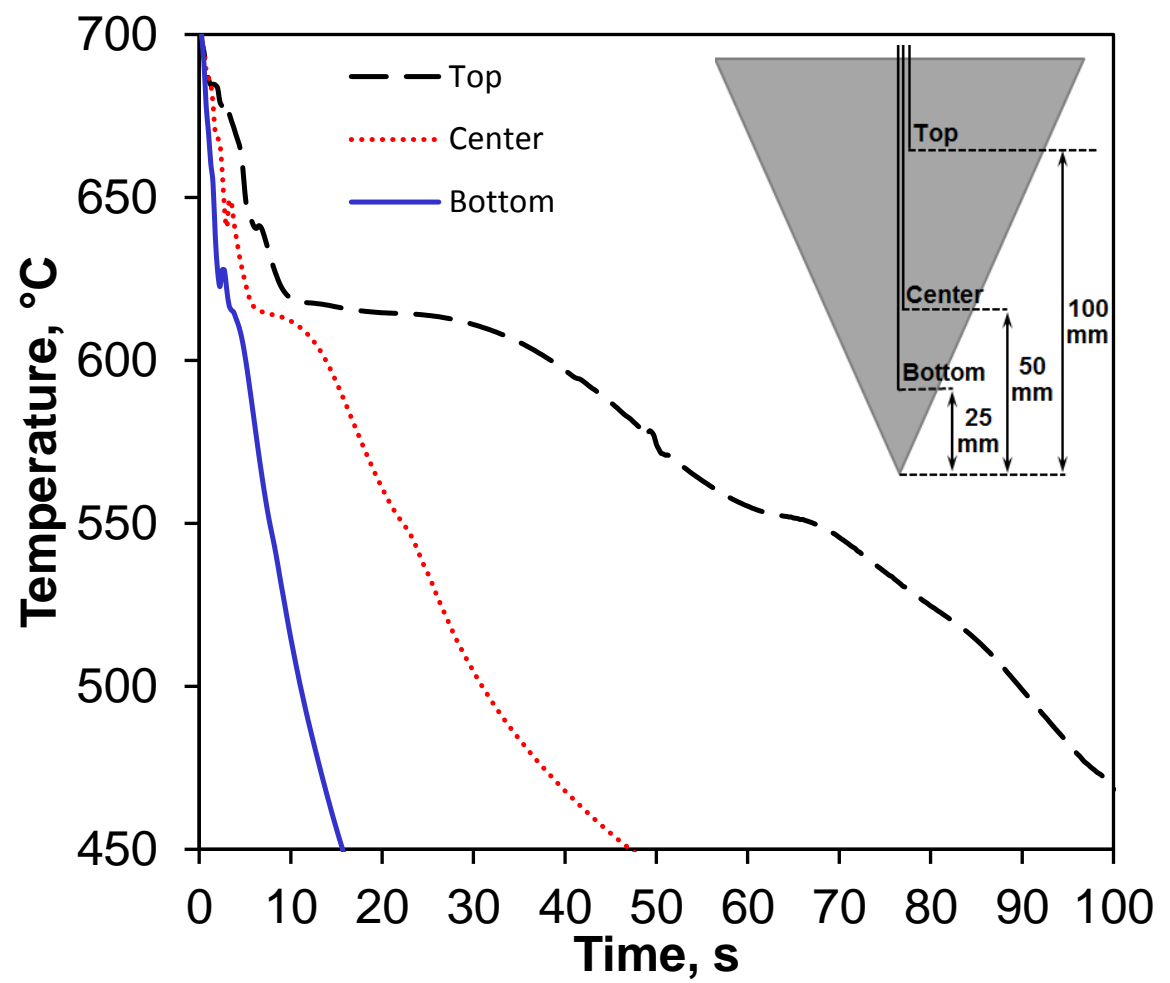

Fig. 4.1. Typical solidification behavior of Al-Si-Cu-Mg alloy modified with addition of Ti-V$\mathrm{Zr}$ at different cooling rates indicating the position of thermocouples in the wedge.

Table 4.1 A comparision of phase transformation temperatures between the base alloy (BA) and modified alloy (MA4) during heating cycle (HC) and cooling cycle (CC).

\begin{tabular}{llcccc}
\multirow{2}{*}{ No. } & $\begin{array}{c}\text { Possible phase transformation during } \\
\text { solidification and melting }\end{array}$ & \multicolumn{2}{c}{$\begin{array}{c}\text { transformation } \\
\text { temperature, }{ }^{\circ} \mathrm{C}\end{array}$} & \multicolumn{2}{c}{$\begin{array}{c}\text { transformation } \\
\text { temperature, }\end{array}$} \\
\cline { 2 - 6 } & \multicolumn{2}{c}{$\mathrm{CC}$} & $\mathrm{HC}$ & $\mathrm{CC}$ & $\mathrm{HC}$ \\
\hline 1 & $\mathrm{~L} \leftrightarrow \mathrm{L}+(\mathrm{AlSi})_{\mathrm{X}}(\mathrm{ZrVTi})$ & - & - & 696 & 705 \\
\hline 2 & $\mathrm{~L} \leftrightarrow \alpha-\mathrm{Aluminum}$ network & 612 & 616 & 610 & 615 \\
\hline 3 & $\mathrm{~L} \leftrightarrow \mathrm{Al}-\mathrm{Si}$ eutectic & 570 & 575 & 571 & 574 \\
\hline 4 & $\mathrm{~L} \leftrightarrow \mathrm{Al}+\mathrm{Si}+\mathrm{Mg}_{2} \mathrm{Si}+\mathrm{Al}_{8} \mathrm{Mg}_{3} \mathrm{FeSi}_{6}$ & 535 & 545 & 532 & 546 \\
\hline 5 & $\begin{array}{l}\mathrm{L}+\mathrm{Mg}_{2} \mathrm{Si} \leftrightarrow \mathrm{Al}+\mathrm{Si}+\mathrm{Al}_{2} \mathrm{Cu}+ \\
\mathrm{Al}_{5} \mathrm{Mg}_{8} \mathrm{Cu}_{2} \mathrm{Si}_{6}\end{array}$ & 505 & 512 & 505 & 513 \\
\hline
\end{tabular}



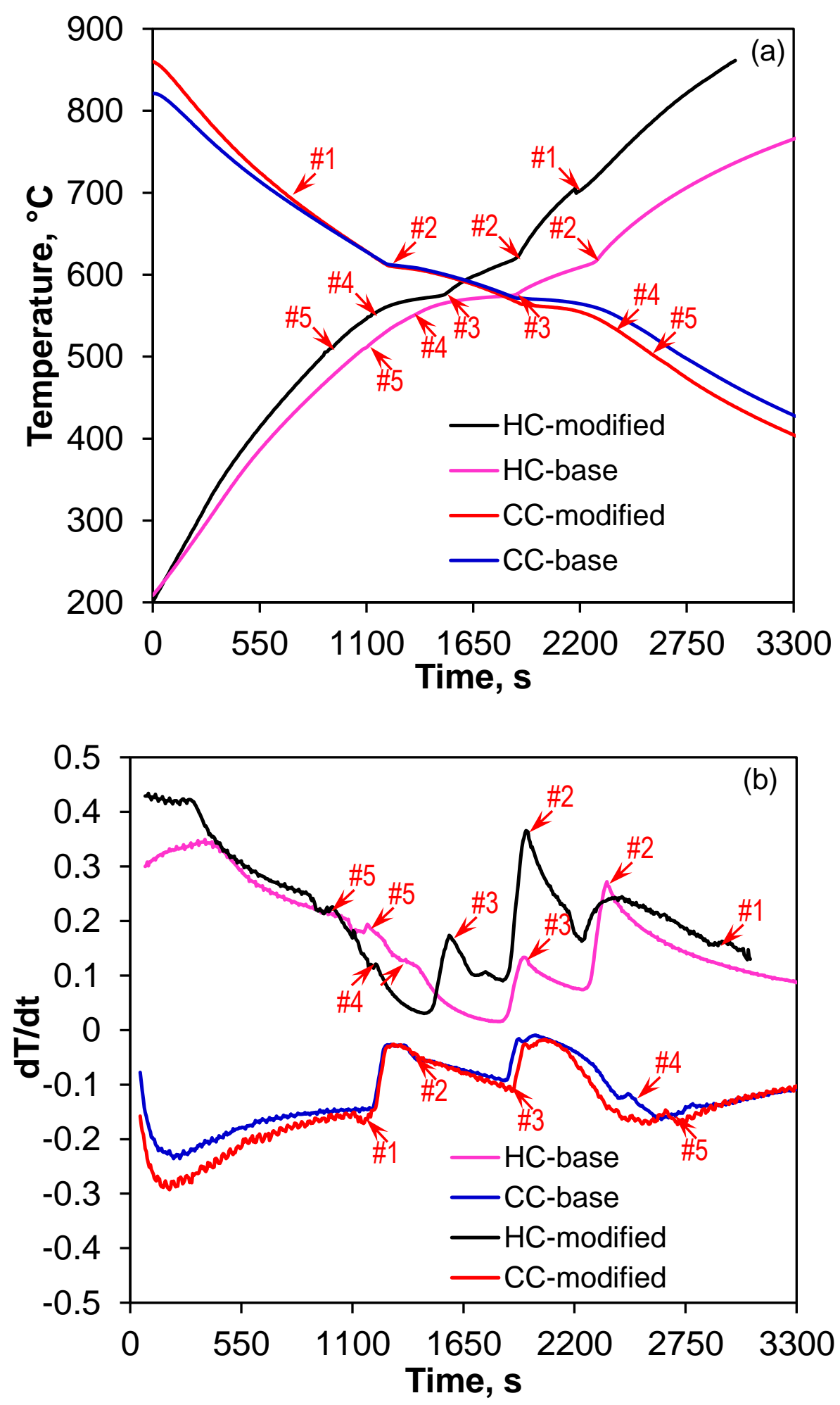

Fig. 4.2. A comparison of melting and solidification behavior of cast Al-Si-Cu-Mg alloy modified with $\mathrm{Ti}, \mathrm{V}$ and $\mathrm{Zr}$ and the base alloy, (a) cooling and heating curves, and (b) first derivatives of the cooling and heating curves. Note: HC-heating cycle, CC-cooling cycle. The numbers (\#1-\#5) indicate the phase transformation reaction as described in Table 4.1. 
In contrast, during heating of the base alloy, the dissolution/melting of phases was in reverse sequence; i.e. at first the $\mathrm{Al}_{2} \mathrm{Cu} / \mathrm{Al}_{5} \mathrm{Mg}_{8} \mathrm{Cu}_{2} \mathrm{Si}_{6}$ phases dissolved at $512^{\circ} \mathrm{C}$, then the $\mathrm{Mg}_{2} \mathrm{Si}_{2} / \mathrm{Al}_{8} \mathrm{Mg}_{3} \mathrm{FeSi}_{6}$ dissolved at $545^{\circ} \mathrm{C}$ followed by the eutectic Si at $575^{\circ} \mathrm{C}$ and finally the $\alpha-\mathrm{Al}$ dendritic network melted at $616^{\circ} \mathrm{C}[112,125]$. The modified alloy shows similar phase transformation reactions at mostly the same temperatures, while the formation and dissolution of TMCP were found to be 696 and $705^{\circ} \mathrm{C}$ during solidification and heating of the alloy. The temperature difference between heating and cooling cycles is due to the hysteresis effect. A similar thermal analysis was reported in the literature [22] revealing that melting of trialuminide $\left(\mathrm{Al}_{3} \mathrm{X}\right)$ occurred after melting of the $\alpha-\mathrm{Al}$ dendritic network in the $\mathrm{Al}-\mathrm{Si}-\mathrm{Cu}-\mathrm{Mg}$ alloy modified with additions of $\mathrm{Ti}, \mathrm{V}$ and Ni. It is concluded that TMCP are stable at $600^{\circ} \mathrm{C}$ which is also supported here by the in-situ XRD measurements of the modified alloy. Since the TMCP forms prior to nucleation of the $\alpha-\mathrm{Al}$ dendritic network, it is reasonable to assume that the Aldendritic network growth occurred around the plate-shaped TMCP as seen in the Fig.4.2b.

\subsection{Microstructure of the Alloys}

\subsubsection{Effect of alloying elements on the microstructures}

Typical LOM microstructures of the studied alloys in the unetched conditions are shown in Fig.4.3. Also, typical SEM images with EDX line scan in the unetched and deep etched condition are depicted in Fig. 4.4. The calculated stoichiometric formula from EDX point analysis along with the phase morphology and literature suggestions are given in Table 4.2. The Al-Si-Cu-Mg base alloy developed a complex microstructure as reported in many studies [22, $65,96,126,127]$. As listed in Table 4.2, the as-cast base alloy (Fig. 4.3a) consisted of dendritic $\alpha$-Al (\#1), modified eutectic silicon (\#2), blocky-type copper base $\theta-\mathrm{Al}_{2} \mathrm{Cu}(\# 3)$ phase and ternary eutectic $\mathrm{Al}-\mathrm{Al}_{2} \mathrm{Cu}-\mathrm{Si}$ (\#4) phase, Mg-rich Chinese script like Q-phase $\mathrm{Al}_{5} \mathrm{Cu}_{2} \mathrm{Mg}_{8} \mathrm{Si}_{6}$ 
(\#5) and Fe-rich needle-like $\pi$-phase $\mathrm{Al}_{8} \mathrm{FeMg}_{3} \mathrm{Si}_{6}$ (\#6). The phases \#1, \#2, \#5 and \#6 were also identified in the studied alloys in the T6 condition. However, phases from \#1 to \#6 were recognized in the as-cast MA4 alloy. It is seen that the presence of the alloying elements $\mathrm{Ti}, \mathrm{Zr}$ and $\mathrm{V}$ in the base alloy led to the development of even more complex microstructures in the modified alloys. The presence of Ti in the MA1 (Fig. 4.3b) alloy formed an additional needlelike phase ( $\mathrm{AlSi})_{3} \mathrm{Ti}(\# 7 \mathrm{a})$. At the same time, the addition of $\mathrm{Ti}$ and $\mathrm{Zr}$ in alloy MA2 (Fig. 4.3c) formed a needle-like phase $(\mathrm{AlSi})_{3}(\mathrm{TiZr})$. It is also seen that $\mathrm{Zr}$ always forms complex intermetallics with the other transition metals ( $\mathrm{Ti}$ and $\mathrm{V}$ ) and increasing the $\mathrm{Zr}$ content in the TiV-Zr-rich phases leads to reduced content of Si and V. The metallographic analysis revealed that both MA3 and MA4 alloys exhibited similar microstructures. The MA4 alloy microstructure in the as-cast condition consisted of $\alpha$-Al dendrites (\#1), fibrous-like modified Al-Si eutectic (\#2) and eight (8) distinct intermetallic phases as listed in Table 4.2 and Fig. 4.3e. As calculated from the phase chemistry, the two types of $\mathrm{Cu}$-rich phases are $\mathrm{Al}_{2.1} \mathrm{Cu}(\# 3$ ) and $\mathrm{Al}_{8.5} \mathrm{Si}_{2.4} \mathrm{Cu}$ (\#4), which are generally suggested as $\theta-\mathrm{Al}_{2} \mathrm{Cu}$ [22] and $\mathrm{Al}-\mathrm{Al}_{2} \mathrm{Cu}-\mathrm{Si}$ ternary eutectic [128] phase, respectively. At the same time, the Mg-and Fe-rich phases are calculated as $\mathrm{Al}_{7.2} \mathrm{Si}_{8.3} \mathrm{Cu}_{2} \mathrm{Mg}_{6.9}$ (\#5) and $\mathrm{Al}_{14} \mathrm{Si}_{7.1} \mathrm{FeMg}_{3.3}$ (\#6) where those phases are suggested as Q$\mathrm{Al}_{5} \mathrm{Cu}_{2} \mathrm{Mg}_{8} \mathrm{Si}_{6}$ and $\pi-\mathrm{Al}_{8} \mathrm{FeMg}_{3} \mathrm{Si}_{6}$ phases, respectively. However, the Cu-rich phases (\#3 and \#4) dissolved completely while the Mg-rich phase (\#5) and Fe-rich phase (\#6) partially dissolved during the solutionizing stage of the T6 heat treatment process. Similar types of phases were found in base alloys in the as-cast condition $[22,65,96,126]$. 

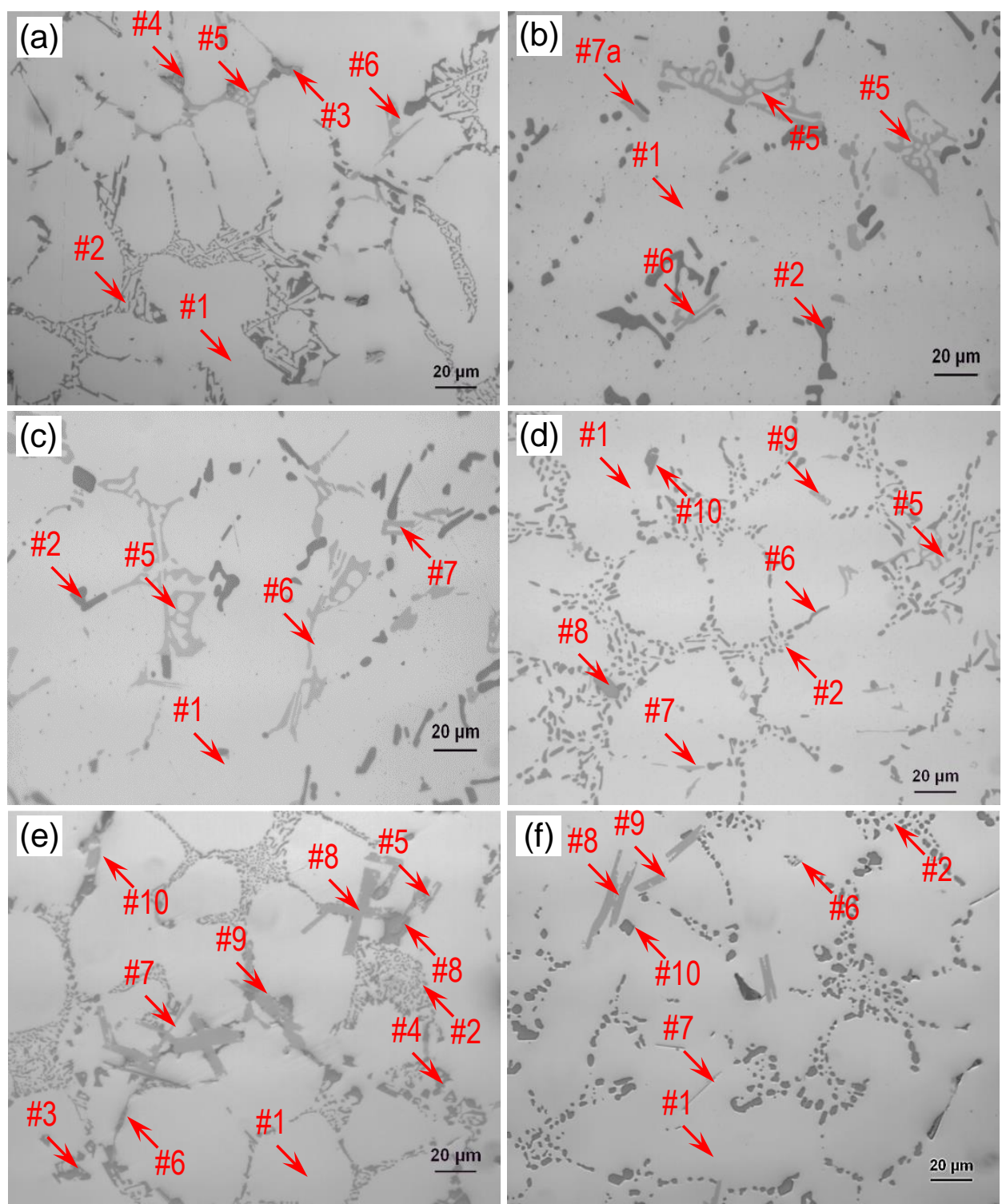

Fig. 4.3. Typical LOM microstructure of the studied Al-Si-Cu-Mg alloy modified with addition of Ti/V/Zr, (a) as-cast base alloy, T6 heat treated alloys (b) MA1, (c) MA2 (d) MA3, (e) as-cast MA4 and (f) T6 heat treated MA4 alloy. Note that numbered arrows correspond to phases as outlined in Table 4.2.

The Ti-V-Zr-containing phases which are unique for this study are also identified in the alloy microstructure. The MA3 (Fig. 4.3d) alloy exhibited needle-like phases. However, increasing the amount of $\mathrm{Zr}-\mathrm{V}-\mathrm{Ti}$ in alloy MA4 (Fig. 4.4b) increased the volume fraction and changed the morphology of the intermetallics from needle-like to plate and bulk shaped. Those phases are frequently noted in the alloy microstructure as seen in Fig. 4.3 (e-f). The calculated Ti-V-Zr- 
containing phases are $\mathrm{Al}_{6.7} \mathrm{Si}_{1.2} \mathrm{TiZr}_{1.8}(\# 7), \mathrm{Al}_{21.4} \mathrm{Si}_{4.1} \mathrm{Ti}_{3.5} \mathrm{VZr}_{3.9}$ (\#8), and $\mathrm{Al}_{2.8} \mathrm{Si}_{3.8} \mathrm{~V}_{1.6} \mathrm{Zr}$ (\#9)

which were designated in the literature as $(\mathrm{AlSi})_{3}(\mathrm{TiZr}),(\mathrm{AlSi})_{3}(\mathrm{TiVZr})$, and $(\mathrm{AlSi})_{2}(\mathrm{VZr})$, respectively [22, 96, 102, 129].

Table 4.2 Summary of the phases present in the studied alloys identified using SEM/EDX.

\begin{tabular}{|c|c|c|c|c|c|c|}
\hline No. & $\begin{array}{c}\text { Calculated phase } \\
\text { from SEM/EDX } \\
\text { analysis }\end{array}$ & $\begin{array}{l}\text { Suggested } \\
\text { phase }\end{array}$ & Phase morphology & $\begin{array}{l}\text { Crystal } \\
\text { Structure }\end{array}$ & $\begin{array}{l}\text { Space } \\
\text { group }\end{array}$ & $\begin{array}{l}\text { Lattice } \\
\text { parameters, } \\
\left(\mathrm{A}^{\circ}\right)\end{array}$ \\
\hline$\# 1$ & $\alpha$-aluminum & $\alpha$-aluminum & Dendritic & Cubic & $\mathrm{m} 3 \mathrm{~m}$ & $\mathrm{a}=\mathrm{b}=\mathrm{c}=4.05$ \\
\hline$\# 2$ & Eutectic silicon & Eutect & prous/spheroids & abic & $3 \mathrm{~m}$ & 5.43 \\
\hline \#3 & $\mathrm{Al}_{2.1} \mathrm{Cu}$ & $\mathrm{Al}_{2} \mathrm{Cu}$ & Blocky & Tetragonal & $\mathrm{I} 4 / \mathrm{mcm}$ & $\begin{array}{l}a=b=6.07, \\
c=4.87\end{array}$ \\
\hline \#4 & $\mathrm{Al}_{8.5} \mathrm{Si}_{2.4} \mathrm{Cu}$ & $\mathrm{Al}-\mathrm{Al}_{2} \mathrm{Cu}-\mathrm{Si}$ & Blocky & - & - & - \\
\hline \#5 & $\mathrm{Al}_{7.2} \mathrm{Si}_{8.3} \mathrm{Cu}_{2} \mathrm{Mg}_{6.9}$ & $\mathrm{Al}_{5} \mathrm{Cu}_{2} \mathrm{Mg}_{8} \mathrm{Si}_{6}$ & $\begin{array}{c}\text { Chinese } \\
\text { script/needle-like }\end{array}$ & Hexagonal & - & $\begin{array}{l}a=10.32, \\
c=4.05\end{array}$ \\
\hline \#6 & $\mathrm{Al}_{14} \mathrm{Si}_{7.1} \mathrm{FeMg}_{3.3}$ & $\mathrm{Al}_{8} \mathrm{FeMg}_{3} \mathrm{Si}_{6}$ & Needle-like & Hexagonal & $\mathrm{P} 6 \overline{2} \mathrm{~m}$ & $\begin{array}{l}a=6.63, \\
c=7.94\end{array}$ \\
\hline$\# 7 \mathrm{a}$ & $\mathrm{Al}_{6.8} \mathrm{Si}_{1.4} \mathrm{Ti}$ & $(\mathrm{AlSi})_{3} \mathrm{Ti}$ & eedle-like & - & - & - \\
\hline \#7 & $\mathrm{Al}_{6.7} \mathrm{~S}$ & $\mathrm{Zr})$ & Needle- & Tet & $\mathrm{I} 4 / \mathrm{mcm}$ & $\begin{array}{l}\mathrm{a}=\mathrm{b}=7.49, \\
\mathrm{c}=3.85\end{array}$ \\
\hline \#8 & $\mathrm{Al}_{21.4} \mathrm{Si}_{4.1} \mathrm{Ti}_{3.5} \mathrm{VZr}_{3.9}$ & $(\mathrm{AlSi})_{3}(\mathrm{TiVZr})$ & Plate/blocky/needle & Tetragonal & $\mathrm{I} 4 / \mathrm{mcm}$ & $\begin{array}{l}a=b=6.07, \\
c=4.87\end{array}$ \\
\hline \#9 & $\mathrm{Al}_{2.8} \mathrm{Si}_{3.8} \mathrm{~V}_{1.6} \mathrm{Zr}$ & $(\mathrm{AlSi})_{2}(\mathrm{VZr})$ & Plate-like & Tetragonal & $\mathrm{I} 4 / \mathrm{mcm}$ & $\begin{array}{l}\mathrm{a}=\mathrm{b}=5.25, \\
\mathrm{c}=5.09\end{array}$ \\
\hline \#10 & $\mathrm{Al}_{5.1} \mathrm{Si}_{35.4} \mathrm{Ti}_{1.6} \mathrm{Zr}_{5.7} \mathrm{Fe}$ & $(\mathrm{AlSi})_{2}(\mathrm{TiZr}) \mathrm{Fe}$ & Blocky & - & - & - \\
\hline
\end{tabular}

As reported in [130], the Ti-V-Zr-containing phases are thermally stable, which is beneficial to improve the alloy high temperature performance. The identified intermetallic phases were found most often in interdendritic regions. Another valuable modification of alloy microstructure was observed for the Fe-containing $\beta-\mathrm{Al}_{5} \mathrm{FeSi}$ phase which is generally needlelike in shape and detrimental for the alloy strength and ductility. However, it is assumed that the Fe-containing $\beta-\mathrm{Al}_{5} \mathrm{FeSi}$ phase turns into the $\mathrm{Al}_{5.1} \mathrm{Si}_{35.4} \mathrm{Ti}_{1.6} \mathrm{Zr}_{5.7} \mathrm{Fe}$ (\#10) phase which could be described as $(\mathrm{AlSi})_{2}(\mathrm{TiZr}) \mathrm{Fe}$, as reported in [63, 102]. Similar types of intermetallics, their formation mechanism, and phase morphology were reported in detail in our previous studies $[63,102,111,129]$. 

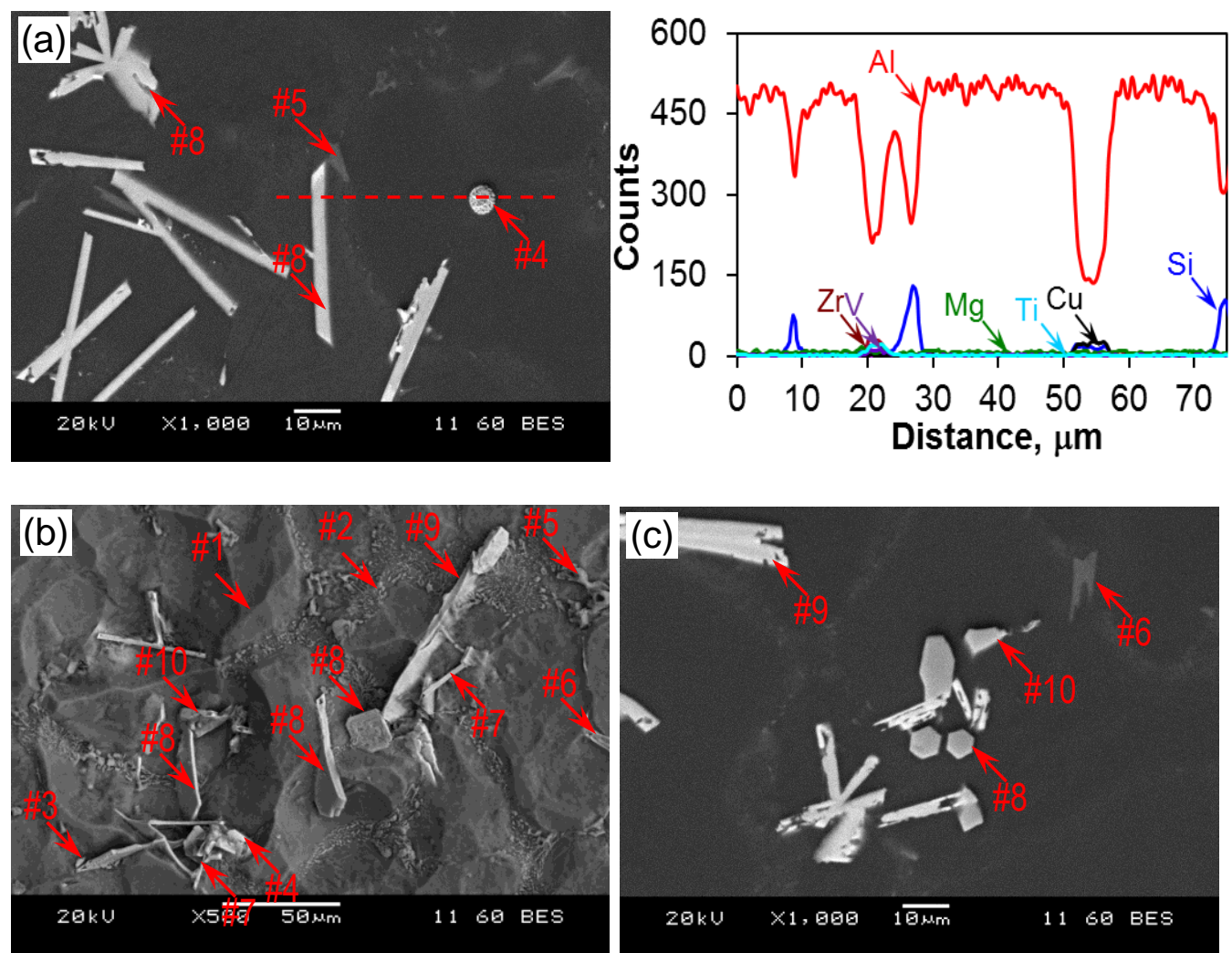

Fig. 4.4. Typical SEM microstructure of Al-Si-Cu-Mg alloy (MA4) modified with Ti, V and Zr, with conjunction of EDX line scans of as-cast alloy in unetched (a, c) and deep etched (b) condition. Note that numbered arrows correspond to phases as outlined in Table 4.2.

The EBSD analysis revealed that $\alpha$-Al dendrites (\#1) and Al-Si eutectics (\#2) have a cubic crystal structure with an $\mathrm{m} 3 \mathrm{~m}$ space group accompanied by different lattice parameters of 4.05 and $5.43 \mathrm{~A}^{\circ}$, respectively (Fig. 4.5). The crystal structure of the $\mathrm{Al}_{2.1} \mathrm{Cu}(\# 3$ phase), identified as tetragonal along with a space group of $\mathrm{I} 4 / \mathrm{mcm}$, had lattice parameters of $\mathrm{a}=\mathrm{b}=6.07 \mathrm{c}=4.87 \mathrm{~A}^{\circ}$, while the $\mathrm{Al}_{7.2} \mathrm{Si}_{8.3} \mathrm{Cu}_{2} \mathrm{Mg}_{6.9}(\# 5)$ and $\mathrm{Al}_{14} \mathrm{Si}_{7.1} \mathrm{FeMg}_{3.3}(\# 6)$ phases show hexagonal crystal structure with lattice parameters of $\mathrm{a}=10.32, \mathrm{c}=4.05$, and $\mathrm{a}=6.63, \mathrm{c}=7.94$, respectively. Of the four distinct TMCP phases identified, in the case of three it was possible to identify their crystallographic structure. They include $\mathrm{Al}_{2.8} \mathrm{Si}_{3.8} \mathrm{~V}_{1.6} \mathrm{Zr}$ (\#9), $\mathrm{Al}_{21.4} \mathrm{Si}_{4.1} \mathrm{Ti}_{3.5} \mathrm{VZr}_{3.9}$ (\#8) and $\mathrm{Al}_{6.7} \mathrm{Si}_{1.2} \mathrm{TiZr}_{1.8}(\# 7)$. It is evident that all three TMCP have similar tetragonal crystal structure with $\mathrm{I} / \mathrm{mcm}$ space group accompanied by $\mathrm{D}_{22} / \mathrm{D}_{23}$ structure. However, they show different 
lattice parameters. In the case of $\mathrm{Al}_{2.8} \mathrm{Si}_{3.8} \mathrm{~V}_{1.6} \mathrm{Zr} \quad$ (\#9) $\mathrm{a}=\mathrm{b}=5.25 \quad \mathrm{c}=5.09 \quad \mathrm{~A}^{\circ}$, for $\mathrm{Al}_{21.4} \mathrm{Si}_{4.1} \mathrm{Ti}_{3.5} \mathrm{VZr}_{3.9}(\# 8) \mathrm{a}=\mathrm{b}=6.07 \mathrm{c}=4.87 \mathrm{~A}^{\circ}$ and for $\mathrm{Al}_{6.7} \mathrm{Si}_{1.2} \operatorname{TiZr}_{1.8}(\# 7) \mathrm{a}=\mathrm{b}=7.49 \mathrm{c}=3.85 \mathrm{~A}^{\circ}$. It should be pointed out that the EBSP patterns of phases \#4, \#5, and \#10 were not possible to generate because of its morphology and very low volume fraction. Similar types of phases were identified in the Al-Si-Cu-Mg alloy and are reported in the literature $[115,131,132]$.
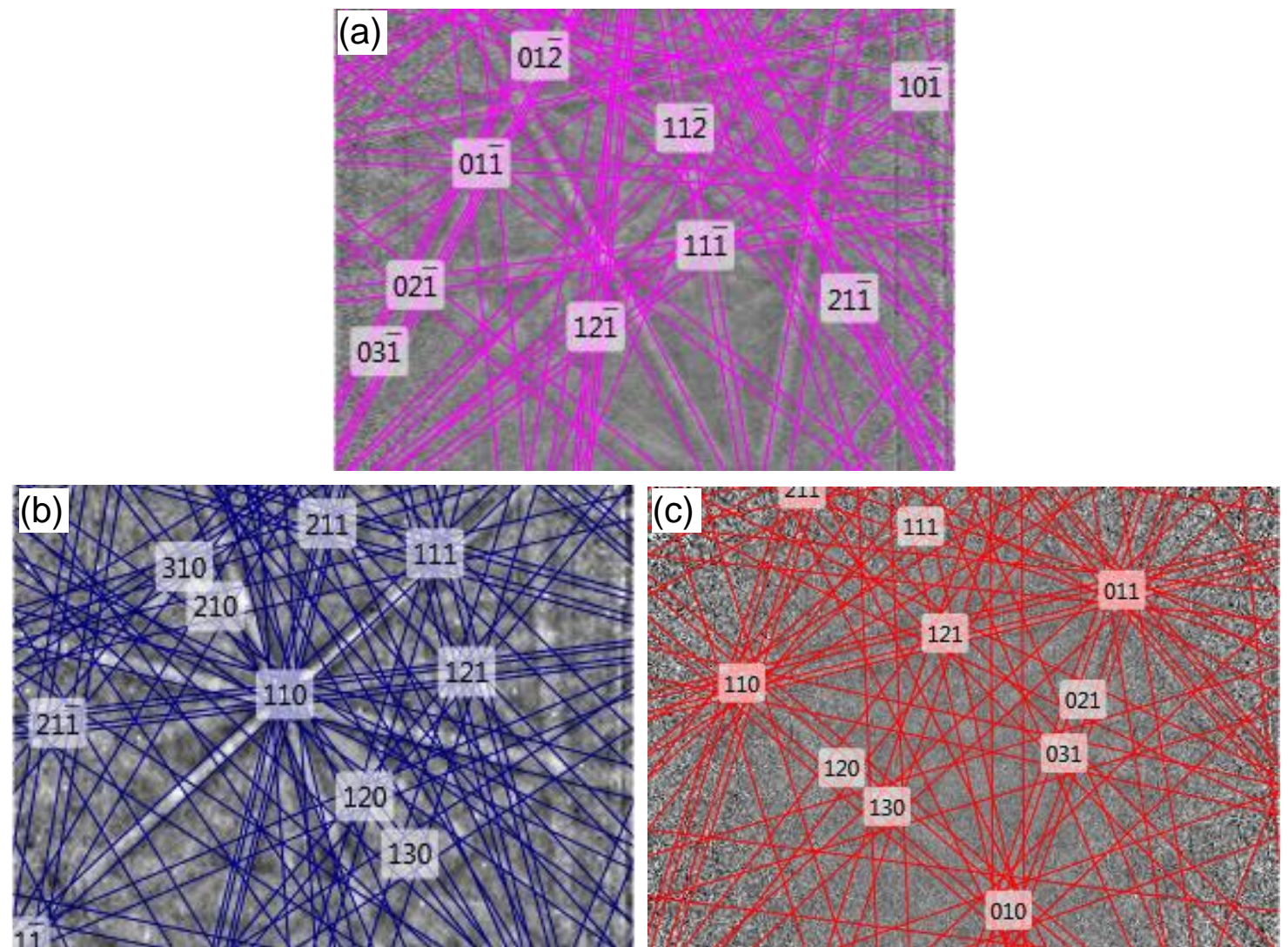

Fig. 4.5. Kikuchi pattern with solution of Ti-V-Zr-rich intermetallics (indicated in Fig.4.4 and listed in Table 4.2) of as-cast Al-Si-Cu-Mg alloy modified with $\mathrm{Ti}, \mathrm{V}$ and $\mathrm{Zr}$, (a) EBSP pattern of phase \#7, (b) EBSP pattern of phase \#8 and (c) EBSP pattern of phase \#9.

The Al-Si-Cu-Mg alloy established a complex microstructure as reported in many studies. The presence of other alloying elements $(\mathrm{Ti}-\mathrm{V}-\mathrm{Zr})$ in the present study developed an even more complex microstructure. There are limited studies on cast $\mathrm{Al}-\mathrm{Si}-\mathrm{Cu}-\mathrm{Mg}$ alloys with the addition of transition metals published by other researchers in the literature which could be used as a direct reference. Most of the studies were performed on wrought aluminum alloys with the 
addition of Zr, Ti, and Sc. Although Garat and Laslaz [118] modified the Al-Si-Cu-Mg alloy with $\mathrm{Zr}$ and $\mathrm{V}$, they focused on the mechanical properties and strengthening processes without a corresponding microstructural analysis. Recently, Hernandez-Sanoval et al. [22] modified the Al-Si-Cu-Mg alloy with minor additions of $\mathrm{Ti}, \mathrm{Zr}$ and $\mathrm{Ni}$, where they reported a very complex microstructure bearing $\mathrm{Zr}$ and $\mathrm{Ti}$, which could be used as a reference for the present study. Present results reveal that $\mathrm{Al}-\mathrm{Si}-\mathrm{Cu}-\mathrm{Mg}$ alloys containing $\mathrm{Zr}, \mathrm{V}$ and $\mathrm{Ti}$ (MA4) exhibit a complex microstructure in the as-cast condition, as seen in Fig. 4.4. Except for the intermetallic phases containing $\mathrm{Zr}, \mathrm{V}$ and $\mathrm{Ti}$, the present as-cast alloy has a similar microstructure to those reported by previous studies on Al-Si-Cu-Mg-based alloys [20, 65, 126]. The results suggest that the phase identified as $\mathrm{Al}_{2.1} \mathrm{Cu}$ (Fig. 4.4b) is most likely related to the $\mathrm{Al}_{2} \mathrm{Cu}$ phase reported in the literature. The $\mathrm{Al}_{8.5} \mathrm{Si}_{2.4} \mathrm{Cu}$ phase is expected to be similar to the ternary eutectic Al$\mathrm{Al}_{2} \mathrm{Cu}-\mathrm{Si}$, the $\mathrm{Al}_{7.2} \mathrm{Si}_{8.3} \mathrm{Cu}_{2} \mathrm{Mg}_{6.9}$ phase is similar to the Q- $\mathrm{Al}_{5} \mathrm{Cu}_{2} \mathrm{Mg}_{8} \mathrm{Si}_{6}$ phase, and the $\mathrm{Al}_{14} \mathrm{Si}_{7.1} \mathrm{FeMg}_{3.3}$ phase is most likely recognized as a Fe-rich, possibly $\mathrm{Al}_{8} \mathrm{FeMg}_{3} \mathrm{Si}_{6}$ phase that is typically formed in similar Al-Si-Cu-Mg cast alloy systems [22, 96, 133].

The addition of $\mathrm{Sc}, \mathrm{Ti}, \mathrm{V}$ and $\mathrm{Zr}$ in Al-alloys can form trialuminides which can be referred to by the general formula $\mathrm{Al}_{3} \mathrm{M}(\mathrm{M}=\mathrm{Sc}, \mathrm{Ti}, \mathrm{V}$ and $\mathrm{Zr})$. The $\mathrm{Al}_{3} \mathrm{M}$ has three types of crystallographic structure. They are the metastable $\mathrm{L}_{2}$ and $\mathrm{D}_{22}$ phases, and the stable $\mathrm{D}_{23}$ phase containing Ti/V/Zr [25]. The observed $\mathrm{Zr}$-Ti-rich intermetallic phase, $\mathrm{Al}_{6.7} \mathrm{Si}_{1.2} \mathrm{TiZr}_{1.8}$ in the as-cast microstructure could be associated with the crystal structure of $\mathrm{Al}_{3} \mathrm{M} /\left(\mathrm{D}_{23}\right)$ [25, $134]$ and the suggested formula $(\mathrm{AlSi})_{3}(\mathrm{TiZr})$ which are directly comparable to the study on AlSi-Cu-Mg alloy with the addition of the $\mathrm{Zr}$, Ti and $\mathrm{Ni}[22,96]$. Other $\mathrm{Zr} / \mathrm{Ti} / \mathrm{V}$-rich intermetallic phases are $\mathrm{Al}_{21.4} \mathrm{Si}_{4.1} \mathrm{Ti}_{3.5} \mathrm{VZr}_{3.9}, \quad \mathrm{Al}_{2.8} \mathrm{Si}_{3.8} \mathrm{~V}_{1.6} \mathrm{Zr}$ and $\mathrm{Al}_{5.1} \mathrm{Si}_{35.4} \mathrm{Ti}_{1.6} \mathrm{Zr}_{5.7} \mathrm{Fe}$ that can be summarized as $(\mathrm{AlSi})_{3}(\mathrm{TiVZr}),(\mathrm{AlSi})_{2}(\mathrm{VZr})$ and $(\mathrm{AlSi})_{2}(\mathrm{TiZr}) \mathrm{Fe}$ respectively [63, 102]. The crystal structure of the first phase is $\mathrm{D}_{22}$ while the crystal structure of the latter two phases can 
be interrelated with the stable phase $\mathrm{D}_{23}$. Although the $\mathrm{Zr}$ content in the investigated alloy was above the peritectic concentration of $0.15 \%$ (Table 4.2$)$, the pre-peritectic primary $\mathrm{Al}_{3} \mathrm{M}(\mathrm{M}=$ $\mathrm{Zr} / \mathrm{V} / \mathrm{Ti}$ ) phase was not formed as a stand-alone structure. Gao and Liu [91] showed that $\mathrm{Zr} / \mathrm{V} / \mathrm{Ti}$ can replace each other in the $\mathrm{Al}_{3} \mathrm{M}$ structure. Also, the presence of $\mathrm{Si}$ in $\mathrm{Al}$ alloys modified with addition of $\mathrm{Zr} / \mathrm{V} / \mathrm{Ti}$ increased the stability of the phases $\mathrm{D} 0_{22}$, while the stability of the $\mathrm{D} 0_{23}$ phase decreased $[134,135]$. It should be noted that there was no detrimental iron-containing needle-like $\beta$ phase present in the studied alloy MA4. Instead, (AlSi) $)_{2}(\mathrm{TiZr}) \mathrm{Fe}$ was formed. This could be a benefit to improve the mechanical properties of the Al-Si-Cu-Mg alloy modified with higher addition of Ti-V-Zr.

\subsubsection{Effect of solution treatment on the microstructure of alloy}

The metallographic analysis of the alloy MA3 in the heat treated condition continued with optical microscopy (Fig. 4.6) and the SEM/EDS analysis (Table 4.3). It confirmed the presence of the following intermetallic phases: $\mathrm{AlSiCuFe}, \mathrm{Al}_{9} \mathrm{Mg}_{12} \mathrm{Si}_{6} \mathrm{Fe}$ as well as $\mathrm{Al}_{27} \mathrm{SiTiZr}_{9}$ and AlSiTiVFe. The former one resulted from addition of transition metals into the alloy base chemistry.

Table 4.3 The main intermetallic phases identified in the alloy MA3 in T6 conditions.

\begin{tabular}{cccc}
\hline No. & Phases Present & $\begin{array}{c}\text { Dimensions } \\
(\mu \mathrm{m})\end{array}$ & Morphology Description \\
\hline$\# 1$ & $\alpha-\mathrm{Al}$ matrix & - & Dendritic \\
\hline$\# 2$ & $\mathrm{Al}-\mathrm{Si}$ eutectic & 20 & Plate like, modified \\
\hline$\# 3$ & $\mathrm{AlSiCuFe}$ & 5 & Fine eutectic \\
\hline$\# 4$ & $\mathrm{Al}_{9} \mathrm{Mg}_{12} \mathrm{Si}_{6} \mathrm{Fe}$ & 15 & Fine blocky \\
\hline$\# 5$ & $\mathrm{Al}_{27} \mathrm{SiTiZr}_{9}$ & 15 & Needle like \\
\hline$\# 6$ & $\mathrm{AlSiTiVFe}$ & 5 & Hexagonal \\
\hline
\end{tabular}




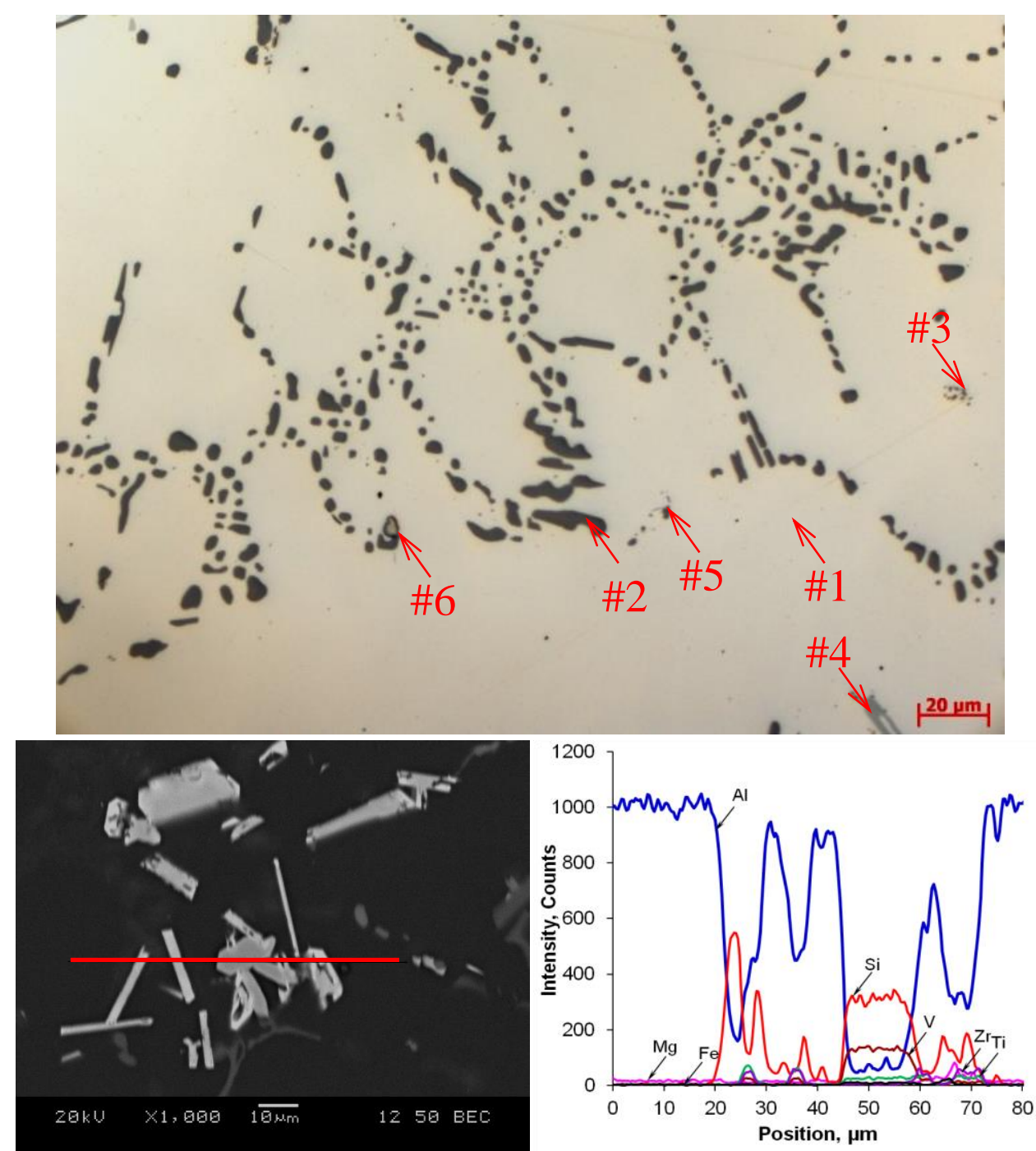

Fig. 4.6. Typical LOM (a) and SEM (b) microstructure with EDX line scan of the modified alloy MA3 in T6 heat treated conditions having SDAS of approximately $25 \mu \mathrm{m}$. Note that numbered arrows correspond to phases outlined in Table 4.3.

Comparative analysis with the as-cast condition confirmed that $\mathrm{Al}_{2} \mathrm{Cu}$ and the Q$\mathrm{Al}_{5} \mathrm{Mg}_{8} \mathrm{Si}_{6} \mathrm{Cu}_{2}$ phases dissolved during the solution treatment operation while the $\mathrm{Fe}$-containing phases partially remained in the microstructure. The $\mathrm{Zr}-\mathrm{V}$-Ti-containing phases, i.e. $\mathrm{Al}_{27} \mathrm{SiTiZr}_{9}$ and AlSiTiVFe were observed as well but their volume fraction decreased by approximately $50 \%$, as compared with the as-cast condition. Image analysis results showed that the dimensional change of the eutectic $\mathrm{Si}$ was more pronounced in the 2-step solution treatment as compared to the 1-step. The aspect ratio (length/width) decreased from $1.86 \pm 0.11$ to $1.65 \pm 0.15$ 
with increasing solutionizing temperature and remained almost constant $(1.65 \pm 0.07$ to $1.64 \pm 0.13)$ regardless of solution treatment duration. In general, the modification of eutectic $\mathrm{Si}$ as a result of the solutionizing temperature was more effective than solution time duration. Fig. 4.7 shows the eutectic silicon morphology change from plate-like to a globular/spherical shape due to the solution treatment effect as observed in the 3D SEM images
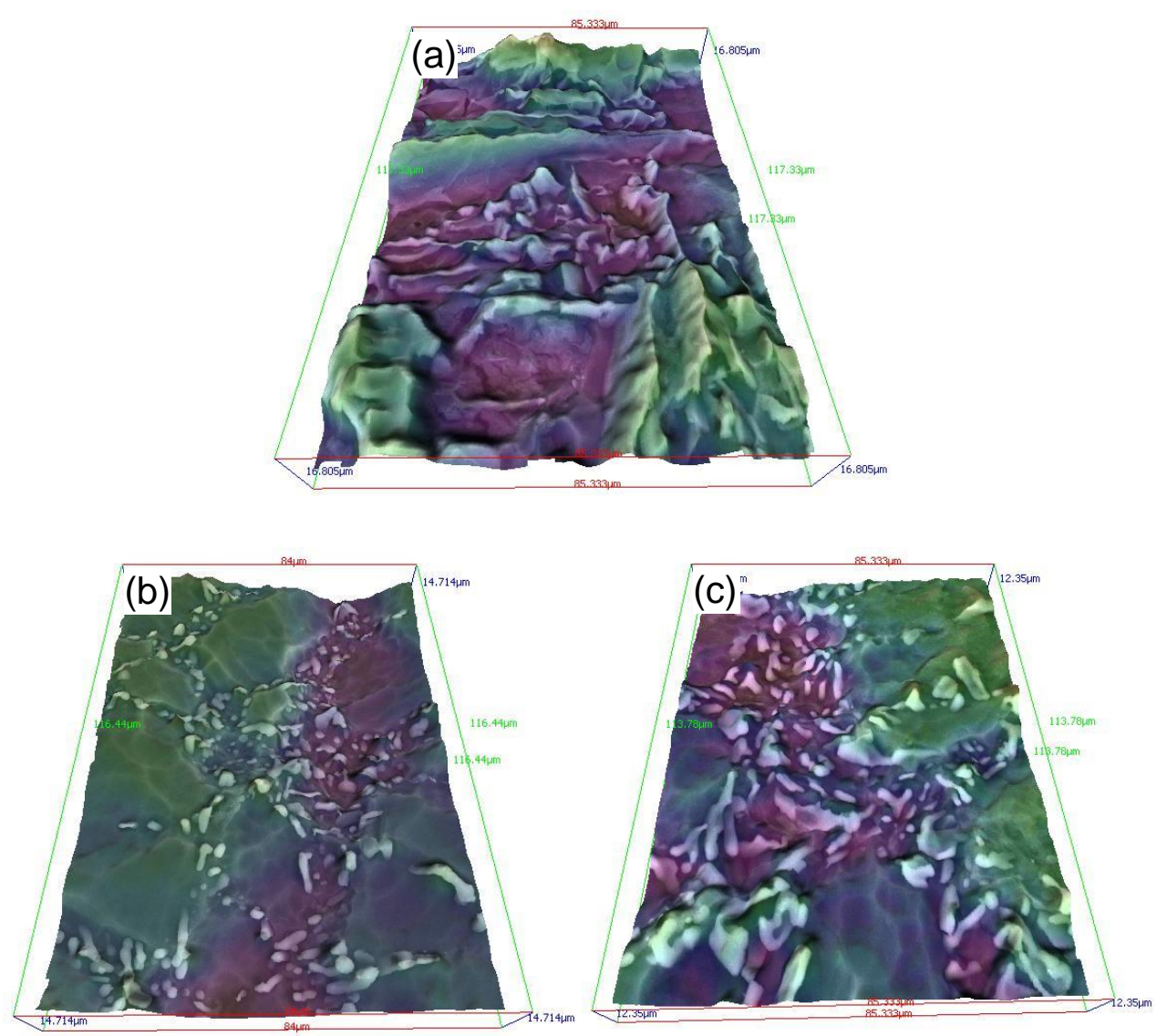

Fig. 4.7. Microstructure of modified $\mathrm{Al}-\mathrm{Si}-\mathrm{Cu}-\mathrm{Mg}$ alloy in 3D mode; (a) As-cast condition, (b) solution treatment at $485^{\circ} \mathrm{C}$ for $0.5 \mathrm{hr}$ and (c) solution treatment at $485^{\circ} \mathrm{C}$ for $4.5 \mathrm{~h}$. Note that with changing the solution treatment time eutectic silicon particles change their plate-like shape to a round or spherical shape.

The TEM characterization combined with EDX and diffraction analysis confirmed the presence of rod-shaped secondary precipitates in the $\mathrm{T} 6$ heat condition as a major phase 
influencing the alloy strength as shown in Fig. 4.8 and Fig. 4.9 for the alloys MA3 and MA4, respectively.

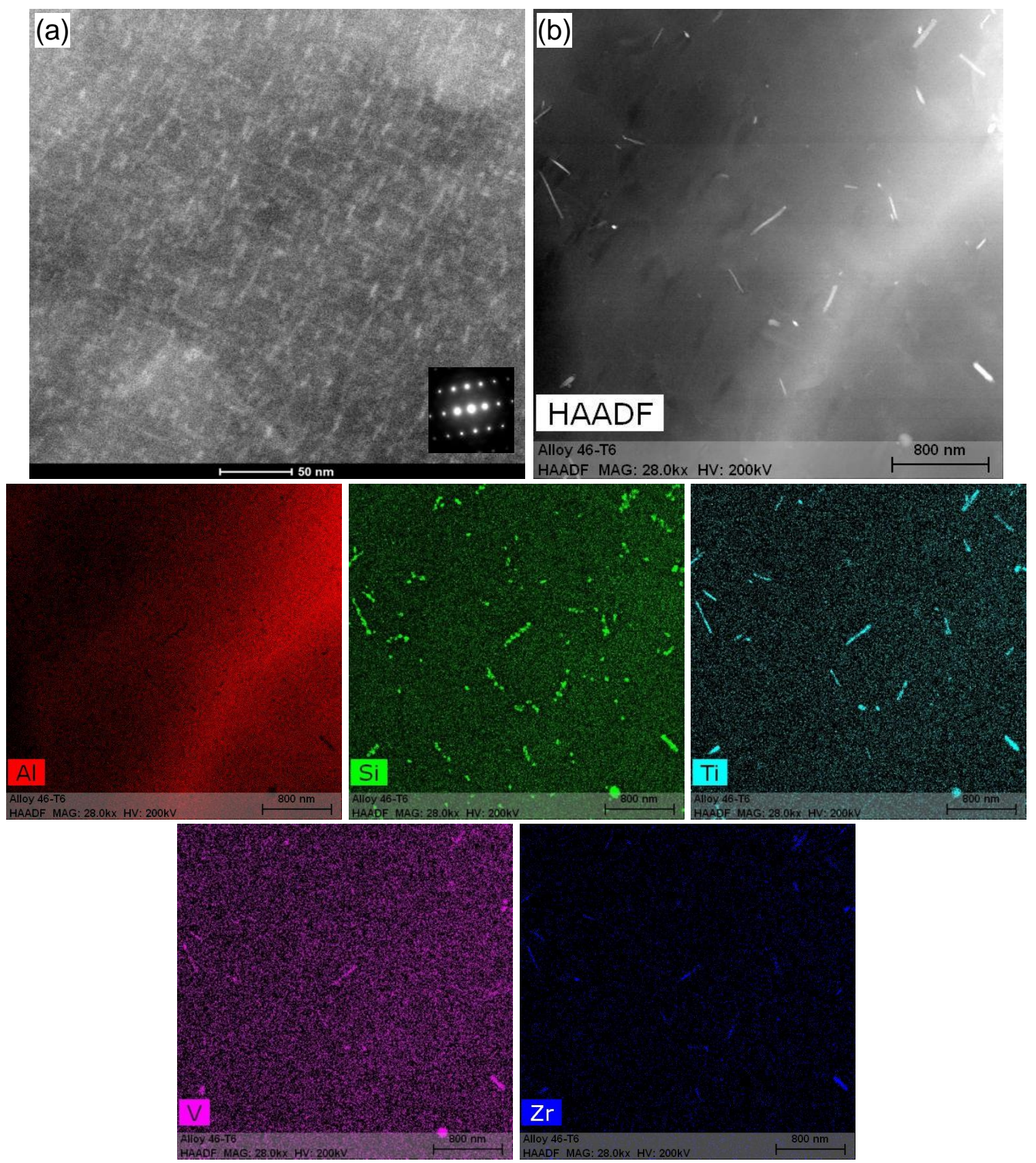

Fig. 4.8. TEM observations of the secondary precipitates in T6 condition (modified alloy MA3) (a) Bright field TEM image and selected area diffraction pattern (SAD) taken from [ $\left[\begin{array}{lll}0 & 1 & 1\end{array}\right]$ zone axis (inset) and (b) HAADF image of the precipitate structure in T6 heat treated condition (ST

@ $510^{\circ} \mathrm{C}$ for $0.5 \mathrm{~h}+525^{\circ} \mathrm{C}$ for $4.5 \mathrm{~h}$ ) showing along with EDX elemental maps of nano-rod precipitates $(\mathrm{AlSi})_{3}(\mathrm{Ti}, \mathrm{V}, \mathrm{Zr})$. (TEM analysis was performed in CANMETMaterials, Hamilton, Canada) 
Electron diffraction analysis and high resolution imageing revealed the secondary precipitates containing $\mathrm{Zr}-\mathrm{V}-\mathrm{Ti}$. They were identified as $(\mathrm{AlSi})_{3}(\mathrm{Zr}-\mathrm{V}-\mathrm{Ti})$ trialuminides with a tetragonal $\mathrm{D}_{23}$ type structure. It should be noted that these precipitates were also found in smaller sizes which are assumed to be of $\mathrm{L}_{2}$ type structure. HRTEM shows that these precipitates are semi-coherent.

It is also noticed that the MA4 alloy (Fig. 4.9) exhibits a higher volume fraction of precipitates compared to the MA3 alloy (Fig.4.8). It is suggested that the presence of $\mathrm{Si}$ and $\mathrm{Cu}$ particulates attached to these precipitates could help to retain the coherency with the matrix. The $\mathrm{Z}$ contrast high angle annular dark field image (HAADF) shown in Fig. 4.8b along with corresponding elemental maps reveals two types of secondary precipitates in the T6 condition. The ubiquitous phase was the rod-shaped $(\mathrm{AlSi})_{3}(\mathrm{Ti}, \mathrm{V}, \mathrm{Zr})$. The metallographic analysis of the T6 heat treated samples of alloy MA4 continued with the optical microscopy (Fig. 4.10a) and the SEM/EDS analysis (Table 4.4). It was confirmed that the Cu-containing phases (\#3-\#5) were completely dissolved, while the phases \#6, \#8 and \#9 including eutectic silicon were partially dissolved during solution treatment. However, the phases \#7 and \#10 were retained in unchanged condition after the T6 temper which indicates that these phases were stable at elevated temperature. The former phases (\#7-\#10) formed as a result of additions of transition metals into the alloy during melting. Similar phases were described in previous studies [63]. 


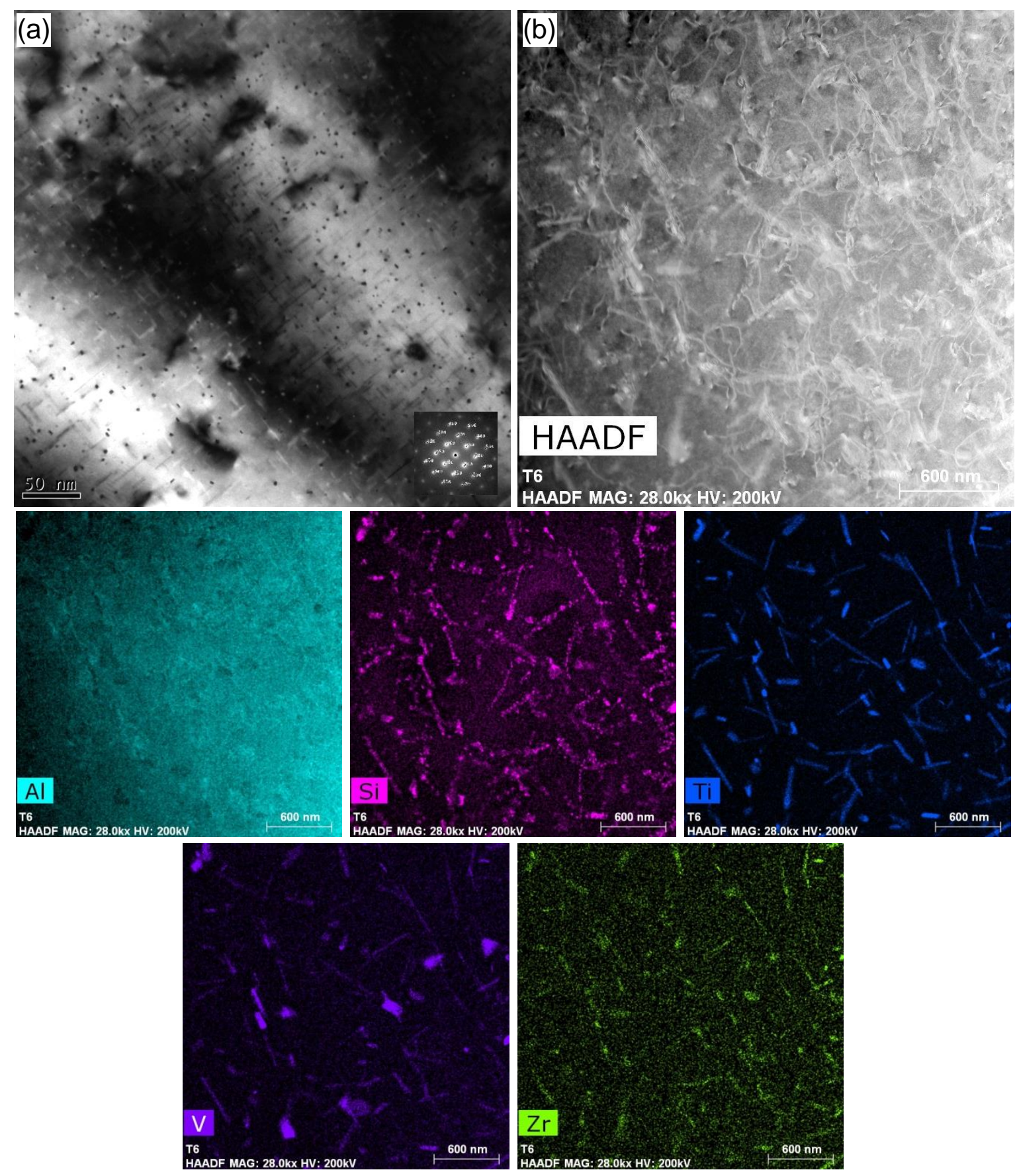

Fig. 4.9. TEM observations of the secondary precipitates in T6 condition (modified alloy MA4) (a) Bright field TEM image and selected area diffraction pattern (SAD) taken from [0 0 1] zone axis (inset) and (b) HAADF image of the precipitate structure in T6 heat treated condition (ST

@ $510^{\circ} \mathrm{C}$ for $0.5 \mathrm{~h}+525^{\circ} \mathrm{C}$ for $4.5 \mathrm{~h}$ ) showing along with EDX elemental maps of nano-rod precipitates $(\mathrm{AlSi})_{3}(\mathrm{Ti}, \mathrm{V}, \mathrm{Zr})$. (TEM analysis was performed in CANMETMaterials, Hamilton, Canada) 
Table 4.4 The major phases identified in the as-cast alloy MA4 and their response during T6 heat treatment process.

\begin{tabular}{llll}
\hline No. & $\begin{array}{l}\text { Calculated phase } \\
\text { from SEM/EDX } \\
\text { point analysis }\end{array}$ & Suggested phase in the literature & Response during T6 temper \\
\hline$\# 1$ & $\alpha$-aluminum & $\alpha$-aluminum & No change \\
\hline$\# 2$ & Eutectic silicon & Eutectic silicon & Partially dissolved \\
\hline$\# 3$ & $\mathrm{Al}_{2.1} \mathrm{Cu}$ & $\mathrm{Al}_{2} \mathrm{Cu}$ & Dissolved \\
\hline$\# 4$ & $\mathrm{Al}_{8.5} \mathrm{Si}_{2.4} \mathrm{Cu}$ & $\mathrm{Al}_{-}-\mathrm{Al}_{2} \mathrm{Cu}-\mathrm{Si}$ & Dissolved \\
\hline$\# 5$ & $\mathrm{Al}_{7.2} \mathrm{Si}_{8.3} \mathrm{Cu}_{2} \mathrm{Mg}_{6.9}$ & $\mathrm{Al}_{5} \mathrm{Cu}_{2} \mathrm{Mg}_{8} \mathrm{Si}_{6}$ & Dissolved \\
\hline$\# 6$ & $\mathrm{Al}_{14} \mathrm{Si}_{7.1} \mathrm{FeMg}_{3.3}$ & $\mathrm{Al}_{8} \mathrm{FeMg} \mathrm{Mg}_{3} \mathrm{Si}_{6}$ & Partially dissolved \\
\hline$\# 7$ & $\mathrm{Al}_{21.4} \mathrm{Si}_{4.1} \mathrm{Ti}_{3.5} \mathrm{VZr}_{3.9}$ & $(\mathrm{AlSi})_{3}(\mathrm{TiVZr})$ & No change \\
\hline$\# 8$ & $\mathrm{Al}_{6.7} \mathrm{Si}_{1.2} \mathrm{TiZr}_{1.8}$ & $(\mathrm{AlSi})_{3}(\mathrm{TiZr})$ & Partially dissolved \\
\hline$\# 9$ & $\mathrm{Al}_{2.8} \mathrm{Si}_{3.8} \mathrm{~V}_{1.6} \mathrm{Zr}_{2}$ & $(\mathrm{AlSi})_{2}(\mathrm{VZr})$ & Partially dissolved \\
\hline$\# 10$ & $\mathrm{Al}_{5.1} \mathrm{Si}_{35.4} \mathrm{Ti}_{1.6} \mathrm{Zr}_{5.7} \mathrm{Fe}$ & $(\mathrm{AlSi})_{2}(\mathrm{TiZr}) \mathrm{Fe}$ & No change \\
\hline
\end{tabular}

The microstructure of the T6 heat treated sample confirms the dissolution of $\mathrm{Cu}$-containing phases. It is also revealed that the Fe-rich phase partially dissolved and changed its morphology. Kasprzak et al. [102] reported that the Fe-rich phase present in the as-cast $\mathrm{Al}-\mathrm{Si}-\mathrm{Cu}-\mathrm{Mg}$ alloy transforms two distinct Fe-rich phases containing $\mathrm{Cu}$ or $\mathrm{Mg}$ i.e., $\mathrm{Al}_{9} \mathrm{Mg}_{12} \mathrm{Si}_{6} \mathrm{Fe}$ and $\mathrm{AlSiCuFe}$ phases, after $\mathrm{T} 6$ heat treatment. It also is clear that Ti-V-Zr-containing plate-shape $\mathrm{Al}_{21.4} \mathrm{Si}_{4.1} \mathrm{Ti}_{3.5} \mathrm{VZr}_{3.9}$ intermetallic phase and hexagonal type $\mathrm{Al}_{5.1} \mathrm{Si}_{35.4} \mathrm{Ti}_{1.6} \mathrm{Zr}_{5.7} \mathrm{Fe}$ are retained in the microstructure after heat treatment because of their stable $\mathrm{D}_{23}$ crystal structure. As discussed earlier, two frequent morphologies, plate- and bulk-shape of the Ti-V-Zr-rich phases are present in the as-cast microstructure. However, both $\mathrm{Al}_{6.7} \mathrm{Si}_{1.2} \mathrm{TiZr}_{1.8}$ and $\mathrm{Al}_{2.8} \mathrm{Si}_{3.8} \mathrm{~V}_{1.6} \mathrm{Zr}$ phases were partially dissolved; in particular, the bulk-shaped intermetallics dissolved during heat treatment while the plate/needle shapes were retained in the $\mathrm{T} 6$ temper microstructure. Studies $[63,102]$ also reported that the volume fraction of Ti-V-Zr phases in the heat-treated Al$\mathrm{Si}-\mathrm{Cu}-\mathrm{Mg}$ alloy decreased by approximately $50 \%$ accompanied by their size reduction as compared to the as-cast alloy. Partial dissolution of these intermetallics indicates that some concentrations of $\mathrm{Zr}$, Ti and $\mathrm{V}$ were available for secondary precipitation processes. 

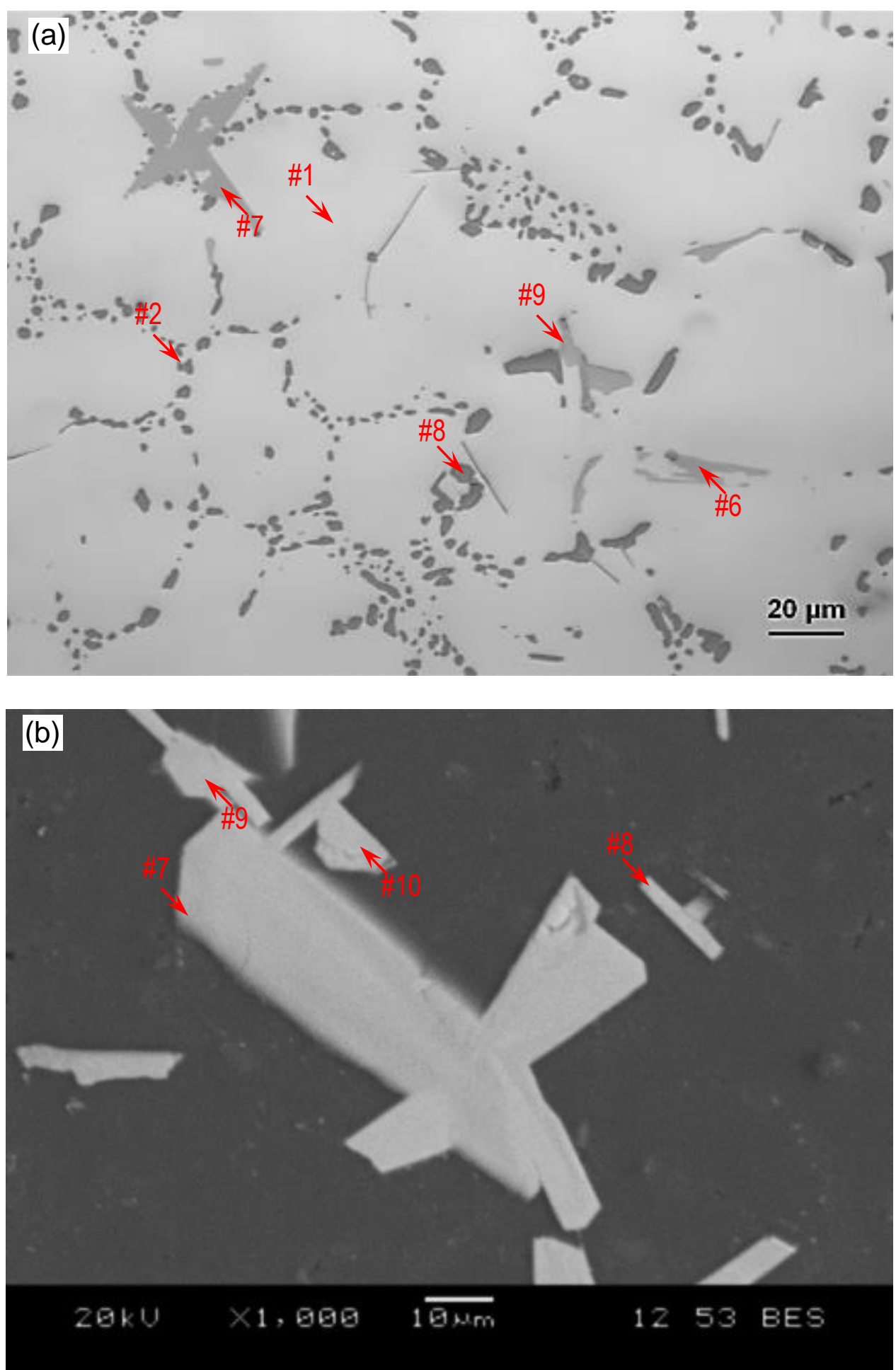

Fig. 4.10. Typical LOM and SEM microstructure in backscattered imaging mode of T6 heat treated Al-Si-Cu-Mg alloy with higher addition of $\mathrm{Ti}, \mathrm{V}$ and $\mathrm{Zr}$ (MA4), Note that numbered arrows correspond to phases outlined in Table 4.2. 
It was also suggested that the formation of these precipitates could decrease the amount of solute concentration in the solid solution and its subsequent quantity in the metal matrix would depend on solutionizing parameters. Further, the presence of trialuminide phases could negatively affect the alloy's ductility since they only partially dissolve during solution treatment $[63,102]$.

\subsubsection{Effect of cooling rate on the microstructure of alloy}

Fig. 4.11 shows the microstructure of the studied alloy in the as-cast and T6 heat treated conditions indicating the location within the wedge. In general, increasing the solidification rate decreased the SDAS value, which was also true after T6 heat treatment. Rapid solidification in a water-cooled mold resulted in significant microstructure refinements, having a SDAS between 34 and $12 \mu \mathrm{m}$. Such variation of the microstructure allowed determination of the effect of solidification rate expressed through SDAS on the solution treatment parameters during heat treatment.

The quantitative image analysis of the studied alloy showed that the dimensional change of the eutectic Si was more pronounced after T6 heat treatment than directly after casting. As seen in Table 4.5, the eutectic silicon had a particle size from $2.01 \pm 1.17$ to $2.36 \pm 1.00 \mu \mathrm{m}$ for the SDAS of 12 to $34 \mu \mathrm{m}$ in the as-cast condition. At the same time, the intermetallics' particle sizes are in the range of 11.99 to $153.24 \mu \mathrm{m}$ with an average size of $37.15 \mu \mathrm{m}$ for SDAS of 12 $\mu \mathrm{m}$. The size of the intermetallics was between 12.35 and $149.93 \mu \mathrm{m}$ with an average of $40.42 \mu \mathrm{m}$ was formed in the region of $34 \mu \mathrm{m}$ SDAS. In contrast, the T6 heat treated sample achieved a larger size of eutectic particle between $2.65 \pm 1.01$ and $2.68 \pm 1.12 \mu \mathrm{m}$ for the same SDAS range. Similarly, the intermetallic particles reached 13.45 to $153.67 \mu \mathrm{m}$ with an average of $41.61 \mu \mathrm{m}$ for SDAS of $12 \mu \mathrm{m}$ and 15.03 to $153.18 \mu \mathrm{m}$ with an average of $47.77 \mu \mathrm{m}$ for 
SDAS of $34 \mu \mathrm{m}$. In general, the eutectic silicon particle size increased with increasing SDAS in the as-cast condition and remained about the same $(\sim 2.66 \mu \mathrm{m}$ in Table 4.5$)$ in the T6 heat treated condition. The average size of intermetallics follows a similar trend as the eutectic silicon. Similar behavior of eutectic silicon in Al-Si was reported in [63]. Cooling rate has a great impact on the microstructure refinement. As proved by microstructural observations, decreasing the solidification rates from 35.8 to $10{ }^{\circ} \mathrm{C} / \mathrm{s}$ increased the SDAS spacing and the size of the eutectic $\mathrm{Si}$ precipitates. As the SDAS decreases, during rapid non-equilibrium solidification the eutectic silicon does not have enough time to grow, which reduces the size of the eutectic silicon particle. Yamagata et al. [136] revealed that structural modification of the Al-20\% Si alloy depended on the cooling rate. They showed that changing the cooling rate from 4.9 to $82.9^{\circ} \mathrm{C} / \mathrm{s}$, the microstructure of the $\mathrm{Al}-20 \% \mathrm{Si}$ alloy was refined by varying the size and distribution of the primary Si particles. The eutectic silicon was also further modified by heat treatment. Due to thermal modification, the eutectic silicon particle size increases which is related to the mechanism of Ostwald ripening theory explained in $[45,137]$. As seen in the AlSi binary phase diagram, the solubility of the silicon in aluminum increases from 0.16 to $\sim 1 \%$ with increasing the solution treatment temperature up to $525^{\circ} \mathrm{C}$. Thus, during solution treatment, the small eutectic particles dissolved in the Al-matrix resulting in an increase of the average particle size. Further, at lower SDAS values the dissolution phenomenon was faster with a higher growth rate of eutectic silicon during solution treatment. This is due to of more nonequilibrium solidification with a cooling rate of $35.8^{\circ} \mathrm{C} / \mathrm{s}$ occurring for lower SDAS values. 

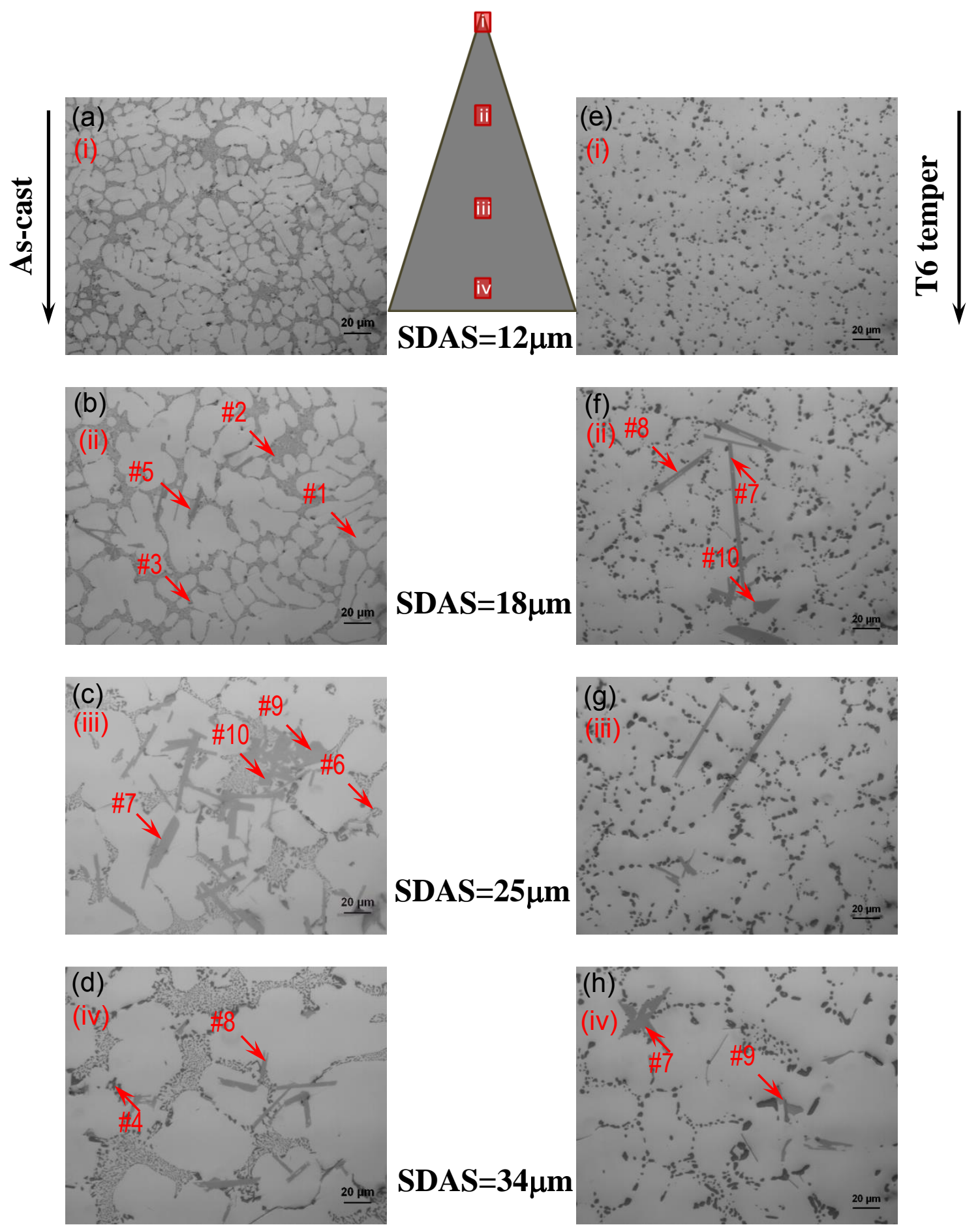

Fig. 4.11 LOM microstructure of (a-d) as-cast and (e-h) T6 heat treated Al-Si-Cu-Mg alloy modified with $\mathrm{Ti}, \mathrm{V}$ and $\mathrm{Zr}$ (MA4), with conjunction of casting wedge indicating the position of corresponding microstructure. Note that numbered (1-10) arrows correspond to phases as outlined in Table 4.4 and the numbers (i-iv) correspond to the location in the wedge. 
Table 4.5 Quantitative image analysis of the eutectic silicon and intermetallics present in the alloy MA4 at different SDAS.

\begin{tabular}{cccc}
\hline \multirow{2}{*}{ Alloy conditions } & $\begin{array}{c}\text { SDAS, } \\
\mu \mathrm{m}\end{array}$ & $\begin{array}{c}\text { Al-Si eutectic, } \\
\mu \mathrm{m}\end{array}$ & $\begin{array}{c}\text { Intermetallics eutectic, } \\
\mu \mathrm{m}\end{array}$ \\
\hline \multirow{3}{*}{$\mathrm{AC}$} & 12 & 2.01 & 37.15 \\
\cline { 2 - 4 } & 25 & 2.28 & 40.42 \\
\cline { 2 - 4 } & 34 & 2.36 & 41.18 \\
\hline \multirow{3}{*}{ T6 } & 12 & 2.65 & 41.61 \\
& 25 & 2.66 & 42.13 \\
\cline { 2 - 4 } & 34 & 2.67 & 47.77 \\
\hline
\end{tabular}

\subsection{X-ray Diffraction Analysis of Alloy MA4}

Typical XRD patterns of alloy MA4 obtained at room temperature are shown in Fig. 4.12. The XRD analysis revealed the presence of $\mathrm{Al}, \mathrm{Si}$ and $\mathrm{Al}-\mathrm{Si}$ eutectic $\left(\mathrm{Al}_{3.21} \mathrm{Si}_{0.47}\right)$, but no peaks of other phases were directly seen due to the low fraction of TMCP intermetallics. An overlap of diffraction peaks with peaks of the base aluminum matrix complicated the identification. Therefore, a bulk extraction technique was employed to dissolve the aluminum matrix and collect the undissolved deposit for X-ray analysis. As seen in Fig. 4.12a, the diffraction pattern of the extracted intermetallics is superimposed on results from the bulk alloy. Thus, after eliminating the Al matrix, some of the peaks likely associated with TMCP phases along with weak peaks of $\mathrm{Cu}$ - and $\mathrm{Mg}$-containing $\mathrm{Al}_{2} \mathrm{Cu}$ and $\mathrm{Q} / \pi$ phases were still present. A similar observation was reported in [23] for the A319 alloy modified with an addition of Zr.

To determine phase transformations, an in-situ XRD analysis of the bulk material was performed. To identify changes of TMCP during heating, in-situ measurements were conducted for $2 \theta$ ranges from 37.5 to $45.5^{\circ}$. The obtained results plotted as X-ray intensity versus $2 \theta$ angles, are given in Fig. 4.12b and Fig. 4.12c. Since the sample was covered by the graphite heating chamber the X-ray intensity was lower than for the uncovered sample, as seen in Fig. 4.12a. In general, the results show that increasing testing temperature from 200 to $400^{\circ} \mathrm{C}$ caused 
an increase in $\mathrm{Al}$ peak intensity. Beyond that temperature the intensity decreased and remained constant to $600^{\circ} \mathrm{C}$. This is an indication of dissolution of the Si eutectic into the Al-matrix which occupies vacancies in the unit cell and reduces the crystal imperfection resulting in higher peak intensity. It is clear that the $\mathrm{Al}_{2} \mathrm{Cu}$ and $\mathrm{Q}$ phases (as marked by circle and arrows in Fig. $4.12 \mathrm{~b}, \mathrm{c})$ were dissolving with increasing testing temperature from 300 to $500^{\circ} \mathrm{C}$ and completely disappeared above $500^{\circ} \mathrm{C}$ which will be correlated in TA. At the same time, peaks related to TMCP remained unchanged until $600^{\circ} \mathrm{C}$, indicating their higher thermal stability. A shift in diffraction peak positions to lower $2 \theta$ values was observed with increasing testing temperature and is related to alloy thermal expansion. A similar phenomenon was reported in [138] for insitu XRD examination of Ag alloy.

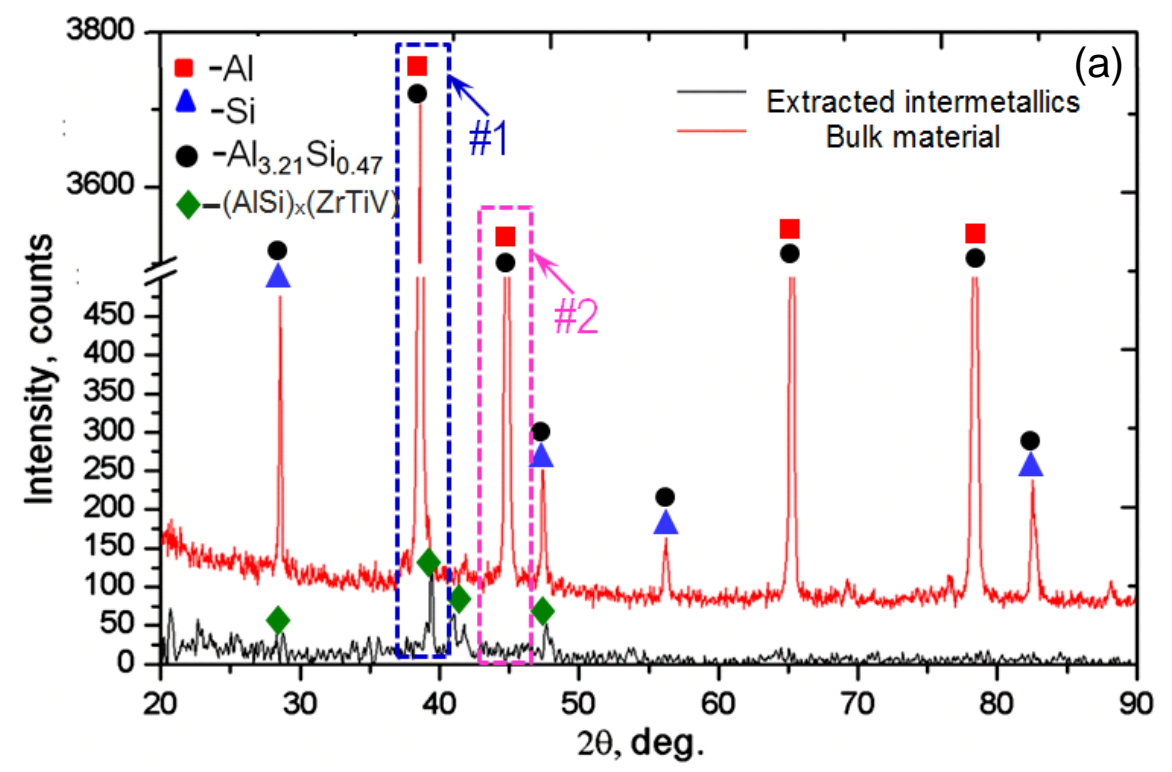

Fig. 4.12. XRD patterns showing the major phases present in the as-cast $\mathrm{Al}-\mathrm{Si}-\mathrm{Cu}-\mathrm{Mg}$ alloy modified with $\mathrm{Ti}, \mathrm{V}$ and $\mathrm{Zr}$; (a) the diffraction patterns obtained from bulk materials and extracted intermetallics (continue to next page). 


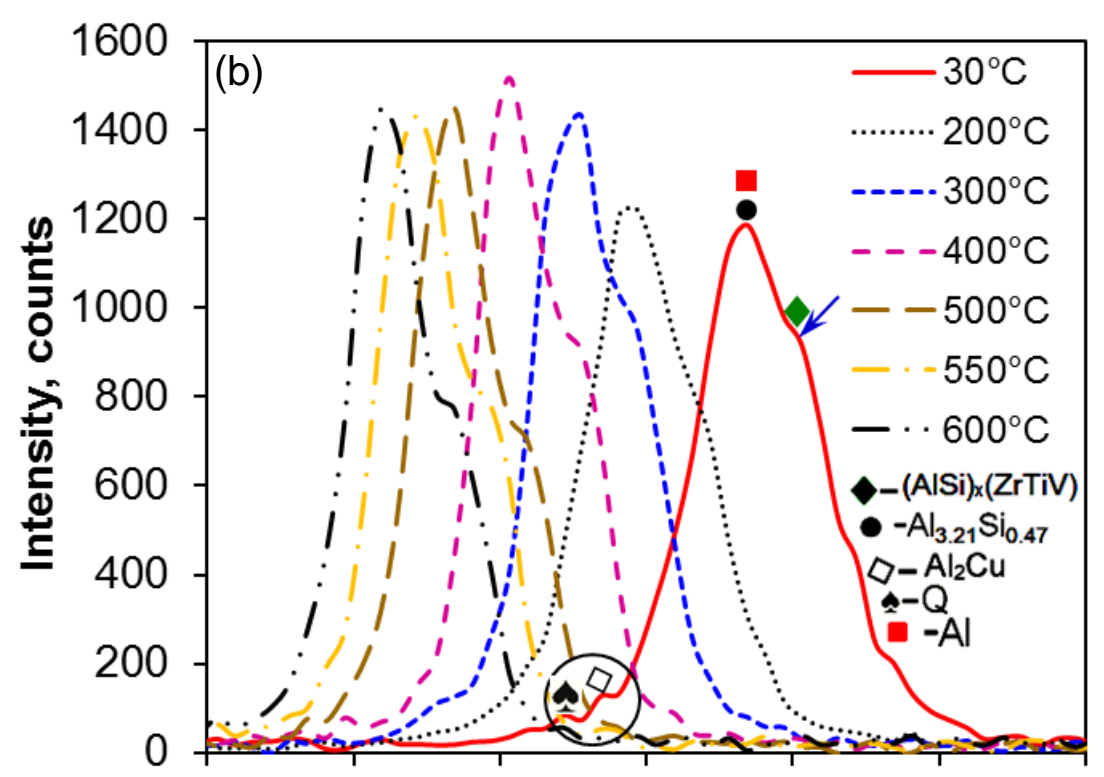

$\begin{array}{lllllll}37.75 & 37.95 & 38.15 & 38.35 & 38.55 & 38.75 & 38.95\end{array}$

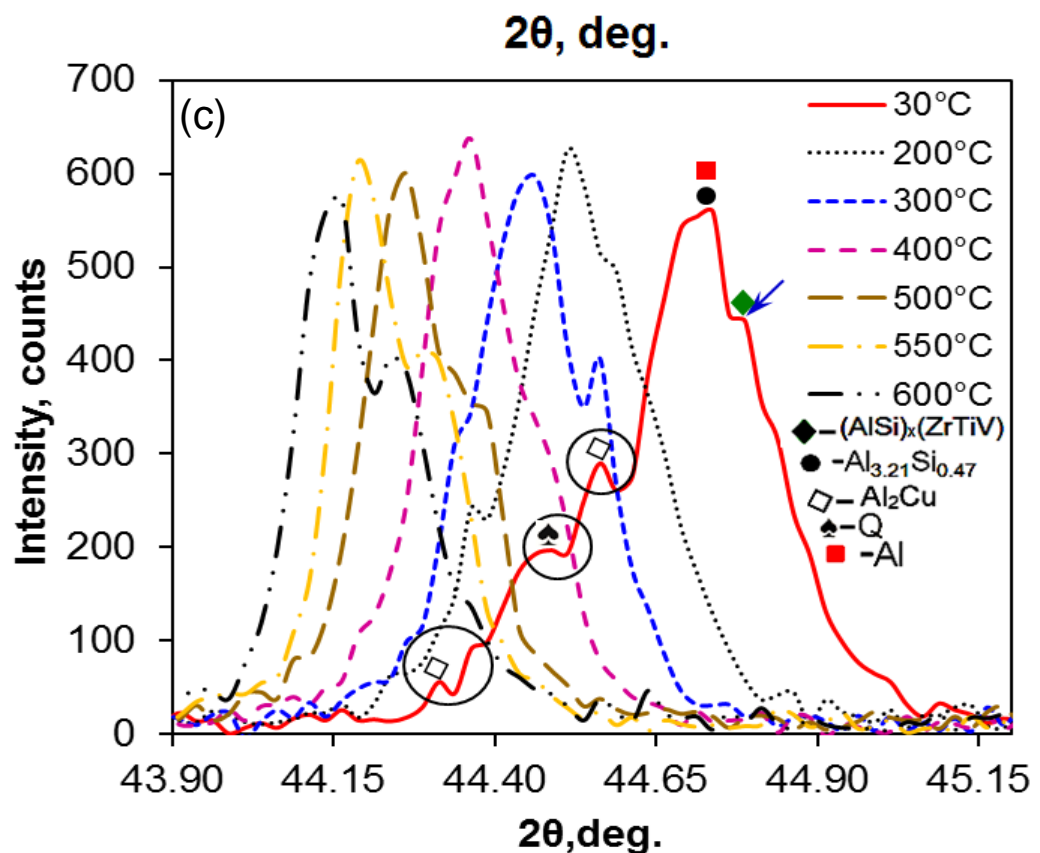

Fig. 4.12. XRD patterns showing the major phases present in the as-cast $\mathrm{Al}-\mathrm{Si}-\mathrm{Cu}-\mathrm{Mg}$ alloy modified with Ti, V and Zr; (a) the diffraction patterns obtained from bulk materials and extracted intermetallics, and selected peaks at different temperatures in the range of 30 to $600^{\circ} \mathrm{C}$ (b) \#1 as marked in (a) and (c) \#2 as marked in (a) obtained from heating cycle.

\subsection{Chapter Summary}

The Al-Si-Cu-Mg cast alloy was modified with additions of $\mathrm{Ti}-\mathrm{V}-\mathrm{Zr}$ to improve the thermal stability of intermetallics at increased temperatures. A combination of electron microscopy 
(SEM and TEM), electron backscatter diffraction and high temperature X-ray diffraction was explored to identify phases and temperatures of their thermal stability. The micro-additions of transition metals led to formation of several $(\mathrm{AlSi})_{\mathrm{x}}(\mathrm{TiVZr})$ phases with $\mathrm{D}_{22} / \mathrm{D}_{23}$ tetragonal crystal structure and different lattice parameters. While $\mathrm{Cu}$ - and $\mathrm{Mg}$-rich phases along with the eutectic Si dissolved at temperatures from 300 to $500^{\circ} \mathrm{C}$, the $(\mathrm{AlSi})_{\mathrm{x}}(\mathrm{TiVZr})$ phases were stable up to $696-705^{\circ} \mathrm{C}$ which is beneficial to enhance the high temperature properties. Findings of this study are useful for selecting temperatures during melting and heat treatment of Al-Si alloys with additions of transition metals. (Most of the data of this chapter 4 was published in the listed paper of Section 9.3) 


\section{CHAPTER 5}

\section{HEAT TREATMENT DEVELOPMENT FOR THE CAST MODIFIED Al-Si-Cu-Mg ALLOYS ${ }^{2}$}

\subsection{Introduction}

Heat treatment is an important part of the casting manufacturing process, thus, cost has to be kept low to gain economic advantages. To date, the existing heat treatment standards do not precisely define tempers for thin-walled castings that solidified with high solidification rates. The R\&D efforts were undertaken to reduce heat treatment process duration but have not led to formalized implementation of revised heat treatment standards [139, 140, 141, 142]. In the interest of improving energy efficiency, several researchers have attempted to study short and/or multiple heat treatment cycles. Zhang et al. [107] reduced the solution treatment time for strontium-modified Al-7wt.\%Si-0.3\% Mg cast alloy from 6 hours to 30 minutes, while maintaining $90 \%$ of the yield strength and $95 \%$ of the ultimate tensile strength. He et al. [106] modified the conventional T6 process and utilized part of the solidification process to create what they called the T6' and the T6' tempers. These processes attempt to quench the metal during solidification or begin solutionizing without complete solidification. Kasprzak et al. [112] illustrated the possibility of reducing the duration of the T6 heat treatment of a hypereutectic Al-20\%Si alloy by $68 \%$ without compromising hardness or tensile properties. This was achieved by increasing the solution treatment temperature and reducing the time of both the solution time and ageing time. Hanim et al. [143] studied the effect of two-step solution heat treatment on the microstructure and mechanical properties of $332 \mathrm{Al}-\mathrm{Si}$ cast alloys and proposed that the two-step heat treatment showed better mechanical properties than the

\footnotetext{
${ }^{2}$ W. Kasprzak, D.L. Chen, and S.K. Shaha, J. Mater. Eng. Perform., Vol. 22(7), pp 1839-1847, 2013.
} 
traditional single step heat treatment process. New processing technologies are being developed in order to produce a more uniform and efficient heat treatment through the use of fluidized beds and basketless heat treatment systems. This is accomplished by transforming the traditional batch process into a continuous process with more stringent control over heat profiles and temperature control $[47,66]$.

In this chapter the effect of various heat treatment processes on the mechanical properties will be discussed and an optimum condition will be chosen for post casting treatment of the AlSi-Cu-Mg alloy modified with addition of $\mathrm{Ti}, \mathrm{V}$ and $\mathrm{Zr}$

\subsection{Alloy Characteristics in the As-Cast Condition}

To establish maximum allowable solution treatment temperature as well as to evaluate the effectiveness of solution treatment duration, thermal analysis during the melting cycle was carried out on the as-cast alloy. It was revealed that the incipient melting temperature, corresponding to the melting of the $\mathrm{Al}_{2} \mathrm{Cu}$ and $\mathrm{Al}_{5} \mathrm{Mg}_{8} \mathrm{Si}_{6} \mathrm{Cu}_{2}$ phases, began at approximately $507^{\circ} \mathrm{C}$ (\#1a) and was completed at $552{ }^{\circ} \mathrm{C}(\# 2)$ (Fig. 5.1 curve as-cast). For this reason, the solution treatment temperature was selected as $485{ }^{\circ} \mathrm{C}$ and $510{ }^{\circ} \mathrm{C}$ (1-step), i.e., below and near solidus temperature and $510+525{ }^{\circ} \mathrm{C}$ (2-steps) to achieve accelerated solutionizing conditions without detrimental incipient melting [6].

Rapid solidification in a water-cooled mold resulted in significant microstructure refinements, having a SDAS between 35-10 $\mu \mathrm{m}$ and consequent thermal modification of structural constituents. Such microstructure variation was suitable for heat treatment optimization experiments required to determine the effect of solidification rate (expressed as SDAS) on the solution treatment parameters. Hardness measurements in the as-cast condition 
showed a linear relation with solidification rate, indicating a hardness increase from 25 to 36 HRB with reducing SDAS size 35-10 $\mu \mathrm{m}$ (Fig. 5.2a). The increase in the as-cast hardness indicated that the analyzed solidification rates were high enough to cause some degree of solid solution saturation (strengthening effect).

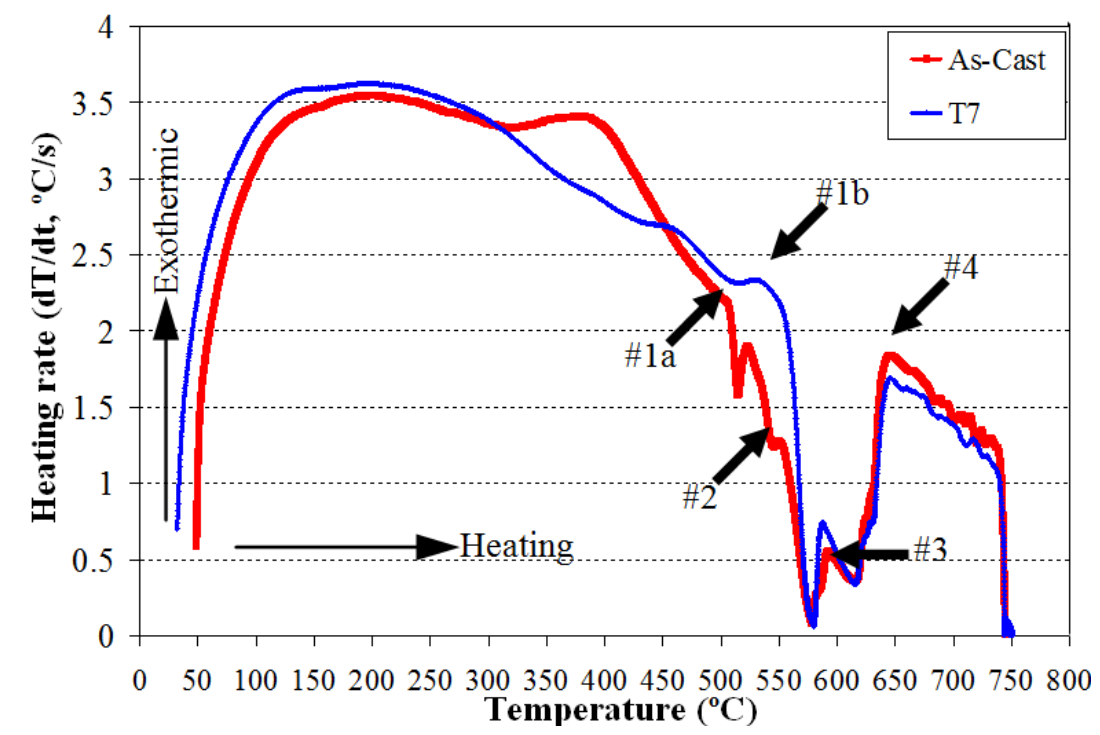

Fig. 5.1. Thermal analysis melting curves for the alloy in the following conditions: a) as-cast and b) T7 (H2) heat treated. Note that alloy in the T7 condition had incipient melting temperature $43^{\circ} \mathrm{C}$ higher $\left(550^{\circ} \mathrm{C}\right)$ than in the as-cast condition $\left(507^{\circ} \mathrm{C}\right)$. Note that the transformation temperatures are indicated by arrows; \#1a, 1b: beginning of alloy melting; \#2: end of melting of $\mathrm{Cu}, \mathrm{Mg}$ based intermetallics; \#3: melting of Al-Si eutectic; \#4: end of alloy melting.

\subsection{Alloy Characteristics in the Heat Treated Condition}

Metallurgical analysis of the test samples subjected to T6 (H2) temper showed approximately 40 points hardness increase from 30 to $69 \mathrm{HRB}$ (Fig. 5.2a) compared with the as-cast condition, which remained constant for the analyzed SDAS range. For the T7 (H3) condition hardness dropped to $25 \mathrm{HRB}$ (Fig.5.2a) which is below that of the as-cast value (i.e., 30) and was constant for the analyzed SDAS range. Hardness changes also reflected the peak-aged, T6 (H2) and over-aged, T7 (H3) heat treatment conditions, for all analyzed SDAS ranges and solution time durations. It was also found that increasing solution treatment temperature from 485 and 
$510^{\circ} \mathrm{C}$ (1-step) to $510+525^{\circ} \mathrm{C}$ (2-steps) resulted in maximum hardness gain from 66 to $71 \mathrm{HRB}$ respectively for SDAS of $18.5 \mu \mathrm{m}$ (compare Fig. 5.2b). The solutionizing treatment time between 0.5 to 4 hours had a statistically significant impact on hardness increase while solution time between 4 to 9 hours had negligible gain. In general, excessive solution treatment duration is not practical from an economical point of view as far as alloy hardness is concerned.
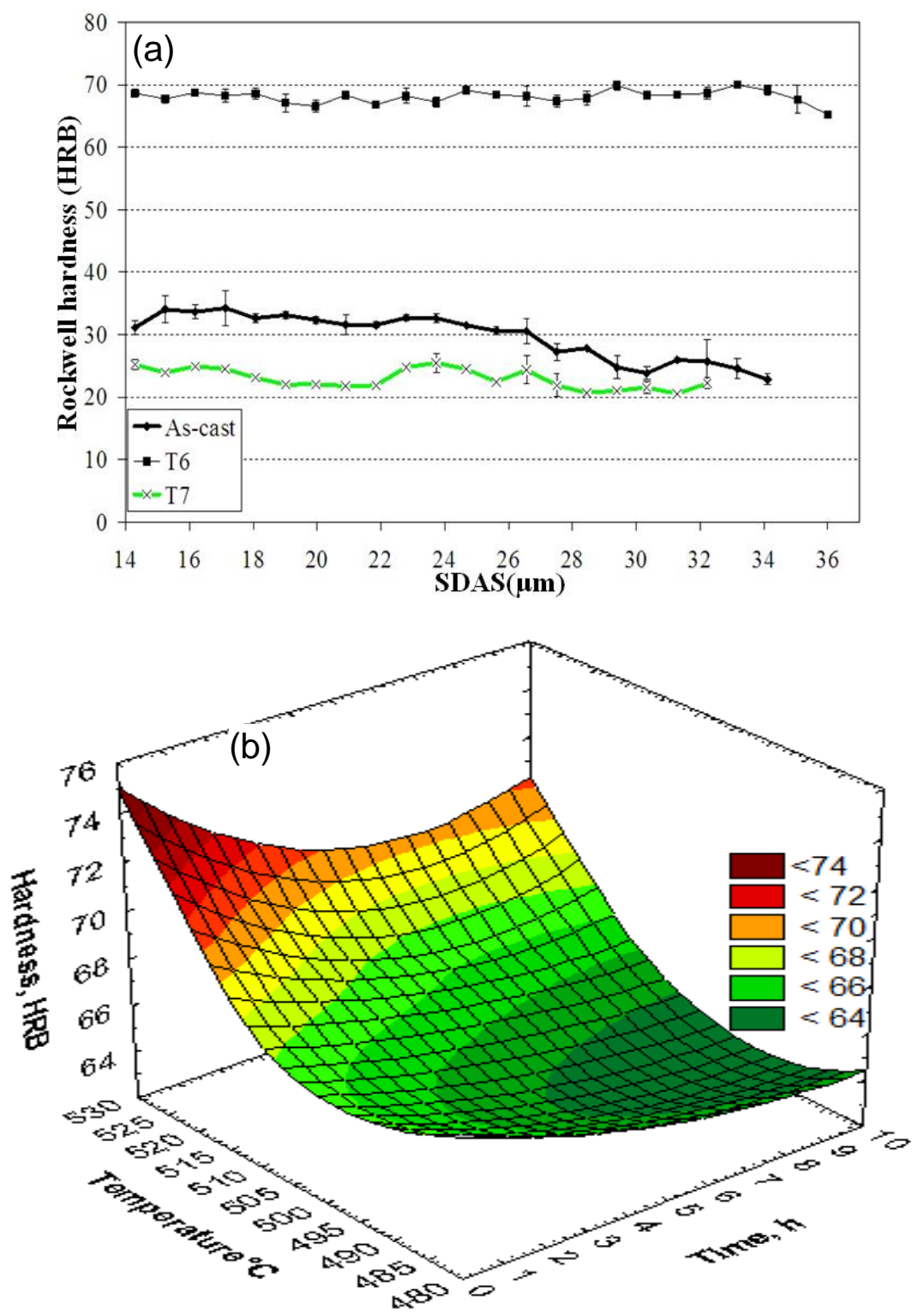

Fig. 5.2. The correlation between hardness, SDAS, solution treatment time and temperature for the alloy MA3 in (a) The as-cast, T6 (H2) and T7 (H3) conditions and (b) T6 at different solution treatment time and temperatures. 
For the test samples in the T6 condition it was found that an ultimate tensile strength (UTS) of $330 \mathrm{MPa}$ and a yield strength (YS) of $300 \mathrm{MPa}$ was achieved for solution treatment time of 9 hours at $510^{\circ} \mathrm{C}$ in 1-step and SDAS of $18 \mu \mathrm{m}$, while UTS (351 MPa), YS (309 MPa) with corresponding elongation of $1.3 \%$ was achieved for 2-steps solution treatment for identical SDAS values (Fig. 5.3). It was observed that reducing the SDAS from 32.5 to $18 \mu \mathrm{m}$ (increasing solidification rate) resulted in an approximate increase of up to $24 \%$ in T6 (H2) tensile strength i.e., from 250-310 to 260-315 MPa for a solution treatment time of 30 minutes and 9 hours respectively, during 1-step solution treatment (Fig. 5.3). Increasing the solution treatment time from 30 minutes to 9 hours resulted in up to $4 \%$ increase in T6 (H2) UTS i.e., from 250-260 to 310-315 MPa for SDAS of 32.5 and $18 \mu \mathrm{m}$ respectively (Fig. 5.3a). For the 2-step T6 (H4) heat treatment process, increasing the solution treatment time from 30 minutes to 9 hours, resulted only in $1.7 \%$ (345 to $351 \mathrm{MPa}$ ) UTS and 2\% (303 to $309 \mathrm{MPa}$ ) YS increase for a microstructure having SDAS of $18 \mu \mathrm{m}$. Reducing the SDAS from 32.5 to $18 \mu \mathrm{m}$ the UTS and YS increased from 276-345 to 305-351 MPa (i.e. 25 to $15 \%$ ) and 272-303 to 284-309 MPa (i.e. 11 to $9 \%$ ) for 2-step solution treatment time of 30 minutes and 9 hours respectively (Fig. 5.3). It was evident that the solidification rate (expressed as a change in SDAS) had a more pronounced effect on the strength development than the increase of solution treatment time. It was observed that increasing the solution treatment time beyond 4 hours at $510{ }^{\circ} \mathrm{C}$ for the 1 -step solution treatment and $30 \mathrm{~min}$ for the 2 -step solution treatment at 510 and $525{ }^{\circ} \mathrm{C}$ are not economically justified, since they did not produce a significant increase in hardness or strength. Similar observations were made in previous optimization studies carried out for hypereutectic Al-Si alloys having SDAS of $\sim 20 \mu \mathrm{m}[3,142]$. The 3D maps showing alloy mechanical property development as a function of SDAS and solution time are presented on Fig. 5.4 for the 1-step solution treatment in 
the T6 $(\mathrm{H} 2)$ condition. It is also noticed that an ultimate tensile strength (UTS) of $253 \mathrm{MPa}$, yield strength (YS) of $247 \mathrm{MPa}$ and elongation of $0.26 \%$ was achieved for the single step solution treatment temperature of $485^{\circ} \mathrm{C}$ and time of $0.5 \mathrm{~h}$. However, in the two step solution treatment, a UTS of $330 \mathrm{MPa}$ (Fig. 5.4a), YS of $291 \mathrm{MPa}$ (Fig. 5.4b) and elongation of 0.76\% (Fig. 5.4c) was achieved for a solution treatment time of $0.5 \mathrm{~h}$ while increasing the time from 0.5 to $9 \mathrm{~h}$, a UTS of $335 \mathrm{MPa}$, YS of $303 \mathrm{MPa}$ and elongation of $0.76 \%$ was achieved. So, increasing the solution treatment temperature and time, the UTS increased about $30 \%$ and $1.7 \%$, respectively. Similar behavior was also observed by Kasprzak et al. [63].

A potential reason for the improvement of mechanical properties of the studied alloy is the dissolution of $\mathrm{Ti}-\mathrm{V}-\mathrm{Zr}$-containing phases and the modification of the eutectic silicon. It was reported that with increasing the solution treatment temperature, hardness and tensile strength increased. However, the hardness and tensile strength initially increased and then decreased with further increase of the time of solution treatment. Recently, Campbell reported that mechanical properties, especially elongation, are significantly ( 10 times $)$ affected by a presence of the oxide bi-film [144]. He mentioned that silicon and some intermetallics nucleate and grow on bi-film substrates. The presence of bi-films weakens grain boundaries during plastic flow which results in a reduction of elongation. Also, Wang [145] reported that tensile ductility is related to the rate of particle cracking and in turn, to the development of stress in the particle. A structure comprised of large and elongated particles exhibits a high particle cracking rate and thus has a low ductility. In contrast, the finer structure with smaller and more rounded particles results in a lower particle cracking rate and a higher ductility which is in agreement with this study. 

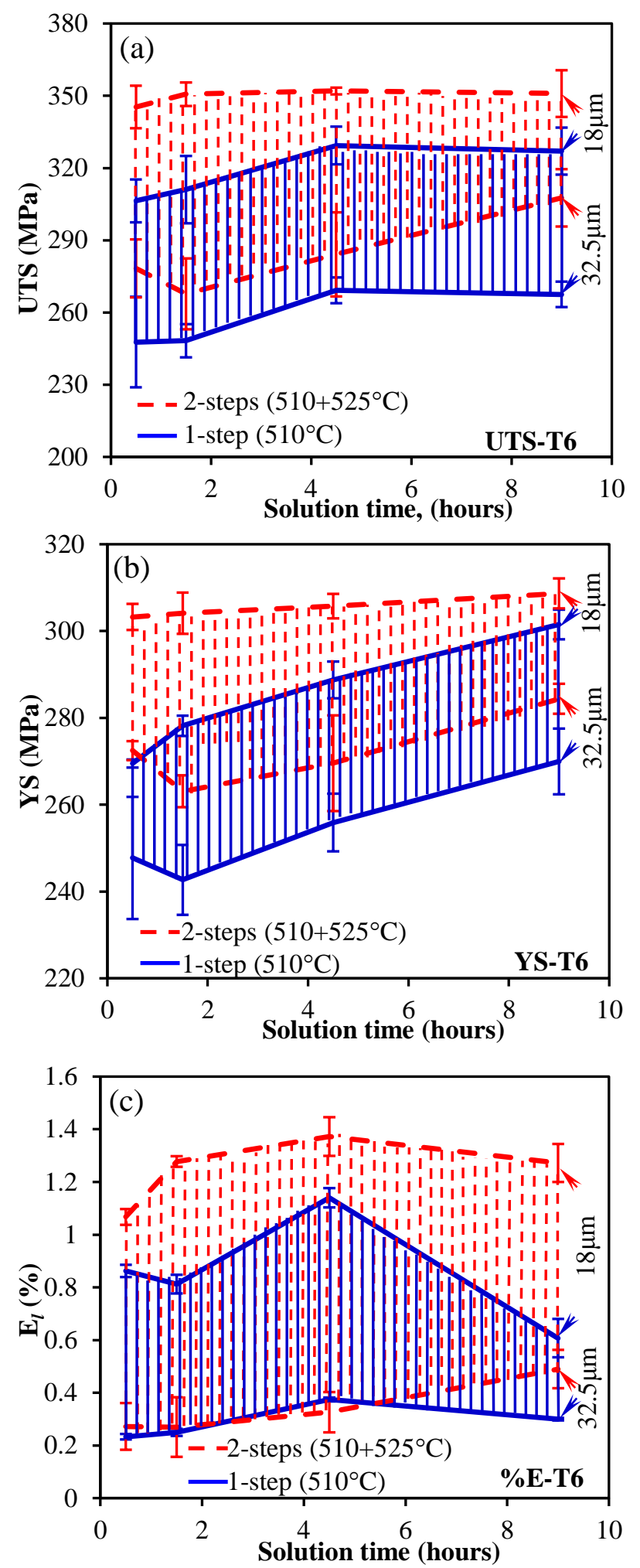

Fig. 5.3. The effect of solution treatment time and SDAS of 18 and $32.5 \mu \mathrm{m}$ on alloy strength development for 1-step (H2) and 2-steps (H4) solution treatment: (a) UTS (T6). (b) YS (T6). (c) $\mathrm{E}_{l}$ (T6). 


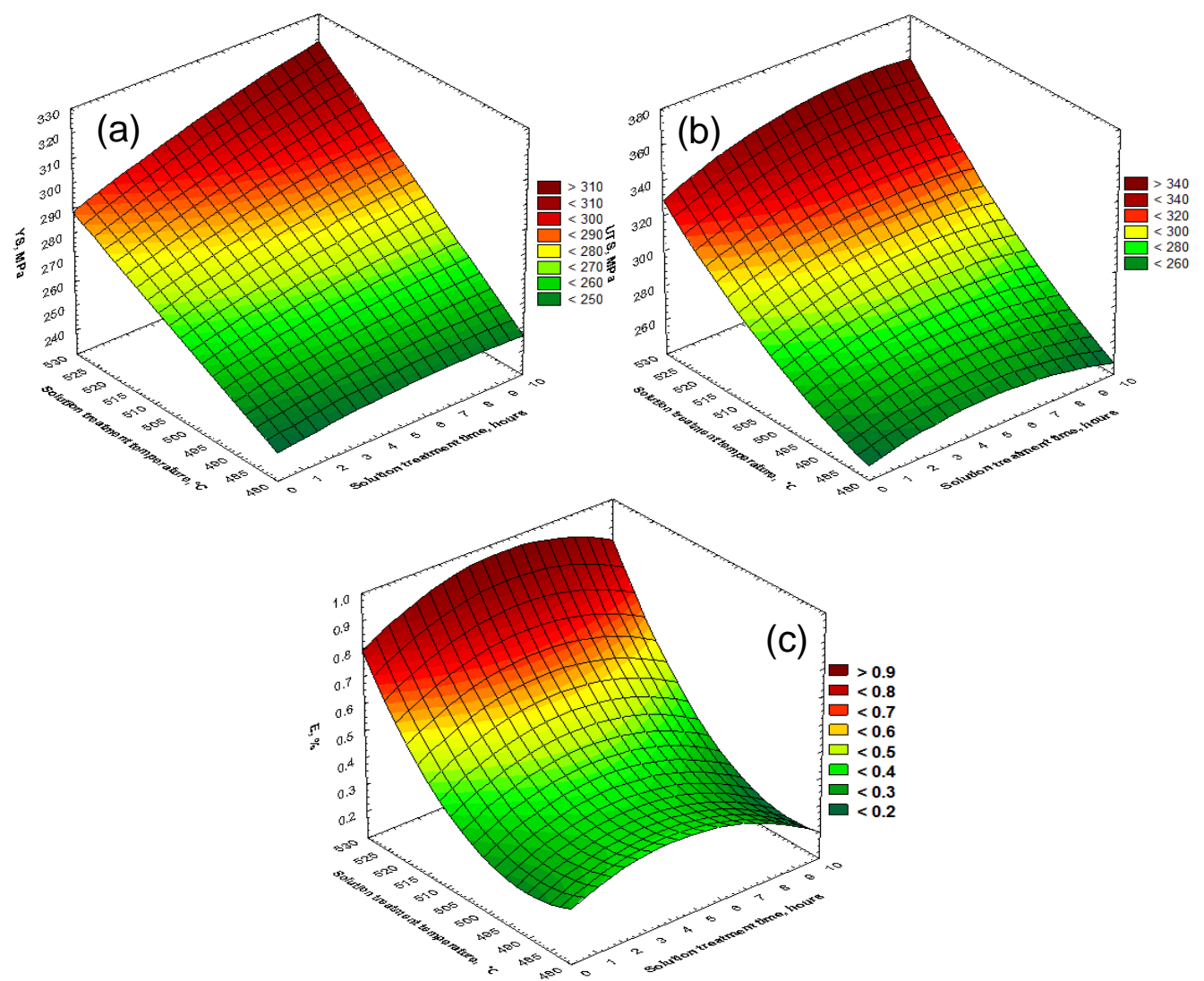

Fig. 5.4. The effect of solution treatment time and temperature on (a) yield strength (YS), (b) ultimate tensile strength (UTS) and (c) percentage of elongation (E) as function of time and temperature. Note: two steps heat treatment was considered as $525^{\circ} \mathrm{C}$. Increasing the solution treatment time and temperature, YS, UTS and E increased.

\subsection{Dimensional Stability Assessment}

Dilatometer analysis of the $\mathrm{T} 6(\mathrm{H} 2)$ and $\mathrm{T} 7(\mathrm{H} 3)$ heat treated test samples showed that artificially ageing at $250{ }^{\circ} \mathrm{C}$ for 16 hours (T7) yielding UTS of $210 \mathrm{MPa}$ resulted in the most dimensionally stable condition, since the samples did not show any solid state transformation during subsequent alloy reheating (Fig. 5.5). Alloy aged at $150{ }^{\circ} \mathrm{C}$ for 100 hours showed that $\mathrm{T} 6$ (H2) heat treated samples had the highest strength but were less dimensionally stable as manifested by strong transformations observed on the derivative curve (Fig. 5.5). It was also found that alloy aged at $250{ }^{\circ} \mathrm{C}$ for 1.5 hours was less dimensionally stable compared to ageing for 16 hours. It indicated that, by increasing the samples aged time from 1.5 to 16 hours at 250 ${ }^{\circ} \mathrm{C}$, the precipitation process was most likely completed, since no further precipitation occurred 
during subsequent reheating. From a physical metallurgical point of view the ageing transformation must be completed so that no further precipitation would occur during in-service operation. The presented approach allowed the selection of heat treatment parameters yielding dimensionally stable microstructure and corresponding optimum strength.

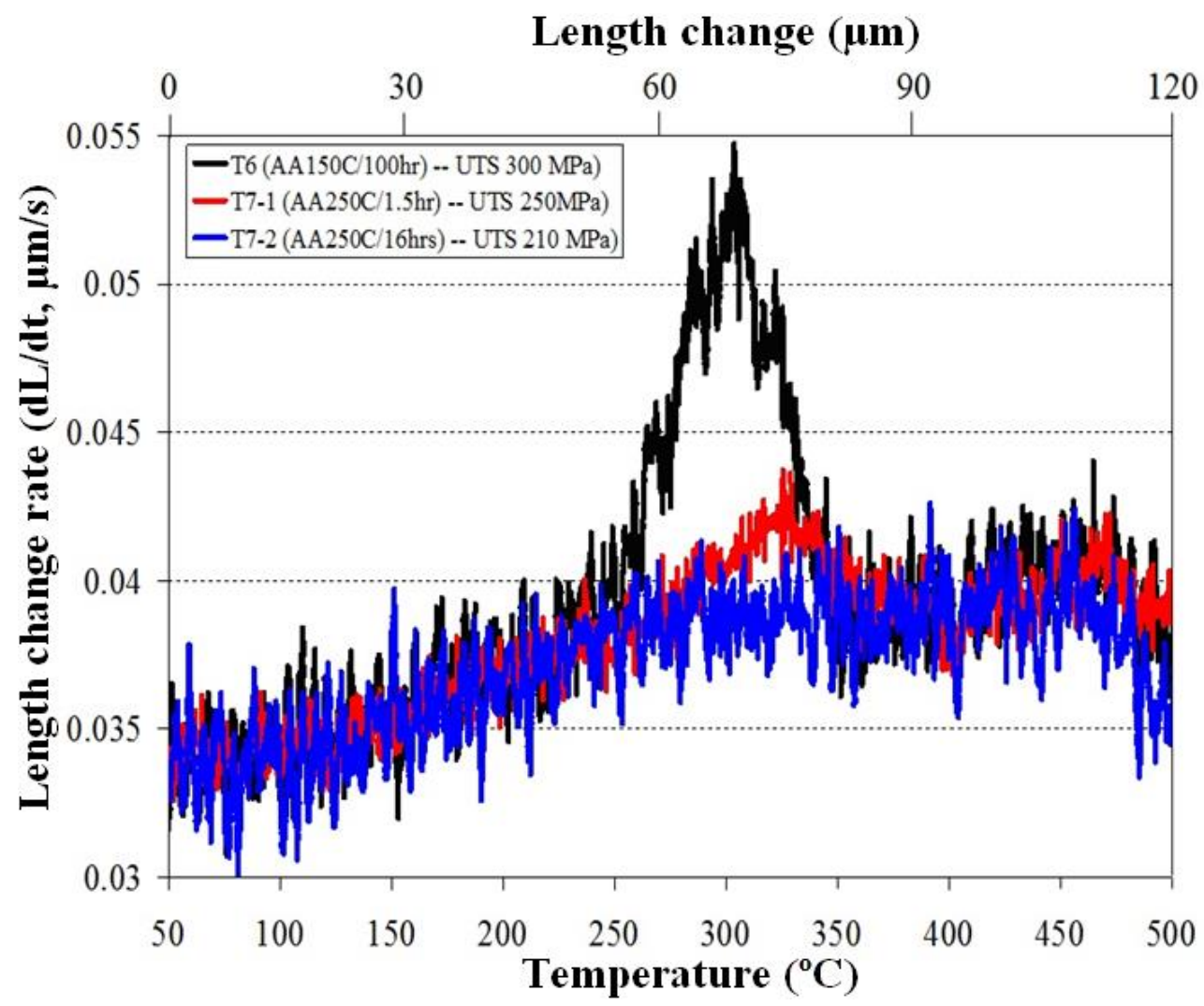

Fig. 5.5. Dimensional analysis assessment of the alloy 2-steps solution treated and aged at the following conditions: (a) T6 (AA $150{ }^{\circ} \mathrm{C} / 100 \mathrm{hrs}$ ) having UTS = $300 \mathrm{MPa}$, (b) T7-1 (AA $250{ }^{\circ} \mathrm{C} / 1.5 \mathrm{hrs}$ ) having $\mathrm{UTS}=250 \mathrm{MPa}(\mathrm{c}) \mathrm{T} 7-2\left(\mathrm{AA} 250^{\circ} \mathrm{C} / 16 \mathrm{hrs}\right)$ having UTS $=210 \mathrm{MPa}$.

Note that the ageing at $250{ }^{\circ} \mathrm{C}$ for 16 hours renders the most dimensionally stable condition without visible transformation peak.

\subsection{Comments on Heat Treatment Development}

As lower melting point of the phases is $507^{\circ} \mathrm{C}$, increasing the heat treatment temperature above $507^{\circ} \mathrm{C}$ incipient melting occurs which causes a reduction of mechanical properties. Thus, tow step solution treatment was introduced where the alloy solution treated at lower temperature for dissolution of lower melting point phases. After that the solution treated temperature increased 
for homogenization. The presented heat treatment studies demonstrated the possibility to flexibly control alloy mechanical properties as a function of solidification rate and solution treatment parameters, allowing the selection of optimum conditions. Approximately 50\% (1step $(\mathrm{H} 2)$ ) to $88 \%$ (2-steps $(\mathrm{H} 4)$ ) process time reduction for alloy with fine microstructures (i.e., SDAS $=18 \mu \mathrm{m}$ ) as compared to alloy having coarse microstructure (i.e., SDAS=35 $\mu \mathrm{m}$ ) could be achieved. Solutionizing for more than 4 hours for 1 -step solution treatment at $510{ }^{\circ} \mathrm{C}$ brings an increase of approximately $4.8 \%$ and $5.6 \%$ for UTS and YS strength, respectively. Solutionizing for more than 30 minutes for a 2-step solution treatment, the UTS and YS strength increased only approximately $2 \%$ for fine microstructures having a SDAS of $18 \mu \mathrm{m}$. Since rapid solidification resulted in modification of the Al-Si eutectic, (Aspect Ratio, AR=1.65 \pm 0.07 and SDAS $=25 \mu \mathrm{m}$ ) the subsequent thermal modification during solution treatment had an additional impact on acceleration of morphological changes of the eutectic Si. Analysis of stereological parameter of the eutectic Si showed that the AR reached a value of $1.64 \pm 0.13$ after 9 hours of solution treatment at $510{ }^{\circ} \mathrm{C}$ and increasing solutionizing time beyond 0.5 hour did not have a statistically significant effect on the AR values. As far as hardness is concerned, up to $95 \%$ process time reduction could be achieved since increasing time beyond 30 minutes of solution treatment (1 and 2-steps) does not produce a hardness increase for SDAS between 35-10 $\mu \mathrm{m}$. In general, reduction of the solution treatment process duration was achieved by i) selecting a solution treatment temperature in the vicinity of alloy solidus (i.e., $507{ }^{\circ} \mathrm{C}$ ) but avoiding incipient melting and ii) by minimizing the diffusion distances and the time of the subsequent solution treatment due to reduced interdendritic spaces for samples having small SDAS size.

Rising energy costs should provide a positive stimulus to revise the existing heat treatment standards - particularly for cast components that solidified under high solidification rates - 
paying careful attention to and taking great advantage of the thermal as-cast microstructure with its potential to leverage the metallurgical response of the component to subsequent heat treatment processing $[110,142]$.

\subsection{Chapter Summary}

The role of solutionizing conditions within the $\mathrm{T} 6$ and $\mathrm{T} 7$ heat treatment of the cast Al-Si-Cu$\mathrm{Mg}$ alloy with micro-additions of $\mathrm{Ti}-\mathrm{V}-\mathrm{Zr}$ was assessed in terms of their influence on microstructure and mechanical properties. As a solution treatment, a single step process at 485 and $510^{\circ} \mathrm{C}$ and two-step process at 510 and $525^{\circ} \mathrm{C}$ for varying time intervals from 0.5 to $9 \mathrm{~h}$, were examined. After solution treatment, artificial ageing was performed. The microstructural analysis showed that the solution treatment changed the eutectic silicon morphology from needle-like, present after casting, to a spherical shape in the T6 state and that the extent of changes was strongly influenced by temperature and time. The $\mathrm{Cu}$ - and $\mathrm{Mg}$-rich phases completely dissolved during solution treatment while the Fe-containing phase, $\mathrm{Al}_{8} \mathrm{Si}_{6} \mathrm{Mg}_{3} \mathrm{Fe}$, remained partially in the microstructure. The Ti-V- $\mathrm{Zr}$-containing phases, $\mathrm{Al}_{13} \mathrm{Si}_{2} \mathrm{Ti}_{3} \mathrm{Zr}$ and $\mathrm{Al}_{3} \mathrm{Si}_{26} \mathrm{FeTiV}_{10}$, present in as-cast state, were partially dissolved during solution treatment, reducing their size by $10-48 \%$. The studied alloy reached the maximum ultimate tensile strength of $335 \mathrm{MPa}$ and yield stress of $303 \mathrm{MPa}$ for two-step solutionizing with a total time of $4.5 \mathrm{~h}$. It is concluded that the two-step solution treatment resulted in higher tensile properties than the single-step process. (Note: Most of the data of this chapter 5 was collected from the publications listed in Section 9.3) 


\section{CHAPTER 6}

\section{WORK HARDENING AND DISLOCATION SLIP DISTANCE DURING COMPRESSION DEFORMATION OF THE CAST MODIFIED Al-Si-Cu-Mg ALLOY ${ }^{3}$}

\subsection{Introduction}

The age-hardenable alloys change their microstructure and mechanical properties due to heat treatment, typically composed of a solutionizing stage and ageing when, depending on ageing parameters and the alloy chemical composition, different types of precipitates are formed [53]. There are two main kinds of precipitates formed during ageing: (i) coherent or semi-coherent, which are shearable, and (ii) incoherent which are non-shearable for moving dislocations. The fine particles are shearable, resisting a movement of the dislocation line which cuts through precipitates. On the other hand, coarse particles are non-shearable and form Orowan loops by bowing the dislocation line. Thus, the presence of precipitates adds to the microstructure complexity and affects mechanical properties of alloys [55, 146, 147].

The work-hardening behavior of age-hardened alloys depends on the nature of precipitates; hence changing precipitates from shearable to non-shearable affects their performance during deformation [146, 147]. The influence of precipitates on work-hardening behavior of AA6111and AA7030 aluminum alloys was studied and from a series of tensile tests a model was developed to determine the hardening behavior due to a transition between shearable and non-shearable precipitates $[148,149]$. Another investigation shows that the precipitation in Al-

\footnotetext{
${ }^{3}$ S.K. Shaha, F. Czerwinski, W. Kasprzak and D.L. Chen, J. Alloys Compd., Vol. 593, pp 290-299, 2014.

S.K. Shaha, F. Czerwinski, W. Kasprzak and D.L. Chen, Mater. Sci. Technol., Vol. 31, pp 63-72, 2015.
} 
Sc alloys resulted in significant differences in work hardening behavior with ageing time and temperature [150].

The plastic deformation in crystalline materials is directly related to the generation, motion and storage of dislocations, which move at a stress far below that required to deform a defectfree crystal [69]. Then, the improvement of material properties such as strength relies on creating internal obstacles to dislocation motion including grain boundaries, precipitates, and other dislocations $[151,152]$. As plastic deformation continues, the density of dislocations increases, causing more frequent interactions that impede their motion [153]. The immobile dislocations obstruct the passage of other dislocations along slip planes and harden the crystal, a phenomenon referred to as strain hardening, also known as forest dislocation hardening [154]. Before being stopped by obstacles, dislocations move along a certain distance, known as dislocation slip distance (DSD), originally proposed by Conrad et al. [155], which controls the alloy deformability [156]. In Conrad's DSD theory, plastic strain is provided by mobile dislocations moving over an average mean free path [157]. The plastic deformation behavior of aluminum cast alloys A356 and A357 has been investigated by Wang [158] with conclusions that strain hardening behavior depends on the microstructural features of the alloys. The hardening model proposed and the calculated strain hardening rates agree well with the results inferred from the experimental measurements. Hou and Jennett [159] stated that the strain hardening during plastic deformation at varying temperatures helps to explain the deformation mechanisms of metals and alloys. Several models have been proposed to describe the strain hardening behavior of alloys. Recently, Taylor's model was applied by Saimoto and Lloyd [160], to derive a constitutive equation related to the DSD from the strain hardening curves. In this model, however, deformation temperature was not incorporated. While the general effect of deformation temperature on the dislocation motion is known, a quantitative description of the 
influence of temperature on DSD, especially at relatively high temperatures during compression deformation, is still missing.

In this chapter, the work-hardening during uniaxial compression of $\mathrm{Al}-\mathrm{Si}-\mathrm{Cu}-\mathrm{Mg}$ alloy modified with additions of $\mathrm{V}, \mathrm{Zr}$ and $\mathrm{Ti}$ was studied to determine the role of precipitates. Also, a constitutive relationship was established based on the Mott's theory of parabolic strain hardening to predict the temperature dependence of the dislocation slip distance in materials.

\subsection{Alloy Microstructure after Compression Deformation}

The typical stress-strain curves of the studied alloy during compression in the as-cast, solution treated and T6 heat treated conditions are depicted in Fig. 6.1. It is seen that the solution treatment of the as-cast alloy, resulting in dissolution of some portion of primary phases and likely an absence of secondary precipitates due to a water quench, reduced the yield stress from $164 \mathrm{MPa}$ to $107 \mathrm{MPa}$. When the solution treated alloy was subjected to ageing, the yield stress increased to $318 \mathrm{MPa}$, substantially exceeding the as-cast level.

The general view of the test sample microstructure, with indicated solidification and compression directions, is shown in Fig. 6.2. As the fine grained zone, adjacent to the mold wall, was removed during sample machining, the dendrite size over the entire surface is generally uniform (Fig. 6.2a) with some internal porosity as mentioned in Table 6.1. Besides, there is no unique microstructure within the sample center and no special alignment of dendrites in regards to the solidification direction. After 15\% compression, there is a visible deformation of dendrites (Fig. 6.2b) with reduction of porosity from 1.37 to $1.20 \%$. It looks also that internal pores, formed during casting, remained open and some cracks were developed within interdendritic regions. The solutionizing and $\mathrm{T} 6$ heat treatment did not completely remove the dendritic morphology, being still visible at low magnification (Fig. 6.2c,d), but the porosity 
decreased (Table 6.1). After 15\% compression deformation of the solution treated and T6 treated samples, the microstructure became more uniform than that observed after compression in the as-cast state (Fig. 6.2c,e). At the macroscopic scale, however, samples did not deform homogeneously.

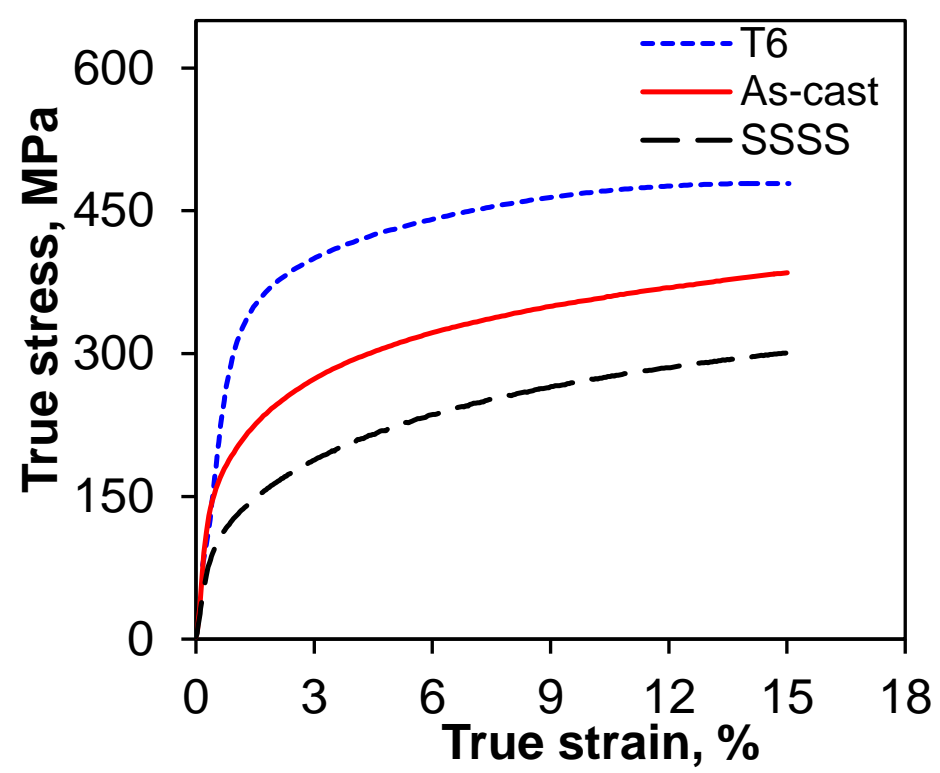

Fig. 6.1. Typical true stress-strain curves of as-cast and T6 heat treated alloy MA 3 obtained under uniaxial compression at a strain rate of $1 \times 10^{-3} \mathrm{~s}^{-1}$.

Table 6.1 Percentage of pores present in the studied alloy MA3 before and after compression.

\begin{tabular}{llll}
\hline Sample ID & AC & SSSS & T6 \\
\hline Before compression & 1.37 & 1.12 & 1.07 \\
\hline After compression & 1.20 & 0.72 & 0.86 \\
\hline
\end{tabular}

It is known that after applying a compressive load, a specimen tends to fail in shear at approximately $45^{\circ}$, with the most deformation occurring near the fracture surface. In addition, the barreling effect prevents the uniform deformation along the top and bottom. Thus, nonuniform and insufficient deformation after compression of $15 \%$ did not cause complete closure of all pores, still visible within the microstructure (Fig. $6.2 \mathrm{~b}, \mathrm{c}, \mathrm{e}$ ), but the porosity did drop off to 0.72 and $0.86 \%$ for the SSSS and T6 samples, respectively. 

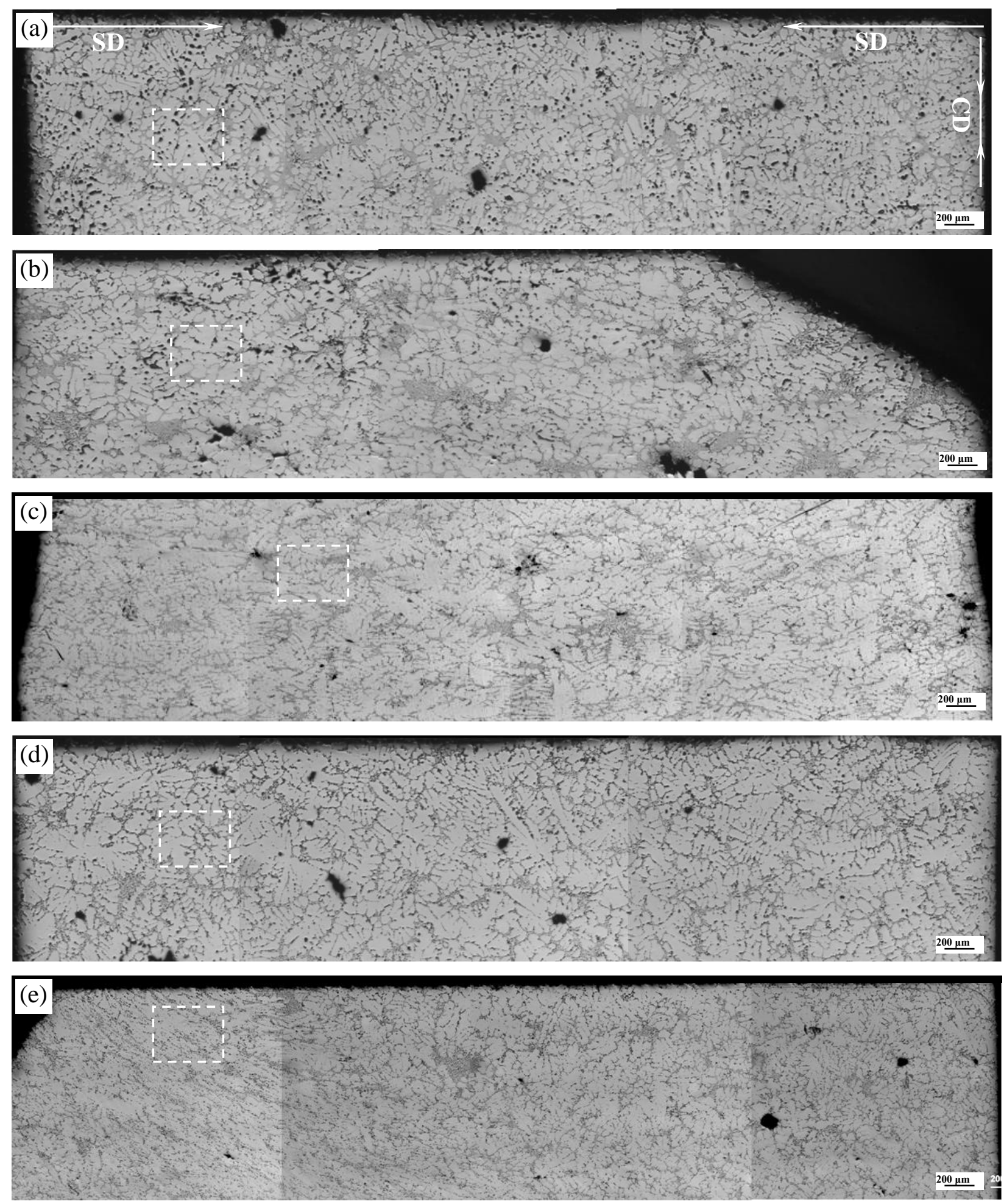

Fig. 6.2. Microstructure of the studied alloy MA3 in (a) as-cast condition before compression, (b) as-cast condition after compression, (c) after solution treated and compression, (d) T6 heat treated before compression and (e) T6 heat treated after compression, where SD stands for the solidification direction, and CD denotes the compression direction. The rectangles represent locations of magnified images shown in Fig. 6.3. 
The more subtle changes of the microstructure as a result of heat treatment and deformation, detectable with an optical microscope, are shown in Fig. 6.3. All three states: as-cast, solution treated and T6 contained $\alpha-\mathrm{Al}(\# 1)$, eutectic silicon (\#2) and intermetallic (\#3) phases. In the ascast condition, the eutectic silicon exhibited a needle- or plate-like morphology (Fig. 6.3a,b). As seen from the metallographic examinations, there was not complete solution of all phases during both the solution treatment and T6 treatment having added the low-temperature ageing step after solutionizing. Due to spheroidization at increased temperatures, the eutectic silicon particles changed their morphology (Fig. 6.3c,d,e). The micrographs show that the major cracks, present in the secondary phases, were mostly parallel to the compressive loading axis (Fig 6.3b,c,e). The precipitate cracking in $\mathrm{Al}$ alloys during deformation is frequently reported in the literature. Agarwal et al. conducted uniaxial compression tests of 6061 (T651) alloy and observed that cracks were formed in Fe-rich intermetallics [161, 162]. Similarly, Dighe et al. [163] and Poole and Dowdle [164] observed the damage evolution in Al-Si-Mg alloys and reported that cracks in Si particles appeared parallel to the loading axis. To determine the size of precipitates in alloys tested an analysis at different scales is required. While large precipitates are seen at the magnification of optical microscope, to see small precipitates formed during T6 treatment, transmission electron microscope is needed. As shown, based on image analysis under magnifications typical for optical microscopy, the volume fraction of precipitates after casting is the largest and experiences a reduction during solution treatment (Fig. 6.4a). After T6 treatment a slight increase in total volume fraction of precipitates is observed, as compared to the solutionizing step. To characterize the particle size, two indicators were used: particle length and width with histograms of their size distribution shown in Fig. 6.4b and 6.4c. Using both parameters, it is seen that after solutionizing and T6 step, the fraction of particles in the $5 \mu \mathrm{m}$ range increases at the expense of larger ones. 

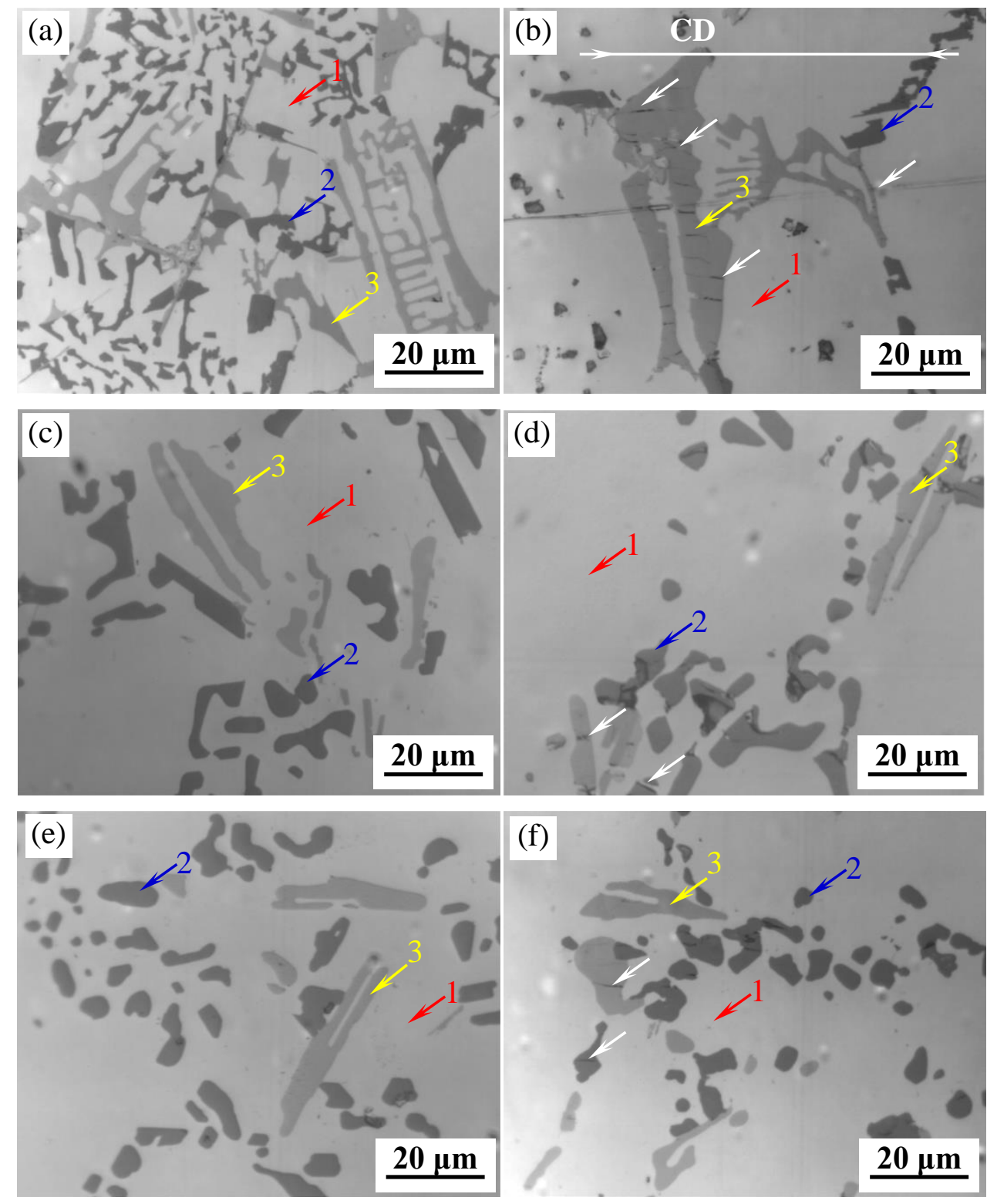

Fig. 6.3. Magnified view of the microstructure, in locations marked with boxes in Fig. 6.2, of the alloy examined: (a) as-cast before compression, (b) as-cast after compression, (c) after solution treated and before compression, (d) after solution treated and compression, (e) T6 heat treated before compression, and (f) T6 heat treated after compression.

Note: 1- $\alpha$-Al, 2- eutectic silicon particles, 3-intermetallics, cracked present in the particles are indicated by white arrows.

At the same time, there is no substantial difference between solutionizing and T6 treatment. As it is widely known, an essential difference of the T6 state is expressed in very small precipitates, formed during ageing. In the case of the alloy tested, precipitates had a form of $\mathrm{Al}_{3} \mathrm{Zr}, \mathrm{Al}_{2} \mathrm{Cu}, \mathrm{MgSi}_{2}$ and other with more complex stoichiometry combining also $\mathrm{V}$, Ti and $\mathrm{Zr}$. 
Details of precipitation during ageing are described separately. For the purpose of analysis in this paper it is assumed that such small precipitates are present in the T6 state. During deformation of multiphase alloys, stresses arise due to a different crystal structure, misfit between phases and their shape. When the interfacial stress exceeds the strength of the interface or the fracture strength of a particle, damage or de-bonding occurs; hence, the load transfer from the matrix to particles is of key importance. If particles are of spherical shape, the interfacial stress that is generated around particles may not be sufficient to fracture or de-bond the interface [165]. In the as-cast condition, Si particles were of plate-like shape, which increased the interfacial stress and the stress generated at the tip of the plate, thus contributing to frequent cracking. On the contrary, the T6 heat treated alloy exhibited less damage of Si particles, which were of near-spherical shape. The particle morphology was one of a number of factors causing that the strength of the as-cast samples to be lower than that of the T6 heat-treated samples.

\subsection{Work Hardening}

The work-hardening behavior of the as-cast, solution treated and T6 aged alloy is shown through the plot of the instantaneous work hardening rate of $\theta=d \sigma / d \varepsilon$ versus net flow stress increments of $\sigma-\sigma_{y}$, referred to as the Kocks-Mecking (KM) plot (Fig. 6.5a). As depicted in Fig 6.5b, the typical KM plot for the fcc single crystal exhibits three stages. Stages II, III and IV represent respectively: linear hardening, falling of hardening rate, and finally saturation. Hardening stages III and IV are generally seen in polycrystalline materials during compression $[165,166]$. 

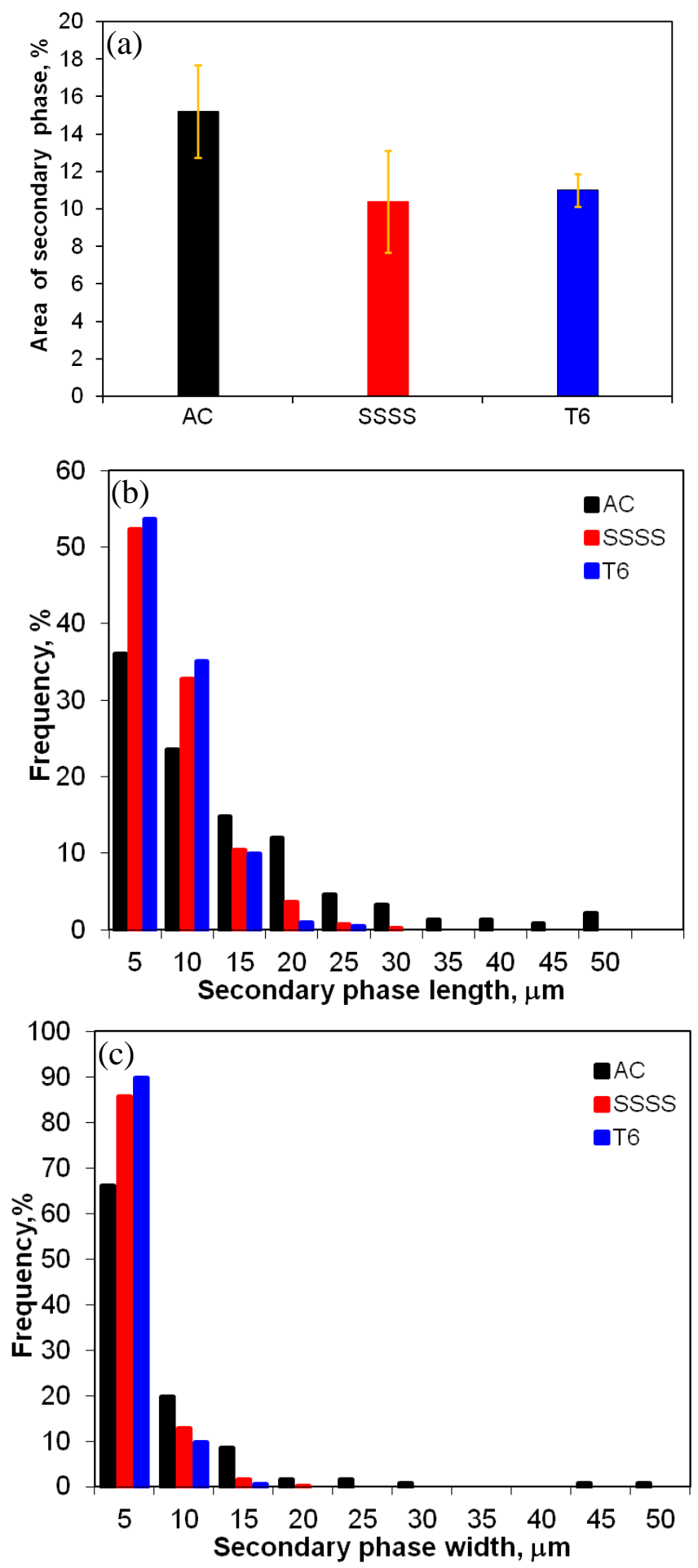

Fig. 6.4. Quantitative image analysis of secondary phases present in the studied alloy after casting (AC), solutionizing (SSSS) and T6 treatment: (a) area percentage (volume fraction), (b) distribution of particle length and (c) distribution of particle width. 
The instantaneous hardening rate of the as-cast, solution treated and T6 aged alloy reveal only hardening stages III and IV. The nature of the curves indicates that the hardening rate is higher for T6 heat treated alloy than for the as-cast and solution treated states. At the beginning of stage III, the forest dislocation hardening occurred due to the dislocation interaction and accumulation, and dynamic recovery of dislocations, which caused a linear reduction of the hardening rate. When extrapolating the stage III to zero hardening rate $(\theta=0)$, the flow stress at that point would be in a steady-state condition, which is known as Voce stress, $\sigma_{v}$. At the same time, the mobile dislocations are generated, stored and recovered very rapidly. The evaluated Voce stresses of the as-cast, solution treated and T6 aged alloys were 256, 188 and $376 \mathrm{MPa}$, respectively (Fig. 6.6). In practice, stage III is replaced by stage IV before it goes to zero during severe plastic deformation, where $d \theta / d \varepsilon$ reaches zero $[167,168]$.

\subsection{Effect of Precipitates on Flow Stress}

The contribution of precipitates to flow stresses for an age-hardened alloy could be expressed using the following equation, suggested by Kocks and adapted by Sharma et al. [147] and Cheng et al. [148] in the following form:

$$
\sigma_{T}=\sigma_{i}+\sigma_{S S}+\sigma_{e u}+\left(\sigma_{\perp}^{n^{\prime}}+\sigma_{p}^{n^{\prime}}\right)^{l / n^{\prime}}
$$

where $\sigma_{T}$ is the total stress, $\sigma_{i}$ is the intrinsic stress, $\sigma_{s s}$ is the solid solution strengthening, $\sigma_{e u}$ is the strengthening by eutectic phase, $\sigma_{\perp}$ is the strengthening by dislocations and $\sigma_{p}$ is the strengthening by precipitates, $n^{\prime}$ is the parameter which varies between 1 and 2 , depending on the average obstacle density. At natural ageing condition, $n^{\prime}=1$ is considered for higher dense of weak obstacles and a lower dense of strong obstacles. For the case of over aging, a 
value of $n^{\prime}=2$ were considered. At intermediate cases for peak ageing, the appropriate value of $\mathrm{n}$ falls between these extremes. Since the alloy studied was peak-aged at $150^{\circ} \mathrm{C}$ for $100 \mathrm{~h}$, a value of $n^{\prime}=1.5$ is used here.
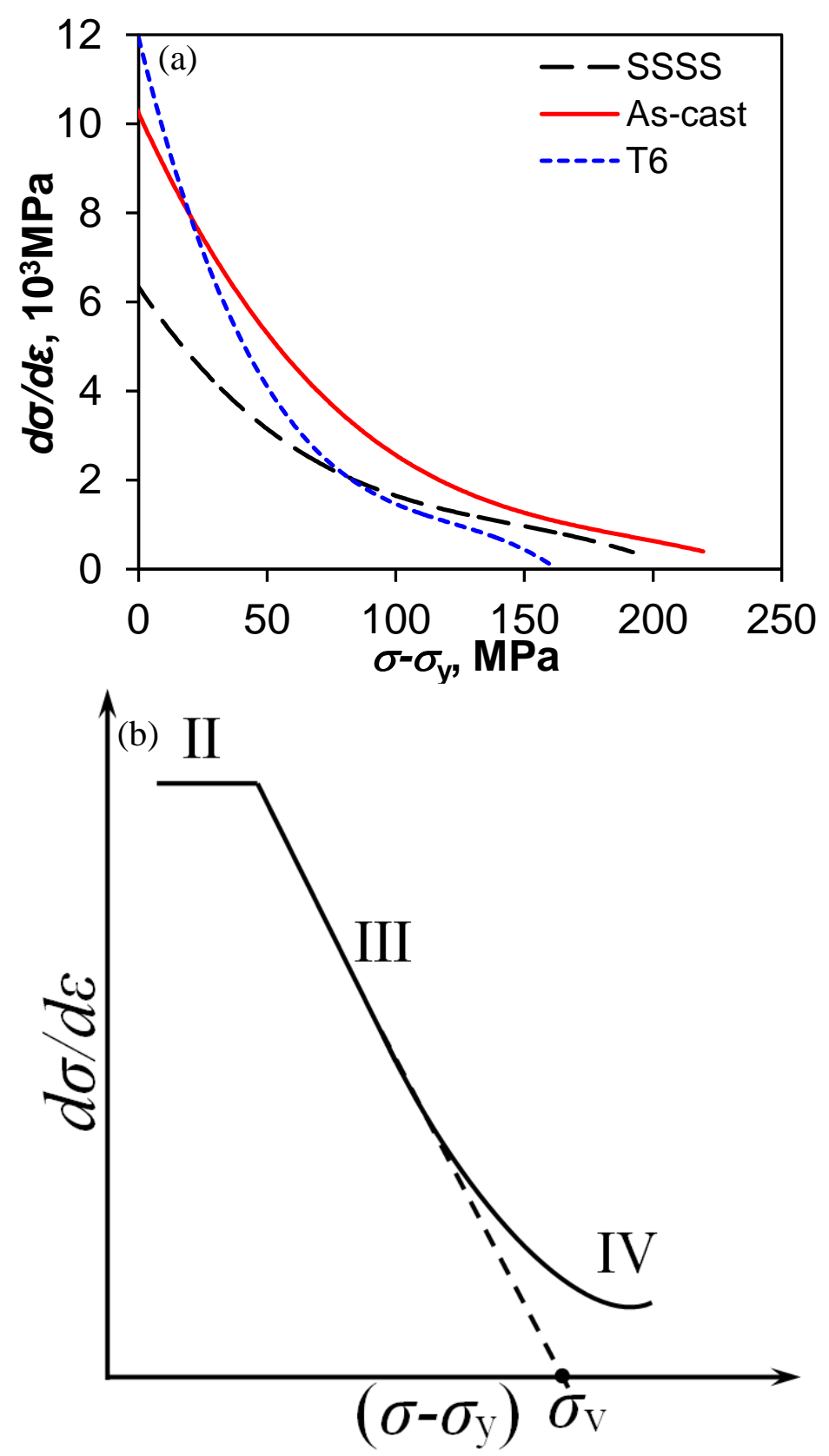

Fig. 6.5. Work-hardening behavior under uniaxial compression: (a) Plot of the instantaneous work hardening rate of $\theta=d \sigma / d \varepsilon$ versus flow stress increments of $\sigma-\sigma_{y}$ for as-cast, solution treated (SSSS) and T6 heat treated alloy (b) typical work-hardening stages in fcc single crystal [165]. 


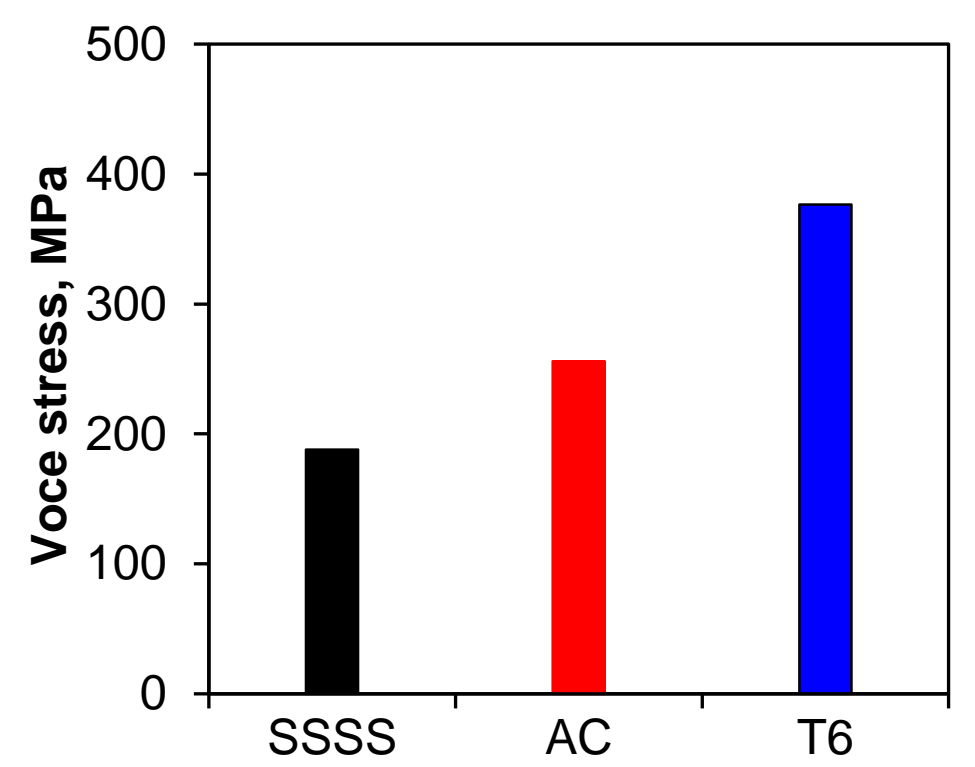

Fig. 6.6. Voce stress of super saturated solid solution (SSSS), as-cast (AC) and T6 heat treated alloy.

For the condition of the supersaturated solid solution $\sigma_{p}=0$, when plastic strain $\varepsilon_{p}=0$ and $\sigma_{\perp}=0$ then the yield strength $\sigma_{y s}$ could be expressed as follows [147]:

$$
\sigma_{y s}=\sigma_{s s} .
$$

For an age-hardened alloy, when the plastic strain $\varepsilon_{p}=0$ and $\sigma_{\perp}=0$ then the yield strength could be expressed as follows [148]:

$$
\sigma_{y s}=\sigma_{s S}+\sigma_{p}
$$

The flow stress contribution by the eutectic phase could be written as follows $[147,148]$ :

$$
\sigma_{e u}=\sigma_{y s}-\sigma_{s s}-\sigma_{i}
$$

Again, the yield stress of a solid solution $\sigma_{s s}$ depends on the solubility $\left(\mathrm{C}_{\mathrm{ss}}\right)$ of alloying elements in the $\alpha$-Al solvent, which could be expressed by the following equation [169]:

$$
\sigma_{s s}=\sqrt{3} \tau_{c r i c}=\sqrt{3} \kappa_{s s}\left(C_{s s}\right)^{m}
$$


where $\tau_{c r i c}$ is the critical resolved shear stress for the solid solution contribution, $\kappa_{s s}$ and $m$ are material constants, and for dilute solutions of $\mathrm{Al}-\mathrm{Mg}$ and $\mathrm{Al}-\mathrm{Cu} \kappa_{s s}=24 \mathrm{MPa}$ per atomic percent and $m=2 / 3$ based on [147].

The yield strength in solution treated condition $\sigma_{s s}$ calculated from the empirical equation (6.5), was $82 \mathrm{MPa}$ where $C_{\mathrm{ss}}$ was considered to be 2.67 according to $\mathrm{Al}-\mathrm{Cu}, \mathrm{Al}-\mathrm{Mg}$ and $\mathrm{Al}-\mathrm{Si}$ phase diagrams assuming that $1 \% \mathrm{Cu}, 0.5 \% \mathrm{Mg}$ and $1.17 \% \mathrm{Si}$ dissolved in the matrix during solution treatment. But the experimentally obtained yield strength was $107 \mathrm{MPa}$ which is 25 MPa higher than the calculated value. Therefore, the empirical equation (6.5) was modified by Sharma et al. [147], by incorporating two constants $A$ and $B$ :

$$
\sigma_{s s}=A\left(C_{s s}\right)^{m}+B
$$

Assuming the constant $B=25 \mathrm{MPa}$ as explained above, the constant $A=42 \mathrm{MPa}$ was calculated from equation (6.6) and used in the present study to calculate $\sigma_{\mathrm{ss}}$ in the solution treated condition.

Mecking and Kocks [170] and Estrin [171] proposed changes in dislocation density approach with plastic strain, using the following equation:

$$
\frac{d \rho}{d \varepsilon_{p}}=k_{1} \rho^{1 / 2}-f k_{2} \rho+k_{D}
$$

where $\rho$ is the dislocation density, $k_{l}=6.86 \times 10^{8} \mathrm{~m}^{-1}$ is a parameter related to the statistical storage of dislocations, $f k_{2}=61$ is a parameter related to the dynamic recovery of dislocations and $k_{D}=3.32 \times 10^{16}$ [147] is a parameter related to the storage of dislocations, geometrically due to the non-sheareable precipitates and forest dislocations.

Taylor [172] proposed that the flow stress contribution by dislocations can be expressed as follows: 


$$
\sigma_{\perp}=\alpha_{\perp} G b M \rho^{1 / 2}
$$

where $\alpha_{\perp}=0.3$ is a constant, $b$ is the Burgers vector $(=0.284 \mathrm{~nm}), G$ is the shear modulus $(=27$ $\mathrm{GPa})$, and $M$ is the Taylor factor for fcc metals (=3.06).

From Eq. (6.7) Sharma et al. [147] proposed that for sheareable precipitates, the term $k_{D}=0$ and the simplified solution is:

$$
\sqrt{\rho}=\frac{k_{1}}{f k_{2}}\left\{1-\exp \left(-\frac{1}{2} f k_{2} \varepsilon_{p}\right)\right\} .
$$

They also proposed for non-sheareable precipitates, the parameter related to the statistical storage of dislocations is $k_{l}=0$. Then, the solution comes out as [146, 148]:

$$
\rho=\frac{k_{D}}{f k_{2}}\left\{1-\exp \left(-f k_{2} \varepsilon_{p}\right)\right\} .
$$

From Eq. (6.8) and Eq. (6.9), the hardening $\sigma_{\perp S D}$ due to sheareable precipitates could be expressed using the following equation:

$$
\sigma_{\perp S D}=\alpha_{\perp} G b M \frac{k_{1}}{f k_{2}}\left\{1-\exp \left(-\frac{1}{2} f k_{2} \varepsilon_{p}\right)\right\} .
$$

From Eq. (6.8) and Eq. (6.10) the hardening $\sigma_{\perp N S D}$ due to non-sheareable precipitates could be expressed using the following equation:

$$
\sigma_{\perp N S D}=\alpha_{\perp} G b M \sqrt{\frac{k_{D}}{f k_{2}}\left\{1-\exp \left(-f k_{2} \varepsilon_{p}\right)\right\}} .
$$

Finally, the total flow stress contribution $\sigma_{T}$ could thus be estimated by combining Eq. (6.1) and Eq. (6.12):

$$
\sigma_{T}=\sigma_{s s}+\left\{\left(\sigma_{\perp S D}+\sigma_{\perp N S D}\right)^{1.5}+\left(\sigma_{y s}-\sigma_{s s}\right)^{1.5}\right\}^{0.67}
$$


Using Eq. (6.13), the flow stress increment was calculated and plotted against the plastic strain, considering the hardening due to sheareable, non-sheareable as well as both kinds of precipitates and compared with the experimental measurements (Fig. 6.7a). It is seen that the experimental curve is in agreement with the model prediction where both types of precipitates were considered. It suggests that the studied alloy was hardened during compression not only by the shearable precipitates but also by the non-shearable ones. However, the flow stress was mainly affected by non-shearable precipitates. Such a finding indicates that the Al-Si-Cu-Mg alloy with micro-additions of $\mathrm{V}, \mathrm{Zr}$ and $\mathrm{Ti}$ contained a larger number of coarse precipitates, as presented earlier in [101]. Sharma et al. [147] and Cheng et al. [148] studied the work hardening behavior during tensile loading of wrought aluminum alloys and reported that both the sheareable and non-sheareable precipitates were present in age hardened alloys and that the hardening behavior was affected by both types of precipitates. According to their explanation, the initial work hardening due to shearable precipitates is low because of their weakness and possibility to be sheared by moving dislocations. In the case of non-shearable precipitates, dislocations do not shear them but form loops around them allowing extra storage of geometrically necessary dislocations, giving rise to a higher initial rate of precipitation hardening. According to Fig. 6.7b, a similar conclusion was reached for compression of casting alloy in this study. There are, however, some differences between our results and literature data. Cheng et al. [148] obtained the same stress saturation level at around $200 \mathrm{MPa}$ for shearable and non-shearable precipitates in wrought AA6111 and AA7030 alloys. Similarly, Sharma et al. [147] obtained in the wrought AA22219 alloy the stress saturation level for shearable precipitates slightly higher than for non-shearable, both within the range of 200-250 MPa. In this study, the saturation stress for shearable precipitates reached around $80 \mathrm{MPa}$ and was substantially lower than the saturation stress for non-shearable precipitates that exceeded 165 
MPa. Since the saturation stress represents a physical limit to the density of dislocations, possible to store in the crystal, the present calculation suggests that for the shearable precipitates the accumulated dislocation pile-ups were relatively low, even at large strains.
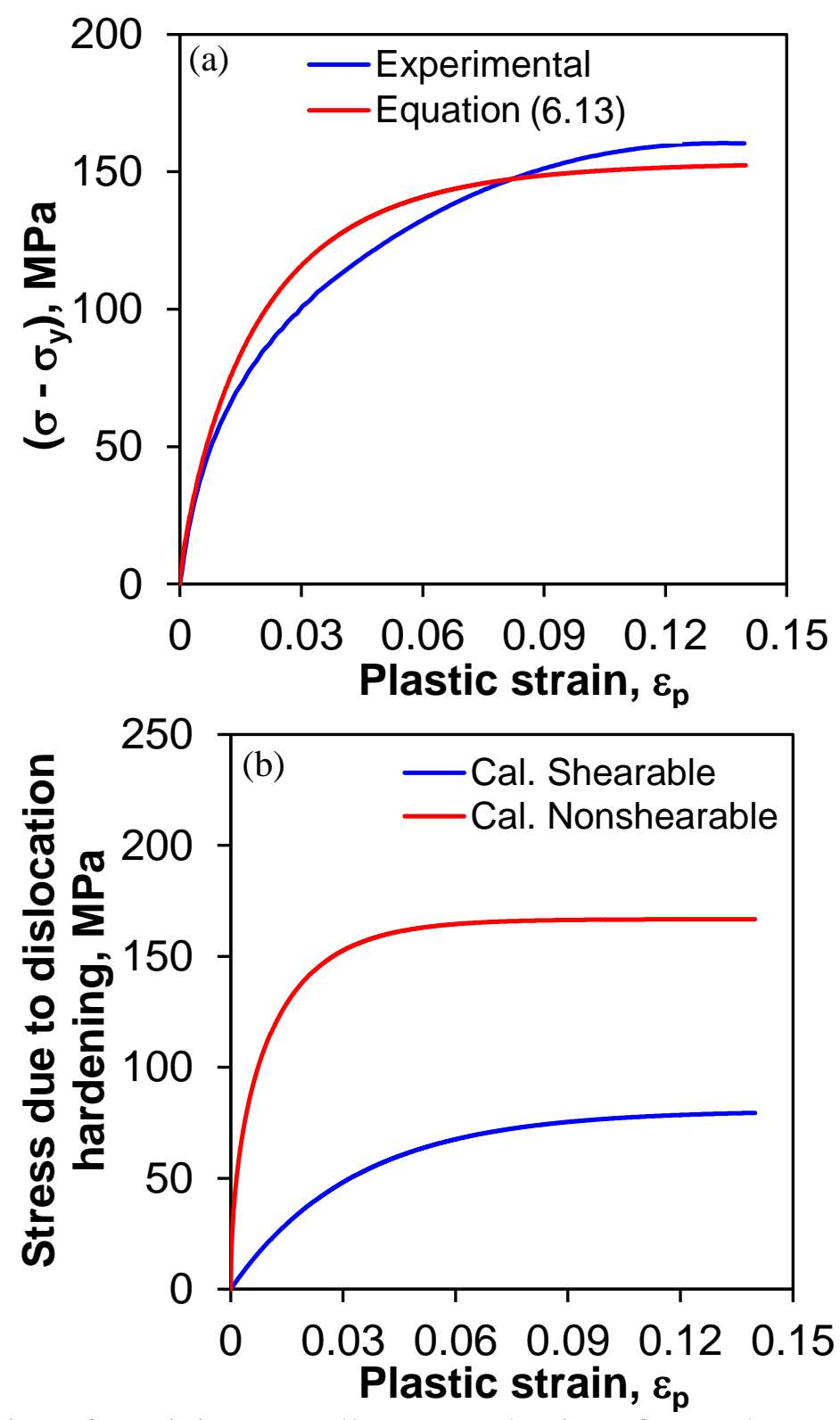

Fig. 6.7. Contribution of precipitates to alloy strengthening after T6 heat treatment: (a) plastic stress-strain comparison of model calculations (Equation 6.13) with the experimental curve; (b) calculated flow stress due to precipitation hardening caused by shearable and non-shearable precipitates. 


\subsection{Dislocation Slips Distance during Compression}

\subsubsection{Compression deformation at different temperature}

Typical true stress-true strain curves of the researched alloy, obtained at temperatures from 25 ${ }^{\circ} \mathrm{C}$ to $400{ }^{\circ} \mathrm{C}$, are plotted in Fig.6.8. As indicated by the shape of the curves in Fig. 6.8a, the deformation temperature exerted a strong effect on the alloy deformation behavior. At the same time, the strain rate in the range from $10^{-3}$ to $1 \mathrm{~s}^{-1}$ had little effect on the alloy deformed at room temperature (Fig. 6.8b). As shown in Fig. 6.9, for a temperature increase from $25{ }^{\circ} \mathrm{C}$ to $400{ }^{\circ} \mathrm{C}$, the peak true stress decreased linearly from $417 \mathrm{MPa}$ to $55 \mathrm{MPa}$. The corresponding true strain reduced from approximately $17 \%$ to $3 \%$. Such changes are related to the temperature-dependent softening of the alloy.

A similar trend was reported by Cui et al. [173] for a spray-formed aluminum-silicon alloy during hot compression. Also, Zhang et al. [174] noticed that increasing test temperature led to decreasing peak stress of the A2219 aluminum alloy. The reduction of strength with increasing temperature is related to the change in the behavior of dislocation generation and movement, coarsening of precipitates such as $\mathrm{Al}_{2} \mathrm{Cu}, \mathrm{Mg}_{2} \mathrm{Si}$ etc., sliding of grain boundaries, phase transformation etc. Generally, during deformation, dislocations slip and subsequently pile up at grain boundaries. When deformation continues at high temperatures, dislocations are thermally activated, i.e., temperature can help dislocations to move forward, leading to the generation of a row of vacancies $[153,173]$. At a temperature at which the thermal energy is sufficient to allow vacancies to diffuse away at an appropriate rate, the pile-up of dislocations at grain boundaries will decrease, causing a reduction of flow stress [153, 175, 176].

According to Feltham and Meakin [177], a modified equation of true stress versus true strain curves with parabolic strain hardening can be expressed as: 


$$
\left(\sigma-\sigma_{y}\right)^{2}=\chi\left(\varepsilon-\varepsilon_{y}\right)
$$

where: $\sigma_{\mathrm{y}}$ is the yield stress, $\varepsilon_{\mathrm{y}}$ is the yield strain, and $\chi$ is the coefficient of parabolic strain hardening.
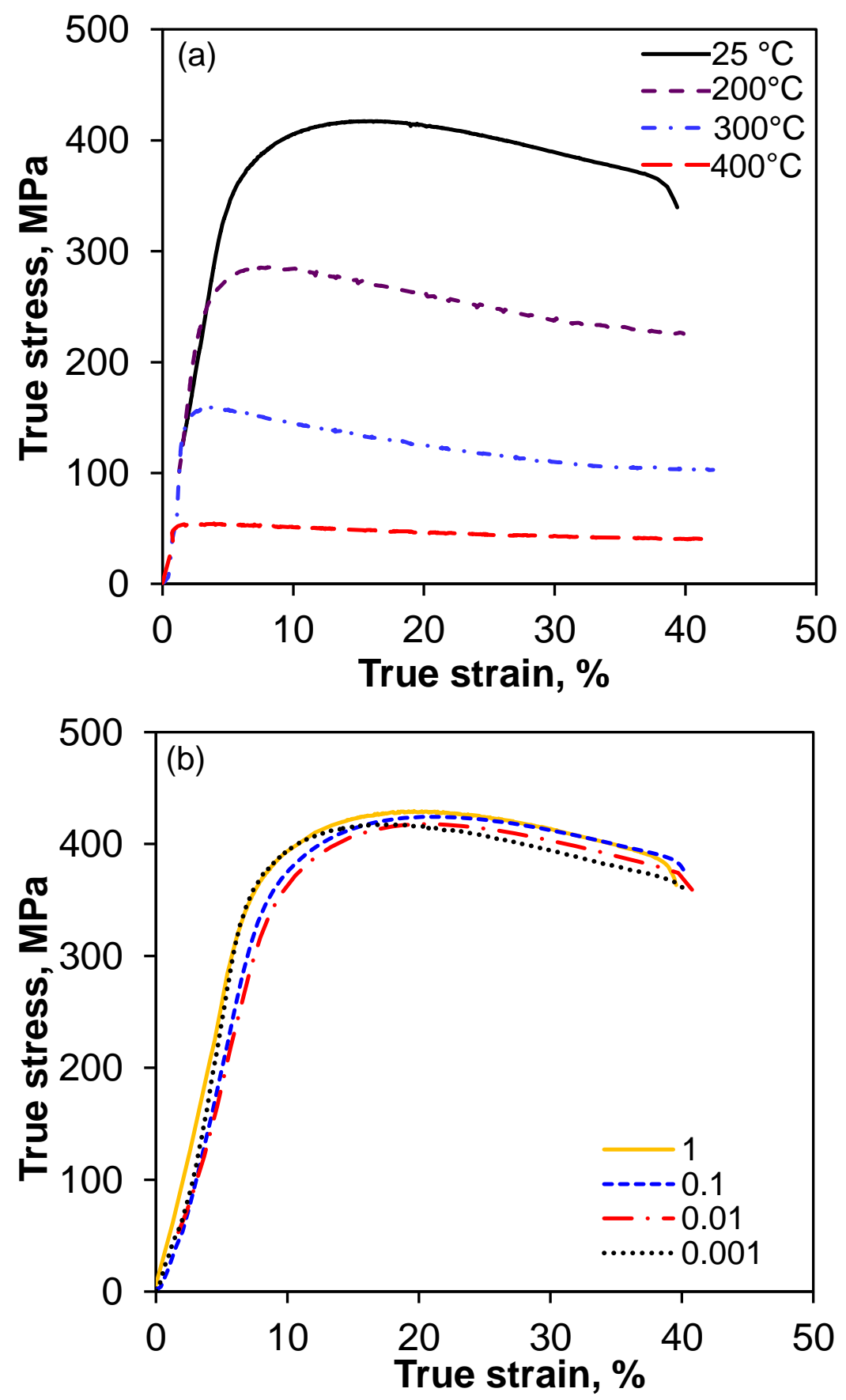

Fig. 6.8. True stress-true strain curves of the Al-Si-Cu-Mg alloy obtained during uniaxial compression, (a) at different temperatures and a strain rate of $10^{-3} \mathrm{~s}^{-1}$, and (b) at different strain rates and room temperature $\left(25^{\circ} \mathrm{C}\right)$. 


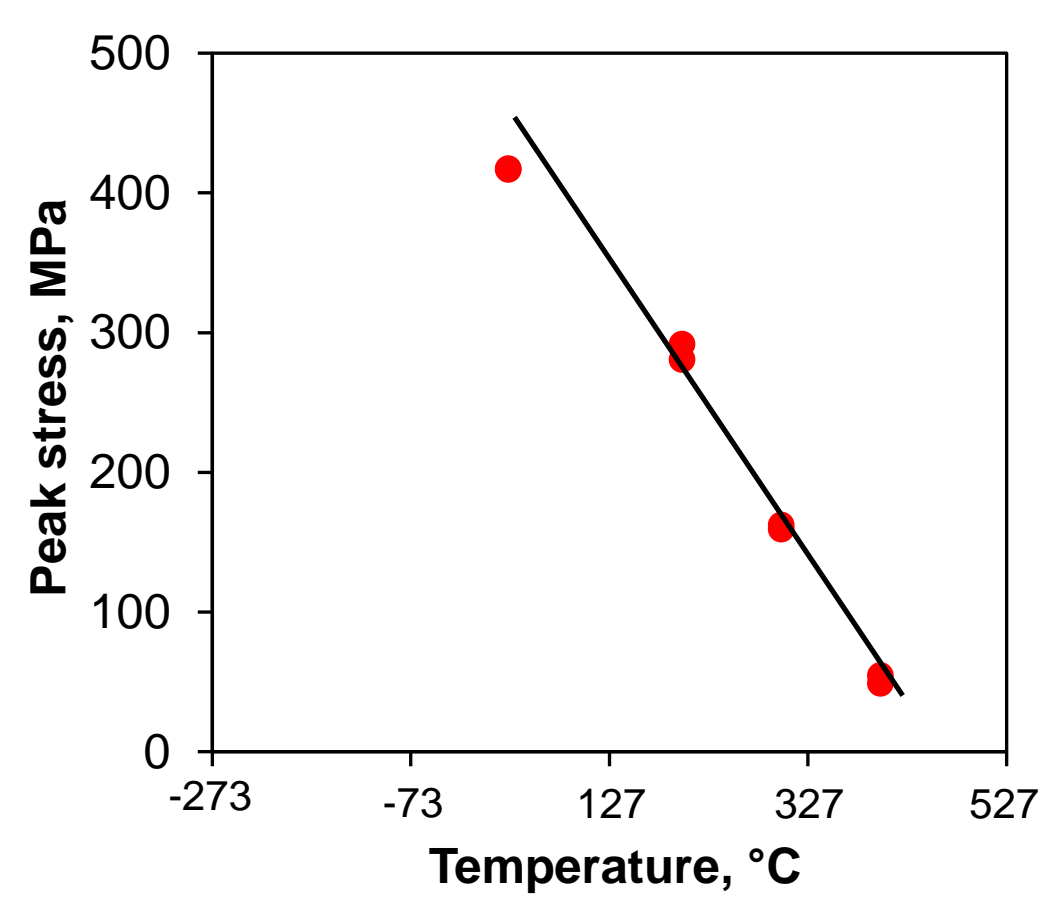

Fig. 6.9. Influence of temperature on peak stresses of the studied alloy at different temperatures.

An plotted example of the square of true stress versus the true strain of the studied alloy at different temperatures is shown in Fig. 6.10a. With increasing deformation temperature the strain hardening of the studied alloy decreased. From the slope of the initial linear portion of the curves, the coefficient of parabolic strain hardening, $\chi$, can be evaluated. As shown in Fig. $6.10 \mathrm{~b}$, the coefficient $\chi$ reduced markedly from about $1.3 \times 10^{5}(\mathrm{MPa})^{2}$ at $25^{\circ} \mathrm{C}$ to $0.01 \times 10^{5}$ $(\mathrm{MPa})^{2}$ at $400{ }^{\circ} \mathrm{C}$.

The phenomena of strain hardening and flow softening compete during deformation of materials. At a given temperature, the initial hardening rate was greater than the softening rate until the peak stress was reached at which the rates of both processes were equal. Beyond the peak stress the flow softening process prevailed, which was associated with dynamic recovery, recrystallization and annihilation of dislocation and particle damage, which will be discussed later $[178,179,180,181]$. 

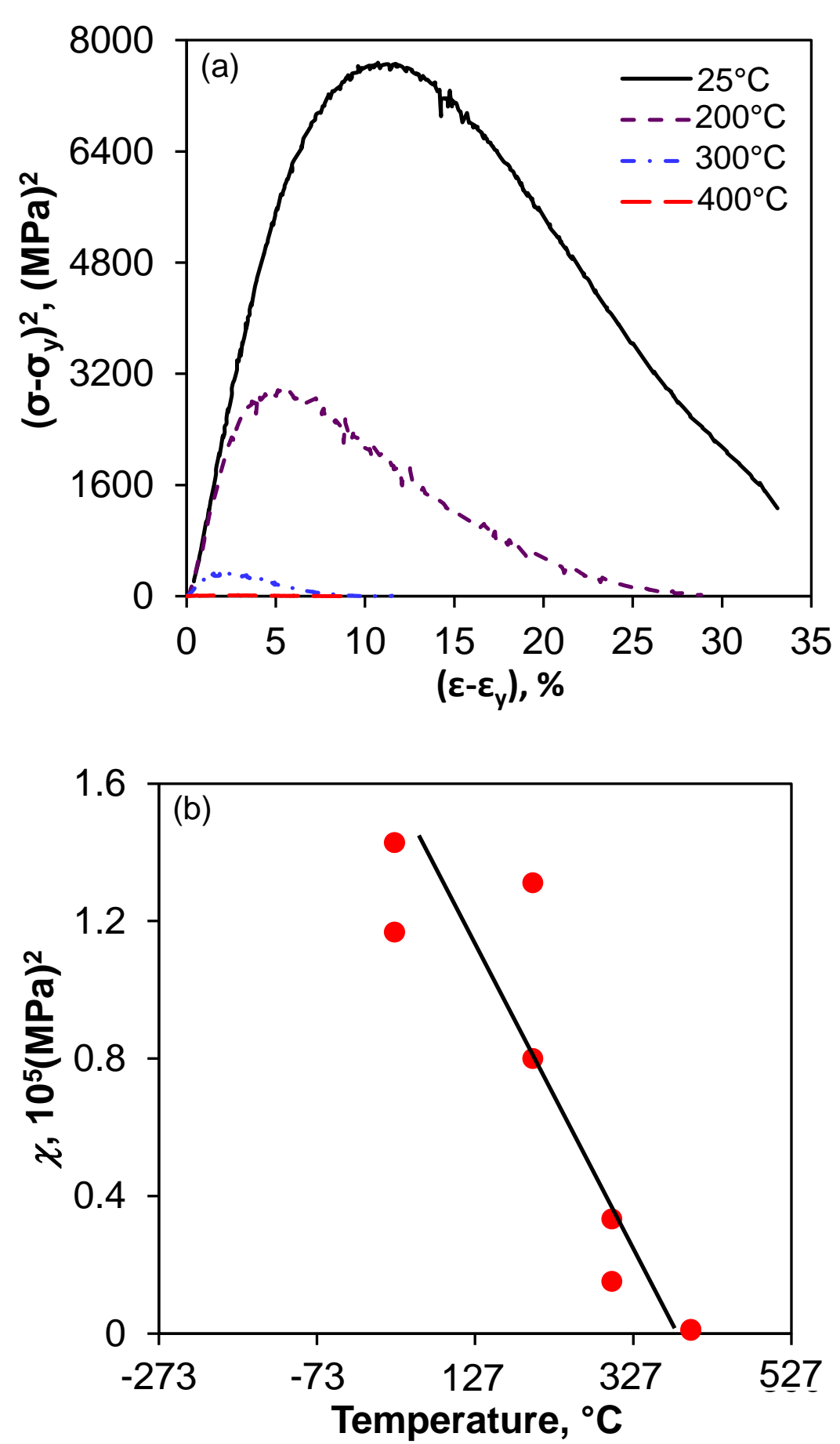

Fig. 6.10. (a) Parabolic strain hardening curves of the Al-Si-Cu-Mg alloy during compression tested at different temperatures, and (b) the effect of temperature on the coefficient of parabolic strain hardening, $\chi$.

As reported by Huang et al. $[181,182]$ there are three irreversible processes which take place during plastic deformation of metals: (1) dislocation generation, (2) dislocation annihilation 
(dynamic recovery) and (3) dislocation glide. However, two dislocation annihilation mechanisms are present at different temperature ranges for FCC metals: at low temperatures (T $<0.3 \mathrm{~T}_{\mathrm{m}}$, where $\mathrm{T}_{\mathrm{m}}$ is the material's melting temperature), the governing mechanism is the annihilation via cross-slip driven by thermally activated glide; at high temperatures $\left(\mathrm{T}>0.6 \mathrm{~T}_{\mathrm{m}}\right)$, annihilation is driven by the climb of dislocations via their interaction with vacancies. At intermediate temperatures $(0.3 \mathrm{Tm}<\mathrm{T}<0.6 \mathrm{Tm})$, both processes are present and exhibit a mixed behavior [183]. The annihilation process leads to dynamic recovery and it is very efficient for pure metals. However, the presence of the second phase precipitates like eutectic silicon, intermetallics etc. can affect the annihilation process. At the lower temperature, the softening process is controlled by dynamic recovery while at higher temperatures the softening process is controlled by partial dynamic recrystallization [184]. More details about the effect of temperature and strain rates on the softening mechanism of the alloy with present chemistry are provided in [75]. Other factors contributing to the reduced flow stresses at elevated temperatures include coarsening and morphological changes of precipitates. For example, during the hightemperature deformation of the A356 alloy, precipitates changed from rod-like (semi-coherent) to a planar shape (non-coherent) arising from the enhanced recovery via pipe diffusion [185]. These changes are expected to be reflected by the change in the dislocation slip distance.

\subsubsection{Constitutive equation describing dislocation slips distance}

In Taylor's model, strain hardening of metals is attributed to the effect of stress field of an array of dislocations lying in the operative slip planes. This is also a feature of Mott's theory of strain hardening [186], but differs from the original Taylor's theory $[176,187]$ in that the dislocations are supposed to pile up at obstacles, instead of being distributed uniformly throughout the crystal. Based on Mott's strain hardening theory $[156,186]$, the flow stress is given by: 


$$
\sigma=\alpha G b / l
$$

where: $G$ is the shear modulus and $b$ is the Burgers vector, $l$ is the average dislocation spacing, $\alpha$ is a constant $(=1 /(2 \pi))$ [156]. If the dislocations in the lattice are assumed to come mainly from grain boundaries, the dislocations have to move an average of half DSD, $L / 2$, giving rise to the strain [187]:

$$
\varepsilon=\rho b L / 2
$$

where: the dislocation density, $\rho$, is related to the average dislocation spacing, $l$, as follows:

$$
\rho=1 / l^{2}
$$

From Eq. (6.15) to Eq. (6.17), the flow stress equation can be derived,

$$
\sigma=\frac{1}{2 \pi} \cdot G \sqrt{\frac{2 b \varepsilon}{L}}
$$

Eq. (6.18) represents a parabolic relationship between the flow stress and plastic strain. Then, the DSD value $(L)$ can be obtained to be associated with the coefficient of parabolic strain hardening via:

$$
\chi=\frac{\partial \sigma^{2}}{\partial \varepsilon}=\frac{G^{2} b}{2 \pi^{2} L}
$$

A number of constitutive equations have been developed to describe the deformation behavior of materials $[180,181,188]$. The following equation with consideration of temperature-related softening [189]:

$$
\sigma=A \varepsilon^{n^{n}} \dot{\varepsilon}^{m}(1-C T)
$$

is used here to account for the effect of deformation temperature, where $m, n^{\prime \prime}, A$ and $C$ are all material constants ( $n^{\prime \prime}$ is the strain hardening exponent and $m$ is the strain-rate sensitivity). The term $\varepsilon^{n}{ }^{\prime \prime} \dot{\varepsilon}^{m}$ stands for a power law dependence of the stress on the strain and strain rate, while 
the term, (1-CT), represents linear thermal softening where $T$ is absolute temperature and $C$ is a softening constant. After squaring both sides and differentiating with respect to strain, Eq. (6.20) becomes:

$$
\frac{\partial \sigma^{2}}{\partial \varepsilon}=A^{2} 2 n^{\prime \prime} \varepsilon^{2 n^{\prime \prime}-1} \dot{\varepsilon}^{2 m}(1-C T)^{2}
$$

Inserting Eq. (6.21) into Eq. (6.19) yields the following equation for determining a temperaturedependent DSD:

$$
L=\frac{G^{2} b}{4 \pi^{2} A^{2} n^{\prime \prime} \varepsilon^{2 n^{\prime \prime}-1} \dot{\varepsilon}^{2 m}(1-C T)^{2}}
$$

The material constants in Eq. (6.22) can be determined from the stress-strain curves obtained at a given temperature, while the softening constant, $C$, can be obtained at a given strain rate and plastic strain at different temperatures. Eq. (6.22) will be validated below using the deformation behavior of a newly-developed automotive alloy and other alloys reported in the literature.

\subsubsection{Validation of the constitutive equation developed}

Based on the true stress-true strain curves obtained at room temperature and varying strain rates, the material constants $A, n^{\prime \prime}$ and $m$ in Eq. (6.22) can be determined, while constant $C$ can be evaluated from the tests performed at a given strain rate at varying temperatures. The value of the strain hardening exponent, $n$, at room temperature and a strain rate of $10^{-3} \mathrm{~s}^{-1}$, was calculated from the slope of the log-log plot of stress vs strain between yield stress and maximum compressive stress of the alloy. As shown in Fig. 6.11(a), the slope of log-log plot of stress vs. strain rate for the fixed stain $(0.35)$ and temperature $\left(25^{\circ} \mathrm{C}\right)$, was considered as strain rate sensitivity, $m$, of the alloy. Other material constants, $A$ and $C$, were calculated from the linear

plot of stress vs. temperature at a fixed strain (0.35) and a strain rate $\left(10^{-3} \mathrm{~s}^{-1}\right)$ (Fig. 6.11b). 

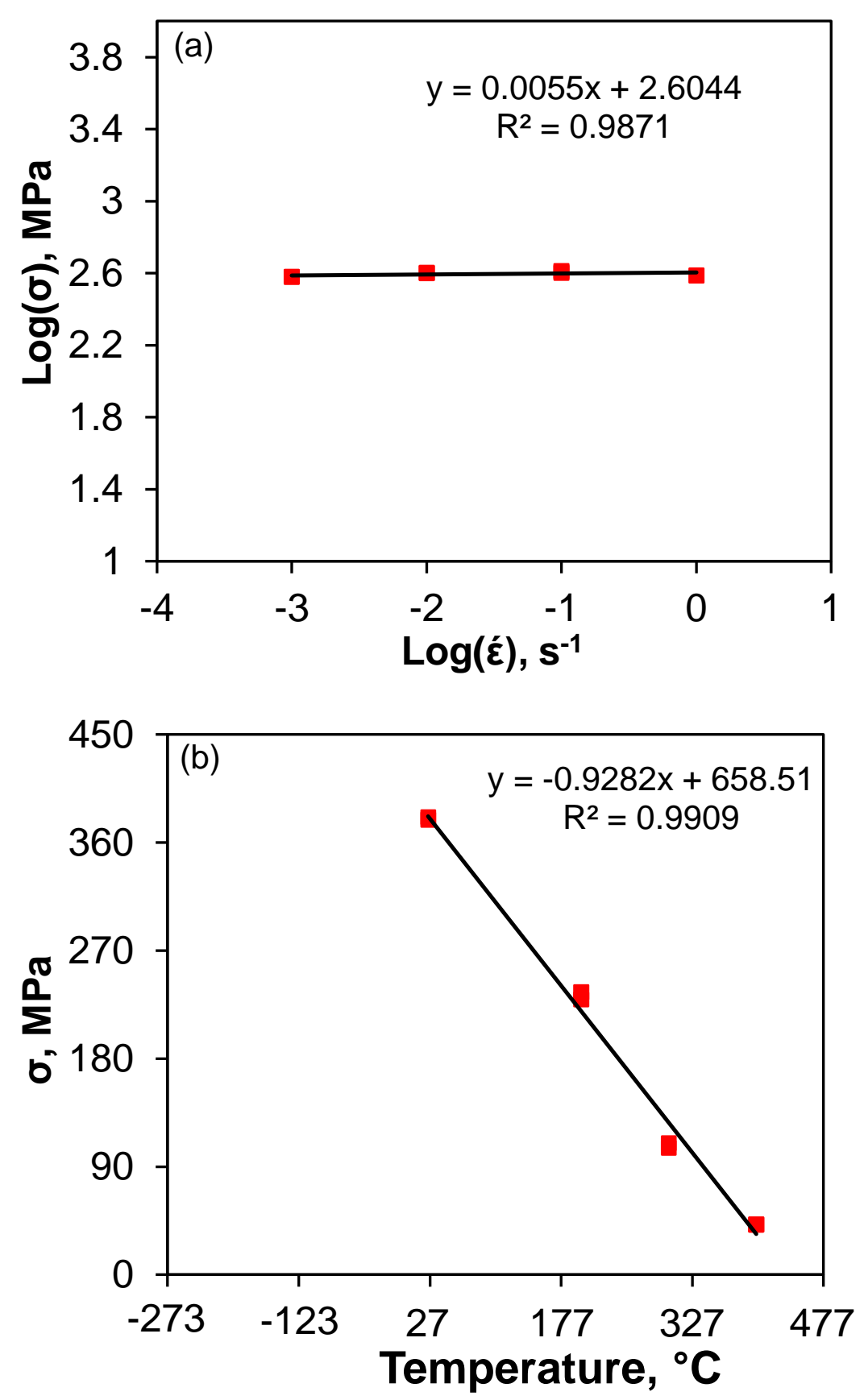

Fig.6.11. (a) Log-log plot of stress vs strain rate to calculate the strain rate sensitivity and (b) linear fitting plot stress vs temperatures to find softening constant $\mathrm{C}$.

All the obtained material constants are listed in Table 6.2, including the values reported in the literature. To examine the predictability of Eq. (6.22) above the critical temperature, the literature data available for lead alloys deformed in tension are used. It is seen from Fig. 6.12 
that in both $\mathrm{Pb}-1.5 \mathrm{Sb}[190,191]$ and $\mathrm{Pb}-10 \mathrm{Sn}[192,193]$ alloys the experimental data are in good agreement with the DSD curve expressed by Eq. (6.22). Then, a comparison of the temperature-dependent DSD predicted from Eq. (6.22) with the experimental data of the present aluminum alloy tested at varying temperatures and other aluminum alloys (AA5754 [160], Al3Si, Al-3Si-1Ag, Al-3Si-1Sn [194], and Al-5Mg [195]) available in the literature is shown in Fig. 6.13. It is clear that Eq. (6.22) can be used to predict well the DSD of the alloys tested at a wide range of deformation temperatures.

Table 6.2 Material constants in Eq. (6.22) for different alloys.

\begin{tabular}{lcccccccc}
\hline Alloy & $\begin{array}{c}A \\
\mathrm{MPa}-\mathrm{s}\end{array}$ & $n^{\prime \prime}$ & $\varepsilon$ & $\begin{array}{c}\dot{\varepsilon} \\
\mathrm{s}^{-1}\end{array}$ & $m$ & $\begin{array}{c}C \\
\mathrm{~K}^{-1}\end{array}$ & $\begin{array}{c}G \\
\mathrm{MPa}\end{array}$ & $\begin{array}{c}b \\
\mathrm{~nm}\end{array}$ \\
\hline $\mathrm{Pb}-1.5 \% \mathrm{Sb}^{*}$ & 25 & 0.29 & 0.16 & 1000 & $0.17^{\ddagger}$ & 0.0018 & 6000 & 0.35 \\
\hline $\mathrm{Pb}-10 \% \mathrm{Sn}^{\dagger}$ & 1968 & 0.19 & 0.17 & 0.01 & $0.6^{\S}$ & 0.0021 & 6000 & 0.35 \\
\hline Present study & 1053 & 0.18 & 0.35 & 0.001 & 0.0055 & 0.0014 & 27000 & 0.29 \\
\hline
\end{tabular}

Experimental data collected from: ${ }^{*}$ Fawzy et al. [190]; ${ }^{\dagger}$ Sakr et al. [191]; ${ }^{\dagger}$ El-Sayed et al. [192]; ${ }^{\S}$ Kashyap and Murty [193]

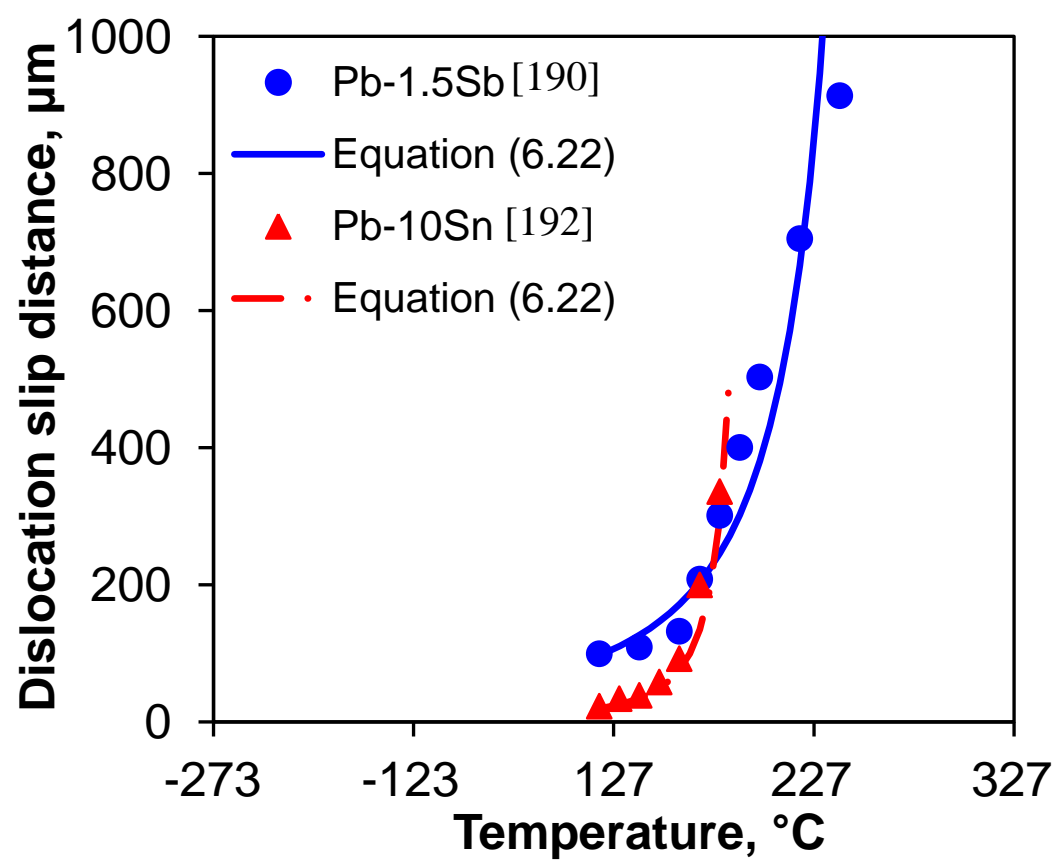

Fig. 6.12. A comparison between the dislocation slip distances predicted from Eq. (6.22) and the experimental data for alloys of $\mathrm{Pb}-1.5 \% \mathrm{Sb}$ and $\mathrm{Pb}-10 \% \mathrm{Sn}$. 

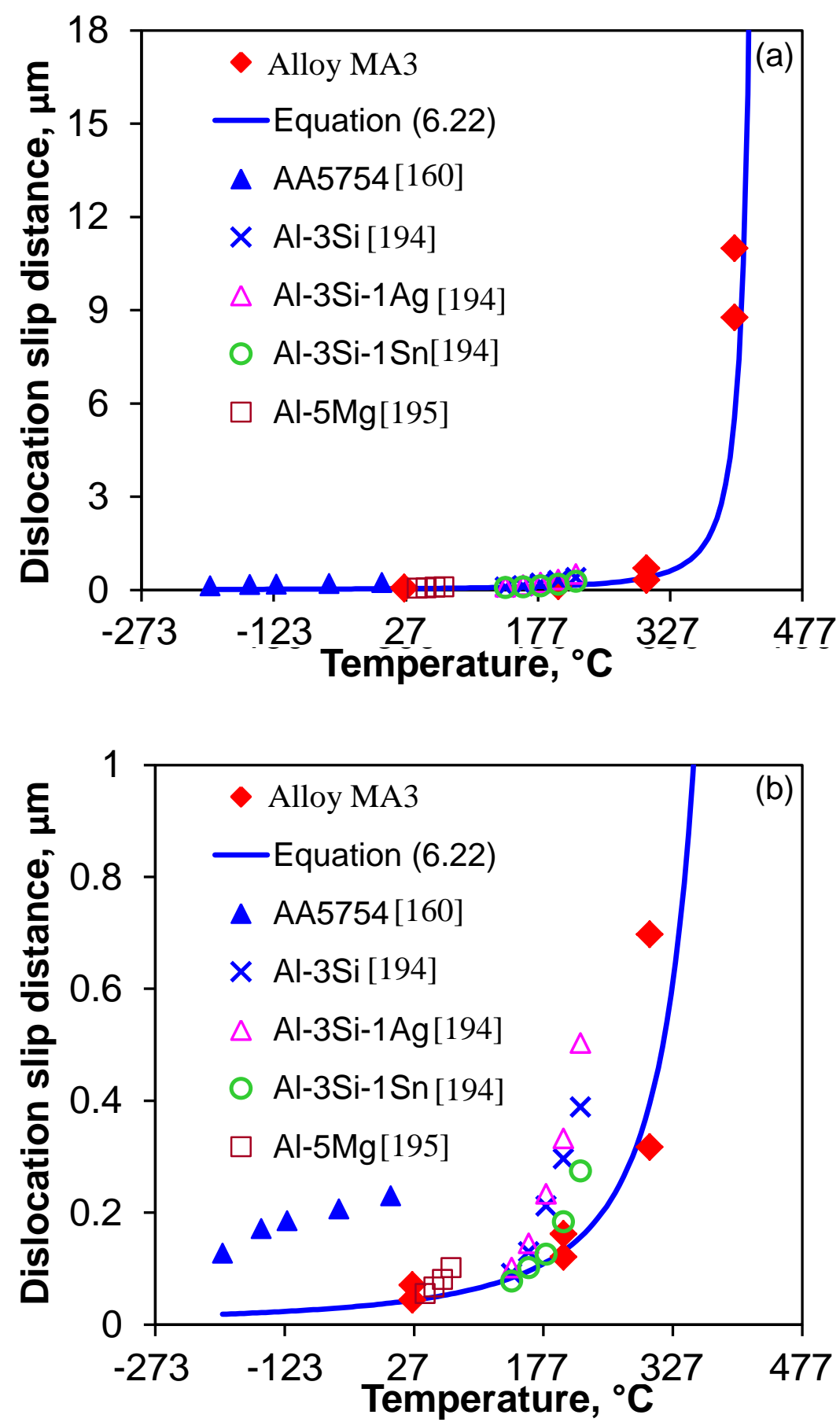

Fig. 6.13. (a) A comparison of the dislocation slip distance predicted from Eq. (6.22) with the experimental data of the Al-Si-Cu-Mg alloy and other Al alloys available in the literature, (b) magnified view of slip distance up to $1 \mu \mathrm{m}$.

While the literature data covered varying temperature segments, the present tests covered a wider range of deformation temperatures. When the deformation temperature reaches a critical temperature of about $357 \sim 377{ }^{\circ} \mathrm{C}$, a drastic increase in DSD occurred, corresponding to the 
change in the deformation mechanisms. The temperature for the dramatic increase of DSD is lower in the lead alloys $\left(\sim 147^{\circ} \mathrm{C}\right.$, Fig. 6.12) than in the aluminum alloys (Fig. 6.13). This is understandable since the high-temperature deformation resistance of an alloy is associated with its melting point $\left(T_{m}\right)$. When the temperature is above $\sim 0.6 T_{m}$, the deformation would also involve creep flow [196], e.g., grain boundary gliding. From the binary phase diagrams the melting point of the $\mathrm{Al}-\mathrm{Si}, \mathrm{Pb}-1.5 \mathrm{Sb}$ and $\mathrm{Pb}-10 \mathrm{Sn}$ is estimated to be $\sim 577, \sim 315$ and $\sim 275{ }^{\circ} \mathrm{C}$. Then the temperature for the onset of creep deformation would be about $56-80{ }^{\circ} \mathrm{C}$ for the lead alloys, which is lower than that of the present cast aluminum alloy $\left(\sim 237^{\circ} \mathrm{C}\right)$, corresponding well to the lower critical temperature for the lead alloys than for the aluminum alloy.

At elevated temperatures, dynamic recrystallization (DRX) is more active compared to dynamic recovery. The DRX involves the nucleation and growth of new grains during deformation. During DRX more rapid annihilation of dislocations occurs which enhances the mobility of dislocations; dislocation substructure also induces the nucleation of sub-grains which allows the migration of grain boundaries $[179,197]$. All of these factors result in an increasing DSD with increasing temperature. It is also observed from Fig.6.13 that the changing rate of DSD (i.e., the slope $d L / d T$ ) in $\mathrm{Pb}-10 \mathrm{Sn}$ is steeper than that in $\mathrm{Pb}-1.5 \mathrm{Sb}$ above the critical temperature. Besides the lower melting point, the $\mathrm{Pb}-10 \mathrm{Sn}$ alloy exhibits a phase transformation from $\alpha+\beta$ to $\alpha$ at $\sim 140{ }^{\circ} \mathrm{C}$ which is lower than the critical temperature $\left(\sim 147{ }^{\circ} \mathrm{C}\right)$, while the phase transformation of $\mathrm{Pb}-1.5 \mathrm{Sb}$ alloy occurs at $\sim 155{ }^{\circ} \mathrm{C}$ which is higher than the critical temperature. Therefore, the movement of dislocations in $\mathrm{Pb}-10 \mathrm{Sn}$ is more pronounced than that in $\mathrm{Pb}-1.5 \mathrm{Sb}$ alloy, leading to a more drastic increase of DSD with increasing deformation temperature. 


\subsection{Chapter Summary}

The uniaxial compression test was used to assess an influence of the precipitate nature on the flow stress, work hardening and dislocation slip distance of the $\mathrm{Al}-7 \% \mathrm{Si}-1 \% \mathrm{Cu}-0.5 \% \mathrm{Mg}$ alloy, modified with micro-additions of $\mathrm{V}, \mathrm{Zr}$ and $\mathrm{Ti}$. A semi-empirical model, adopted to interpret the work-hardening rate during plastic deformation, was able to predict the contribution of shearable and non-shearable precipitates to the dislocation-induced hardening during compression. At the same time, a new constitutive equation for the temperature-dependent dislocation slip distance was developed, based on Mott's theory of strain hardening. The dislocation slip distance predicted by the model was in good agreement not only with values achieved for the Al-Si-Cu-Mg alloy tested but also for other Al-based and $\mathrm{Pb}-\mathrm{Sb}$ alloys with deformation data available in the literature. It is concluded that while work hardening of the alloy during compression deformation at room temperature is affected mainly by non-shearable, coarse precipitates, the slip distance is controlled by the testing temperature. (Note: Most of the data of this chapter 5 was collected from the published as listed in Section 9.3). 


\section{CHAPTER 7}

\section{COMPRESSIVE DEFORMATION BEHAVIOR OF THE CAST MODIFIED Al-Si-Cu-Mg ALLOYS ${ }^{4}$}

\subsection{Introduction}

There is a continuous effort to improve the high temperature performance of aluminum alloys where one of a number of avenues being explored is an addition of transition metals. The properties of Al-Si alloys were modified by introducing Fe, Ni and Cr transition metals [198, 199, 200]. Compared to other transition metals, Ti, V and Zr have low diffusivity and solubility in $\mathrm{Al}$ and form thermally stable intermetallics that are promising in maintaining high strength at temperatures up to $350^{\circ} \mathrm{C}[63,100]$. In recent studies, Mohamed et al. [22, 96] showed that additions of $\mathrm{Ti}, \mathrm{Zr}$ and $\mathrm{Ni}$ in the $\mathrm{Al}-\mathrm{Si}-\mathrm{Cu}-\mathrm{Mg}$ alloy could improve their high temperature strength. They also reported that the combinations exceeding $0.2 \% \mathrm{Zr}$ and $0.2 \% \mathrm{Ni}$ in the Al-Si$\mathrm{Cu}-\mathrm{Mg}$ base decreased the alloy performance. The previous studies have been focused mainly on determining various material constants in the constitutive equations describing the hot deformation behavior [201, 202, 203, 204, 205, 206, 207]. However, according to the authors' knowledge, there has been no study on the impact of addition of transition metals, especially $\mathrm{Ti}$, $\mathrm{V}$ and $\mathrm{Zr}$ in $\mathrm{Al}-\mathrm{Si}-\mathrm{Cu}-\mathrm{Mg}$ alloys on the hot deformation behavior. It is also not clear how these additions influence the dynamic recrystallization and the flow stress of the alloy. There is also no assessment of the behavior of complex intermetallic phases, formed in Al-based alloys modified with the addition of $\mathrm{Ti}, \mathrm{V}$ and $\mathrm{Zr}[71,163,162,158,208]$. Besides the influence of simultaneous additions of $\mathrm{Ti}, \mathrm{V}$ and $\mathrm{Zr}$, it is of interest to assess the individual role of each element in this triple combination [101, 102].

\footnotetext{
${ }^{4}$ S.K. Shaha, F. Czerwinski, W. Kasprzak, J. Friedman and D.L. Chen, J. Alloys Compd., Vol. 615, pp 1019-1031, 2014.
} 
The objective of this chapter is to characterize the influence of $\mathrm{V}$ and $\mathrm{Zr}$ on the hot deformation behavior of the Al-Si-Cu-Mg cast alloy containing micro-additions of Ti.

\subsection{High Temperature Deformation Characteristics}

The true stress-true strain compression curves of the MA1 and MA3 alloys, obtained at different temperatures and strain rates, are plotted in Fig. 7.1. As seen in Fig. 7.1a, the testing temperature in the range of $200-400^{\circ} \mathrm{C}$ had a strong effect on the deformation curves of both alloys. By contrast, the strain rate in the range of $1-10^{-3} \mathrm{~s}^{-1}$ had a weaker effect on the deformation behavior at constant temperatures (Fig. 7.1b and c). For all testing conditions, the flow stress increased sharply with increasing true strain during the initial stages of deformation. In all cases, the shape of the deformation curves was similar; i.e. after reaching the peak value, the stress decreased slightly and finally reached a saturation level with further increases in the strain.

An analysis of the compression test results is shown in Fig. 7.2. In general, the strength of both alloys decreased with increasing testing temperature and decreasing strain rate (Fig. 7.2a). It is seen that the peak stress of the base alloy decreased from $316 \mathrm{MPa}$ to $75 \mathrm{MPa}$ with increasing temperature from 200 to $400^{\circ} \mathrm{C}$ at a strain rate of $1 \mathrm{~s}^{-1}$. Similarly, the change of peak stress from $316 \mathrm{MPa}$ to $271 \mathrm{MPa}$ at $200^{\circ} \mathrm{C}$ occurred with decreasing strain rate from $1 \mathrm{~s}^{-1}$ to $10^{-3}$ $\mathrm{s}^{-1}$. The modified alloy MA3 showed higher strength compared to the alloy MA1; i.e. a reduction of the peak stress occurred from $380 \mathrm{MPa}$ to $80 \mathrm{MPa}$ with increasing temperature from 200 to $400^{\circ} \mathrm{C}$ at a constant strain rate of $1 \mathrm{~s}^{-1}$ and from $380 \mathrm{MPa}$ to $286 \mathrm{MPa}$ with decreasing strain rate from $1 \mathrm{~s}^{-1}$ to $10^{-3} \mathrm{~s}^{-1}$ at a constant temperature of $200^{\circ} \mathrm{C}$. To better compare the test results, the contour plot of peak stress, natural logarithm of strain rates and temperatures 
were linearly fitted using Statistica Software. A comparison between plots in Fig. 7.2b and 7.2c shows the influence of modification with $\mathrm{V}$ and $\mathrm{Zr}$ on the change in peak stress.
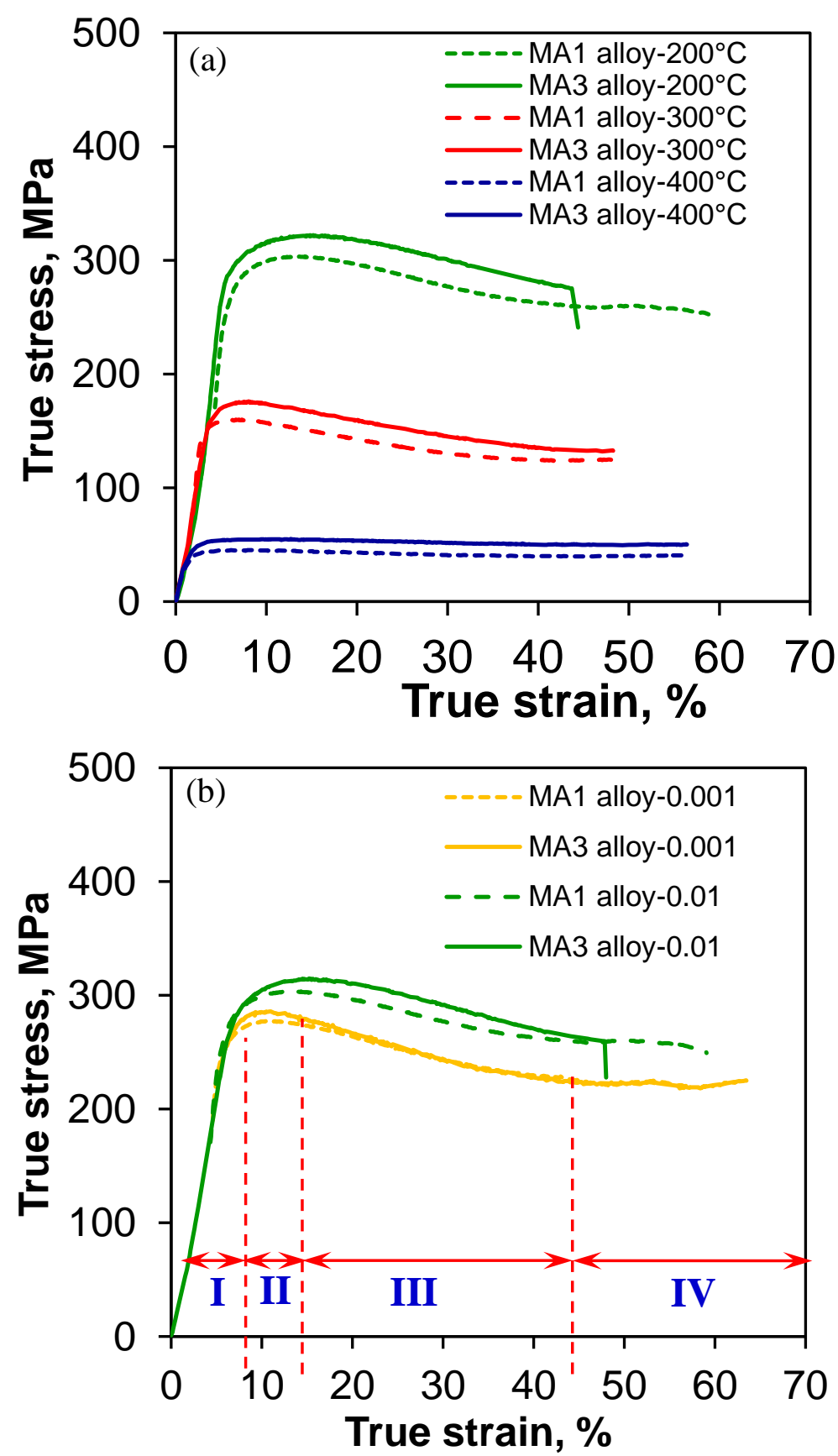

Fig.7. 1. Typical true stress strain behavior of the studied alloys of MA1 and MA3 under uniaxial compression (a) at different temperatures and constant strain rate of $10^{-2} \mathrm{~s}^{-1}$, and $(\mathrm{b}, \mathrm{c})$ at constant temperature of $200^{\circ} \mathrm{C}$ and different strain rates expressed in $\mathrm{s}^{-1}$ (continue to next page). 


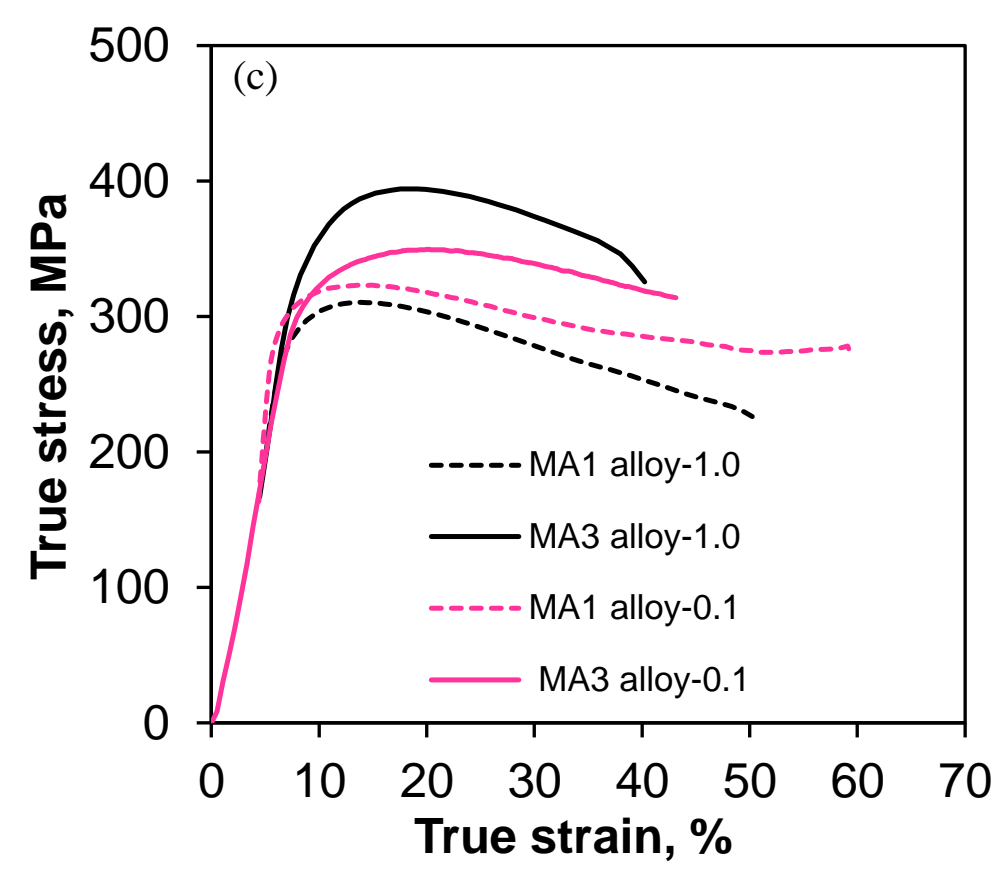

Fig.7. 1. Typical true stress strain behavior of the studied alloys of MA1 and MA3 under uniaxial compression (a) at different temperatures and constant strain rate of $10^{-2} \mathrm{~s}^{-1}$, and (b, c) at constant temperature of $200^{\circ} \mathrm{C}$ and different strain rates expressed in s $\mathrm{s}^{-1}$. Note: Stage I: work hardening stage, Stage II: transition stage, Stage III: softening stage, Stage IV: steady stage.

To emphasize the increase in the alloy strength after modification, a histogram for each deformation temperature was built (Fig. 7.2d). For all testing conditions, the peak stress of the modified alloy was higher with the growth increment being apparently higher for lower deformation temperatures. It is also of interest that the increased peak stress after alloy modification was consistently recorded for all temperatures and deformation rates. For the small additions of $\mathrm{V}$ and $\mathrm{Zr}$ used in this study, the alloy chemistry effect was, however, lower than the influence of temperature and strain rate. 


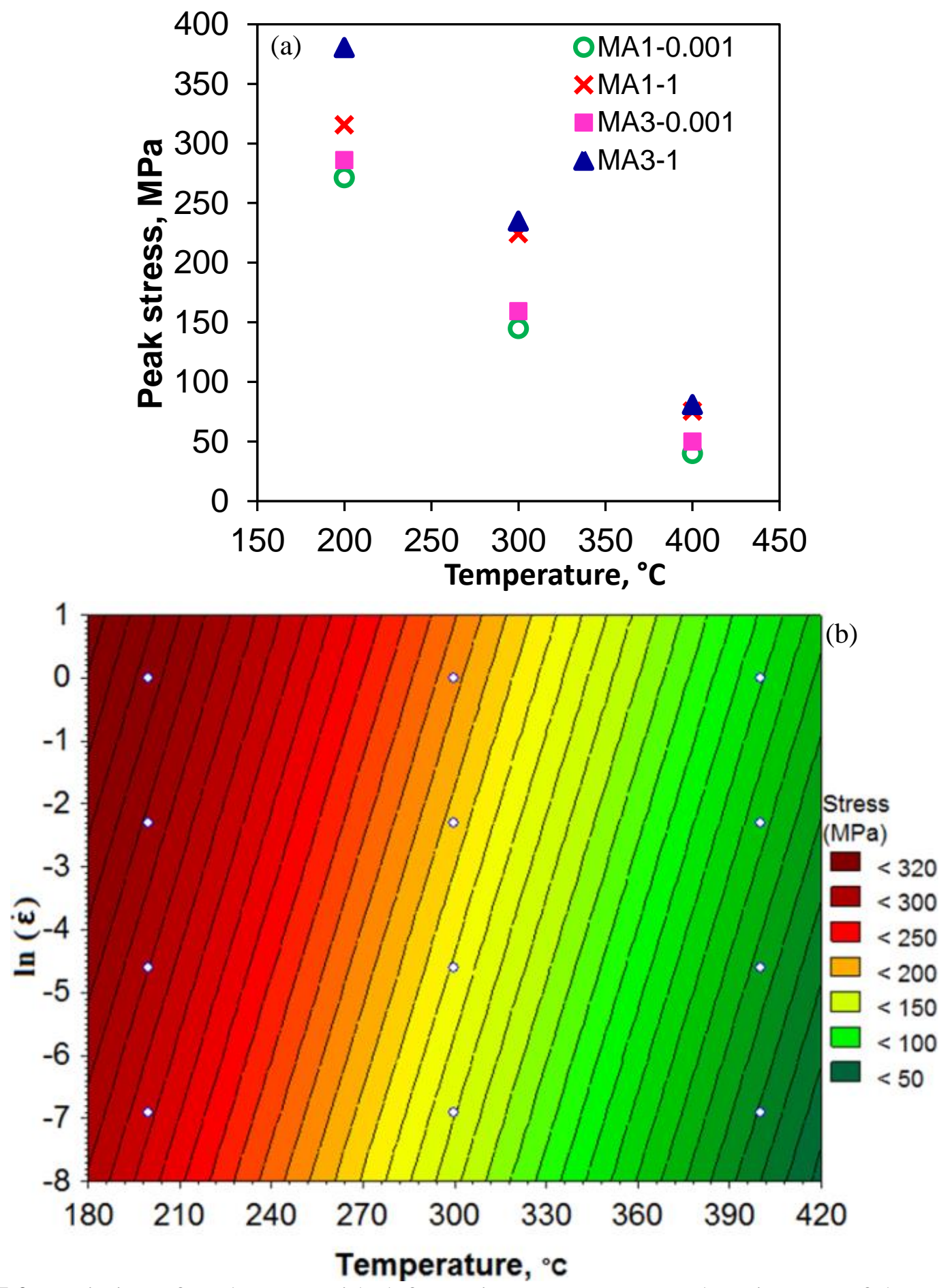

Fig.7.2. Variation of peak stress with deformation temperature and strain rates of the studied alloys, (a) peak stress vs temperature plot for strain rates of $10^{-3} \mathrm{~s}^{-1}$ and $1 \mathrm{~s}^{-1}$; contour plot of peak stress corresponding to temperature and strain rate for, (b) MA1 alloy (continue to next page). 

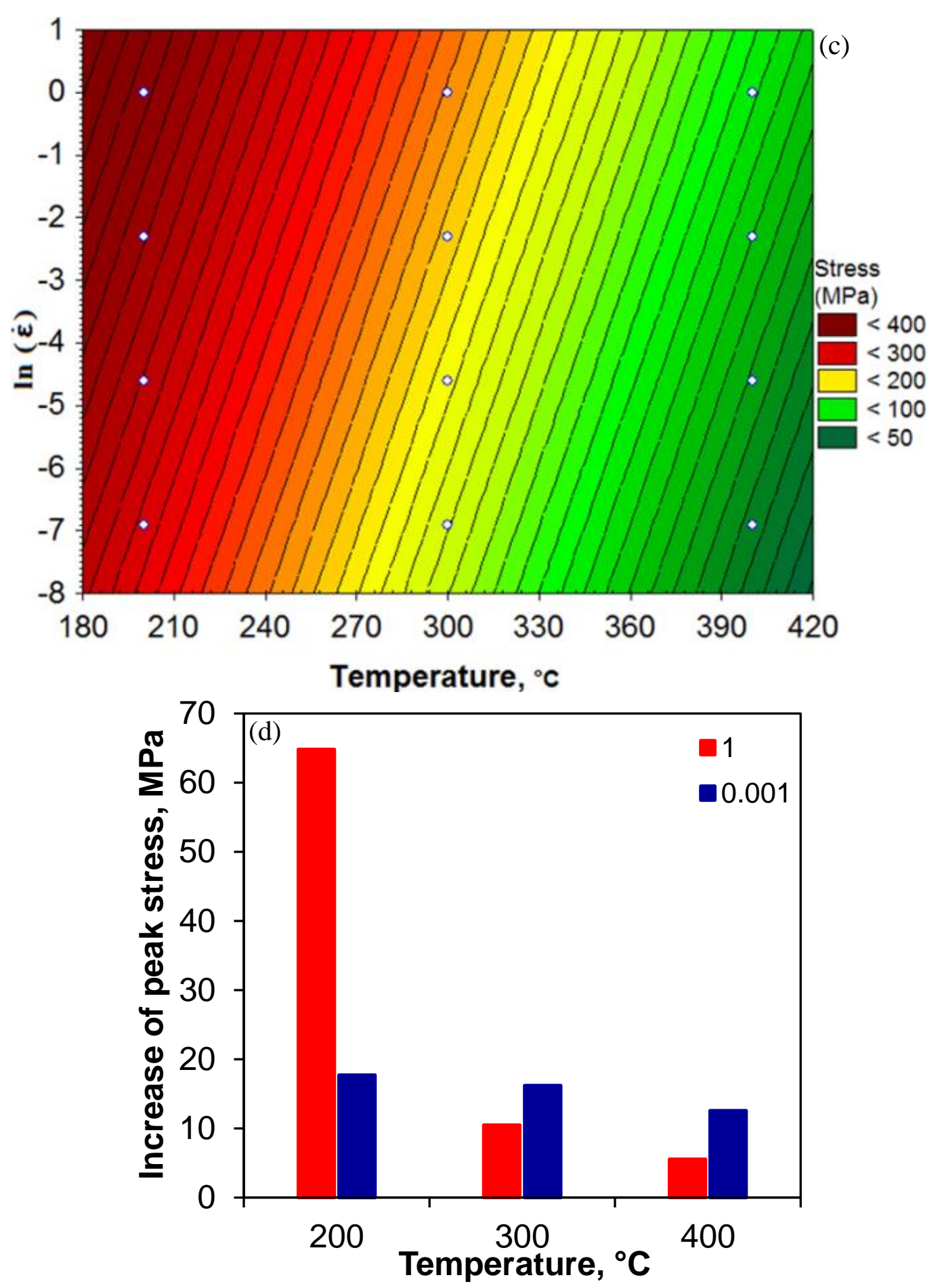

Fig.7.2. Variation of peak stress with deformation temperature and strain rates of the studied alloys, (a) peak stress vs temperature plot for strain rates of $10^{-3} \mathrm{~s}^{-1}$ and $1 \mathrm{~s}^{-1}$; contour plot of peak stress corresponding to temperature and strain rate for, (b) MA1 alloy and (c) MA3 alloy, (d) peak stress increase calculated as a difference in peak stress between the MA3 and the MA1 alloy for different testing temperatures and strain rates of 1 and $10^{-3} \mathrm{~s}^{-1}$. 


\subsection{Constitutive Equations}

Several constitutive equations are commonly used to calculate the material constants during hot deformation. The related parameters, such as peak stress, temperature, strain rate, etc., can be expressed using the following equations $[185,201]$ :

$$
\begin{gathered}
Z=\dot{\varepsilon} \exp \left(\frac{Q}{R T}\right) \\
\dot{\varepsilon}=A_{1} \sigma^{m_{1}} \exp \left(-\frac{Q}{R T}\right) \\
\dot{\varepsilon}=A_{2} \exp \left(\beta_{1} \sigma\right) \exp \left(-\frac{Q}{R T}\right) \\
\dot{\varepsilon}=A_{3}[\sinh (\alpha \sigma)]_{2}^{n} \exp \left(-\frac{Q}{R T}\right) \\
Z=A_{3}[\sinh (\alpha \sigma)]_{2}^{n}
\end{gathered}
$$

where $n_{2}, m_{1}, \alpha, \beta_{l}, A_{l}, A_{2}$, and $A_{3}$ are constants independent of temperature, $\alpha=\beta_{l} / m_{l}, \sigma$ is the flow stress in $\mathrm{MPa}, \dot{\varepsilon}$ is the strain rate in $\mathrm{s}^{-1}, Q$ is the activation energy of deformation in $\mathrm{kJ} / \mathrm{mol}, R$ is the universal gas constant, $T$ is the temperature in Kelvin, and $Z$ is the ZenerHollomon's parameter. The power law, Eq. (7.2), and the exponential law, Eq. (7.3), break down at high stress and at low stress, respectively. The hyperbolic Sine law, Eq. (7.4), is a more general one, suitable for a wider range of stresses.

The linear plots of $\ln \dot{\varepsilon}-\ln \sigma$ and $\ln \dot{\varepsilon}-\sigma$ for the MA1 and MA3 alloys are shown in Fig.7.3a and Fig. 7.3b, respectively. From the line slope plots in both graphs, the average values of $m_{l}$ and $\beta_{1}$ were calculated and $\alpha=\beta_{1} / m_{1}$ was applied for the remaining equations. The obtained material constants for both alloys are listed in Table 7.1. 

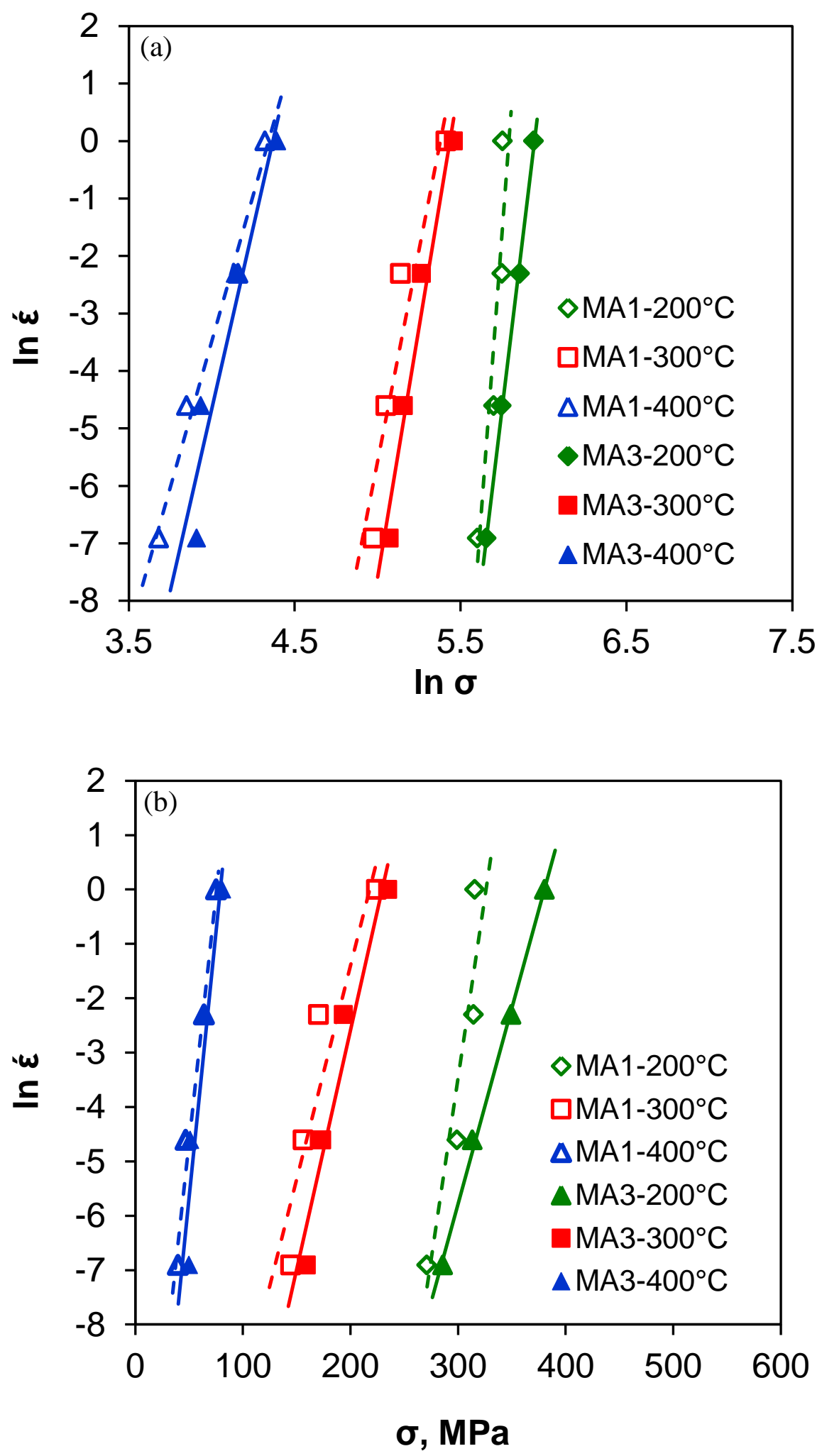

Fig. 7.3. The relationship of peak stress, strain rate and temperature of the MA1 and MA 3 alloys (a) $\ln (\dot{\varepsilon})$ versus $\ln (\sigma)$, and (b) $\ln (\dot{\varepsilon})$ versus $\sigma$. 
Table 7.1 Material constants of the hot deformed cast aluminum alloy, evaluated from the constitutive equation.

\begin{tabular}{lcccccc}
\hline & $m_{1}$ & $\beta_{1}$ & $\alpha$ & $\begin{array}{c}Q, \\
\mathrm{~kJ} / \mathrm{mol}\end{array}$ & $\begin{array}{c}A_{3}, \\
\mathrm{~s}^{-1}\end{array}$ & $n_{2}$ \\
\hline Base alloy & 0.13 & 24.76 & 0.005 & 282.6 & $5.0 \times 10^{23}$ & 9.1 \\
\hline Modified alloy & 0.20 & 12.66 & 0.015 & 315.2 & $2.6 \times 10^{25}$ & 9.1 \\
\hline
\end{tabular}

\subsubsection{Activation energy of hot deformation}

The activation energy of hot deformation $Q$ is an important physical parameter indicating how difficult the plastic deformation of the alloy is. After partial differentiation of Eq. (7.4), the activation energy for deformation can be calculated as follows:

$$
Q=R\left[\frac{d \ln \dot{\varepsilon}}{\operatorname{dln}[\sinh (\alpha \sigma)]}\right]_{T} \cdot\left[\frac{d \ln [\sinh (\alpha \sigma)]}{d(1 / T)}\right]_{\dot{\varepsilon}}
$$

The activation energy of deformation, $Q$, was determined to be 282.6 and $315.2 \mathrm{~kJ} / \mathrm{mol}$ (Fig. 7.4) for the MA1 and MA3 alloys, respectively. It should be noted that the value of $Q$ for the modified alloy MA3 of $315.2 \mathrm{~kJ} / \mathrm{mol}$ is higher than value of $282.6 \mathrm{~kJ} / \mathrm{mol}$ obtained for the MA1 alloy. At the same time, values are higher than $154 \mathrm{~kJ} / \mathrm{mol}$, reported as the activation energy for deformation of the thixocast A356 alloy [185] and similar to the $312.7 \mathrm{~kJ} / \mathrm{mol}$ reported for the spray-formed hypereutectic Al alloy [201]. 

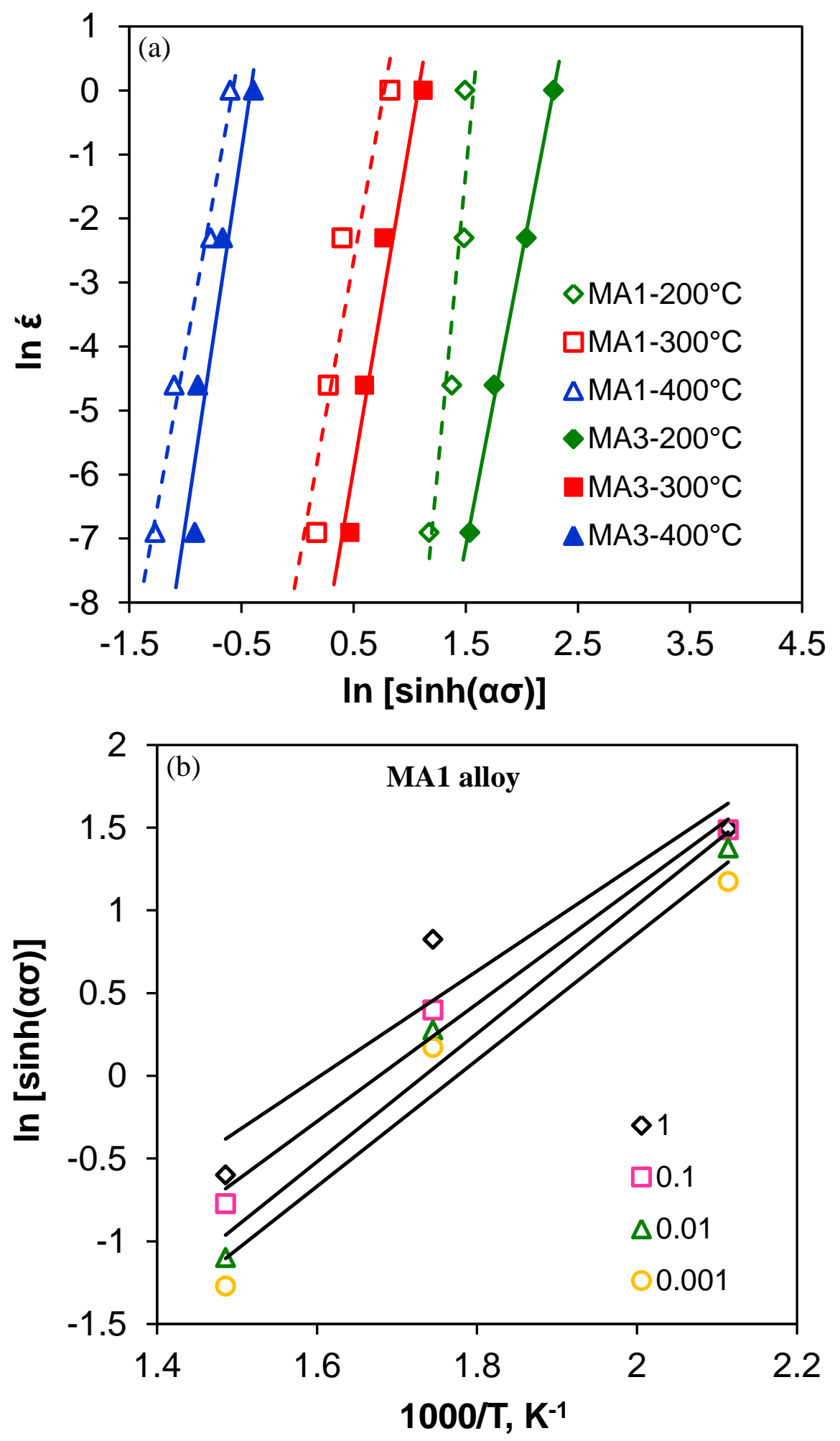

Fig. 7.4. Plots of peak stress, strain rate and temperature of the alloys: (a) $\ln (\varepsilon)$ versus $\ln [\sinh (\alpha \sigma)]$ of the MA1 and MA3 alloys; (b) $\ln [\sinh (\alpha \sigma)]$ versus $1000 /$ T of the base; (c) $\ln [\sinh (\alpha \sigma)]$ versus $1000 /$ T of the modified alloy. Strain rates are expressed in $\mathrm{s}^{-1}$. (continue to next page) 


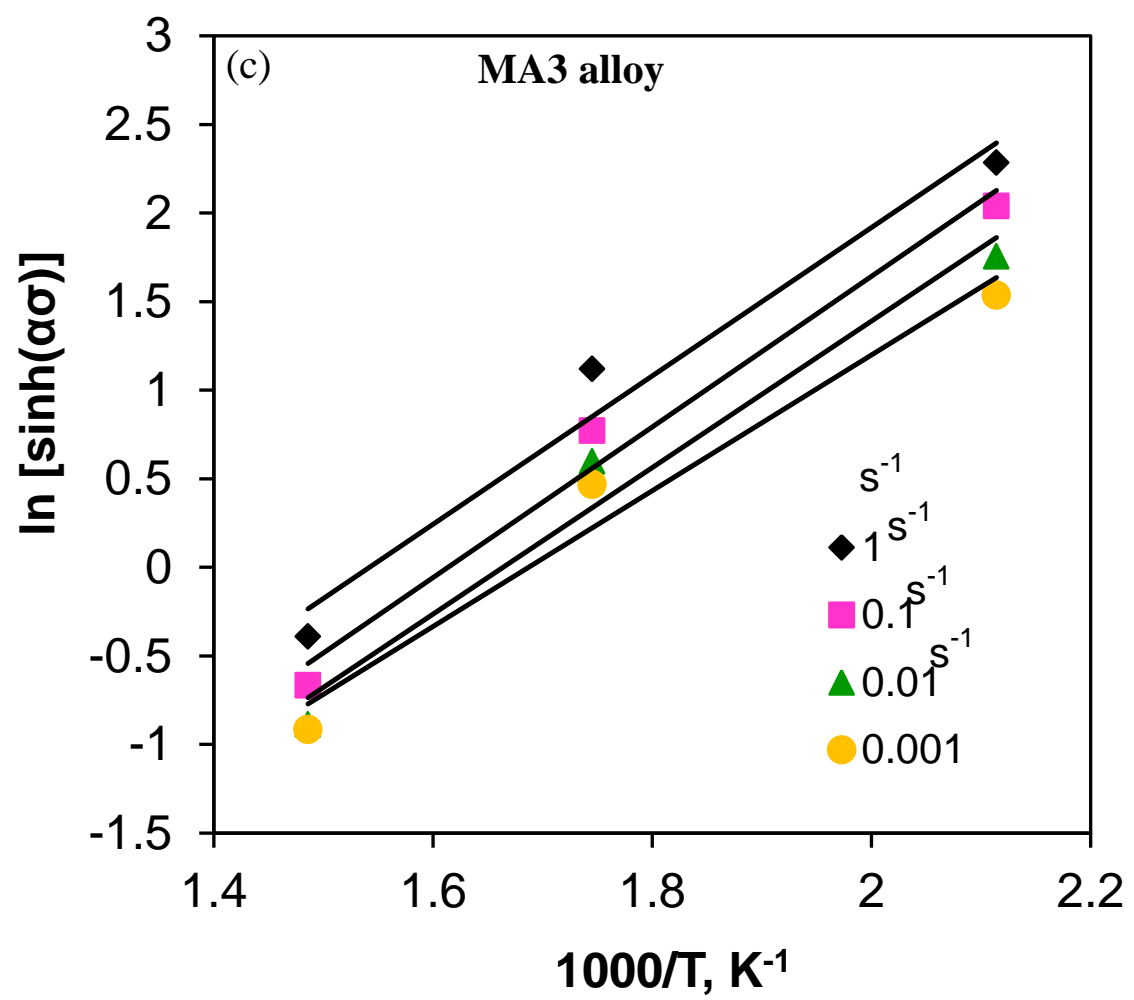

Fig. 7.4. Plots of peak stress, strain rate and temperature of the alloys: (a) $\ln (\dot{\varepsilon})$ versus $\ln [\sinh (\alpha \sigma)]$ of the MA1 and MA3 alloys; (b) $\ln [\sinh (\alpha \sigma)]$ versus $1000 /$ T of the base; (c) $\ln [\sinh (\alpha \sigma)]$ versus $1000 / \mathrm{T}$ of the modified alloy. Strain rates are expressed in $\mathrm{s}^{-1}$.

\subsubsection{Zener-Hollomon parameter}

At temperatures where thermally activated deformation and recovery processes occur, the microstructural evolution is dependent on the deformation temperature $(T)$ and strain rate $(\dot{\varepsilon})$ in addition to the strain level $(\varepsilon)$. The strain rate and deformation temperature are often incorporated into a single parameter of Zener-Hollomon $(Z)$, which can be calculated using Eq. (7.1). The values of the Zener-Hollomon's parameter for testing temperatures and strain rates are listed in Table 7.2. For the alloy MA1 at a temperature of $200^{\circ} \mathrm{C}$, the $\mathrm{Z}$ value grew from $1.8 \times 10^{28}$ to $1.8 \times 10^{31} \mathrm{~s}^{-1}$ with increasing the strain rate from $10^{-3}$ to $1 \mathrm{~s}^{-1}$. Although the modified alloy MA3 showed a similar tendency of changes, the $\mathrm{Z}$ values being in the range from $8.7 \times 10^{34}$ to $8.7 \times 10^{31} \mathrm{~s}^{-1}$ were higher than that for the alloy MA1 for all testing conditions. 
Table 7.2 The calculated Zener-Hollomon parameter of the MA1 and MA3 alloys at different strain rates and corresponding temperatures (DRV - dynamic recovery; DDRX - discontinuous dynamic recrystallization; CDRX - continuous dynamic recrystallization).

\begin{tabular}{|c|c|c|c|c|c|c|}
\hline \multirow{3}{*}{$\begin{array}{c}\text { Strain rates, } \\
\mathrm{s}^{-1} \\
\begin{array}{c}\text { Temperature, } \\
{ }^{\circ} \mathrm{C}\end{array}\end{array}$} & \multicolumn{3}{|c|}{$\begin{array}{c}\text { Zener-Hollomon parameter, Z, of } \\
\text { alloy MA1 }\end{array}$} & \multicolumn{3}{|c|}{$\begin{array}{l}\text { Zener-Hollomon parameter, } \mathrm{Z} \text {, of alloy } \\
\text { MA3 }\end{array}$} \\
\hline & \multicolumn{3}{|c|}{ DRV $\longrightarrow$ DDRX } & \multicolumn{3}{|c|}{ DRV $\longrightarrow$ CDRX } \\
\hline & 200 & 300 & 400 & 200 & 300 & 400 \\
\hline 1 & $1.8 \times 10^{31}$ & $6.3 \times 10^{25}$ & $9.3 \times 10^{21}$ & $8.9 \times 10^{34}$ & $7.1 \times 10^{28}$ & $3.6 \times 10^{24}$ \\
\hline 0.1 & $18 \times 10^{30}$ & $6.3 \times 10^{24}$ & $9.3 \times 10^{20}$ & $8.9 \times 10^{33}$ & $7.1 \times 10^{27}$ & $3.6 \times 10^{23}$ \\
\hline 0.01 & $1.8 \times 10^{29}$ & $6.3 \times 10^{23}$ & $9.3 \times 10^{19}$ & $8.9 \times 10^{32}$ & $7.1 \times 10^{26}$ & $3.6 \times 10^{22}$ \\
\hline 0.001 & $1.8 \times 10^{28}$ & $6.3 \times 10^{22}$ & $9.3 \times 10^{18}$ & $8.9 \times 10^{31}$ & $7.1 \times 10^{25}$ & $3.6 \times 10^{21}$ \\
\hline
\end{tabular}

From the plot of $\ln [\sinh (\alpha \sigma)]-\ln Z$, the material constants $A_{3}$ and $n_{2}$ were determined (Fig. 7.5a). As indicated on the plot in Fig. 7.5b and Table 7.2, at lower temperatures and higher strain rates, $Z$ exhibits higher values emphasizing a domination of the dislocation generation supporting the fact that work hardening results in the higher peak stress. Conversely, at higher temperatures and at lower strain rates, $Z$ reached lower values, which implies that dynamic recovery and dynamic recrystallization occurred, thus causing a reduction in the peak stress. A similar trend was reported by Jin et al. [206] during hot compression of the AA7150 wrought aluminum alloy, tested at various strain rates and temperatures. According to that study, the microstructure of the deformed alloy was influenced by dynamic recrystallization, which could be related to the value of the Zener-Hollomon's parameter.

\subsection{Microstructure Evolution during Deformation}

The optical micrographs of the alloys deformed at a strain rate of $10^{-3} \mathrm{~s}^{-1}$ and a temperature of 200 and $400^{\circ} \mathrm{C}$ are shown in Fig. 7.6. It is clear that no new grains formed within the microstructure of both alloys compressed at a lower temperature of $200^{\circ} \mathrm{C}$ (Fig. $7.6 \mathrm{a}$ and c). However, with increasing testing temperature, the microstructure of the base alloy revealed well developed grains with incomplete grain boundaries, suggesting the occurrence of discontinuous 
dynamic recrystallization (DDRX) (Fig. 7.6b). In contrast, the modified alloy showed relatively fine grains, which support the continuous dynamic recrystallization (CDRX) occurring, possibly due to a presence of $\mathrm{V}$ and $\mathrm{Zr}$ additions.
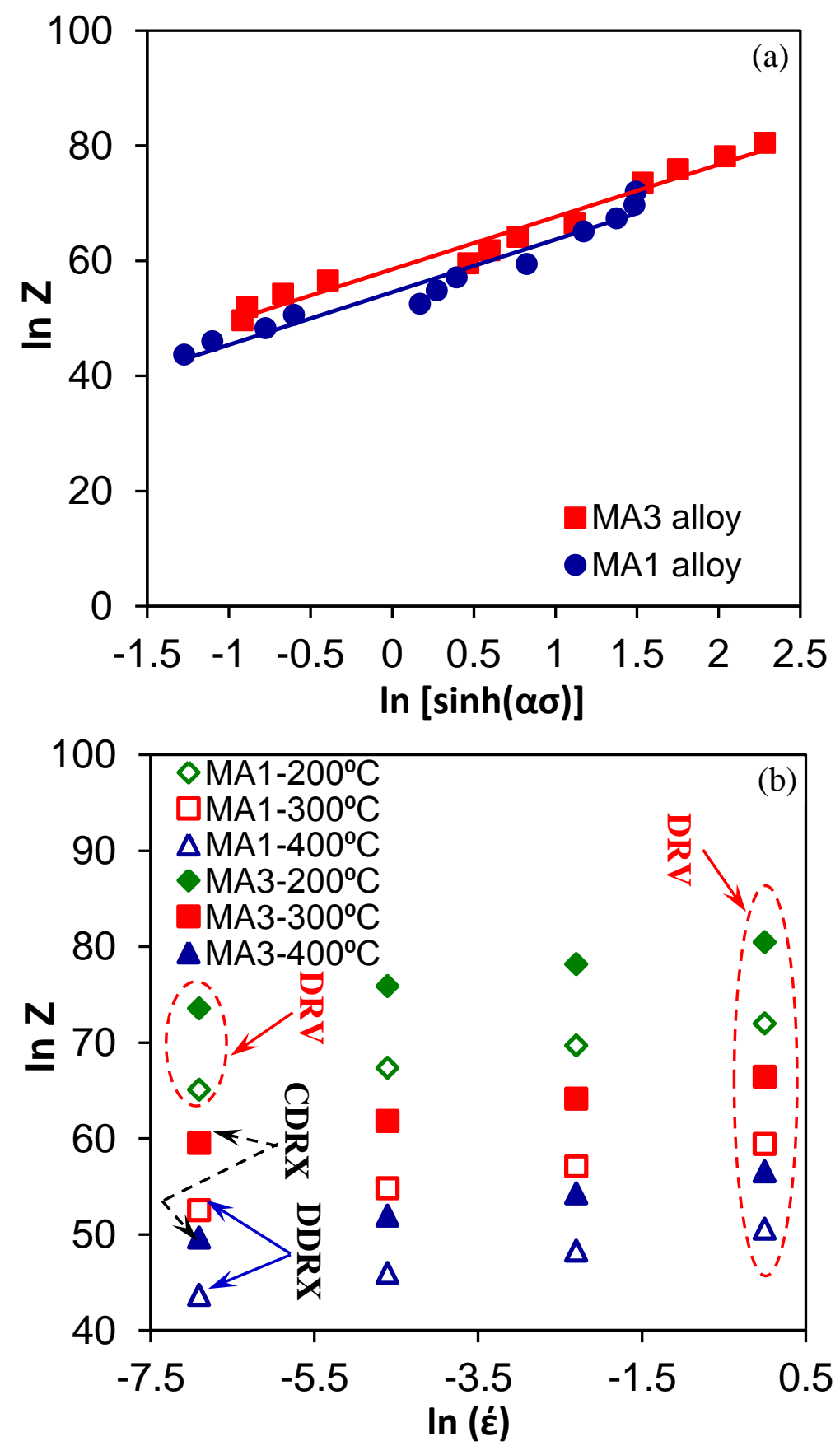

Fig. 7.5. (a) Typical plot of $\ln Z$ vs. $\ln [\sinh (\alpha \sigma)]$ of Zener-Hollomon parameter and peak stress at different strain rates and temperatures of the MA1 and MA3 alloys, and (b) the relationship between Zener-Holomon parameter and strain rates at different temperatures. 

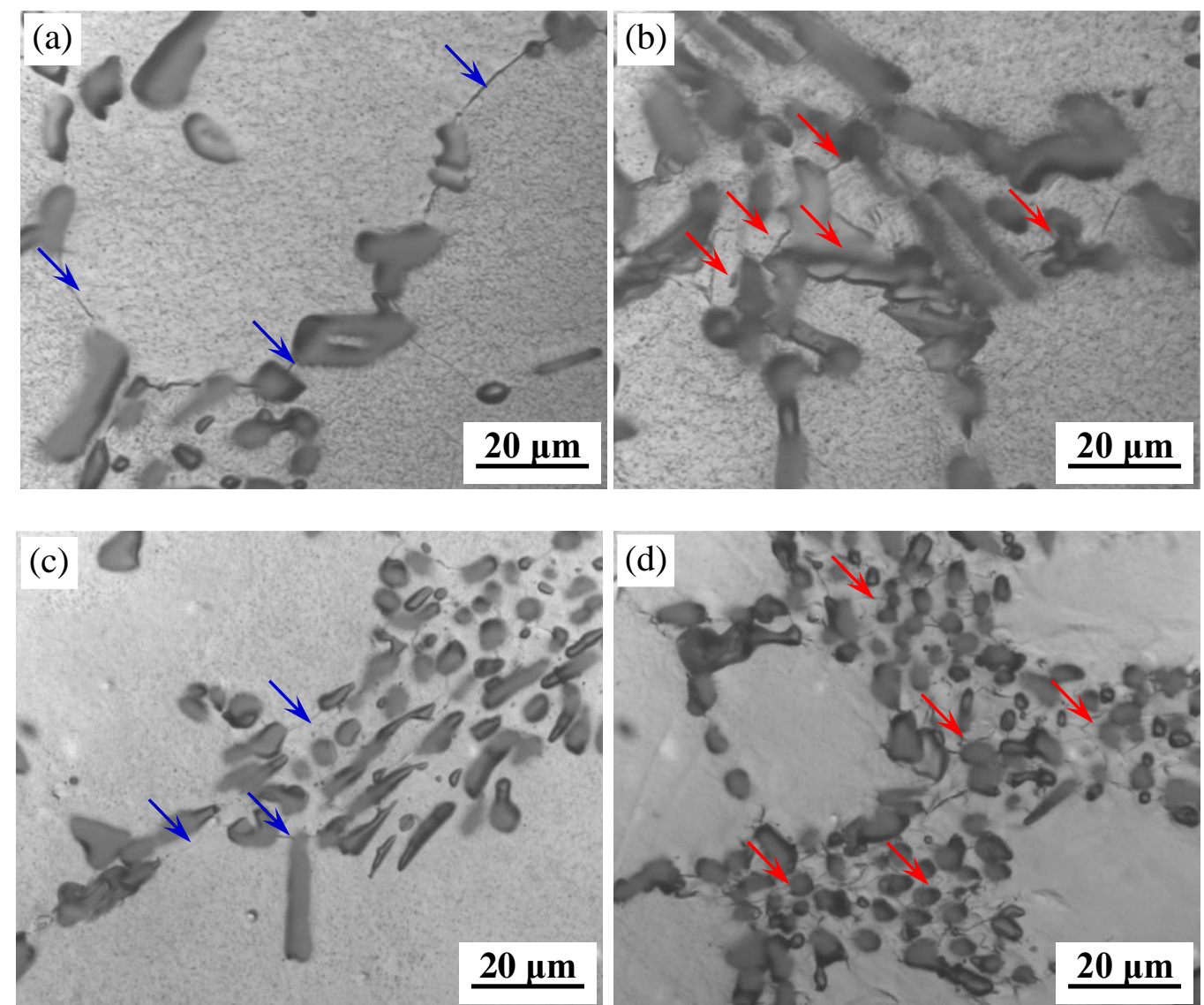

Fig. 7.6. Microstructure of etched Al-Si-Cu-Mg alloy after hot deformation at a strain rate of $10^{-}$ ${ }^{3} \mathrm{~s}^{-1}$ and different temperatures: (a) MA1 alloy deformed at $200^{\circ} \mathrm{C}$; (b) MA1 alloy deformed at $400^{\circ} \mathrm{C}$; (c) MA3 alloy defromed at $200^{\circ} \mathrm{C}$; (d) MA3 alloy deformed at $400^{\circ} \mathrm{C}$. The red and blue arrows indicate the recrystalized grains, and grain boundary without recrystalization, respectively.

\subsubsection{Effect of temperature on precipitate cracking}

The microstructure emphasizing precipitates in the MA1 and MA3 alloys after compression at 200 and $400^{\circ} \mathrm{C}$ is shown in Fig. 7.7 and Fig. 7.8. Examples of particle chemistry determined by SEM/EDX are given in chapter 4 . In this chapter, precipitates are divided based on the image contrast in optical microscope images into eutectic silicon and intermetallics. As seen in Fig. 7.7 and Fig. 7.8, cracking of the eutectic silicon particles and intermetallics occurred. In both alloys, cracks tend to be parallel to the macroscopic compression axis, indicating that fracturing was caused by the local shear stress. 

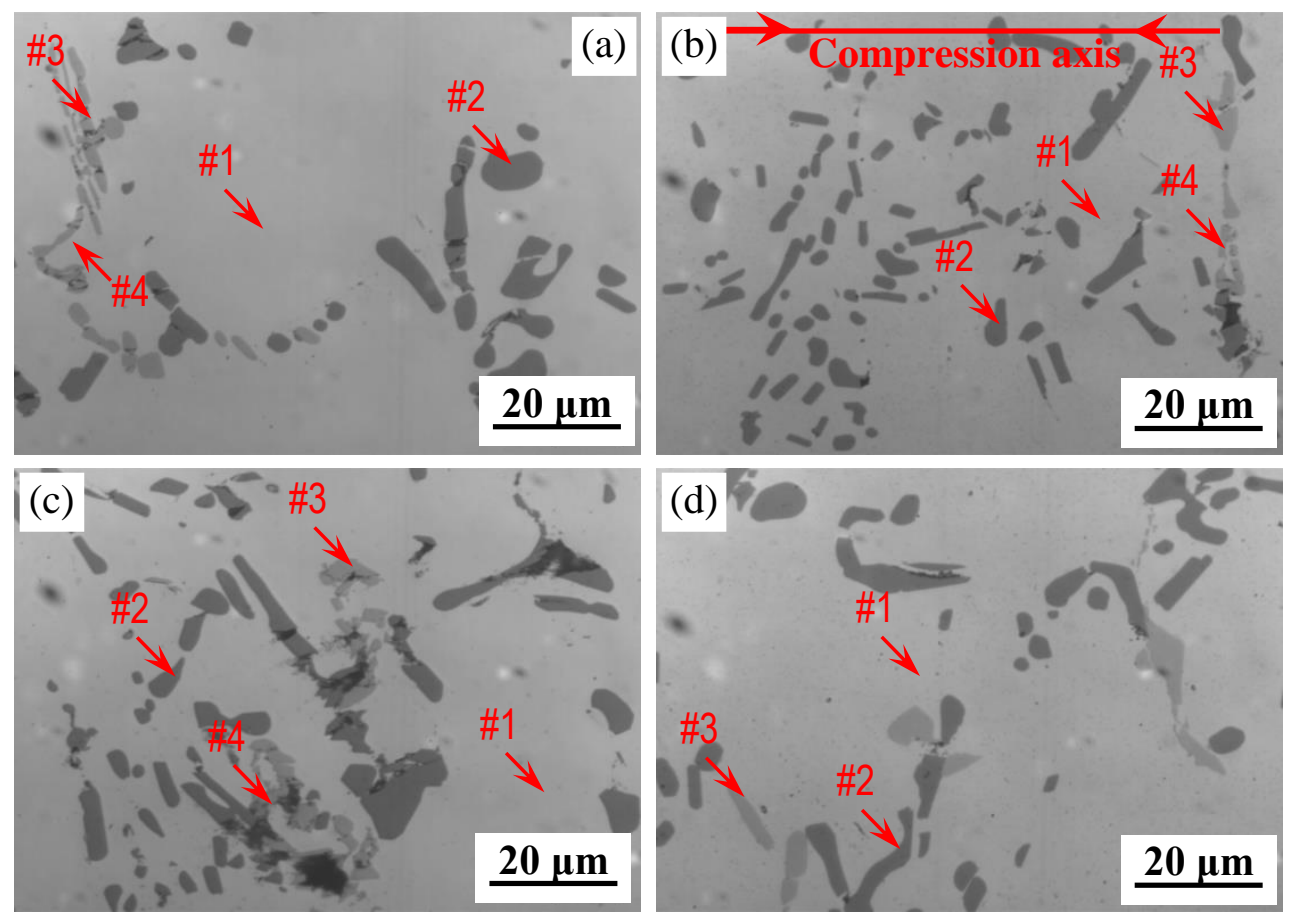

Fig. 7.7. Precipitate particle cracking in the MA1 alloy after compression tests at strain rates of $1 \mathrm{~s}^{-1}$ and temperatures of (a) $200^{\circ} \mathrm{C}$ and (b) $400^{\circ} \mathrm{C}$, and strain of $10^{-3} \mathrm{~s}^{-1}$ and temperatures of (c) $200^{\circ} \mathrm{C}$ and (d) $400^{\circ} \mathrm{C}$. Note: 1 - $\mathrm{Al}$ dendrite, 2 - eutectic Si phase, $3-\mathrm{Al}_{9} \mathrm{Mg}_{12} \mathrm{Si}_{6} \mathrm{Fe}$ related to $\pi$ phase, $4-\mathrm{Al}_{7.2} \mathrm{Si}_{8.3} \mathrm{Cu}_{2} \mathrm{Mg}_{6.9}$ related to $\mathrm{Q}-\mathrm{Al}_{5} \mathrm{Cu}_{2} \mathrm{Mg}_{8} \mathrm{Si}_{6}$ phase. Composition of particles is given in Appendix B.

To determine the size of precipitates in the Al-based alloys examined, an analysis at different scales is required. For the purpose of this study, magnifications typical for optical microscopy were used. To characterize dimensions of precipitates, two indicators were employed: particle length and width. Based on measurements it is seen that after deformation the distribution of length and width exhibited similar trends for both alloys. An example of dimension of eutectic silicon and intermetallics for the alloys tested at a temperature of 200 and $400^{\circ} \mathrm{C}$, and a strain rate of $1 \mathrm{~s}^{-1}$ is shown in Fig. 7.9a,b and Fig. 7.9c,d for the length and width, respectively. It was determined that the length and width of particles in the MA1 alloy were in the range of 2-10 $\mu \mathrm{m}$ and 1-5 $\mu \mathrm{m}$, respectively. In contrast, the MA3 alloy contained generally smaller particles 2-4 $\mu \mathrm{m}$ in length and 1-3 $\mu \mathrm{m}$ in width. No substantial difference in precipitate size after deformations at 200 and $400^{\circ} \mathrm{C}$ was noted. 

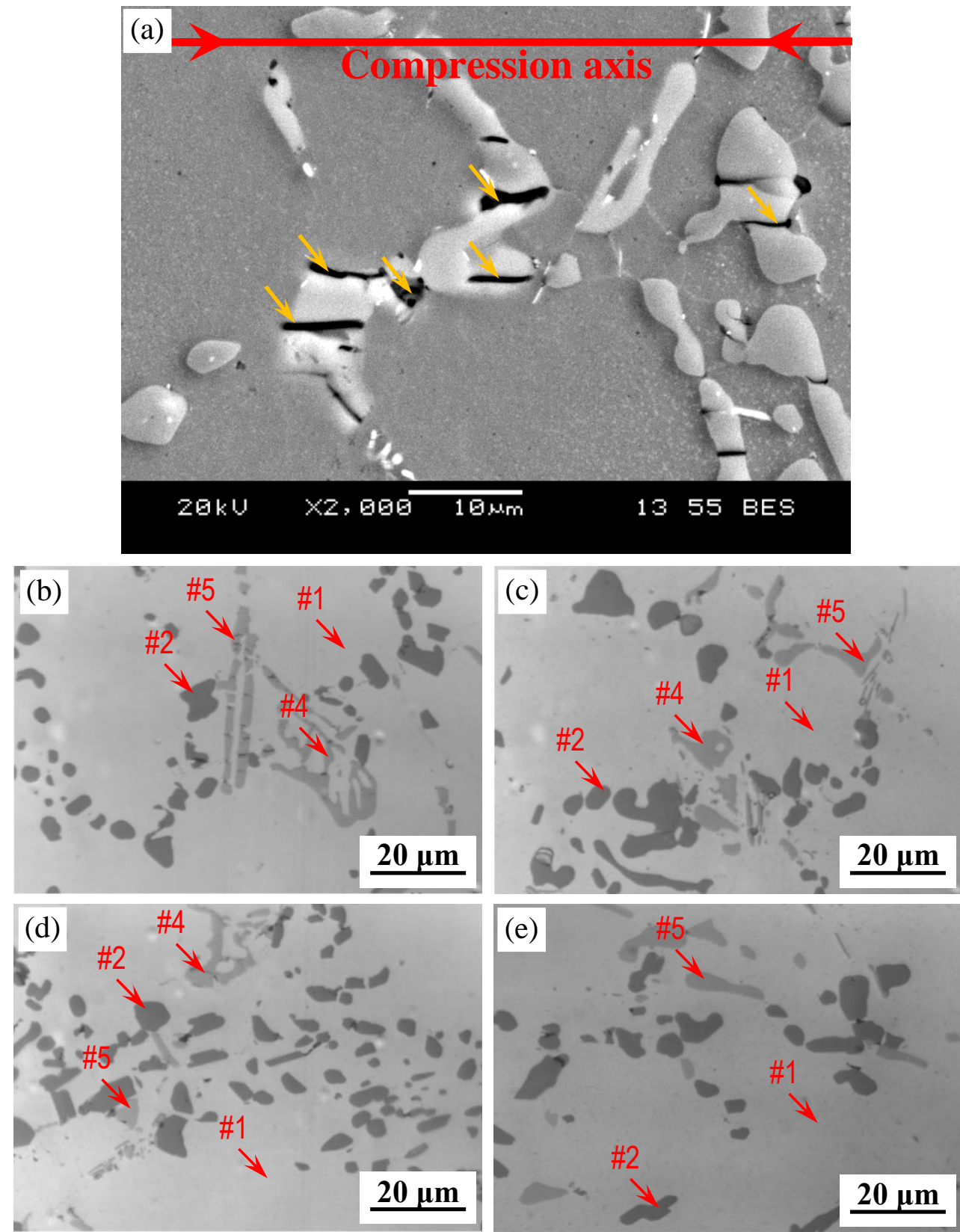

Fig. 7.8. (a) SEM image showing particle cracking of the MA3 alloy after compression tests at strain rates of $1 \mathrm{~s}^{-1}$ and $200^{\circ} \mathrm{C}$ temperature (yellow arrows indicated the cracked in the particles). Optical microscopy images showing particle cracking of the MA3 alloy after compression tests at strain rates of $1 \mathrm{~s}^{-1}$ and temperatures of (b) $200^{\circ} \mathrm{C}$ and (c) $400^{\circ} \mathrm{C}$, and strain of $10^{-3} \mathrm{~s}^{-1}$ and temperature of (d) $200^{\circ} \mathrm{C}$ and (e) $400^{\circ} \mathrm{C}$ temperature. Note: $5-\mathrm{Al}_{26} \mathrm{Si}_{5} \mathrm{Ti}_{4} \mathrm{VZr}_{4}$ phase. Composition of particles is given in Appendix B.

The deformation temperature and strain rates affected the cracking frequency of particles. As shown in Fig. 7.10 and Fig. 7.11, increasing the deformation temperature from 200 to $400^{\circ} \mathrm{C}$ 
resulted in a reduction of the fraction of cracked eutectic silicon particles in the MA1 alloy from 0.53 to 0.21 at a strain rate of $1 \mathrm{~s}^{-1}$ (Fig. 7.10a).
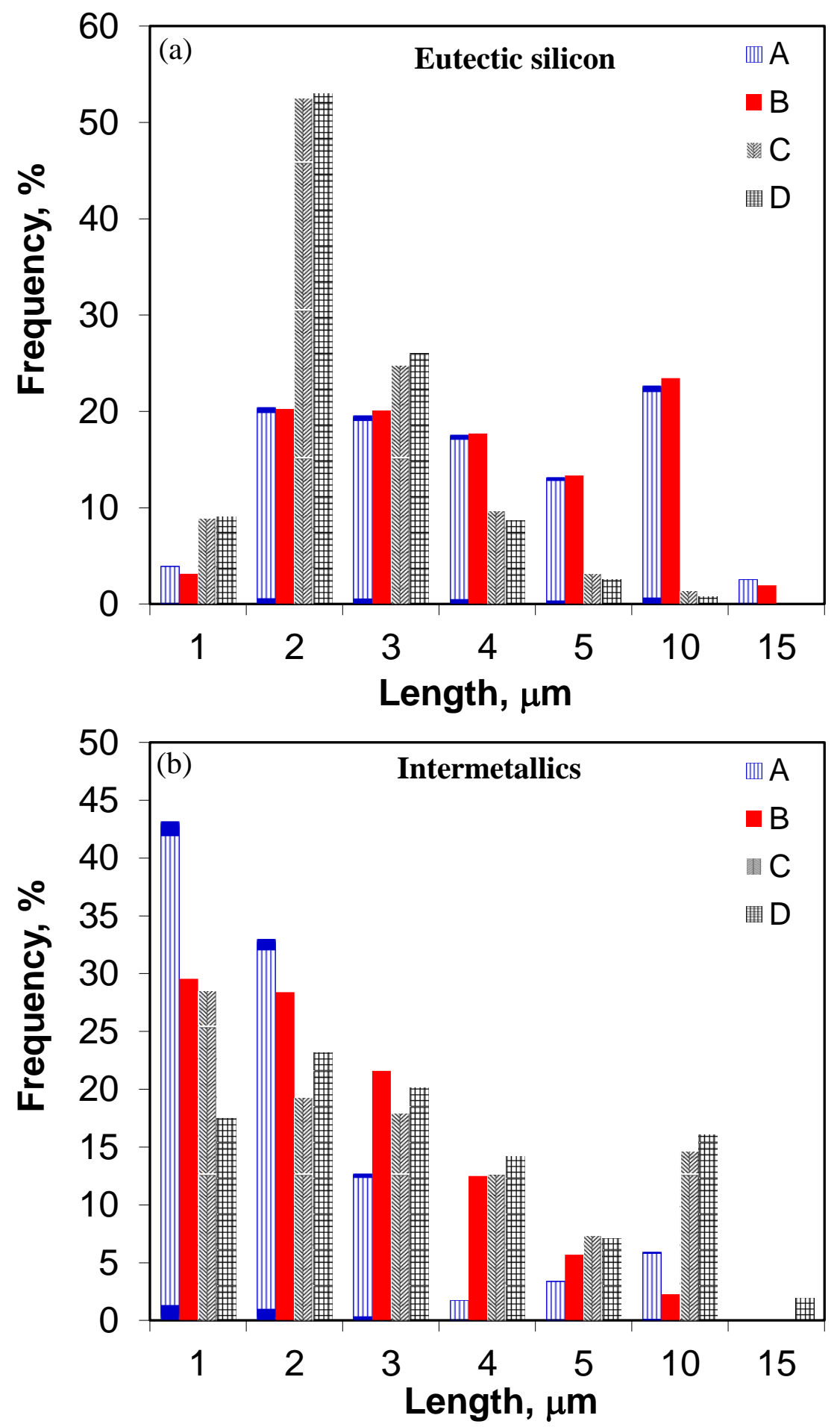

Fig. 7.9. A comparative distribution of quantitative image analysis of particles present in the studied alloys after hot compression at different temperatures with a strain rate of $1 \mathrm{~s}^{-1}$ for, (a) length of eutectic Si particle, (b) length of intermetallics particles (continue to next page). 

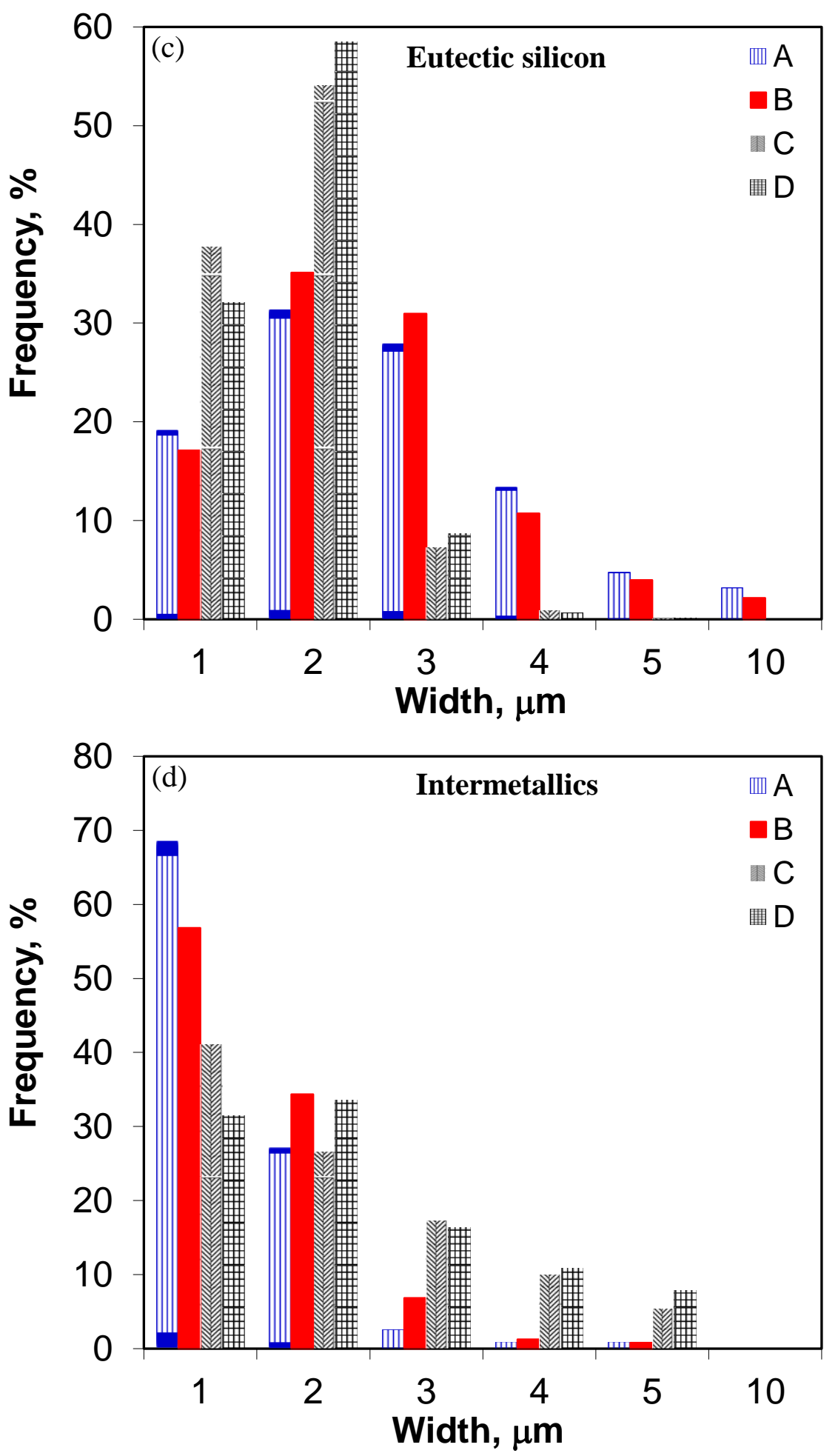

Fig. 7.9. A comparative distribution of quantitative image analysis of particles present in the studied alloys after hot compression at different temperatures with a strain rate of $1 \mathrm{~s}^{-1}$ for, (a) length of eutectic Si particle, (b) length of intermetallics particles, (c) width of eutectic $\mathrm{Si}$ particle and (d) width of intermetallics particles. Note: A - MA1 alloy deformed at $200^{\circ} \mathrm{C}, \mathrm{B}$ MA1 alloy deformed at $400^{\circ} \mathrm{C}, \mathrm{C}-\mathrm{MA} 3$ alloy deformed at $200^{\circ} \mathrm{C}$, and D - MA3 alloy deformed at $400^{\circ} \mathrm{C}$. 

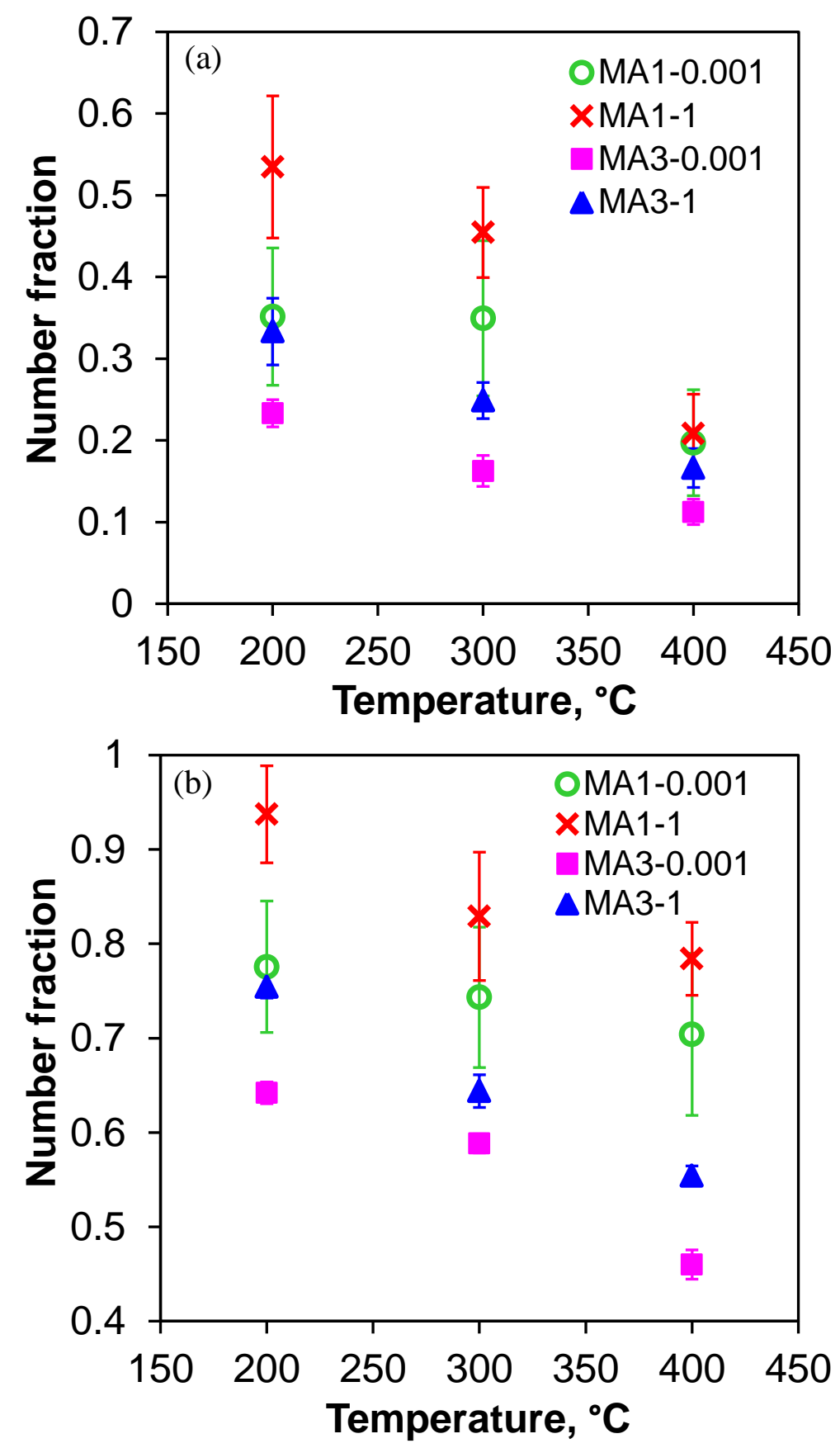

Fig. 7.10. Development of damage accumulation with temperature for studied alloys MA1 and MA3, (a) eutectic silicon particles and (b) intermetallics, where the strain rate is in $\mathrm{s}^{-1}$.

At the same time, there was a reduction in the fraction of cracked intermetallic particles from 0.94 to 0.78 (Fig. 7.10b). In contrast, for the MA3 alloy, raising the deformation temperature from 200 to $400^{\circ} \mathrm{C}$ resulted in a drop of the fraction of cracked eutectic silicon particles from 0.33 to 0.17 at a strain rate of $1 \mathrm{~s}^{-1}$. Also, there was a reduction in the fraction of cracked 
intermetallic particles from 0.75 to 0.55 for the same testing parameters. A similar trend was recorded for both alloys with increasing strain rates at a constant temperature. The quantitative image analysis revealed that in both alloys the intermetallic particles experienced more frequent cracking, in some cases almost double that measured for the eutectic silicon. It also showed that precipitates in the MA3 alloy are stronger, experiencing less frequent cracking (as seen in Fig. 7.11). This finding applies for the eutectic silicon and intermetallics. An additional observation was that the number of cracked particles decreased with increasing deformation temperature. Thus, the substantially lower fraction of particles cracked in the MA3 alloy experienced further reduction during increasing deformation temperature.

\subsubsection{Effect of temperature on Precipitate rotation}

It was observed that in addition to cracking, during the alloy deformation, some precipitates experienced rotation. As an indicator of the particle orientation, the angle between the loading direction and the longitudinal axis of the particle was used. As in cracking analysis, eutectic silicon and intermetallic particles were distinguish here based on image contrast using an optical microscope. The orientation distribution of the eutectic silicon particles after deformation at a strain rate of $1 \mathrm{~s}^{-1}$, and temperature of 200 and $400^{\circ} \mathrm{C}$ is summarized in Fig. 7.12. It is seen that large fractions of precipitates fall within the orientation angle between $70^{\circ}$ and $90^{\circ}$. The MA1 alloy deformed at $200^{\circ} \mathrm{C}$ and $1 \mathrm{~s}^{-1}$ contained $39.0 \%$ of silicon particles and $51.1 \%$ of intermetallic particles with an orientation angle in the range of $70-90^{\circ}$. 


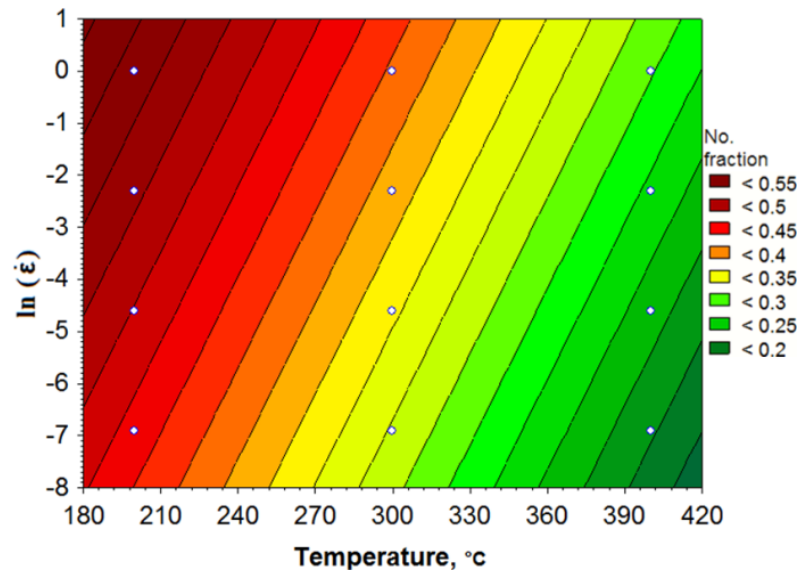

(a)

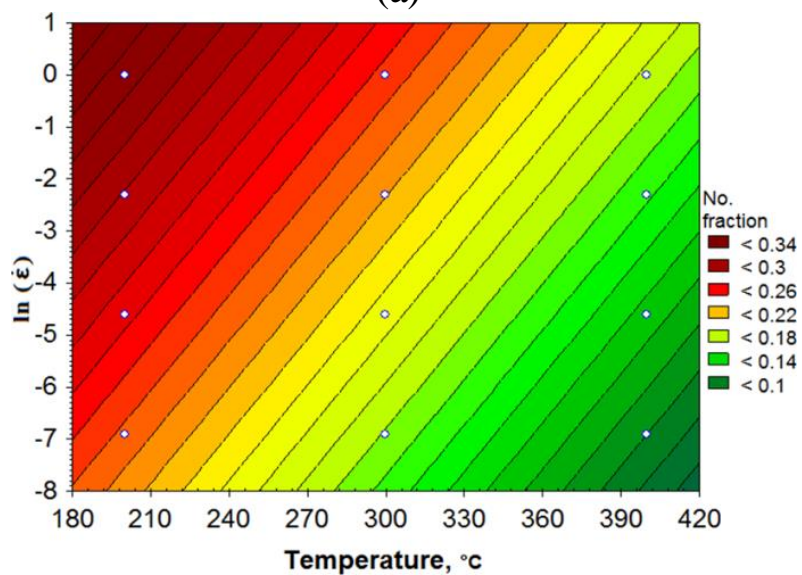

(c)

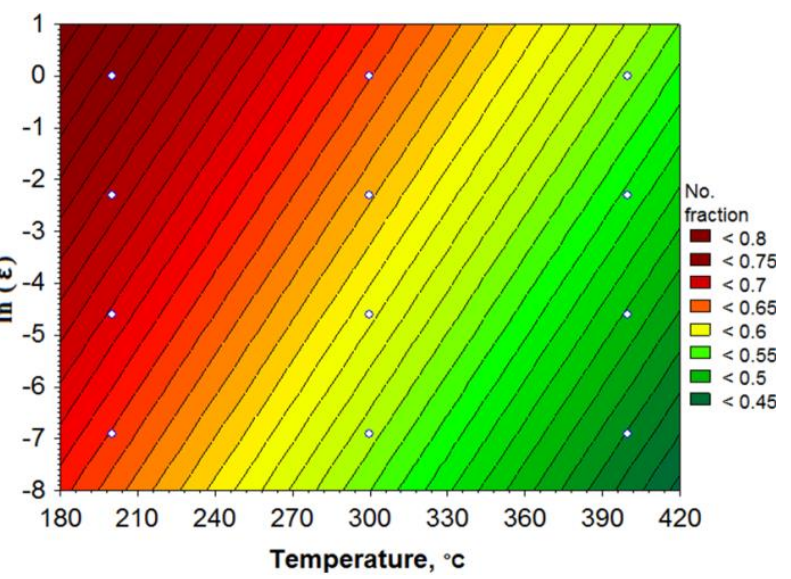

(b)

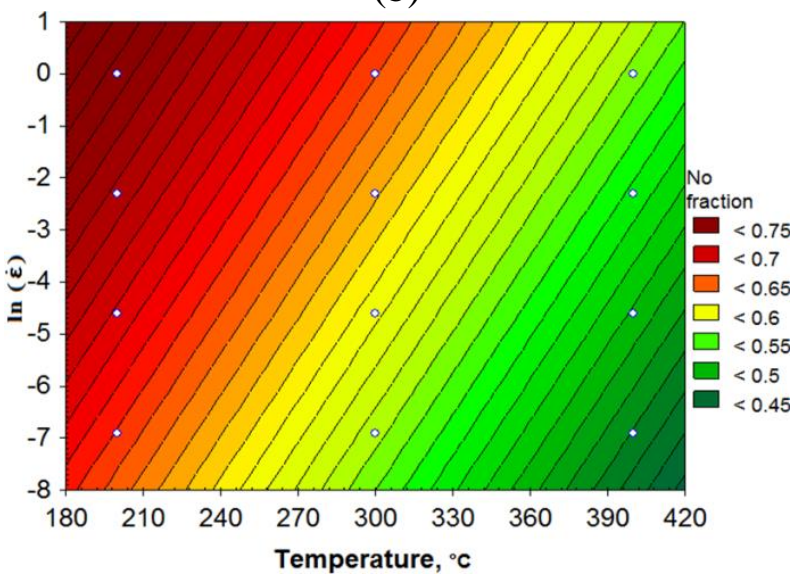

(d)

Fig. 7.11. The contour plot of damage accumulation during hot compression at different temperatures and strain rates for the studied alloys; (a) eutectic silicon particles and (b) intermetallics of MA1 alloy, and (c) eutectic silicon particles and (d) intermetallics of MA3 alloy where the strain rate is in $\mathrm{s}^{-1}$.

Increasing testing temperature from 200 to $400^{\circ} \mathrm{C}$, increased that number fraction of silicon particles to $45.7 \%$, while the number fraction of intermetallic particles decreased to $39.0 \%$. For the modified alloy MA3, the same temperature change from 200 to $400^{\circ} \mathrm{C}$ caused the eutectic silicon orientation migration from 38.2 to $40.9 \%$. With the same experimental parameters and orientation range the intermetallic precipitate fraction changed from 36.4 to $32.6 \%$. As an indicator of the precipitate orientation stability, the average orientation was found useful. For the MA1 alloy, deformed at a strain rate of $1 \mathrm{~s}^{-1}$, the average orientations of eutectic silicon particles were $44.3^{\circ} \pm 3.3^{\circ}$ at $200^{\circ} \mathrm{C}$ and $50.2^{\circ} \pm 3.1^{\circ}$ at $400^{\circ} \mathrm{C}$ thus increasing by $5.9^{\circ}$. 

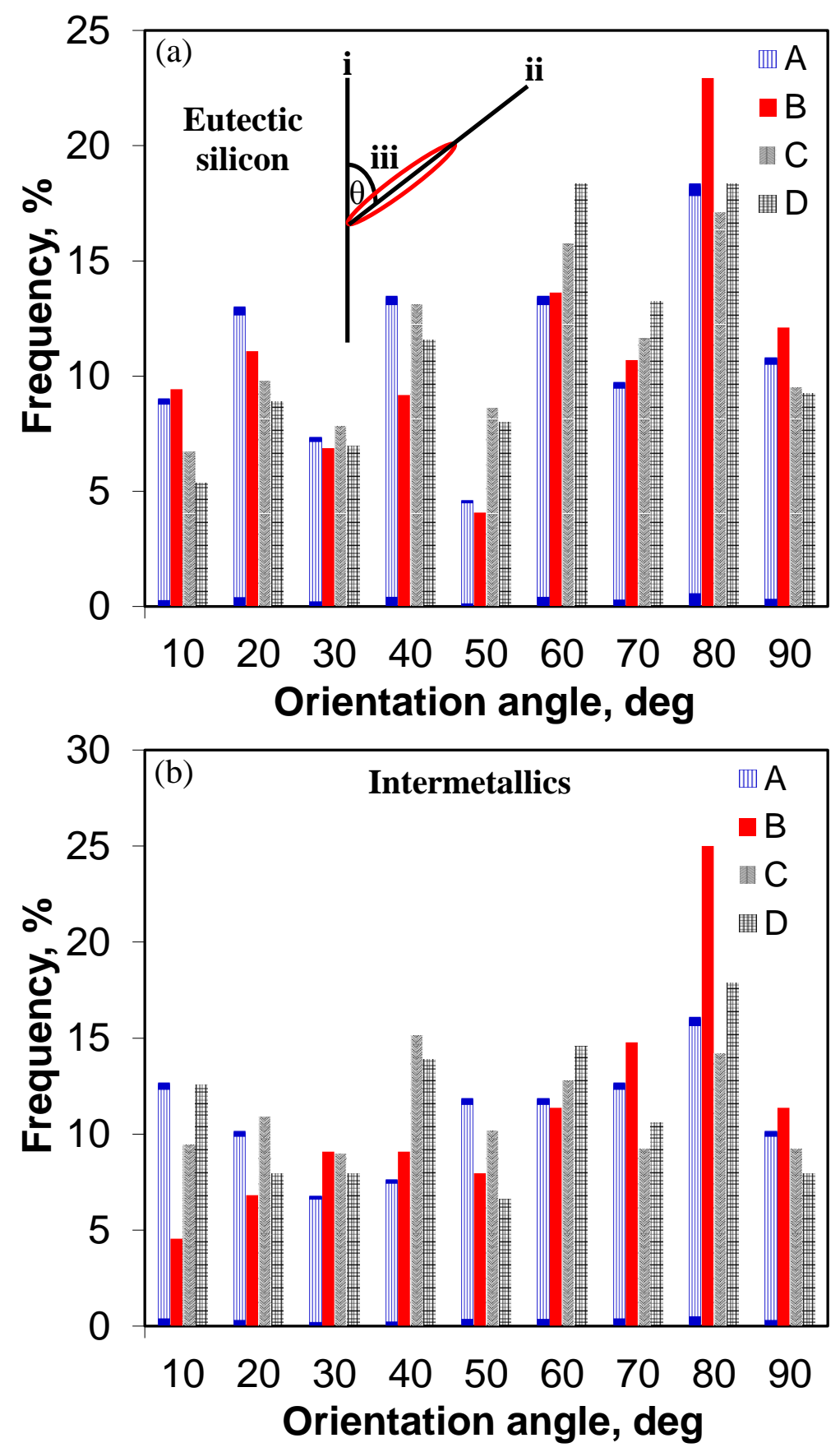

Fig. 7.12. A comparison of the morphological orientation distribution of particles present in the MA1 and MA3 alloys deformed at different temperatures and a constant strain rate of $1 \mathrm{~s}^{-1}$ for (a) eutectic Si particles and (b) intermetallics particles. Note: A - base alloy deformed at $200^{\circ} \mathrm{C}$, $\mathrm{B}$ - base alloy deformed at $400^{\circ} \mathrm{C}, \mathrm{C}$ - modified alloy deformed at $200^{\circ} \mathrm{C}$, and D - modified alloy deformed at $400^{\circ} \mathrm{C}$; i - loading axis, ii - major axis, and iii - particle orientation angle $(\theta)$. 
At the same time the average orientations of intermetallic particles in the MA1 alloy were $47.2^{\circ} \pm 3.6^{\circ}$ at $200^{\circ} \mathrm{C}$ and $48.8^{\circ} \pm 2.8^{\circ}$ at $400^{\circ} \mathrm{C}$ thus differing by only $1.6^{\circ}$. For the modified alloy MA3, deformed at a strain rate of $1 \mathrm{~s}^{-1}$, the average orientations of eutectic silicon particles were $47.4^{\circ} \pm 2.9^{\circ}$ at $200^{\circ} \mathrm{C}$ and $48.5^{\circ} \pm 2.4^{\circ}$, at $400^{\circ} \mathrm{C}$. At the same time the average orientations of intermetallic particles in the MA1 alloy were $43.3^{\circ} \pm 4.3^{\circ}$ at $200^{\circ} \mathrm{C}$ and $45.7^{\circ} \pm 3.2^{\circ}$, at $400^{\circ} \mathrm{C}$. Thus, in the MA3 alloy the orientation difference of both types of precipitates after deformation was just around $1^{\circ}$. In summary, the average orientations of precipitates after hot deformation and detailed histograms indicate that in the MA1 alloy the eutectic silicon experienced reorientation with increasing deformation temperature. In contrast, in the MA3 alloy both the eutectic silicon and intermetallics have their orientations relatively stable. Such a difference in rotation of the eutectic silicon particles is believed to be associated with the high deformation level, DDRX, CDRX, fine precipitates present in the aluminum matrix, void nucleation, their growth and coalescence.

\subsection{Compression Characteristics and Activation Energy of Deformation}

The flow behavior of materials during hot deformation is complex since it is influenced by many factors such as strain level, strain-rate and temperature [202]. A given combination of thermo-mechanical parameters changes the microstructure which affects the flow stress [209, 210]. Hence, dynamic recovery and dynamic recrystallization, which influence the microstructural change, are the typical softening mechanisms in metals and alloys during hot deformation [211, 212]. Metals like Al, containing high stacking fault energy, experience difficulties in dynamic recrystallization during hot deformation. The presence of impurities and/or alloying elements, especially $\mathrm{Mg}$, in aluminum alloys enhances the tendency to dynamic recrystallization [213]. Also the presence of $\mathrm{Ti}, \mathrm{V}$ and $\mathrm{Zr}$ influence the mechanism of 
deformation of grains which is discussed in the next paragraph. The DDRX was observed in Al alloys, which involves development of high angle grain boundaries via nucleation and growth of new grains that typically initiate at original grain boundaries, boundaries of dynamically recrystallized grains and boundaries created during deformation [212]. Recently, CDRX was also reported in aluminum alloys [184]. This mechanism differs from that of DDRX in that new grains are formed progressively within the deformed original low angle grains from a continuous increase of subgrains with low misorientations, as a result of the accumulation of dislocations in low angle boundaries [211, 212, 213].

During hot compression of aluminum alloys, four stages of stress-strain curve are commonly reported. As shown in Fig. 7.1b, those stages cover I: work hardening stage, II: transition stage, III: softening stage and IV: steady stage, as reported by Lin and Chen [209]. During stage I, the work hardening rate is higher than the softening rate induced by dynamic recovery, and thus the stress rises steeply with strain, and then increases at a decreasing rate, followed by Stage II. At the transition stage, the competition between the work hardening and the softening phenomenon induced by dynamic recovery as well as the DDRX or CDRX takes place. In addition, the flow stress still increases, but the rate of increase continuously decreases. During stage III, the stress drops steeply, which is related to dynamic recovery and dynamic recrystallization. Finally, at stage IV, the stress becomes steady when a new balance between softening and hardening is reached $[209,214]$. It is clear that with increasing the testing temperature and decreasing the strain rate, the stages II and III are decreasing and at $400^{\circ} \mathrm{C}$, they completely disappear. This indicates that higher temperatures and lower strain rates are favorable for dynamic recrystallization, which influences the peak stress.

The changes in peak stress shown in Fig. 7.2 are related to the temperature-dependent softening of the alloy and the presence of $\mathrm{Ti}, \mathrm{V}$ and $\mathrm{Zr}$. A similar tendency was reported during 
hot compression of Al-Si cast alloys at temperatures between 300 and $500^{\circ} \mathrm{C}$, where increasing test temperature led to decreasing peak stress [185, 201, 215]. A reduction of strength with increasing temperature is related to the change in dislocation generation and their movement, coarsening of precipitates, sliding of grain boundaries and phase transformations. Generally, during deformation, slip of dislocations and their subsequent pile-up at grain boundaries occurs. When the deformation continues at high temperatures, the dislocations are thermally activated, i.e., temperature can help dislocations to move forward leading to the generation of rows of vacancies [156]. At a temperature at which the thermal energy is sufficient to allow vacancies to diffuse away at an appropriate rate, the pile-up of dislocations at grain boundaries will decrease, causing a reduction of flow stress [175]. Another factor contributing to the reduced flow stress at elevated temperatures includes coarsening and morphological changes of precipitates. For example, during the high-temperature deformation of the A356 aluminum alloy the precipitates changed from the rod-like (semi-coherent) to the planar shape (non-coherent) arising from enhanced recovery via pipe diffusion [185].

For alloys tested under stable conditions, the values of activation energy of deformation were close to the activation energy of self-diffusion of Al in Al-based alloys [205]. Indeed, after slow cooling or after over-ageing of the AA6062 alloy, the precipitates exert a minor strengthening effect due to the larger size and larger spacing between them. By contrast, where the alloy was examined in solution-treated and peak-aged conditions, very high values of the activation energy and the stress exponent (even approaching infinity or negative values [205]) were observed. The stationary dislocations in a solid solution could be pinned by the solute atoms if they are able to diffuse to the dislocation core so an additional increment of stress will be required to free the dislocation from its energetically favorable position. Further, as stated in [71, 102], the Al-Si-Mg-Cu alloys modified with $\mathrm{Ti}, \mathrm{Zr}$ and $\mathrm{V}$ contain thermally stable fine 
precipitates of $\mathrm{Al}_{3} \mathrm{X}(\mathrm{X}=\mathrm{Ti}, \mathrm{V}$ and $\mathrm{Zr})$, which during hot deformation exerted more strengthening effect compared to the MA1 alloy, resulting in higher deformation activation energy of the MA3 alloy in this study. That is to say that the energy barrier in the MA3 alloy is higher than in the MA1 alloy, which causes the reduction of the ability to diffuse atoms and migrate the grain boundary, thus accelerating the dynamic recrystallization in the modified alloy.

Dislocations moving through a solid solution will encounter friction drag, thus raising the energy required for their movement. Hence, a higher content of foreign atoms held in a solid solution will increase the activation energy [206]. It is believed that the higher activation energy of $315.2 \mathrm{~kJ} / \mathrm{mol}$ determined in this study for the MA3 alloy, is associated with the presence of $\mathrm{Ti}, \mathrm{V}$ and $\mathrm{Zr}$ held in solution by the homogenization treatment. During high strain rate deformation, recovery processes are also hindered by a higher energy of the solute-vacancy binding, which effectively reduces the number of vacancies available for dislocation climb while the misfit strain effectively raises the dislocation density; both processes contribute to an increase in the activation energy of hot deformation. However, the presence of $\mathrm{Al}_{3} \mathrm{X}(\mathrm{X}=\mathrm{Ti}, \mathrm{V}$ and $\mathrm{Zr}$ ) particles hinders the DDRX by the pinning effect at the grain boundary and accelerates the CDRX [207, 216]. Thus, CDRX will occur in the MA3 alloy rather than the conventional DDRX in the MA1 alloy. In should be pointed out here that in Al-Si alloys the dynamic recrystallization is unlikely. Here, the nucleation occurs from the sub-grains and form very fine micro-size grains which do not grow further due to the presence of second phase precipitates. From the above discussion, it could be concluded that the presence of $\mathrm{Ti}, \mathrm{V}$ and $\mathrm{Zr}$ increased the activation energy, which led to the higher resistance of the alloy to hot deformation.

It is reported [217] that during hot compression of alloy steel at higher temperatures, the grain size of dynamic recrystallization is related to the Zener-Hollomon's parameter. The higher 
values of $Z$ lead to finer grain during hot deformation due to dynamic recrystallization. With an increase of strain rate and decrease of deformation temperature, parameter $Z$ will increase and the corresponding flow stress peak value will be higher. It was also reported [218] that the higher value of $Z$ accelerated the migration of atoms and dislocations causing merging of some grains, and the low-angle grain boundaries transformed into high-angle grain boundaries through absorbing dislocations. Subsequently, the recrystallized grains coarsened through the migration of dislocations and high-angle grain boundaries. As illustrated in Fig. 7.13 (a, d), in both alloys, the precipitates are situated along grain boundaries.
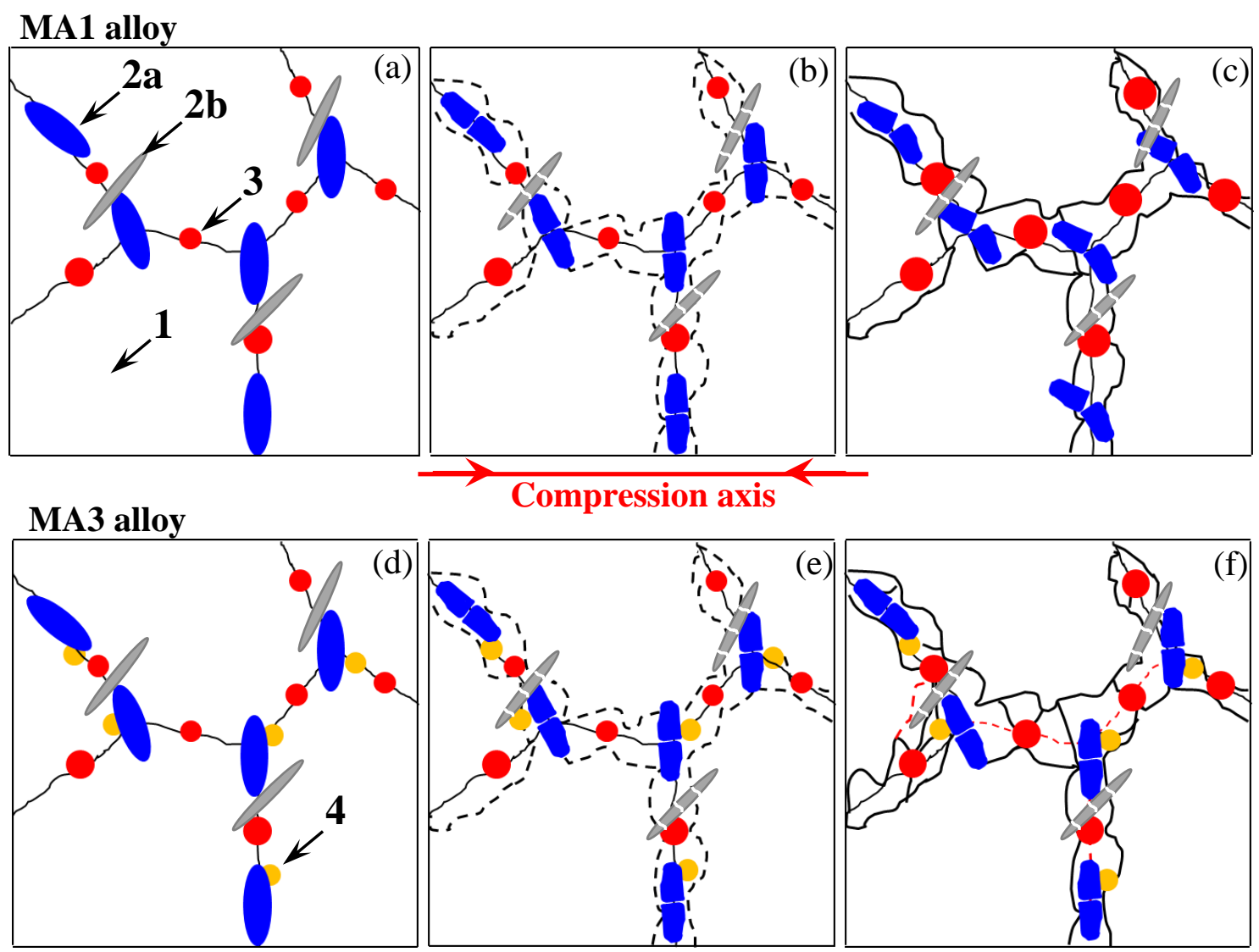

Fig. 7.13. A schematic model depicting the successive steps of recrystallization of the MA1 (ac) and MA3 (d-f) alloys during hot deformation. Note: 1 - Al matrix, $2 \mathrm{a}$ - eutectic silicon and $2 \mathrm{~b}$ - intermetallic particles analyzed under optical microscope; 3-precipitates present in the base alloy; $4-\mathrm{Al}_{3} \mathrm{X}(\mathrm{X}=\mathrm{Ti}, \mathrm{V}, \mathrm{Zr})$ additional precipitates present in the modified alloy. The precipitates 3 and 4 were observed using transmission and scanning microscopy and their morphology and chemistry are given in [71]. 
During deformation, the dislocations are tangled with each other and prevent the movement of dislocation by precipitates, resulting in the formation of cells which turn to sub-grains around the precipitates (Fig. $7.13 \mathrm{~b}$, e). When the deformation continues and temperature increases, the precipitates in the base alloy grew and hindered the pinning effect which stopped the continuation of the recrystallization and formed high angle grains (Fig. 7.13c). In contrast, more stable precipitates in the modified alloy MA3 sustain the behavior of stopping the movement of the dislocation by retaining the pinning effect which allows the formation of sub-grains and recrystallization, as shown in Fig. 7.13f. Thus, the alloy MA1 developed conditions for DDRX while the modified alloy MA3 was more prone to CDRX.

\subsection{Role of Precipitates in Deformation}

It was reported that cracking of the eutectic silicon particles during hot deformation of the Al$15 \% \mathrm{Si}$ alloy increased with decreasing deformation temperature [201]. The cracking frequency was affected by the size, shape, aspect ratio, deformation conditions, internal stresses developed during deformation, and secondary dendrite arm spacing of the matrix. The higher frequency of particle cracking in the MA1 alloy of this study (Fig. 7.10 and 7.11) suggests that the stress concentration around precipitates of the MA1 alloy was higher compared to the MA3 alloy. On the other hand, during deformation at higher temperature the aluminium matrix became softer and the interface between the particles and matrix became weaker. Thus, increasing strain rate and decreasing deformation temperature lead to an increasing interfacial stress, which promotes particle cracking, as observed in this study.

The occurrence of such a substantial fraction of multiple cracking suggests strong bonding of the interface between the particle and matrix. This is because the secondary multiple cracking can only occur under load transferred by shear across particles and through normal stresses at 
one end [69]. From the microstructural observations of this study (Fig. 7.7 and 7.8) it is clear that particle cracking forms a cavity in the matrix and influences the hot deformability. The majority of models considering the damage evolution were created based on an assumption that the particles remain stationary during loading with all deformation taking place within the ductile $\mathrm{Al}$ matrix $[163,219]$. According to experimental observations, however, particles are not stationary but rather experience a significant rotation $[162,208]$. It is believed that the rotation of brittle phase particles can facilitate particle cracking [76, 220]. It is known that during plastic deformation, particles rotate and align themselves along the loading direction [208]. As described above, at a lower temperature of $200^{\circ} \mathrm{C}$, dynamic recovery was more prominent than the DDRX or CDRX, resulting in a lower fraction of rotation of eutectic silicon particles. In contrast, the $\mathrm{Al}$ matrix becomes softer with increasing testing temperature up to $400^{\circ} \mathrm{C}$ and DDRX/CRDX enhanced the particle rotation during hot deformation. The quantitative analysis of this study shows that the alloy MA1 developed a higher rotation of eutectic silicon particles (Fig. 7.12). This could be a result of the DDRX process. In the DDRX process, high angle grain boundaries are formed and the grains are larger. Conversely, in CDRX, the grains are comparatively smaller in size with lower dislocation density, which influences the rotation of the particles. Hence, the grain boundaries act as a barrier to rotating the eutectic silicon particles. It may be concluded, therefore, that during hot deformation of the MA3 alloy, eutectic silicon particles showed a lower fraction of rotation, compared to the MA1 alloy.

\subsection{Chapter Summary}

The uniaxial compression test was used to assess the influence of micro-additions of $\mathrm{V}$ and $\mathrm{Zr}$ on the hot deformation behavior of the Al-7Si-1Cu-0.5Mg-0.1Ti (wt $\%$ ) base cast alloy. The temperature in the range of $200-400^{\circ} \mathrm{C}$ and, to a lesser extent, strain rate in the range of $10^{-3}-1$ 
$\mathrm{s}^{-1}$ affected the flow stress of both alloys with the peak stress of the $\mathrm{V}$ - and $\mathrm{Zr}$ - modified alloy being consistently higher. Constitutive equations were employed to evaluate the material constants and to correlate them with the hot deformation behavior. The presence of $\mathrm{V}$ and $\mathrm{Zr}$ increased the activation energy of plastic deformation from $282.6 \mathrm{~kJ} / \mathrm{mol}$ to $315.2 \mathrm{~kJ} / \mathrm{mol}$, supporting improved resistance to hot deformation. As revealed through metallographic examinations, fracturing and re-orientation of the second phase particles occurred during compression. For both alloys, the intermetallic particles experienced substantially more frequent cracking than the eutectic silicon. At the same time, in the modified alloy MA3, both the eutectic silicon and intermetallics experienced less frequent fracturing. The precipitates in the modified alloy MA3 were also more resistant to rotation within the alloy matrix as a result of hot deformation. The beneficial role of the transition metals $\mathrm{V}, \mathrm{Zr}$ and $\mathrm{Ti}$ in improving the high temperature performance of cast Al alloys was discussed. (Note: Most of the data of this chapter 5 was collected from the published material as listed in Section 9.3). 


\section{CHAPTER 8}

\section{MONOTONIC AND CYCLIC DEFORMATION BEHAVIOR OF THE CAST MODIFIED Al-Si-Cu-Mg ALLOYS ${ }^{5}$}

\subsection{Introduction}

The influence of $\mathrm{Zr}$ and $\mathrm{Ti}$ additions in $\mathrm{Al}$ alloys was a subject of a number of studies with major conclusions that the morphology and type of phases formed during either casting or heat treatment control the high temperature properties $[46,73]$. During engine heating and cooling, a cyclic loading causes the natural expansion of the inter-valve regions during service which induces local compressive stresses, resulting in plastic deformation of the material. During engine cooling-down, in turn, tensile stresses are set. This cyclic loading initiates the cracks by first accumulating the plastic damage leading to the formation of cracks, followed by propagation of the cracks, and eventually causing the fatigue failure of the materials [127, 221]. Therefore, it is an important issue to evaluate the fatigue properties of the alloys modified with addition of $\mathrm{Ti} / \mathrm{V} / \mathrm{Zr}$ in $\mathrm{Al}-\mathrm{Si}-\mathrm{Cu}-\mathrm{Mg}$. The previous studies $[63,101,129,130]$ showed that additions of Ti-V-Zr in Al-Si-Cu-Mg alloys did not form any copper-containing phases with Ti$\mathrm{V}-\mathrm{Zr}$ but rather modified the Fe-containing $\beta-\mathrm{Al}_{5} \mathrm{FeSi}$ phases, improving the tension/compression strength and low cycle fatigue (LCF) strength in the T6 heat treated condition. The study of LCF fatigue resistance of cast $\mathrm{Al}-\mathrm{Si}-\mathrm{Cu}-\mathrm{Mg}$ alloys for automotive power train applications, especially the Al-Si-Cu-Mg alloys $\mathrm{Zr}-\mathrm{V}-\mathrm{Ti}$ modified is very limited in the literature. The study of the influence of rapid solidification (similar to high pressure die

\footnotetext{
${ }^{5}$ S.K. Shaha, F. Czerwinski, W. Kasprzak, J. Friedman and D.L. Chen, Mater. Sci. Eng., A, 2015 (Submitted). S.K. Shaha, F. Czerwinski, W. Kasprzak, J. Friedman and D.L. Chen, Metall. Mater. Trans. A, 2015.

S.K. Shaha, F. Czerwinski, W. Kasprzak, J. Friedman and D.L. Chen, Mater. Sci. Eng., A, Vol. 636, pp 361-372, 2015.

S.K. Shaha, F. Czerwinski, W. Kasprzak, J. Friedman and D.L. Chen, Int. J. Fatigue, Vol. 70, pp 383-394, 2015
} 
casting) on SDAS, compression and LCF fatigue resistance of cast $\mathrm{Al}-\mathrm{Si}-\mathrm{Cu}-\mathrm{Mg}$ alloys for automotive power train applications, especially the Al-Si-Cu-Mg alloys modified with additions of $\mathrm{Zr}$, $\mathrm{Ti}$ and $\mathrm{V}$ is not available in the literature.

Thus, this chapter describes the investigation of the effect of solidification rate of Al-Si-Cu$\mathrm{Mg}$ alloy with micro-additions of $\mathrm{Zr}$, Ti and $\mathrm{V}$ on SDAS, monotonic and cyclic deformations. Also, a comparison of the high temperature tensile properties of the Al-Si-Cu-Mg alloys modified with additions of $\mathrm{Ti}, \mathrm{V}$ and $\mathrm{Zr}$ is presented

\subsection{Hardness}

A plot of hardness of MA4 alloy vs SDAS is given in Fig. 8.1. Hardness measurements in the as-cast condition showed a steady state relation with solidification rate, indicating a similar hardness of about $35 \mathrm{HRB}$ with reducing SDAS size between 34 and $12 \mu \mathrm{m}$. In contrast, the samples subjected to T6 temper showed an approximately 35 point hardness increase to $70 \mathrm{HRB}$ compared with the as-cast condition. For the same analyzed SDAS range the T6 hardness decreased from 70 to $67 \mathrm{HRB}$. A similar behavior of the Al-Si-Cu-Mg alloy modified with addition of Zr-V-Ti was reported by Kasprzak et al. [63].

The obtained results of alloy MA4 show that increasing the SDAS values of the Al-Si-Cu$\mathrm{Mg}$ alloy with addition of $\mathrm{Zr}-\mathrm{V}-\mathrm{Ti}$ resulted in a consistent hardness in the as-cast state (Fig. 8.1). At lower cooling rates, the SDAS and the grain sizes are smaller with finer precipitates, which translate to a hardness of $35 \mathrm{HRB}$. With decreasing cooling rates, the grain size increases and at the same time the size of precipitates increases which leads to balancing the hardness. By contrast, the obtained increased hardness after T6 heat treatment could be explained by the presence of tri-aluminide precipitates, as shown in Fig. 4.9 However, the trend of hardness 
change with respect to the SDAS is reducing in nature which could be correlated with the homogeneous size $(\sim 2.66 \mu \mathrm{m})$ of the precipitates. As reported in previous studies [101, 222], the remarkable enhancement in alloy strength was mainly attributed to both the composite-like role of $\mathrm{Cu}-$, Fe-, and $\mathrm{Mg}$-containing Si particles (Fig. 4.11), and the precipitation strengthening of nano-sized tri-aluminide particles which were uniformly distributed in the aluminum matrix or along with the eutectic silicon particles. The presence of these micro- and nano-sized particles (Fig. 4.9 and 4.11) would effectively impede the movement of dislocations during uniaxial deformation, thus appreciably enhancing strength of the cast aluminum alloy.

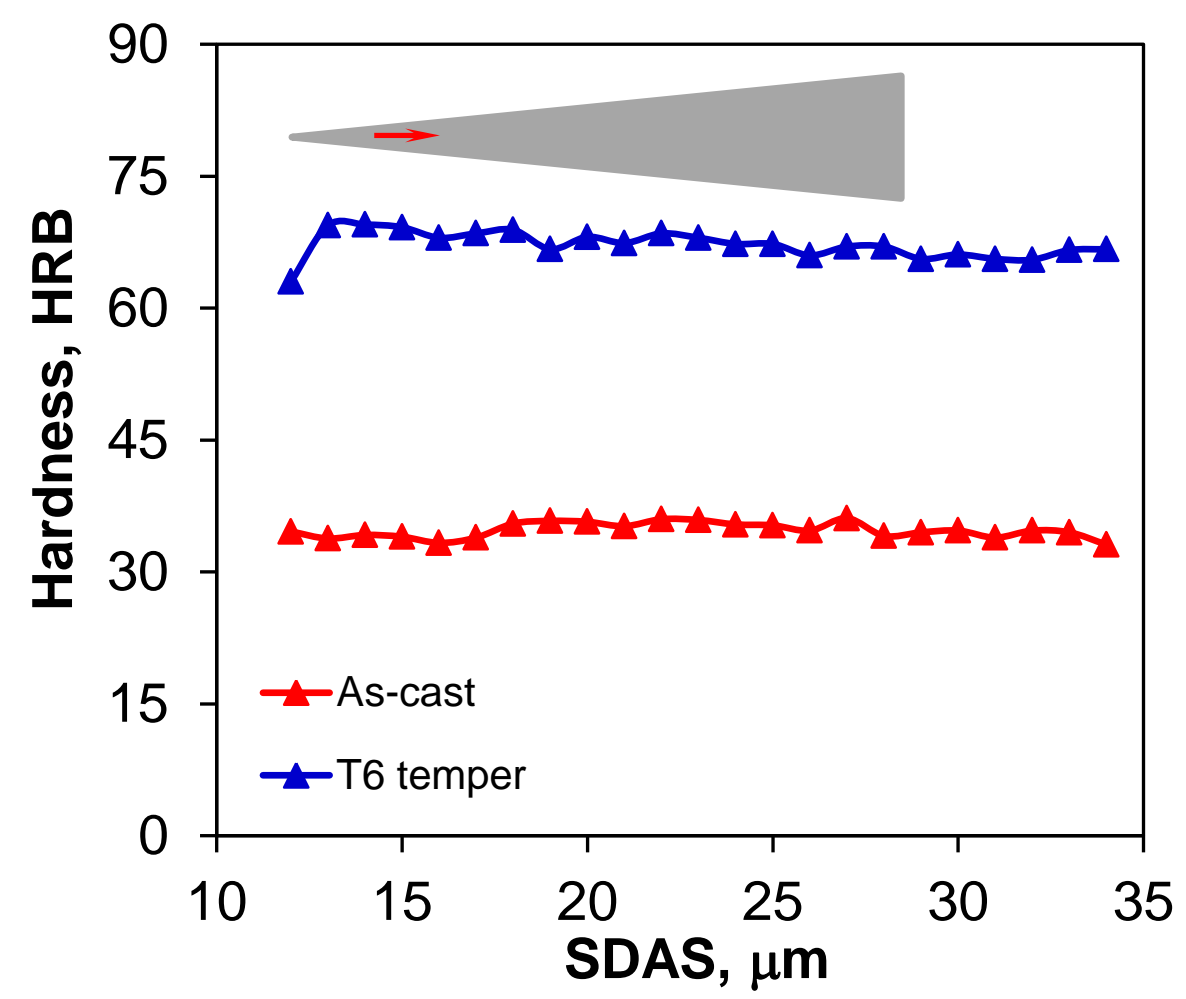

Fig. 8.1. The correlation between hardness and SDAS for as-cast and T6 heat treated Al$\mathrm{Si}-\mathrm{Cu}-\mathrm{Mg}$ alloy modified with $\mathrm{Ti}, \mathrm{V}$ and $\mathrm{Zr}$. 


\subsection{Tensile and Compressive Properties}

\subsubsection{Influence of alloying elements on the tensile properties}

The yield strength (YS), ultimate tensile strength (UTS), ductility in terms of percentage of elongation and quality index of the modified alloys, obtained at room temperature at a strain rate of $10^{-3} \mathrm{~s}^{-1}$, are plotted in Fig. 8.2 and compared with the base Al-Si-Cu-Mg alloy. As seen in Fig. 8.2a, compared to the as-cast base alloy the YS of the alloy MA4 in the as-cast state increased from $139 \mathrm{MPa}$ to $161 \mathrm{MPa}$ (Fig. 8.2a). At the same time, the base alloy modified with additions of Ti, Ti-Zr, and Ti-Zr-V at lower amounts exhibited yield strengths of 292, 306 and $313 \mathrm{MPa}$ respectively in the T6 heat treated condition. However, further increasing the amount of Ti-Zr-V in MA4 alloy caused in the T6 heat treated condition a reduction of YS to $287 \mathrm{MPa}$ which is $126 \mathrm{MPa}$ higher than the alloy MA4 in as-cast state and $26 \mathrm{MPa}$ lower than alloy MA3 in the T6 heat treated condition. In contrast, the as-cast base alloy achieved an UTS of $211 \mathrm{MPa}$ which is significantly lower (50 MPa) than the alloy modified with Ti-Zr-V (Fig. 8.2b). It is also noticed that the T6 heat treated MA4 alloy obtained superior properties compared to the other modified alloys in this study. The T6 heat treated MA4 alloy UTS is $343 \mathrm{MPa}$ which is $\sim 29, \sim 3$ and $\sim 8$ point higher than the T6 heat treated alloys of MA1, MA2 and MA3, respectively. Although the alloy modified with higher additions of $\mathrm{Ti}, \mathrm{Zr}$ and $\mathrm{V}$ showed lower yield strength, the changing trend in YS is lower than for the $354[22,96]$ and A356 [223] alloys and the AlSi-Cu-Mg alloy modified with additions of $\mathrm{Ti}, \mathrm{Zr}$ and $\mathrm{Ni}[22,96]$. However, the studied MA4 alloy also achieved a higher UTS compared to the published data for 354 grade $(\sim 12 \%)$, A356 $(\sim 18 \%)$ and the Al-Si-Cu-Mg alloy modified with addition of $\mathrm{Ti}, \mathrm{Zr}$ and $\mathrm{Ni}$ in the as-cast state $(\sim 5 \%)$ at room temperature. Another important tensile property, ductility of the base alloy in the as-cast condition and alloy modified with additions of Ti (MA1), Ti-Zr (MA2) and Ti-Zr-V (MA3) were between 2.2 and $2.3 \%$ (Fig. 8.2c). 

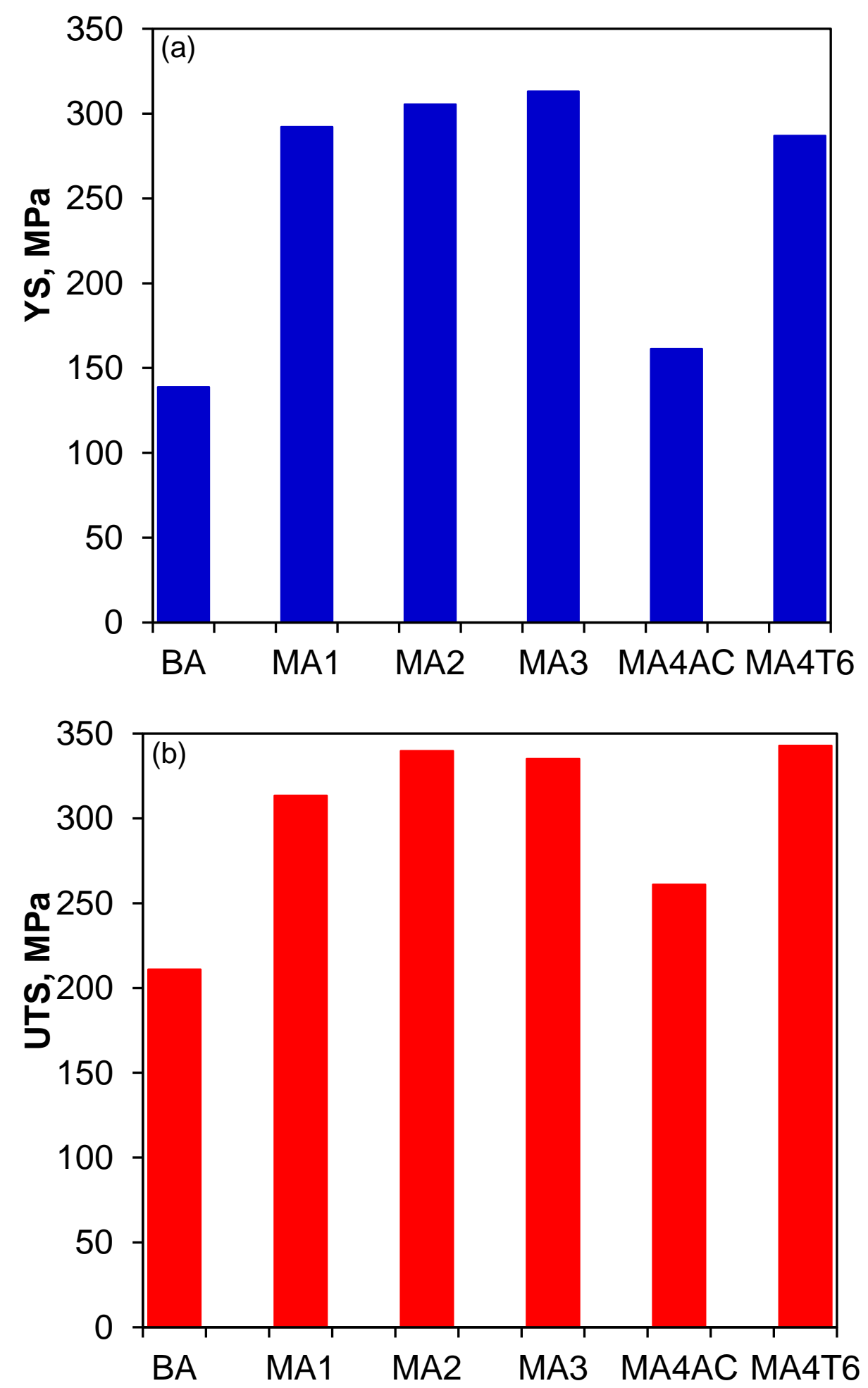

Fig. 8.2. A comparison of the tensile property of the studied Al-Si-Cu-Mg alloys with addition of Ti/V/Zr obtained at room temperature, (a) yield strength (YS) and (b) ultimate tensile strength (UTS) (continue to next page). 

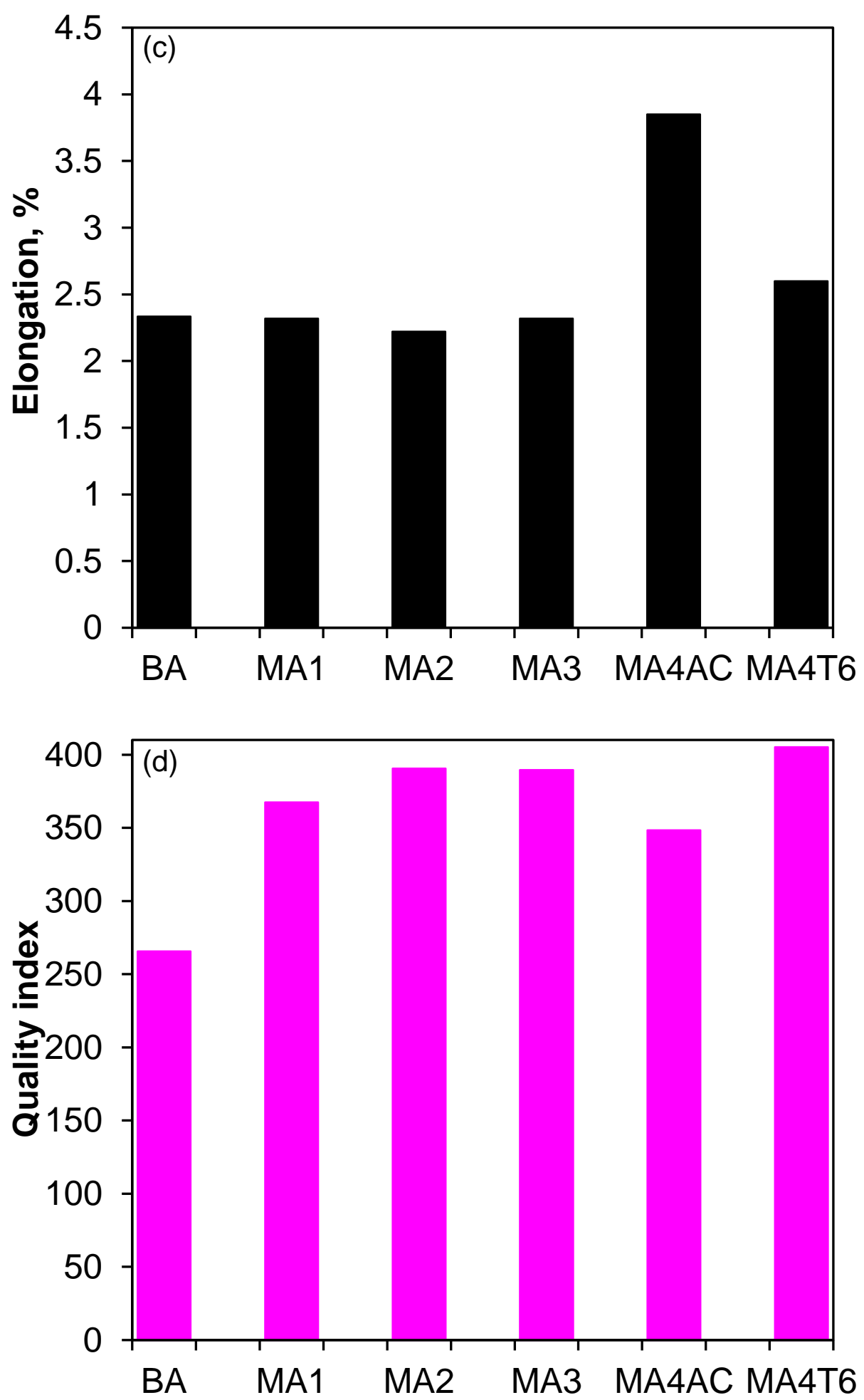

Fig. 8.2. A comparison of the tensile property of the studied Al-Si-Cu-Mg alloys with addition of Ti/V/Zr obtained at room temperature, (a) yield strength (YS) and (b) ultimate tensile strength (UTS), (c) elongation and (d) quality index. 
By contrast, the ductility of the alloy MA4 in the as-cast state was significantly higher than that of the other studied alloys. However, the MA4 alloy elongation decreased from $\sim 3.9$ to $\sim 2.6 \%$ due to the T6 heat treatment process. The cause of the change in tensile properties is believed to be the change of morphology of the $\mathrm{Zr}-\mathrm{V}$-Ti-rich intermetallics and the presence of thermally stable precipitates $[22,96]$ which will be discussed in later sections.

The YS, UTS and ductility alone cannot explain the quality of the cast product. Thus, from the design point of view, the quality of an alloy is associated with the essential mechanical properties for safe operation. Thus, UTS and ductility of the material are essential parameters to characterize the material's quality. Using following equation, the quality index, $Q_{\text {index }}$, was evaluated [224, 225]:

$$
Q_{\text {index }}=U T S(M P a)+M \times \log (\% E)
$$

Where: UTS is the ultimate tensile strength, $M$ is the materials constant and $E$ is the percentage of elongation. Here, $M=150$ was consider for both alloys as adopted from [225].

As seen in Fig. 8.2d, the calculated quality index $Q_{\text {index }}$ for the MA4 alloy in the T6 heat treated alloy is higher than that for the other studied alloys including theas-cast base grade. It is noticed that the BA obtained a $\mathrm{Q}_{\text {index }}$ value of 226 whereas the MA4 alloy in the same state gained a higher $\mathrm{Q}_{\text {index }}$ of $\sim 348$. In contrast, the alloys modified with additions of Ti (MA1), Ti$\mathrm{Zr}$ (MA2) and Ti-Zr-V (MA3) attained higher $\mathrm{Q}_{\text {index }}$ values of $~ 367, ~ 391$ and $~ 390$. However, the MA4 alloy in the T6 heat treated condition acquired 14 to 38 points higher Qindex $_{\text {compared }}$ to the other modified alloy in the same T6 heat treated condition. Thus, it can be concluded that the alloy MA4 in the T6 state obtained superior tensile properties compared to the other chemical compositions studied here. 


\subsubsection{Influence of temperature on the alloy strength}

The yield strength (YS) and ultimate tensile strength (UTS) of the as-cast alloy MA4, obtained at different temperatures at a strain rate of $10^{-3} \mathrm{~s}^{-1}$, are plotted in Fig. 8.3 and compared with AlSi alloys 354, A356 and the Al-Si-Cu-Mg alloy modified with additions of $\mathrm{Ti}, \mathrm{Zr}$ and $\mathrm{Ni}$. As seen in Fig. 8.3, the testing temperature in the range of $25-400^{\circ} \mathrm{C}$ had a strong effect on alloy strength. The YS decreased from $161 \mathrm{MPa}$ to $84 \mathrm{MPa}$ with increasing testing temperature from $25^{\circ} \mathrm{C}$ to $400^{\circ} \mathrm{C}$ (Fig. 8.3a). However, the YS remained rarely constant at $\sim 145 \mathrm{MPa}$ between 200 and $300^{\circ} \mathrm{C}$. In contrast, the alloy UTS decreased linearly with the testing temperature (Fig. $8.3 \mathrm{~b})$. It is seen that the UTS of the alloy decreased from $262 \mathrm{MPa}$ to $102 \mathrm{MPa}$ with increasing temperature from 25 to $400^{\circ} \mathrm{C}$ at a strain rate of $10^{-3} \mathrm{~s}^{-1}$. It should be pointed out that though the alloy modified with additions of $\mathrm{Ti}, \mathrm{Zr}$ and $\mathrm{V}$ showed lower yield strength, the changing trend in YS is lower than for the 354 [22, 96] and A356 [223] alloys and the Al-Si-Cu-Mg alloy modified with additions of $\mathrm{Ti}, \mathrm{Zr}$ and $\mathrm{Ni}[22,96]$. However, the studied alloy achieved consistently higher UTS compared to the published data for $354(\sim 12 \%)$, A356 ( 18\%) and the Al-Si-Cu-Mg alloy modified with additions of $\mathrm{Ti}, \mathrm{Zr}$ and $\mathrm{Ni}$ in the as-cast state $(\sim 5 \%)$ at room temperature. In comparison with the 354 and A356 alloys and the Al-Si-Cu-Mg alloy modified with additions of $\mathrm{Ti}, \mathrm{Zr}$ and $\mathrm{Ni}$, the UTS at $200^{\circ} \mathrm{C}$ for the present studied alloy improved to $11 \%, \sim 94 \%$ and $7 \%$ respectively. It is believed that the presence of the thermally stable precipitates improved the alloy strength at higher temperatures [96, 22].

The MA4 alloy shows higher strength and ductility that the A380 grade for all testing temperatures. The YS of the A380 alloy at room temperature is $159 \mathrm{MPa}$, being slightly lower ( 2\%) than $162 \mathrm{MPa}$ measured for the MA4 alloy. The YS of the MA4 alloy is decreased by $11 \%$ with increasing testing temperature to $200^{\circ} \mathrm{C}$. A similar trend was recorded for the UTS change of both alloys. The UTS of A380 decreased from 211 to $155 \mathrm{MPa}$ with increasing 
temperature to $200^{\circ} \mathrm{C}$. It is clear that the reduction of strength efficiency for the A380 alloy is 0.36 while for the MA4 alloy it was lower, just reaching 0.16 . The calculated quality index

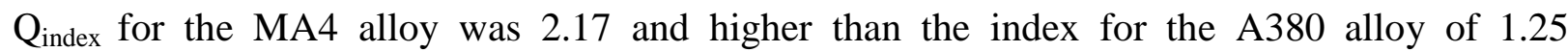
confirming better performance of the former one.
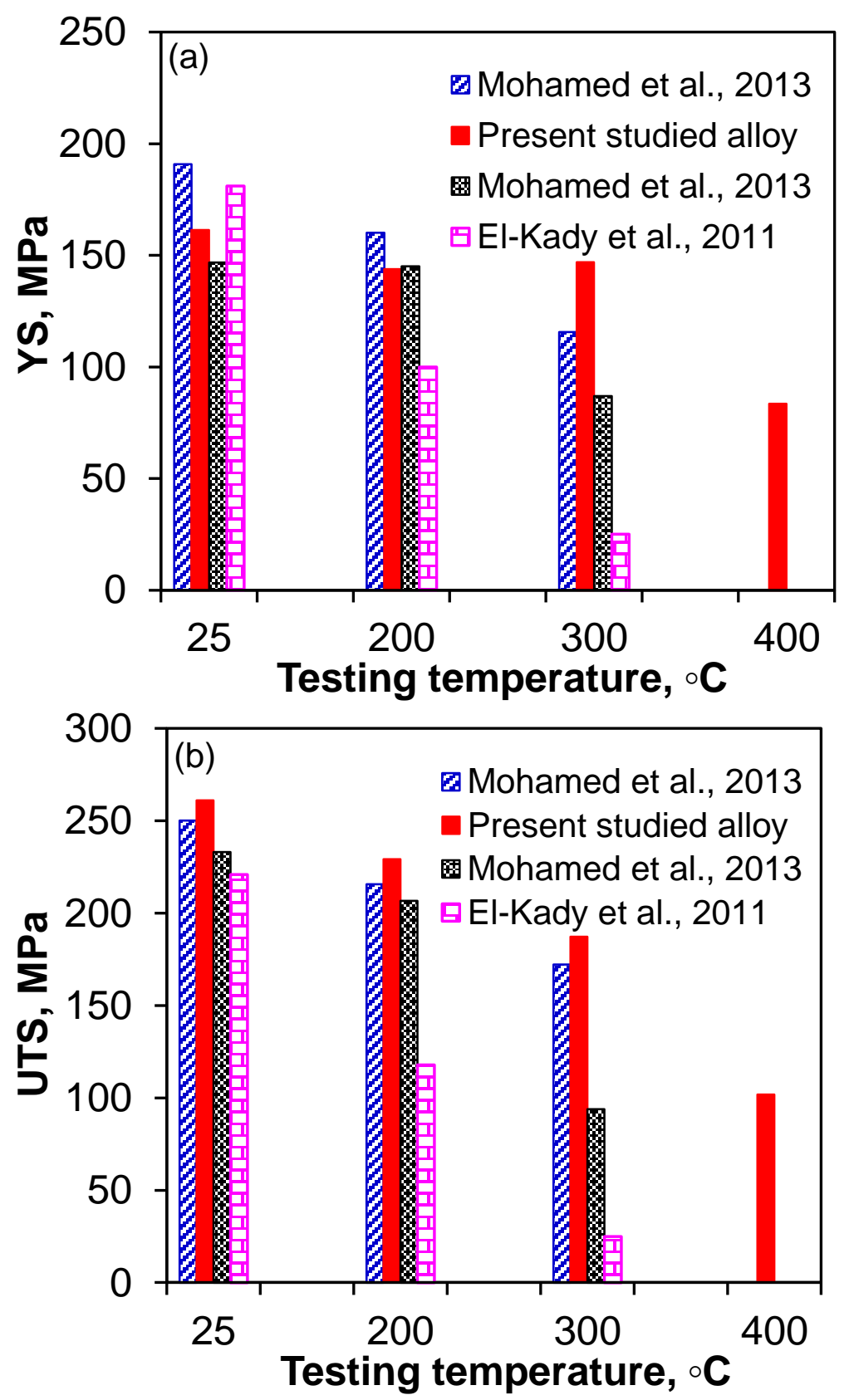

Fig. 8.3. A comparison of the tensile property of the studied cast Al-Si-Cu-Mg alloy with literature data obtained at different temperatures, (a) yield strength (YS) and (b) ultimate tensile strength (UTS). Note: the testing temperature for the study of Mohamed et al., 2013 was $190^{\circ} \mathrm{C}$, instead of $200^{\circ} \mathrm{C}$. 
Present results reveal that $\mathrm{Al}-\mathrm{Si}-\mathrm{Cu}-\mathrm{Mg}$ modified alloys containing $\mathrm{Zr}, \mathrm{V}$ and $\mathrm{Ti}$ exhibited better tensile strength compared to reference alloys [96], at different temperatures as seen in Fig. 8.3. It is noticed that the MA4 alloy room temperature tensile strength is significantly higher than the alloy modified with addition of Zr-Ni in alloy 354. As mentioned by Mohamed et al. [96], addition of Ni to the Al-Si-Cu-Mg alloy has a poisonous effect on the age hardening which reduces the copper content in the matrix and lowers the strength of the MA4 alloy. In contrast, the addition of $\mathrm{Zr}-\mathrm{V}-\mathrm{Ti}$ to the $\mathrm{Al}-\mathrm{Si}-\mathrm{Cu}-\mathrm{Mg}$ alloy caused thermally stable precipitates to form during solidification of the alloy MA4 in conjunction with the copper-containing phases that together increased the alloy strength. Also, the detrimental Fe-containing phase reacts with $\mathrm{Zr}$ $\mathrm{Ti}$ and forms thermally stable precipitates which enhance the alloy performance. As reported in previous studies $[222,101]$, the remarkable enhancement in UTS could be attributed to both the composite-like role of $\mathrm{Cu}-, \mathrm{Fe}-$, and $\mathrm{Mg}$-containing Si precipitates (Fig. 4.4), and the nano-sized trialuminide precipitates which were uniformly distributed in the aluminum matrix or along with the eutectic silicon precipitates. The presence of these micro- and nano-sized precipitates (Fig. 4.4 and 4.9) would effectively impede the movement of dislocations during uniaxial deformation, thus appreciably enhancing the strength of the cast aluminum alloy (Fig. 8.3). Also, the addition of transition metals containing $\mathrm{Zr}-\mathrm{V}-\mathrm{Ti}$ to $\mathrm{Al}$ alloys, changes the morphology of the primary precipitates which can improve the strength and ductility of the alloys [73]. Therefore, it is reasonable to say that the bulk/plate-shaped Ti-V-Zr-rich phases improved the as-cast alloy strength.

As mentioned above, with increasing testing temperature, the tensile strength of $\mathrm{Al}-\mathrm{Si}-\mathrm{Cu}-$ $\mathrm{Mg}$ alloy modified with additions of $\mathrm{Zr}$, Ti and $\mathrm{V}$ decreased linearly. This was primarily due to the change in the microstructure and the presence of trialuminide precipitates, as also reported in [73]. The deformation in crystalline materials is directly related to the generation, motion and 
storage of dislocations, which move at a stress far below that required to deform a defect-free crystal [69]. Therefore, the improvement of material properties such as strength relies on creating internal obstacles to dislocation motion including grain boundaries, precipitates, and other dislocations $[151,152]$. As plastic deformation continues, the density of dislocations increases, causing more frequent interactions that impede their motion [153]. When the temperature is increased, the cross slips are thermally activated by climbing of dislocations resulting in reduction of strength of the materials $[22,96]$. At the same time, grain boundary sliding is also considered to be a reason for the reduction of the alloy strength at higher temperatures. However, the strong resistance to the motion of dislocations, due to the trialuminide precipitates pinning grain and sub-grain boundaries during all thermal and mechanical processing of aluminum alloys causes the improvement of the alloy high temperature properties $[226,227][222,96,126,101]$.

\subsubsection{Effect of SDAS on compressive properties}

The compressive strength and compressability of the MA4 alloy in the as-cast and T6 heat treated conditions tested at room temperature are plotted as a function of SDAS corresponding to the cooling rates in Fig. 8.4 and Table 8.1. It is seen that increasing the SDAS or decreasing the cooling rate caused a reduction in strength while the compressibility increased for both the as-cast and T6 heat treated conditions. The as-cast sample achieved an ultimate strength (US) from $354 \mathrm{MPa}$ to $367 \mathrm{MPa}$ and a compression from $41.6 \%$ to $42.5 \%$ for the SDAS of 18 to 30 $\mu \mathrm{m}$ during monotonic compression loading. In contrast, the T6 heat treated samples show significantly higher US value of $413 \mathrm{MPa}$ to $419 \mathrm{MPa}$ with a higher compressibility value of $51.0 \%$ to $52.4 \%$ in compression for the similar range of SDAS. It is obvious that the present 
studied alloy shows improved US and compressibility than reported in the literature for lower additions of Zr-V-Ti $[63,76]$. The hardening capacity of a material can be expressed by the following equation [228]:
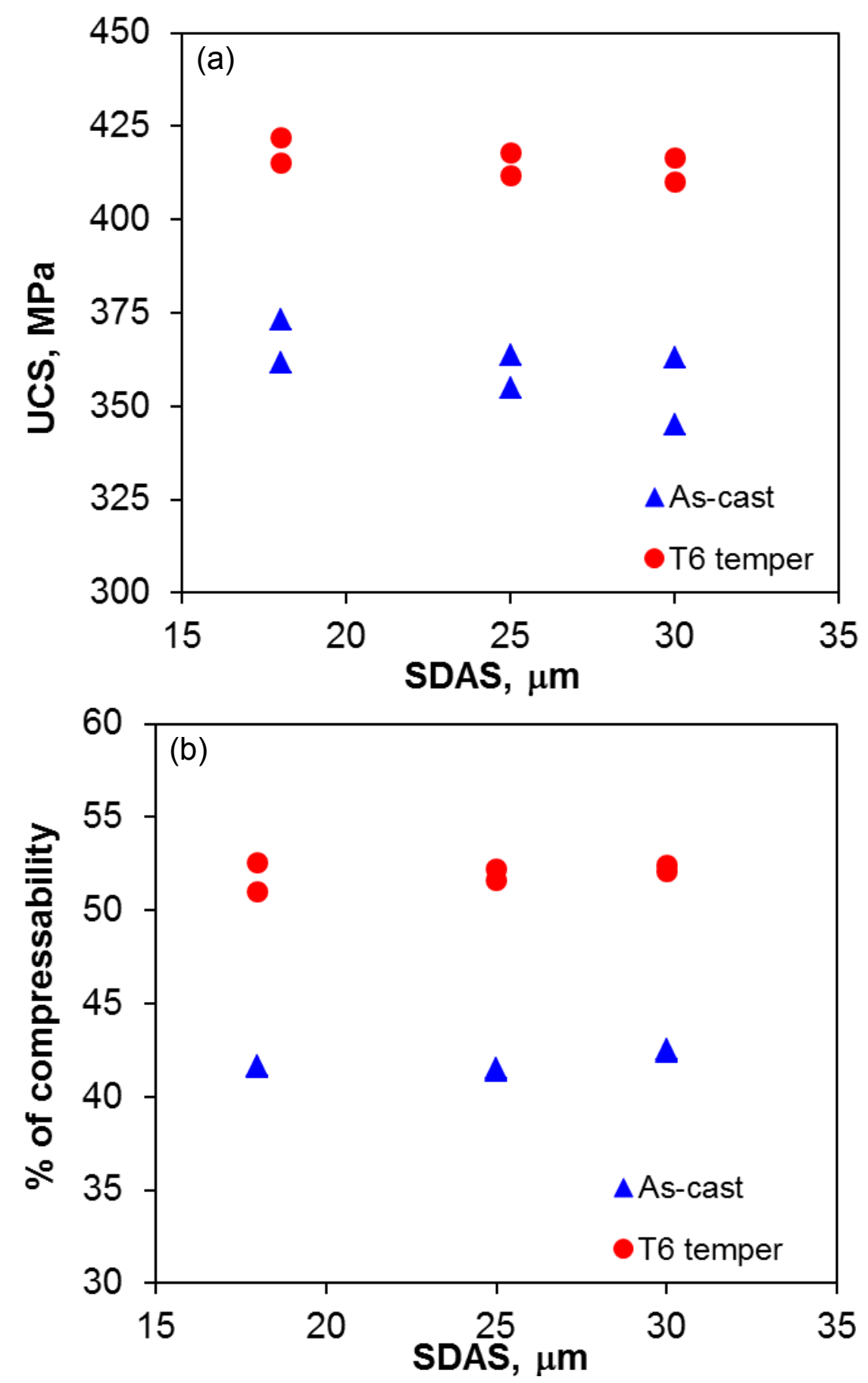

Fig. 8.4. The correlation between compression properties, (a) ultimate compressive stress (UCS) and (b) \% of compressability, and SDAS for as-cast and T6 heat treated Al$\mathrm{Si}-\mathrm{Cu}-\mathrm{Mg}$ alloy modified with $\mathrm{Ti}, \mathrm{V}$ and $\mathrm{Zr}$. 


$$
H_{C}=\frac{\sigma_{U S}-\sigma_{Y}}{\sigma_{Y}}=\frac{\sigma_{U S}}{\sigma_{Y}}-1
$$

where $H_{c}$ is the hardening capacity, $\sigma_{\mathrm{US}}$ is the ultimate strength, and $\sigma_{Y}$ is the yield strength. The calculated values of the hardening capacity during compression are given in Table 8.1. It is evident that due to changes of SDAS from 18 to $30 \mu \mathrm{m}$, the hardening capacity decreased from 0.68 to 0.57 in the as-cast condition and from 0.41 to 0.39 in the T6 heat treated condition during compression loading.

Table 8.1 Hardening parameters of the studied alloy MA4 during compression test.

\begin{tabular}{cccccccc}
\hline $\begin{array}{c}\text { Sample } \\
\text { condition }\end{array}$ & $\begin{array}{c}\text { SDAS, } \\
\mu \mathrm{m}\end{array}$ & $\begin{array}{c}\text { Cooling } \\
\text { rates, }{ }^{\circ} \mathrm{C} / \mathrm{s}^{-1}\end{array}$ & $H c$ & $n_{1}$ & $\begin{array}{c}K, \\
\mathrm{MPa}\end{array}$ & $n^{*}$ & $\begin{array}{c}K^{*}, \\
\mathrm{MPa}\end{array}$ \\
\hline \multirow{3}{*}{ As-cast } & 18 & 10 & 0.68 & 0.25 & 563 & 0.52 & 392 \\
\cline { 2 - 7 } & 25 & 18.6 & 0.57 & 0.23 & 506 & 0.44 & 367 \\
\cline { 2 - 7 } & 30 & 35.8 & 0.52 & 0.27 & 546 & 0.43 & 364 \\
\hline \multirow{3}{*}{ T6 } & 18 & 10 & 0.41 & 0.17 & 584 & 0.40 & 408 \\
\cline { 2 - 7 } & 25 & 18.6 & 0.40 & 0.18 & 587 & 0.63 & 459 \\
\hline
\end{tabular}

It is also seen that the hardening capacity of the currently studied alloys was significantly higher than reported in the literature for lower additions of $\mathrm{Zr}-\mathrm{V}-\mathrm{Ti}$. Usually, when a material is strengthened, the YS increases while the hardening capacity increases due to an increase in capacity of dislocation storage during plastic deformation [228, 229]. This was mainly attributed to the lower YS, and higher US and deformability of the alloy in this study.

Another parameter characterizing plastic deformation of a material is the strain hardening exponent $n$, which can be evaluated from the true stress-true strain curves. The values of $n_{l}$ and strengthening coefficient $K$ could be determined according to the following Hollomon's equation:

$$
\sigma=K \varepsilon^{n}{ }_{1}
$$

where $\sigma$ is the true stress, and $\varepsilon$ is the corresponding true strain. The strain hardening exponent $n_{1}$ was evaluated for the uniform plastic deformation region from the YS point up to 
the US point (Table 8.1). The as-cast samples exhibited an increasing tendency of strain hardening exponent from 0.25 to 0.27 with increasing the SDAS value from 18 to $30 \mu \mathrm{m}$ during compression loading. In contrast, for the T6 temper samples, the strain hardening value decreased to $\sim 0.18$ which was almost constant for similar ranges of SDAS. The obtained strengthening coefficient $K$ also decreased from 563 to $546 \mathrm{MPa}$ for the SDAS values of 18 to $30 \mu \mathrm{m}$ in the as-cast state; while it increased from 584 to $594 \mathrm{MPa}$ for the similar range of SDAS for the T6 heat treated condition. The $n_{1}$ value of the T6 temper sample is in agreement with that reported in $[222,230]$ for A356-T6 alloy where $n \approx 0.17$ was obtained. The strain hardening exponent was also reported to be strongly dependent on the ageing temperature for the A356-T6 alloy with $n_{1}$ values ranging from 0.08 to 0.17 [101, 231].

Feltham and Meakin [177] modified Eq [8.2] by incorporating the uniform plastic deformation for better understanding of hardening behavior of the materials as follows:

$$
\left(\sigma-\sigma_{y}\right)=K *\left(\varepsilon-\varepsilon_{y}\right)^{n^{*}}
$$

where $\left(\sigma-\sigma_{y}\right),\left(\varepsilon-\varepsilon_{y}\right), n^{*}$ and $K^{*}$ are the plastic flow stress, the corresponding plastic strain, plastic strain hardening exponent and strengthening coefficient of plastic flow stress, respectively. It is seen in Table 8.1 that increasing the SDAS from 18 to $30 \mu \mathrm{m}$ caused a decrease in the hardening exponent from 0.52 to 0.43 in the as-cast state while increasing from 0.40 to 0.62 in the T6 heat treated condition. In comparison with the strengthening coefficient $K$ of Hollomon's equation, the strengthening coefficient $K^{*}$ shows similar trends for both as-cast and T6 heat treated conditions. It is found that after decreasing the SDAS value from 30 to 18 $\mu \mathrm{m}$, the as-cast sample achieved a strengthening coefficient, $K^{*}$ between 364 and $392 \mathrm{MPa}$. In contrast, the T6 heat treated sample attained a significantly higher strengthening coefficient 
between 532 and $408 \mathrm{MPa}$ for the same range of SDAS. This can be attributed to the secondary precipitate presents in $\mathrm{T} 6$ heat treated samples.

The effect of cooling rate during solidification on the deformability is complex, since it modified not only the SDAS spacing but also the size of primary precipitates. Thus, the relationship between deformability and cooling rate is not simply beneficial to the ductility. Deformability is related to casting defects and the rate of particle cracking is related, in turn, to the stress build up. The microstructure contained large, elongated particles with sharp edges but small dislocation slip distances and exhibited a high rate of particle cracking which resulted in lowering the deformability of the as-cast alloy (Fig. 8.4b). In contrast, the finer structure with more rounded particles as well as long dislocation slip distances resulted in a lower particle cracking rate causing higher deformability. As the cooling rate increases, the eutectic particles experience refining accompanied by reduced dislocation slip distance due to smaller SDAS $[145,158,232]$. Therefore, the relationship between ductility and the cooling rate during solidification depends on the combination of these two counteracting effects. In contrast, the T6 heat treated alloy further modified the size and morphology of the eutectic silicon, $\mathrm{Cu}-, \mathrm{Mg}$ - and $\mathrm{Zr}-\mathrm{V}-\mathrm{Ti}$-containing precipitates. As a result, in the $\mathrm{T} 6$ heat treated alloy the ductility significantly increased with decreasing cooling rate (Fig. 8.4b).

\subsection{Low Cycle Fatigue Properties}

\subsubsection{Influence of alloying elements on fatigue life}

The advancement of cyclic stress amplitude is shown as a function of the number of cycles for different strain amplitudes in Fig 8.5, for base Al-Si-Cu-Mg alloy and alloys modified with addition of Ti/V/Zr. Generally, all the alloys including the as-cast base alloy showed higher 
hardening behavior during the progress of cyclic loading. It is depicted that with increasing strain amplitudes, stress amplitude is increased and fatigue life decreased.

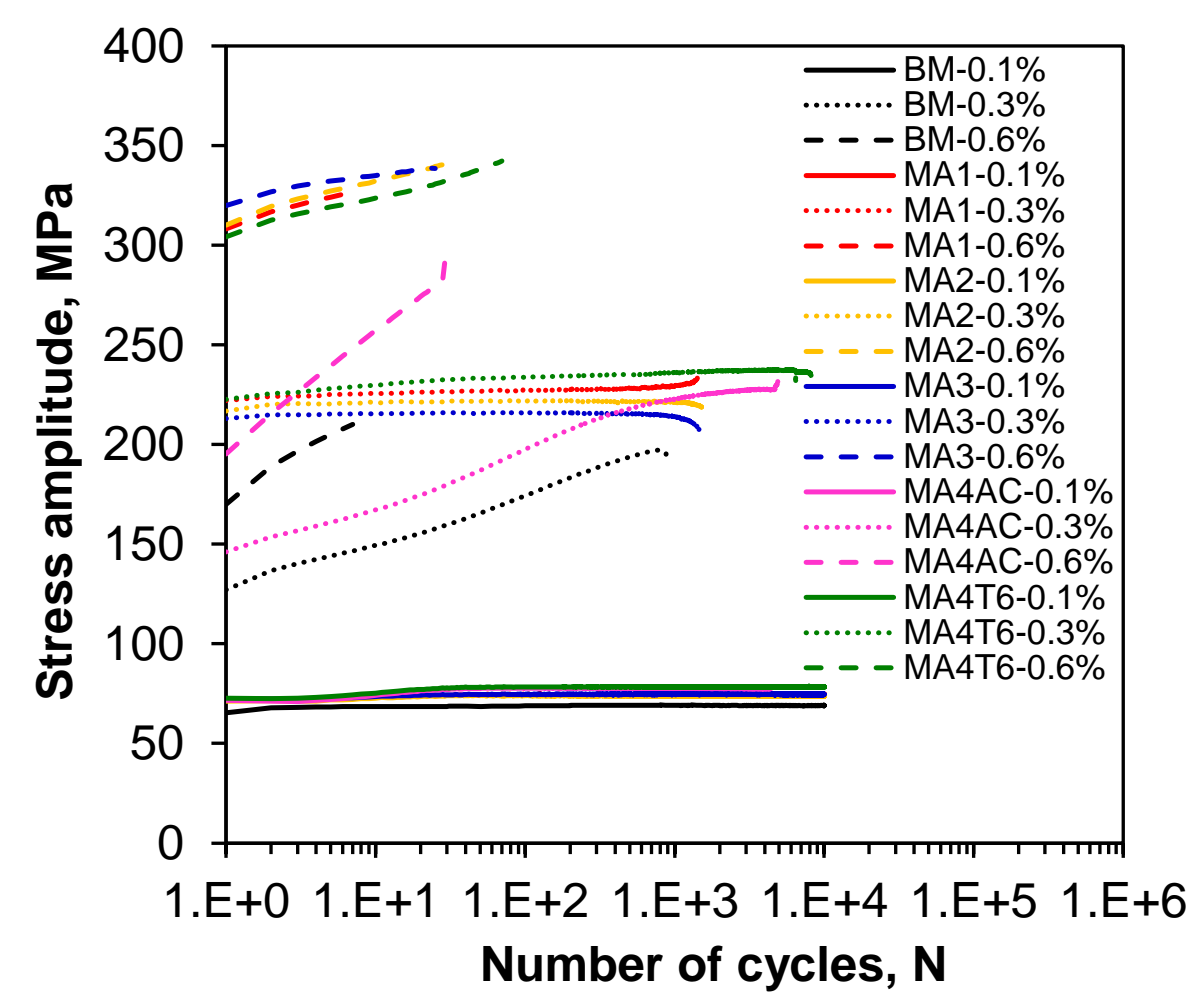

Fig. 8.5. A plot of stress amplitude versus number of cycles for the studied alloys with the base alloy obtained from LCF testing.

It is also noticed that the as-cast alloy attained a higher hardening rate compared to the T6 heat treated alloys. The studied alloys show hardening behavior, a property that has been reported for both cast Al-Si-Cu-Mg alloy and Ti/V/Zr intermetallics [101, 129]. For higher total strain amplitude $(0.6 \%)$, strain hardening continues from initial cycles up to failure for all alloys. At lower total strain amplitudes $(0.1 \%)$ the cyclic stress was almost constant for the entire fatigue life. However, the total stress amplitude increased for the as-cast alloys and was almost constant for the T6 heat treated alloys at a total strain amplitude of $0.3 \%$. The initial cyclic stress amplitudes for the as-cast base alloy and as-cast modified alloy MA4 are about the same at a lower strain amplitude of $0.1 \%$. At the same time, with increasing the total strain amplitude from $0.3 \%$ to $0.6 \%$, the initial cyclic stress amplitudes increased from $\sim 20$ to $25 \mathrm{MPa}$ for the as- 
cast modified alloy MA4 compared to the as-cast base alloy. In contrast, the values of initial cyclic stress amplitudes are very close for the four modified alloys in the T6 heat treated condition at lower stain amplitude of $0.1 \%$, while a value of $\sim 15 \mathrm{MPa}$ higher stress amplitude was seen for the modified alloy MA3 compared to the alloy MA4 for the sample tested at a higher strain amplitude of $0.6 \%$.

Fig. 8.6 shows the plot of strain and the number of cycles to failure (generally known as $\varepsilon-N$ curves) for the alloys in the as-cast and T6 tempered conditions along with the base alloy. It is seen that the fatigue life increased with decreasing total strain amplitudes for all the alloys. It is also evident that with increasing the level of alloying additions the fatigue life of the modified alloys increased. The fatigue life of the base alloy was the shortest one as compared to the modified alloys in the as-cast state MA4, which is even longer that the alloys MA1, MA2 and MA3 in the T6 heat treated state. The fatigue life of alloy MA4 further increased due to T6 heat treatment. It should be noted that, if the alloy fatigue life reached $10^{7}$ cycles without failure, referred as an infinite fatigue life, it is considered that the alloy passed the fatigue test. Hence, at a strain amplitude of $0.1 \%$, the alloy MA4 in both states, (as-cast and T6) passed the fatigue test, while the other alloys MA1, MA2 and MA3 including the as-cast base alloy failed to achieve an infinite fatigue life. It also should be noted that the fatigue data of cast alloys normally exhibited a fairly large scatter due to the microstructural variations, especially the type and size of casting defects [233], which will be discussed later. The improved fatigue resistance of the MA4 alloy was mainly attributed to the composite-like strengthening and precipitation strengthening of tri-aluminide phases that became more significant upon introducing more alloying elements (i.e., $\mathrm{Zr}$, Ti and V). 


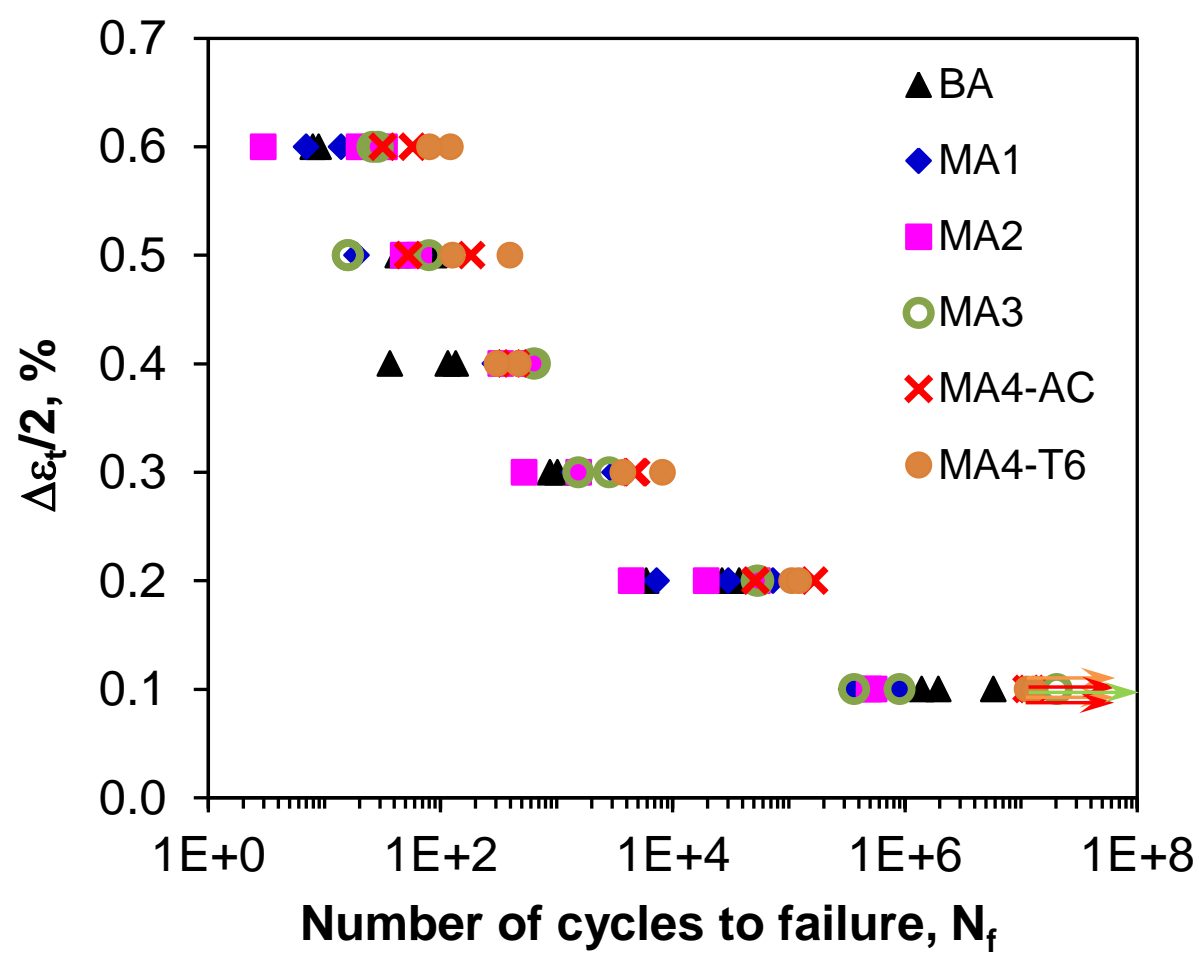

Fig. 8.6. Fatigue life of the cast $\mathrm{Al}-\mathrm{Si}-\mathrm{Cu}-\mathrm{Mg}$ alloys with addition of $\mathrm{Ti} / \mathrm{V} / \mathrm{Zr}$ obtained at total strain amplitudes of $0.1-0.6 \%$ in comparison with base alloy.

To quantify better the cyclic strain hardening behavior of the alloys, the cyclic stress-strain parameters were characterized using the Hollomon power law described as follows [111, 234]:

$$
\frac{\Delta \sigma}{2}=K^{\prime}\left(\frac{\Delta \varepsilon_{p}}{2}\right)^{n_{l}^{\prime}}
$$

where $\Delta \sigma$ is the total stress range at mid-life and $\Delta \varepsilon_{p}$ is the corresponding total plastic strain range, $n_{l}{ }^{\prime}$ is the cyclic strain hardening exponent, and $K^{\prime}$ is the cyclic strength coefficient.

During LCF, the total strain amplitude consists of elastic strain amplitude and plastic strain amplitude as shown in the following relation [111, 231]:

$$
\frac{\Delta \varepsilon_{t}}{2}=\frac{\Delta \varepsilon_{e}}{2}+\frac{\Delta \varepsilon_{p}}{2}
$$


where $\frac{\Delta \varepsilon_{\mathrm{t}}}{2}$ is the total elastic strain amplitude, $\frac{\Delta \varepsilon_{e}}{2}$ is the elastic strain amplitude and $\frac{\Delta \varepsilon_{p}}{2}$ is the plastic strain amplitude.

The relation between elastic strain amplitude and number of reversals fatigue life $\left(2 N_{f}\right)$ can be represented by the well-known Basquin equation as follows [101, 231]:

$$
\frac{\Delta \varepsilon_{e}}{2}=\frac{\sigma_{f}^{\prime}}{E}\left(2 N_{f}\right)^{b^{\prime}}
$$

where $E$ is Young's modulus, $N_{f}$ is the number of cycles to failure, $\sigma_{f}^{\prime}$ is the fatigue strength coefficient and $b^{\prime}$ is the fatigue strength exponent.

Again, the relation between plastic strain amplitude and the number of reversals fatigue life $\left(2 N_{f}\right)$ can be represented by the well-known Coffin-Manson equation as follows [101, 231]:

$$
\frac{\Delta \varepsilon_{p}}{2}=\varepsilon_{f}^{\prime}\left(2 N_{f}\right)^{c}
$$

where $\varepsilon_{f}^{\prime}$ is the fatigue ductility coefficient and $c$ is the fatigue ductility exponent.

Combining both Eq. (8.7) and Eq. (8.8), fatigue life can be estimated using the following relationship known as Coffin-Manson-Basquin [231]:

$$
\frac{\Delta \varepsilon_{t}}{2}=\frac{\Delta \varepsilon_{e}}{2}+\frac{\Delta \varepsilon_{p}}{2}=\frac{\sigma_{f}^{\prime}}{E}\left(2 N_{f}\right)^{b}+\varepsilon_{f}^{\prime}\left(2 N_{f}\right)^{c}
$$

In the present study, the values of elastic or plastic strain amplitudes are taken at half-life from the hysteresis loops of each material considering the stable condition of the LCF. As seen in Fig. 8.7, the log-log plot of Eq. (8.7) and Eq. (8.8) were used to evaluate the fatigue parameters. The evaluated fatigue parameters of the studied alloys including the as-cast base alloy are summarized in Table 8.2. 

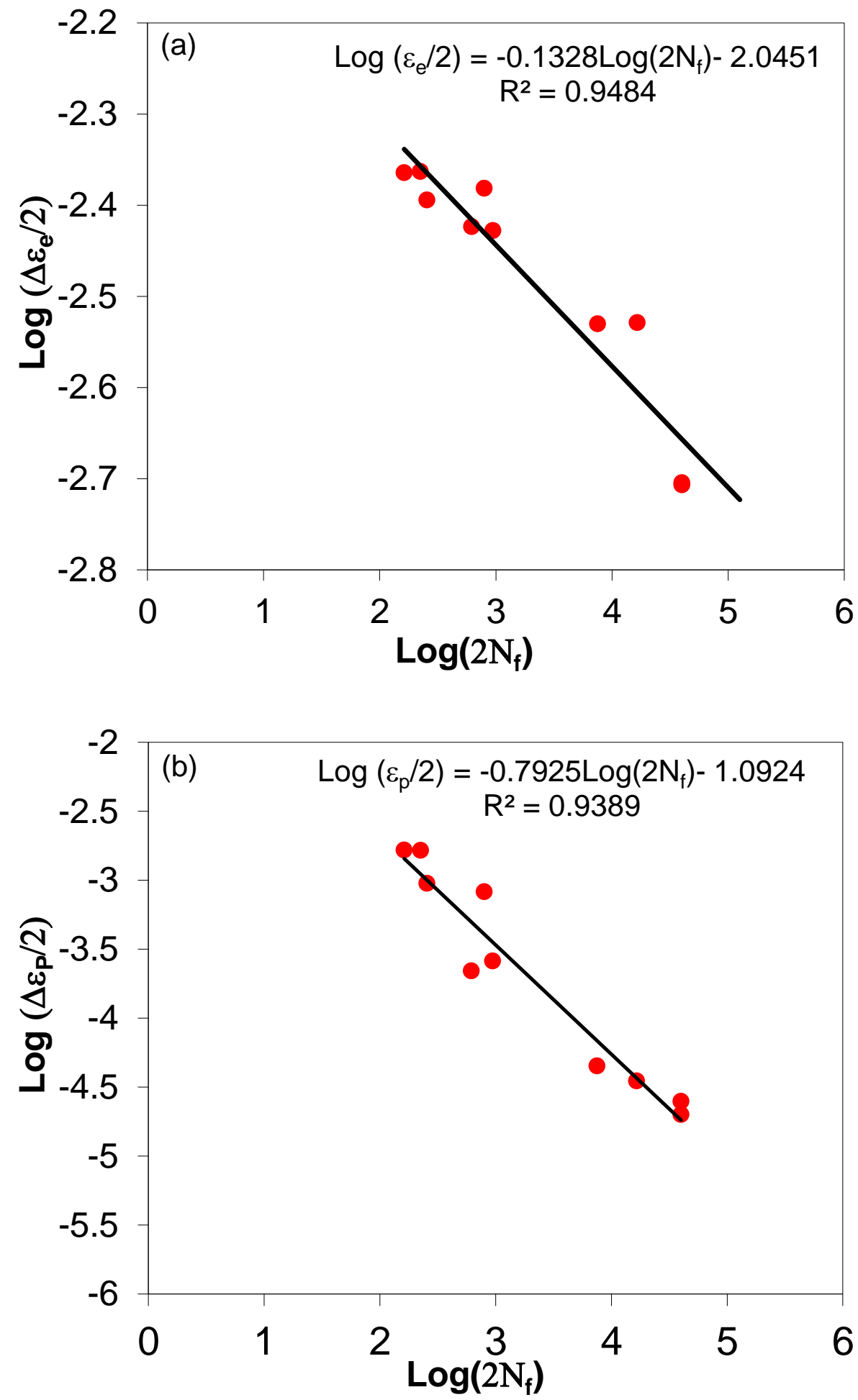

Fig. 8.7. Plot of fatigue tested data of Al-Si-Cu-Mg alloy with addition of Ti, $\mathrm{V}$ and $\mathrm{Zr}$ in $\mathrm{T} 6$ heat treated condition; (a) Basquin plot and (b) Coffin-Manson plot. 
The as-cast samples exhibited cyclic strain hardening parameters, $n_{l}{ }^{\prime}$ and $K^{\prime}$ of 0.07 and 323 $\mathrm{MPa}$ for the base and 0.09 and $474 \mathrm{MPa}$ for the alloy MA4 which is similar to the alloy modified with addition of $\mathrm{Ti}$ in the amount of 0.1 to $0.14 \mathrm{wt} \% .\left(n_{l}^{\prime}=0.115-0.154\right.$ and $K^{\prime}=335$ $380 \mathrm{MPa}$ ) [235]. In contrast, the $n_{1}^{\prime}$ and $K^{\prime}$ values significantly improved due to T6 heat treatment. The presently investigated alloys modified with addition of Ti (MA1), Ti-Zr (MA2) and Ti-Zr-V (MA3) obtained the $n_{l}{ }^{\prime}$ and $K^{\prime}$ values of 0.24 and $1758 \mathrm{MPa}, 0.27$ and $2138 \mathrm{MPa}$, and 0.28 and $2393 \mathrm{MPa}$ similar to the A356-T6 alloy $\left(n^{\prime}=0.24\right.$ and $\left.K^{\prime}=1628 \mathrm{MPa}\right)$ [222].

Table 8.2 Evaluated materials constants for LCF of the base and modified alloys of Al-Si-Cu$\mathrm{Mg}$ alloy with addition of $\mathrm{Ti} / \mathrm{V} / \mathrm{Zr}$ in as-cast and $\mathrm{T} 6$ heat treated conditions.

\begin{tabular}{|c|c|c|c|c|c|c|}
\hline \multirow{2}{*}{ Low cycle fatigue parameters } & \multirow{2}{*}{$\mathrm{BA}$} & \multirow{2}{*}{ MA1 } & \multirow{2}{*}{ MA2 } & \multirow{2}{*}{ MA3 } & \multicolumn{2}{|c|}{ MA4 } \\
\hline & & & & & $\mathrm{AC}$ & T6 \\
\hline Cyclic yield strength, $\sigma_{y}^{\prime}, \mathrm{MPa}$ & 205 & 330 & 344 & 347 & 262 & 335 \\
\hline Cyclic strain hardening exponent, $n^{\prime}$ & 0.07 & 0.24 & 0.27 & 0.28 & 0.09 & 0.16 \\
\hline Cyclic strength coefficient, $K^{\prime}, \mathrm{MPa}$ & 323 & 1758 & 2183 & 2393 & 474 & 958 \\
\hline Fatigue strength coefficient, $\sigma_{f}^{\prime}$, & 268 & 560 & 648 & 609 & 386 & 694 \\
\hline Fatigue strength exponent, $b^{\prime}$ & -0.05 & -0.13 & -0.15 & -0.14 & -0.08 & -0.13 \\
\hline Fatigue ductility coefficient, $\varepsilon_{f}^{\prime}, \%$ & 4.21 & 0.43 & 0.51 & 0.46 & 9.21 & 8.08 \\
\hline Fatigue ductility exponent, $c$ & -0.71 & -0.43 & -0.46 & -0.43 & -0.77 & -0.79 \\
\hline $\begin{array}{l}\text { Plastic strain energy density } \\
\text { exponent, } \gamma\end{array}$ & -0.75 & -0.73 & -0.81 & -0.75 & -0.84 & -0.92 \\
\hline $\begin{array}{l}\text { Plastic strain energy density } \\
\text { coefficient, } \Delta W p, \mathrm{MJ}^{*} \mathrm{~m}^{-3}\end{array}$ & 37 & 14 & 26 & 16 & 120 & 162 \\
\hline
\end{tabular}

However, the alloy MA4 in the T6 state obtained $n_{l}{ }^{\prime}$ and $K^{\prime}$ values of 0.16 and $958 \mathrm{MPa}$, which is lower than the alloy MA3 in the T6 state. Also, the alloy cyclic hardening is related to the monotonic tensile YS and cyclic YS. If the alloy cyclic YS is higher than the monotonic tensile YS, it will have a stronger hardening ability under cyclic loading. In other words, if the alloy cyclic YS is lower than the monotonic tensile YS, it will have a softening ability under cyclic loading. In the present study, all the alloys including the as-cast base and modified alloys 
exhibited remarkably higher cyclic YS (Table 8.2) compared to the monotonic tensile YS (Fig. 8.2a) leading to the strong cyclic hardening of the alloys. Another parameter, fatigue ductility coefficient, $\varepsilon_{f}$ for the modified alloys MA1 to MA3 was between 0.43 and $0.51 \%$. However, the fatigue ductility coefficient of the alloy MA4 in both conditions, as-cast and T6 state was 9.21 and $8.08 \%$ leading to the fatigue life which is considerably longer than the other as-cast base and modified alloys. Thus, it could be concluded that the present alloy MA4 has significantly better fatigue properties compared to the other $\mathrm{Al}-\mathrm{Si}-\mathrm{Cu}-\mathrm{Mg}$ alloys modified with lower additions of $\mathrm{Zr} / \mathrm{Ti} / \mathrm{V}$.

\subsubsection{Influence of alloying elements on strain energy density}

The fatigue failure process of alloys is a typical energy-absorption process. It is associated with the nucleation of the cracks and subsequent propagation of the fatigue crack due to local yielding and absorbing the irreversible plastic work. So, the fatigue properties of the alloys can be characterized and evaluated by the change of deformation energy during the cyclic loading. A cyclically loaded material absorbs a certain amount of energy in every cycle, which is usually characterized by a hysteresis loop area. Numerous experiments have proved that the accumulation of fatigue damage is clearly governed by the plastic strain amplitude $\varepsilon_{p}$. Thus, the plastic strain energy density is an important parameter to characterize the fatigue failure considering both cyclic stress and cyclic strain. Similar to Eq. (8.5), the well-known CoffinManson relationship, the total strain energy $\Delta W_{t}$ are the combination of the elastic strain energy density $\Delta W_{e}$ and the plastic strain energy density $\Delta W_{p}$ which can be described as follows:

$$
\Delta W_{e}=\frac{\Delta \sigma e^{\Delta \varepsilon} e}{2}=\frac{\Delta \varepsilon_{e}^{2} E}{2}
$$




$$
\begin{gathered}
\Delta W_{p}=4 \frac{\Delta \varepsilon}{2} \cdot \frac{\Delta \sigma}{2} \cdot \frac{1-n^{\prime}}{1-n^{\prime}}=\Delta \varepsilon_{p} \cdot \Delta \sigma \cdot \frac{1-n^{\prime}}{1-n^{\prime}} \\
\Delta W_{t}=\Delta W_{e}+\Delta W_{p}
\end{gathered}
$$

where E is the elastic modulus, $\frac{\Delta \sigma}{2}$ is the elastic stress amplitude.

Using the experimental data and Eq. (8.1)-(8.12), the elastic strain energy density $\Delta W_{e}$, the plastic strain energy density $\Delta W_{p}$ and the total strain energy $\Delta W_{t}$ were calculated and plotted with respect to the number of cycles to failure $\left(N_{f}\right)$. As seen in Fig. 8.8, the elastic, plastic and total energy at a lower strain amplitude of $0.1 \%$ was remain basically constant throughout the entire LCF for all the alloys in both conditions. Increasing the total strain amplitude from $0.3 \%$ to $0.6 \%$, the elastic strain energy density increased, while the plastic and total strain energy density decreased through the entire fatigue life of the as-cast alloy.

In comparison with the as-cast alloys, the elastic strain energy density was constant at $0.3 \%$ total strain amplitude and increased at $0.6 \%$ total strain amplitude for the T6 heat treated alloy. At the same time the plastic strain energy density decreased with the progress of fatigue life cycles for the strain amplitude of $0.3 \%$ and $0.6 \%$. It is also noticed that the initial plastic strain density for the as-cast base alloy was lower than the as-cast MA4 alloy at a strain amplitude of $0.6 \%$. In contrast, the plastic strain energy density of alloy MA1 and MA2 in the T6 state is about the same. At the same time the MA4 alloy exhibits higher plastic energy density compared to the other T6 heat treated alloys while the MA3 alloy shows lower plastic energy density.

Since the plastic strain of the alloys dominates the key role in determining the LCF properties, the fatigue life can be described by the plastic strain energy density under cyclic 
loading. Hence, the fatigue resistance of the alloy can be defined by the well-known HalfordMarrow equation:
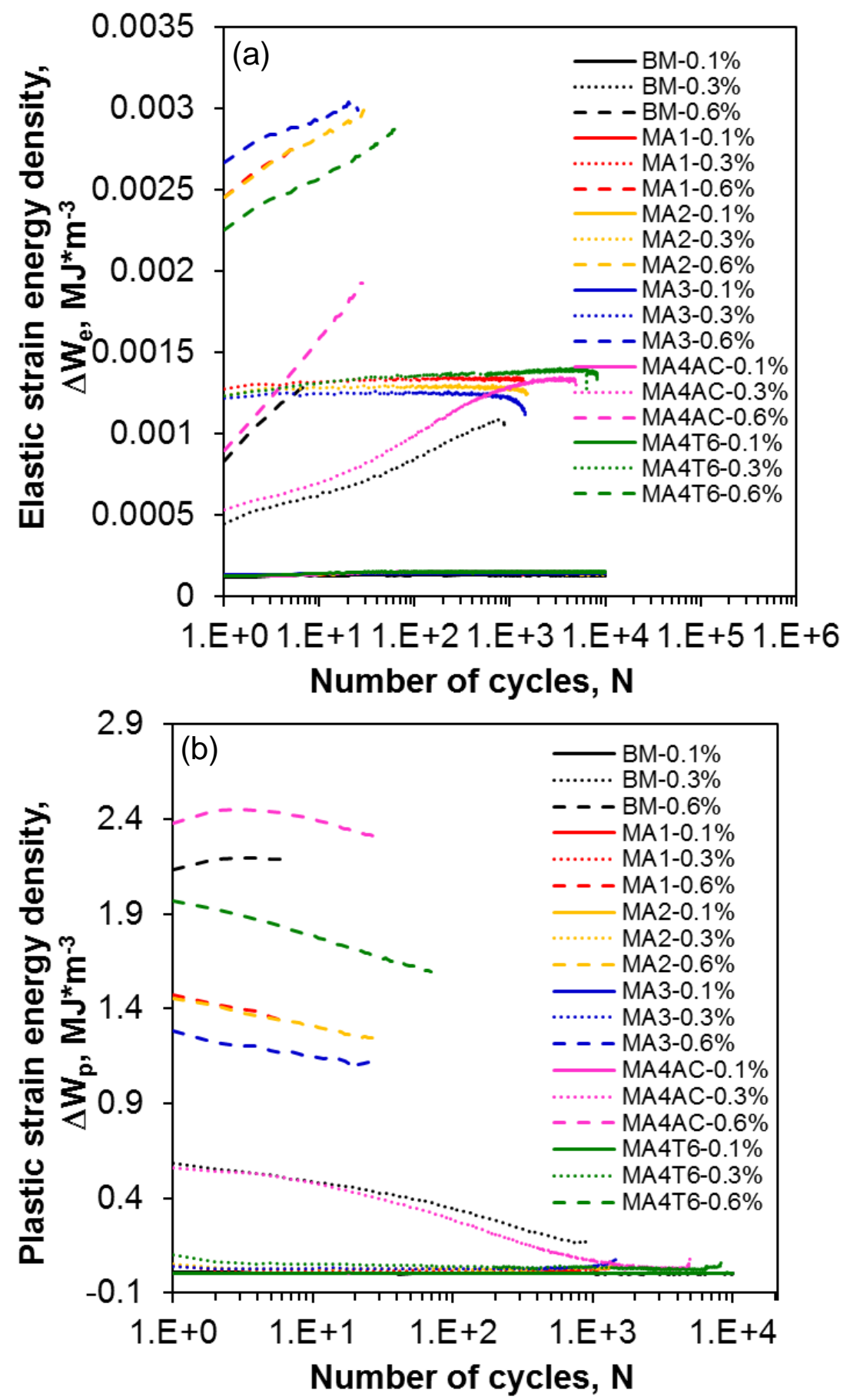

Fig. 8.8. Plot of the low cycle fatigue tests data of cast Al-Si-Cu-Mg alloy with addition of $\mathrm{Ti} / \mathrm{V} / \mathrm{Zr}$, (a) cyclic elastic strain energy density versus the number of cycles, (b) cyclic plastic strain energy density versus the number of cycles (continue to next page). 


$$
\Delta W_{p}=W_{f}^{\prime}\left(2 N_{f}\right)^{\gamma}
$$

where $\Delta W_{f}^{\prime}$ and $\gamma$ are the plastic strain energy density coefficient and exponent which are employed to evaluate the fatigue resistance of alloys.

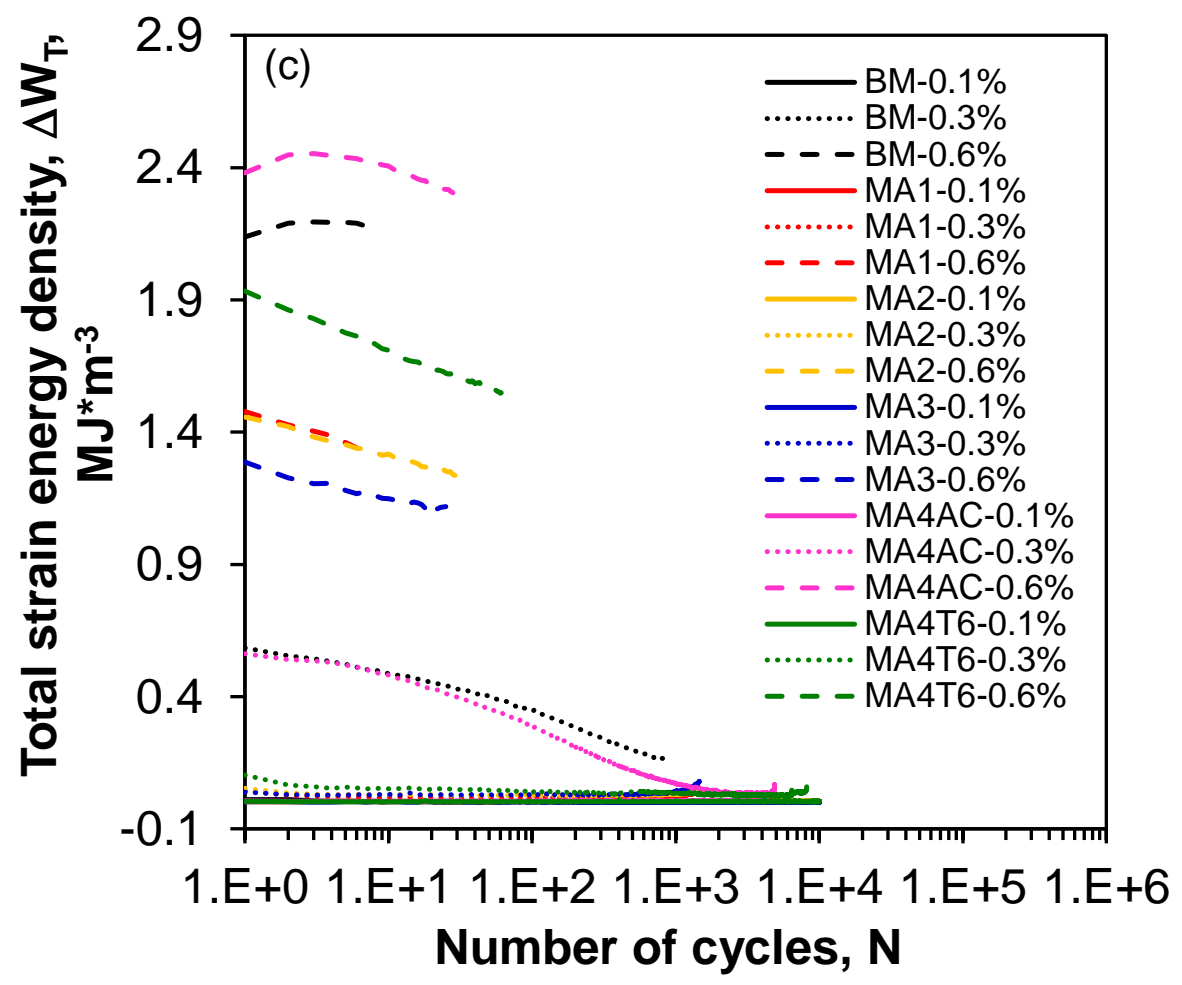

Fig. 8.8. Plot of the low cycle fatigue tests data of cast Al-Si-Cu-Mg alloy with addition of $\mathrm{Ti} / \mathrm{V} / \mathrm{Zr}$, (a) cyclic elastic strain energy density versus the number of cycles, (b) cyclic plastic strain energy density versus the number of cycles and (c) cyclic total strain energy density versus the number of cycles.

In general, if the materials constant is higher, the consumption of the total energy during the cyclic deformation will be larger, leading to a longer fatigue life. As seen in Fig. 8.9, a typical $\log -\log$ plot of Eq. (8.13) for the alloy MA4 in the T6 heat treated condition was used to evaluate the fatigue parameters. The values of the above fatigue parameters were determined using linear regression and are provided in Table 8.2 for the present studied alloys with the base alloy. 


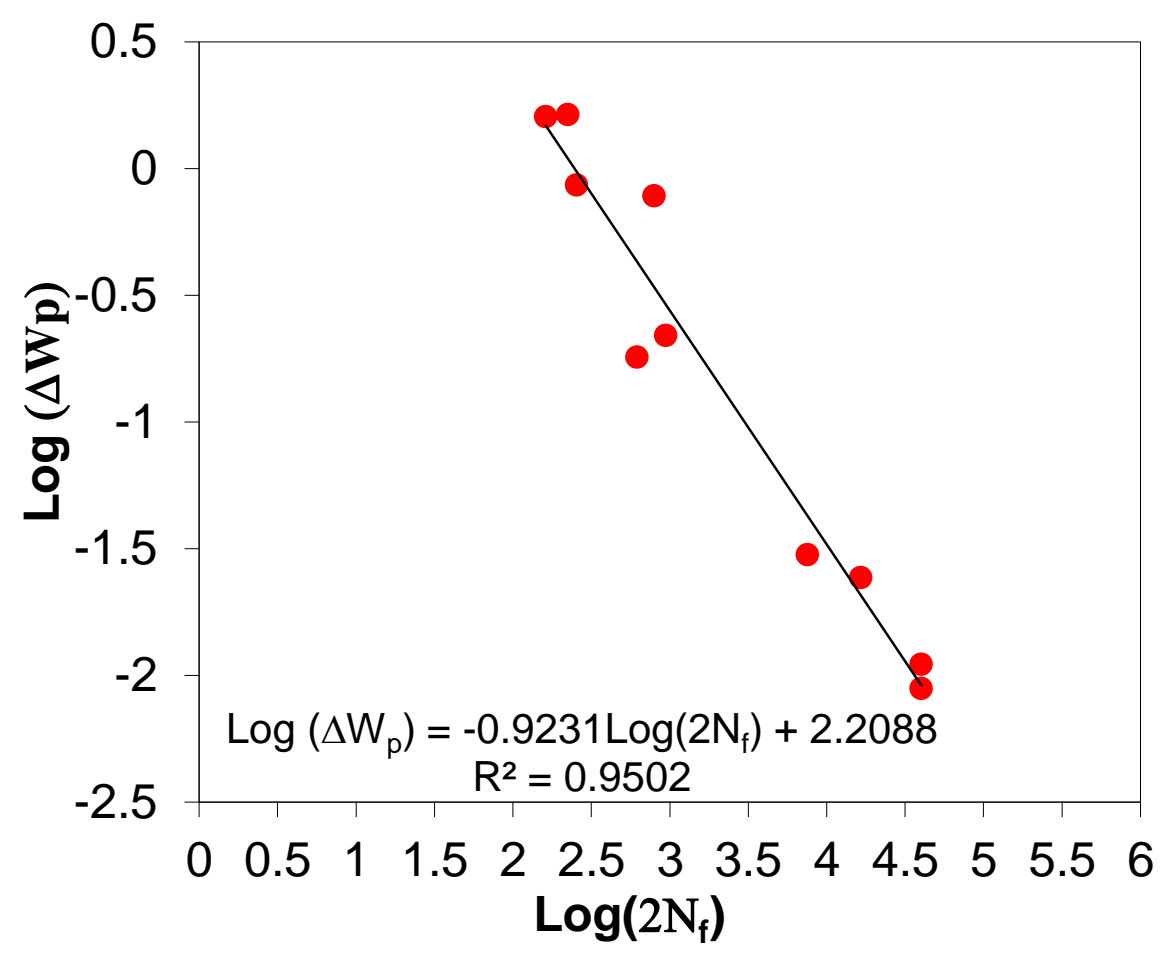

Fig. 8.9. Plot of Halford-Marrow equation for the fatigue tested data of Al-Si-Cu-Mg alloy with addition of $\mathrm{Ti}, \mathrm{V}$ and $\mathrm{Zr}$ in $\mathrm{T} 6$ heat treated condition.

It is seen that the as-cast base alloy obtained a plastic strain energy density coefficient and exponent of $37 \mathrm{MJ} \cdot \mathrm{m}^{-3}$ and -0.75 . In contrast, the other $\mathrm{Al}-\mathrm{Si}-\mathrm{Cu}-\mathrm{Mg}$ alloys with lower additions of Ti (MA1), Ti-Zr (MA2) and Ti-Zr-V (MA3) in the T6 temper condition, the plastic strain energy density coefficient and exponent both decreased between 14 and $26 \mathrm{MJm}^{-3}$, and between -0.73 and -0.81 , respectively. In comparison with the other modified alloys including as-cast base alloy, the alloy MA4 contains a higher addition of $\mathrm{Ti}-\mathrm{V}-\mathrm{Zr}$ that significantly increased the parameters to $120 \mathrm{MJ} \cdot \mathrm{m}^{-3}$ and -0.84 in the as-cast state. The parameters further increased to $162 \mathrm{MJ} \cdot \mathrm{m}^{-3}$ and -0.92 in the T6 heat treated MA4 alloy. Thus, it could be concluded that the MA4 alloy has significantly better fatigue properties compared to the other tested Al-Si$\mathrm{Cu}-\mathrm{Mg}$ alloys with additions of Ti (MA1), Ti-Zr (MA2) and Ti-Zr-V (MA3) in the T6 temper condition. 


\subsubsection{Effect of SDAS on fatigue behavior of the alloy}

The response of fatigue life as a function of different SDAS corresponding to the cooling rates at a fixed total strain amplitude during LCF tests is shown in Fig. 8.10 for the modified alloy MA4 in the T6 temper condition. In general, the fatigue life decreased with increasing SDAS or decreasing cooling rate. At a lower SDAS of $18 \mu \mathrm{m}\left(35.8^{\circ} \mathrm{C} / \mathrm{s}\right.$ cooling rate), the alloy achieved a fatigue life of $\sim 11484$ cycles. With an increase of the SDAS from 18 to $30 \mu \mathrm{m}\left(35.8\right.$ to $10^{\circ} \mathrm{C} / \mathrm{s}$ cooling rate), the fatigue life of the alloy decreased to $~ 3910$ cycles. Wang et al. [233, 236] studied the influence of SDAS on the HCF fatigue behavior of A356/A357 Al-Si alloy in the T6 heat treated conditions).

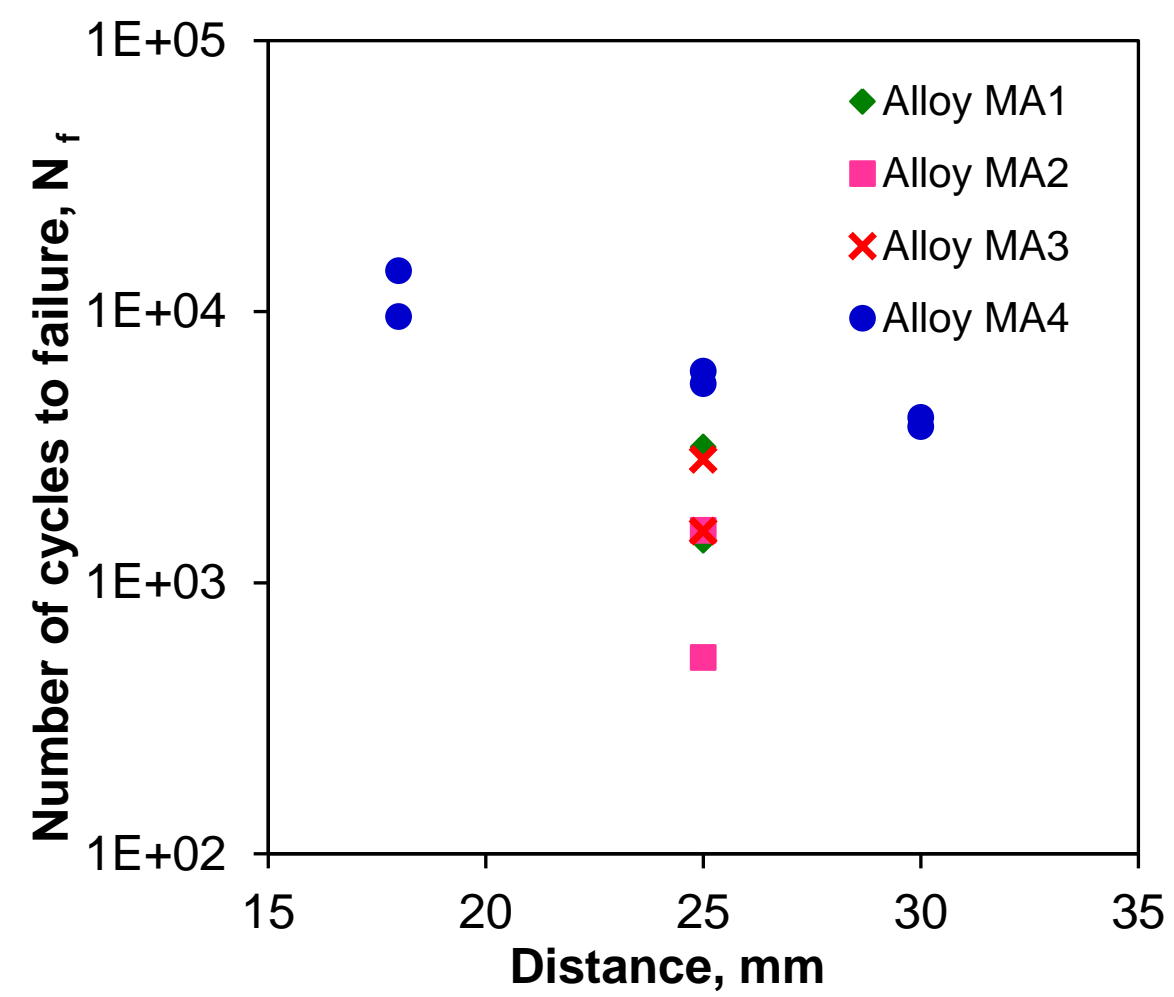

Fig. 8.10. The correlation between fatigue life and SDAS for $\mathrm{T} 6$ heat treated $\mathrm{Al}-\mathrm{Si}-\mathrm{Cu}-\mathrm{Mg}$ alloy modified with $\mathrm{Ti}, \mathrm{V}$ and $\mathrm{Zr}$ accompanied by reference data.

They reported that with increasing the SDAS up to $60 \mu \mathrm{m}$, the fatigue life decreased, though after that the fatigue life increased with increasing the SDAS. It is also observed that the fatigue 
life of the presently developed alloy MA4 appeared significantly longer than the other existing references of the $\mathrm{Al}-\mathrm{Si}-\mathrm{Cu}-\mathrm{Mg}$ alloy modified with additions of $\mathrm{Ti}, \mathrm{Zr}-\mathrm{Ti}$ and $\mathrm{Ti}-\mathrm{V}-\mathrm{Zr}$ (MA3) for the SDAS of $25 \mu \mathrm{m}$ [101]. It should also be noted that the fatigue data of cast alloys normally exhibit a fairly large scatter due to the microstructural variations, especially the type and size of casting defects [236]. The improved fatigue resistance of the presently studied alloy MA4 was mainly attributed to the composite-like strengthening and precipitation strengthening of trialuminide phases that became more significant upon introducing higher contents of alloying elements (i.e., $\mathrm{Zr}$, Ti and V.

\subsection{Fractography}

\subsubsection{Fractography of the alloy during monotonic loading}

Since the compression tested samples are not fractured apart, their fracture surface was not available for study in this condition. Fig. 8.11 depicts the typical SEM microstructure with EDX spectrum showing the major intermetallics on the fracture surfaces obtained during tensile tests of the base alloy and modified alloy MA4 in the as-cast condition. It is seen that the base alloy exhibits an intergranular brittle-type fracture while the modified alloy MA4 shows mixed-type fracture; ie., ductile fracture in matrix and brittle fracture in intermetallics. As illustrated in Fig. 8.11a, the identified intermetallics which control the fracture of the base alloy are \#4 to \#6 phases (Table 4.2 and Fig. 4.3a). At the same condition, the fracture surface of the modified alloy MA4 in Fig. 4.3e portrays the phases of \#7 to \#10 (Table 4.2 and Fig. 4.3) which control the deformation behavior rather than the phases of \#4 to \#6. It is clear that the properties of the modified alloys are strongly influenced by the thermally stable intermetallics formed due to the addition of $\mathrm{Ti} / \mathrm{V} / \mathrm{Zr}$. 

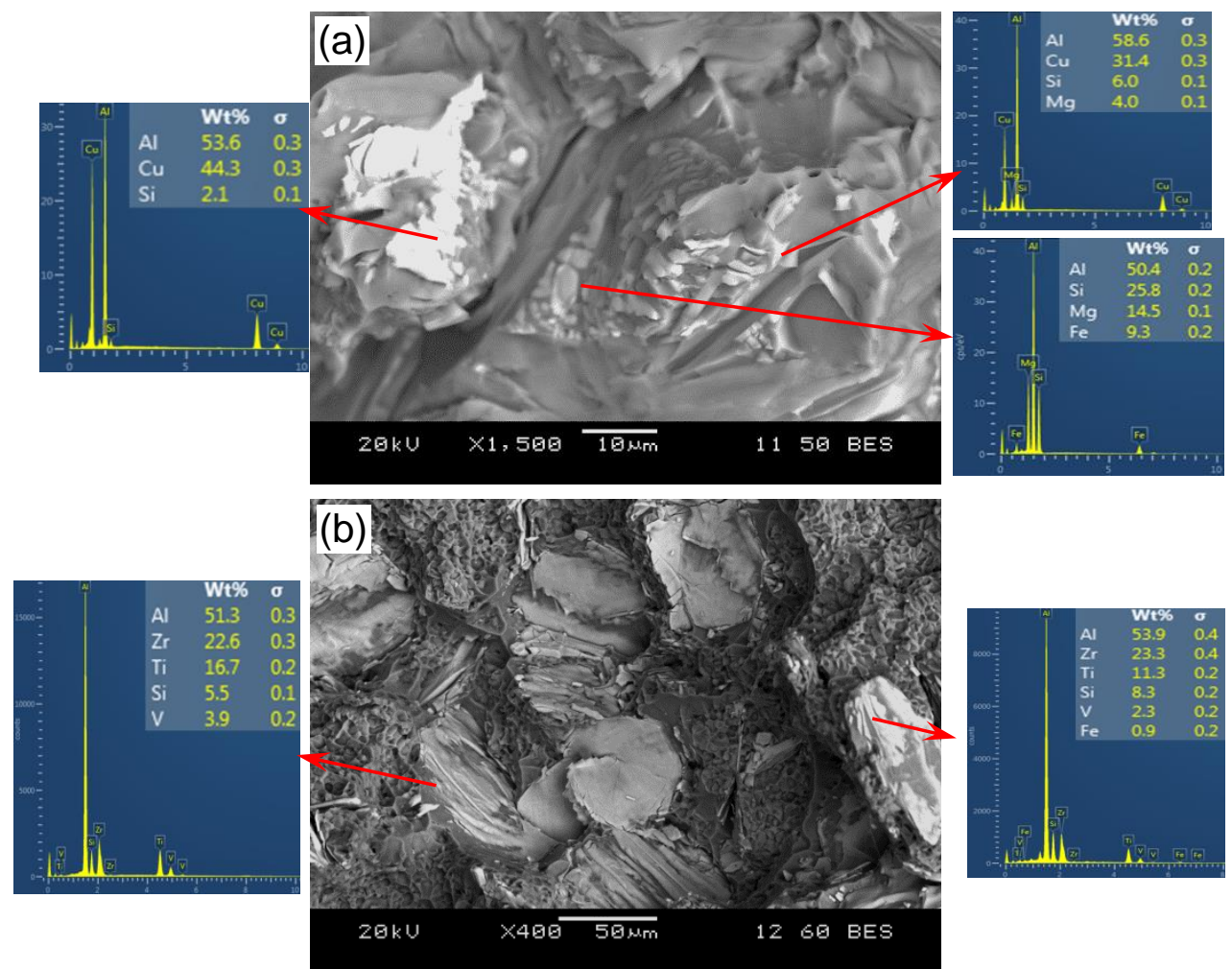

Fig. 8.11. Typical SEM microstructure with EDX spectrum showing the major intermetallics on the fracture surfaces obtained during tensile test of (a) base alloy and (b) alloy MA4 in as-cast condition.

In general, the ductile fracture starts from a formation of voids around the second-phase particles. After exceeding the critical stress to break the interfacial bonds between the particle and the ductile matrix, voids are formed. An alternative mechanism is an initiation of cracks within hard particles. However, casting defects such as internal pores, dry oxide, shrinkage, act as origin sites for crack nucleation as well. The fractographic observations revealed that the fracture characteristics were most likely similar for all alloys (Fig. 8.11 and Fig. 8.12). The fracture surface after tensile loading showed mostly intergranular features (Fig. 8.12) along with some flat areas, especially cleavage-type fracture in the plate-shaped intermetallics (Fig8.11b). Some intermetallics and eutectic silicon particles were debonded from the matrix (as pointed out by blue arrow) which was accompanied by secondary cracks between dendrites (red arrows) and tear ridges (pink arrows) (Fig. 8.12). Such morphology suggests that there was a strong 
interaction between the plastic flow or slip bands and the eutectic silicon particles especially at grain boundaries leading to a contribution to intergranular cracking. Similar types of fracture behavior were also pointed out by other researchers for the $\mathrm{Al}-\mathrm{Si}-\mathrm{Cu}-\mathrm{Mg}$ alloy with additions of $\mathrm{Zr}$, Ti and $\mathrm{V}$ during tensile loading $[76,101,129]$.
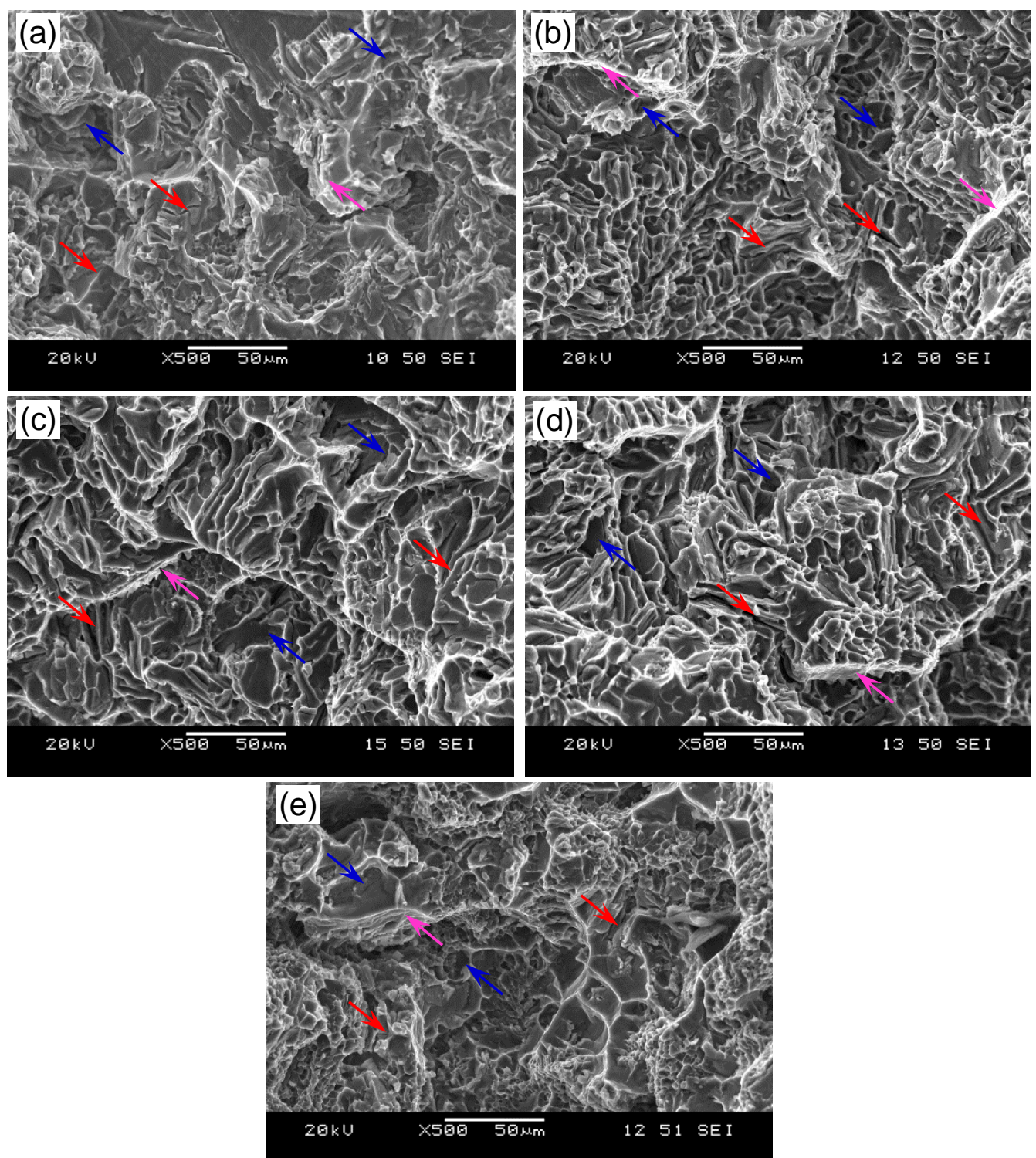

Fig. 8.12. Typical SEM micrographs showing the types of fracture of the studied alloys occurred during tensile test of (a) as-cast base alloy, T6 heat treated alloys (b) MA1, (c) MA2

(d) MA3, (e) T6 heat treated MA4 alloy. Note: Red arrow-secondary cracks, Blue arrowdebonding of intermetallics/eutectic silicon and pink arrow- tear ridge. 


\subsubsection{Fractography of the alloy during cyclic loading}

Fig. 8.13 (a, c, e, g and i) shows overall low-magnification SEM images of fatigue crack initiation (FCI) sites (marked by red arrows) and fatigue crack growth/propagation (FCG) zone (enclosed by blue line) for the studied alloys of BA, MA1, MA2, MA3 and MA4, respectively, tested at $0.2 \%$ total strain amplitude. Since the alloy MA4 passed the LCF test at total strain amplitude of $0.1 \%$, there was no fracture surface for this condition. Here, samples tested at $0.2 \%$ were considered as the lowest strain amplitude where the failure occurred for all the alloys. In general, the size of the propagation zone decreased from the as-cast base alloy to T6 heat treated modified alloys MA1, MA2, MA3 and MA4 consecutively. It is seen that the fracture surfaces were flat in general with no slant fracture. The higher magnification images (enclosed by red line in Fig. 8.13 a, c, e, g and i) shown in Fig. 8.13 (b, d, f, h and j) indicated that crack initiation occurred basically from the larger defects near the sample surface. A combination of three kinds of fatigue crack generators; oxide layer (Fig. 8.13b, d, f and h), surface porosity (Fig. 8.13b), sub-surface porosity (Fig. 8.13d f, h) and slip bands (Fig.8.13j), were found to affect failure of the studied alloys. Those locations acted as stress concentrators that initiated the fatigue cracks [222, 237, 238]. However, the size of the FS is decreased and MC increased from the as-cast base alloy to T6 heat treated modified alloys MA1, MA2, MA3 and MA4 successively which is the indication of higher fatigue life of the alloy MA4. As seen in Fig. 8.14f, the unique feature of fatigue striations on the Ti-V-Zr-containing intermetallics which are the indication of ductile type-particles, which were also discovered in the alloy MA4. Some secondary cracks in the matrix (Fig.8.15 a-e) and in Ti-V-Zr-containing particles (Fig. 8.15f) were detected in the stage of final fracture with transgranular fracture in the matrix. The fatigue striations are normally generated via a repeated plastic blunting-sharpening process due to the slip of dislocations in the plastic zone in front of the fatigue crack tip in face-centered cubic materials [239]. 

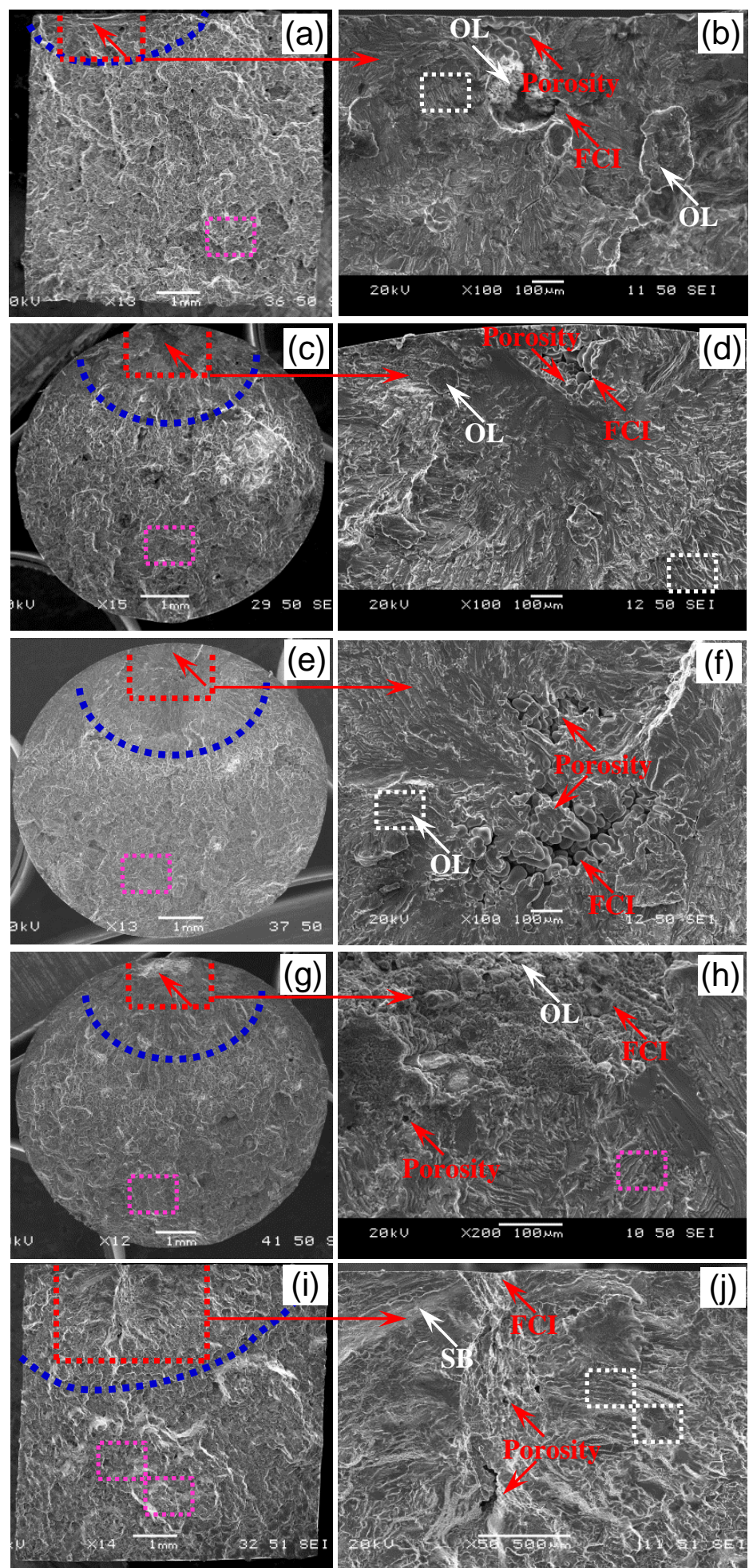

Fig. 8.13. SEM images of fatigue fracture surfaces of the samples tested at a total strain amplitude of $0.2 \%$ showing an overall view and the corresponding fatigue crack initiation sites at higher magnifications for the studied alloys of (a-b) as-cast base alloy, T6 heat treated alloys (c-d) MA1, (e-f) MA2 (g-h) MA3, (i-j) T6 heat treated MA4 alloy. White and pink boxes are magnified in Fig. 8.14 and Fig. 8.15. Note: FCI-fatigue crack initiation zone, SB-slip band, OLoxide layer. 

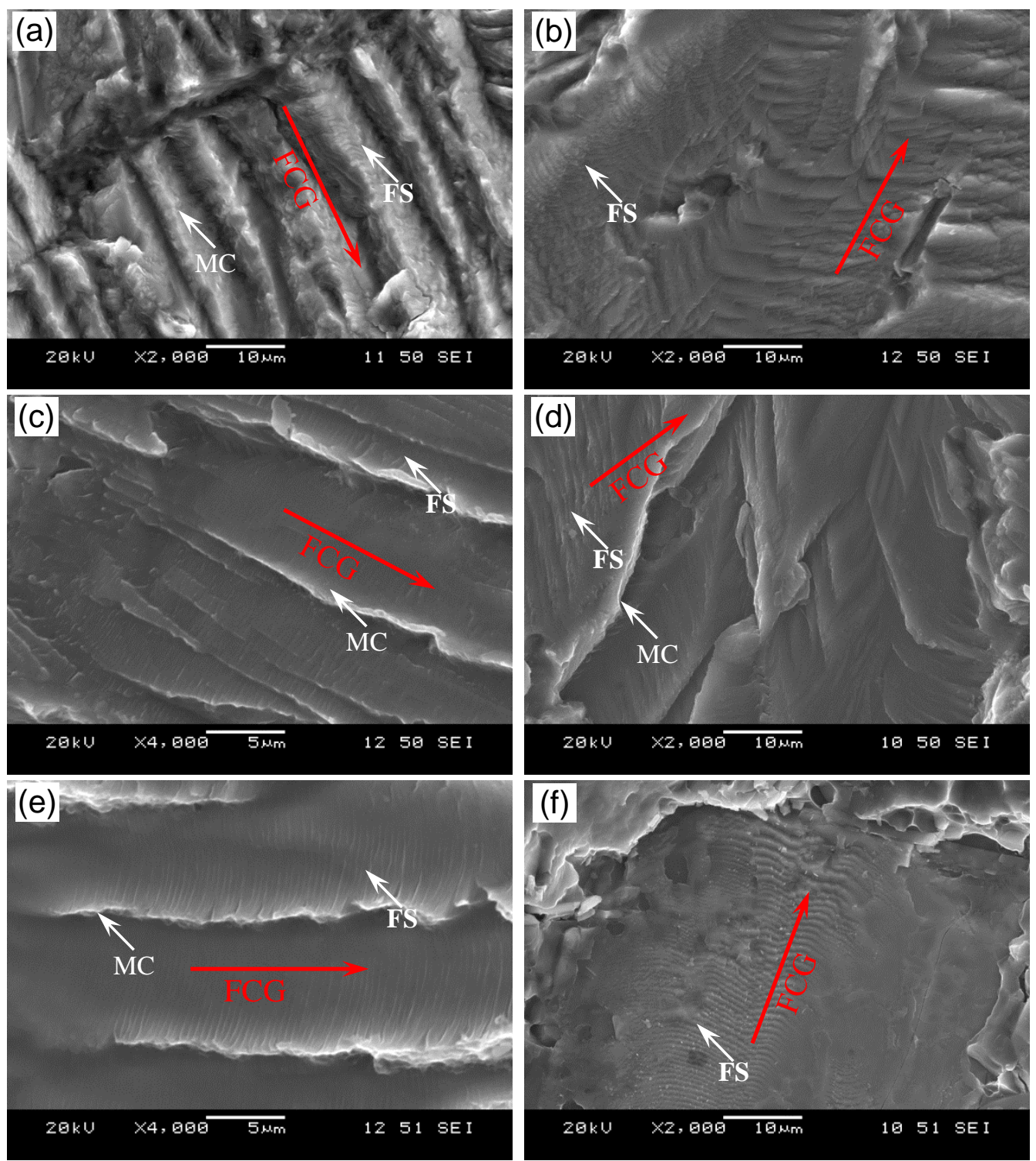

Fig. 8.14. SEM images of fatigue fracture surfaces (corresponding enclosed by white boxes in Fig. 9) of the samples tested at a total strain amplitude of $0.2 \%$ showing the fatigue striation at the crack propagation zone in the matrix for the studied alloys of (a) as-cast base alloy, T6 heat treated alloys (b) MA1, (c) MA2 (d) MA3, (e) MA4 and (f) intermetallics of T6 heat treated MA4 alloy. Note: FCG- fatigue crack growth/propagation, FS- fatigue striation, MC- Micro cliffs. 

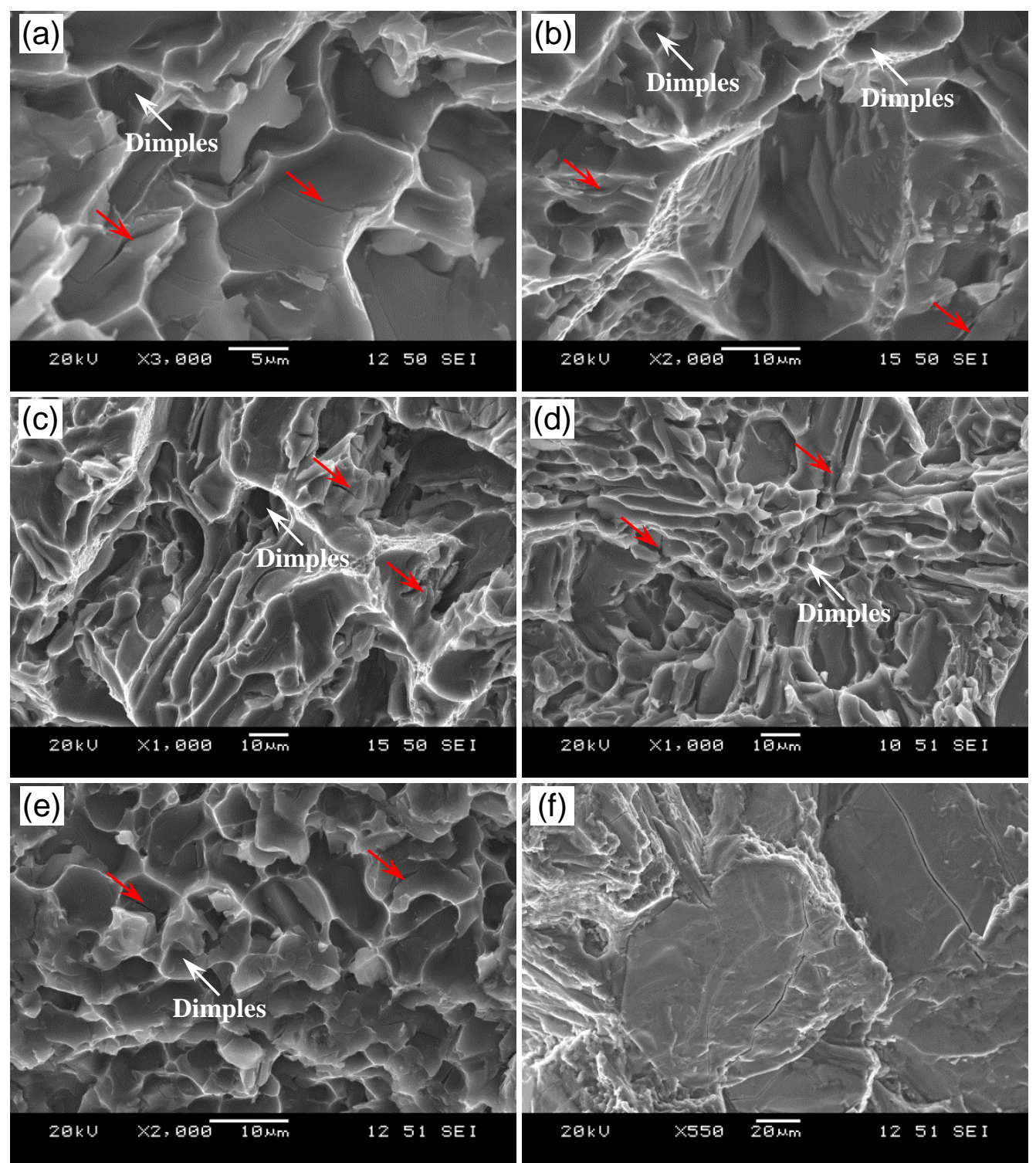

Fig. 8.15. SEM images of fatigue fracture surfaces (corresponding enclosed by pink boxes in Fig. 9) of the samples tested at a total strain amplitude of $0.2 \%$ showing tensile like fracture at the fast fracture zone in the matrix (a-e) and intermetallics (f) for the studied alloys of (a) as-cast base alloy and T6 heat treated alloys of (b) MA1, (c) MA2 (d) MA3 and (e-f) MA4. Note: Red arrow indicates secondary cracks in the matrix.

As the material exhausted the final stage of fatigue crack propagation, the remaining volume was not strong enough to withstand the applied stress/strain. Then, the crack advanced mainly through the eutectic Si, creating a non-flat appearance and tensile-like features in the final rapid fracture, as shown in Fig.8.15 (a-e) which was very similar to the tensile fracture surface (Fig. 
8.12). Similar features of LCF fracture characteristics were also observed by other researchers in cast aluminum alloys [111, 129].

\subsection{Comments on Alloy Performance}

The present study shows that additions of $\mathrm{Ti} / \mathrm{Zr} / \mathrm{V}$ in $\mathrm{Al}-\mathrm{Si}-\mathrm{Cu}-\mathrm{Mg}$ alloy achieved better mechanical properties compared to the base alloy. In comparison with the alloy BA, MA1, MA2 and MA3, increasing the amount of added $\mathrm{Zr}$, Ti and $\mathrm{V}$ to the $\mathrm{Al}-\mathrm{Si}-\mathrm{Cu}-\mathrm{Mg}$ alloy achieved higher tensile properties of the alloy MA4 in both the as-cast and T6 temper conditions. This was primarily due to the change in the microstructure and the presence of trialuminide precipitates, as reported in $[73,129]$.

As reported in previous studies [101, 129], the remarkable enhancement in UTS was mainly attributed to both the composite-like role of $\mathrm{Cu}-, \mathrm{Fe}-$, and $\mathrm{Mg}$-containing Si particles (Fig. 4.3), and the precipitation strengthening of nano-sized trialuminide particles which were uniformly distributed in the aluminum matrix or along with the eutectic silicon particles (Fig. 4.8 and 4.9). The presence of these micro- and nano-sized particles (Fig. 4.3) would effectively impede the movement of dislocations during uniaxial deformation, thus appreciably enhancing the strength of the cast aluminum alloy (Fig. 8.2). In addition to the strong resistance to the motion of dislocations, the trialuminide precipitates were reported to be very effective in pinning grain and sub-grain boundaries during all thermal and mechanical processing of aluminum alloys [101, 227]. This would restrict the grain growth during T6 heat treatment with a two-step solution treatment. As a result, the grain refinement strengthening would also play a significant role. As seen in Fig. 8.2b, the UTS of MA2 alloy is higher than the alloy MA1 due to the presence of the additional alloying element $\mathrm{Zr}$ which enhances the volume of nano-size precipitates in the Almatrix resulting in higher strength of alloy MA2. At the same time, the addition of $0.25 \% \mathrm{~V}$ in 
alloy MA3 does not affect the UTS which indicate that the addition of $0.25 \% \mathrm{~V}$ or below cannot influence the alloy tensile properties. Further increments of $\mathrm{Zr}-\mathrm{V}-\mathrm{Ti}$ in the alloy MA4 significantly change the alloy microstructure and result in better tensile properties. By increasing the transition metal content (Zr-V-Ti) in alloy MA4, changes in the morphology of the primary precipitates occur which improves the strength and ductility of the alloy [73]. Therefore, it can be concluded that the bulk/plate-shape Ti-V-Zr-rich phases improved the ascast MA4 alloy strength and ductility as well. However, the achieved higher strength and lower ductility of the T6 samples reflected the presence of secondary precipitates which were formed during the ageing process $[22,96]$.

The LCF results of alloy MA4 also showed superior properties over the other studied alloys including the base alloy. Compared to the alloys BA, MA1, MA2 and MA3, the obtained cyclic yield strength of the MA4 alloy in the T6 heat treated condition was always higher than the tensile yield strength which indicates the higher hardening and better dislocation storage capacity in cyclic loading. It should be pointed out that the alloys MA2 and MA3 with lower additions of $\mathrm{Ti} / \mathrm{Zr} / \mathrm{V}$ in the $\mathrm{T} 6$ heat treated condition had 9 and 12 point higher cyclic yield strength compared to the MA4 alloy. However, at the same testing condition, the modified alloy MA4 has significantly higher ( 15-17 times) fatigue ductility, which leads to longer fatigue life and pass the test at a total strain amplitude $(0.1 \%)$. As the cyclic loading progresses at higher strain amplitude $(0.6 \%)$, the alloys become stiffer which causes an increase of elastic modulus and decrease in plastic deformation by generation and tangling of dislocations in each cycle. In contrast, at the lower strain amplitudes $(0.3-0.1 \%)$, the T6 heat treated alloy reached a saturation stage where a continuous generation and annihilation of dislocations occurred that results in constant absorption of energy during the entire fatigue life. However, the energy density coefficient of the alloy MA4 was significantly higher than the alloys of BA, MA1 to MA3. This 
observation can be attributed to the morphological changes of $\mathrm{Ti}-\mathrm{V}-\mathrm{Zr}$-rich intermetallics and modification of eutectic Si as well remarkably improving the fatigue life of the MA4 alloy.

The fatigue crack initiation, growth and propagation are related to casting defects such as gas porosity, dry oxide, secondary dendrite arm spacing and morphology of the second phases present in the microstructure $[233,238]$. The surface pores are prone to initiate cracks as seen in Fig 8.13a. It was previously demonstrated that fatigue cracks preferentially initiated at pores (or voids) and inclusions during cyclic deformation [111, 240]. As seen in Fig. 8.13, the fatigue fracture surfaces exhibited surface and sub-surface porosity with oxides which eventually increase the possibility of crack initiation and reduce the fatigue life of the alloy, especially the base alloy. Also, needle-like precipitates in alloy BA, MA1 to MA3 enhance the stress concentration around them which accelerates the fatigue crack growth, consequently reducing the fatigue life $[233,238]$. Further, the plate-shaped Ti-V-Zr-rich particles, which alter the crack path by forming a plastic zone at the tip of the crack, are more fatigue resistant compared to brittle ones. Since fatigue striations were observed on the plate-shaped Ti-V-Zr-rich particles, it seems that those are comparatively ductile, causing the MA4 alloy fatigue life to increase considerably.

Fatigue cracks propagate by crack initiation followed by crack propagation followed by final fracture. It is shown in the literature that the fatigue cracks propagate by connecting and branching of micro-cracks [111]. Since the cast Al-alloy possesses randomly orientated crystals and inhomogeneous grains, crack branching and deflection occurred during LCF deformation. It is also well known that $\mathrm{Al}(\alpha)$ belongs to the faced-centered cubic lattice, which has a high stacking fault energy with some propagated slipping systems $\{111\}<110>[111]$. Thus, the fatigue striations were noticed at the propagation zone and generated in front of the fatigue crack tip in the face-centered cubic materials because of dislocations in the plastic zone [111, 
241, 242]. In this circumstance, the fatigue striations went from coarse to fine on the matrix fracture surface from BA to MA4 alloy. Finally, the nature of fracture at its last stage within all alloys (BA to MA4) is apparently similar to each other. In this final stage, tensile-like fracture was developed which exhibited extensive dimple-like features in the fast-propagation region (Fig. 8.15). Also, ductile tearing was observed in conjunction with secondary cracks in grains as well as along grain boundaries and deboning of particles, especially eutectic silicon, occurred. These phenomena are known to increase fatigue life of materials characterized by a ductile type of fracture [111, 243].

\subsection{Chapter Summary}

Tensile and low cyclic fatigue tests were used to assess the influence of micro-additions of $\mathrm{Ti} / \mathrm{V} / \mathrm{Zr}$ on the performance of the $\mathrm{Al}-7 \mathrm{Si}-1 \mathrm{Cu}-0.5 \mathrm{Mg}$ (wt.\%) alloys in the as-cast and $\mathrm{T} 6$ heat treated conditions and compared with the base alloy. The tensile test results showed that the T6 heat treated alloy modified with additions of higher content of Ti-V-Zr achieved the highest tensile strength of $343 \mathrm{MPa}$ over the base alloy and alloys modified with additions of $\mathrm{Ti}$, Ti- $\mathrm{Zr}$ and lower content of Ti-V-Zr. The plastic strain energy density coefficient of the alloy modified with addition of a higher content of $\mathrm{Ti}-\mathrm{V}-\mathrm{Zr}$ in the $\mathrm{T} 6$ temper condition was higher than the other studied alloys and reached $162 \mathrm{MJm}^{-3}$. The fatigue life of the same alloy was considerably longer than that of the other studied alloys including the base alloy. The fractography revealed that all the studied alloys showed similar fracture behavior. The tensile cracks propagate through the eutectic Si and primary phases, exhibiting intergranular fracture along with some cleavage-like features of the plate-shape Ti-V-Zr-rich intermetallics with a presence of fatigue striations on the latter, indicating their ductile nature. It is believed that the morphological changes of intermetallic precipitates containing $\mathrm{Zr}$, Ti and $\mathrm{V}$ enhance the fatigue life of the alloy 
modified with additions of higher contents of $\mathrm{Ti}-\mathrm{V}-\mathrm{Zr}$ in the $\mathrm{T} 6$ condition. (Note: Most of the data of this chapter 8 was collected from the published papers listed in Section 9.3). 


\section{CHAPTER 9}

\section{CONCLUSIONS AND FUTURE WORK}

\subsection{Conclusions}

The Al-Si-Cu-Mg base alloy was modified with additions of transition metals at different levels of additions to produce 4 alloys: Ti (MA1), Ti-Zr (MA2) and Ti-V-Zr in lower (MA3) and higher (MA4) amounts to improve the alloy performance at elevated temperatures. From the above discussed results, the following conclusions can be made:

1. Increasing the solidification rate from 10 to $35.8{ }^{\circ} \mathrm{C} / \mathrm{s}$ of the $\mathrm{Al}-7 \mathrm{Si}-1 \mathrm{Cu}-0.5 \mathrm{Mg}$ (wt.\%) alloy with micro-additions of $\mathrm{Ti}, \mathrm{V}$ and $\mathrm{Zr}$ reduced the SDAS value from 30 to $18 \mu \mathrm{m}$ which was accompanied by a slight refinement of the eutectic silicon particles and $\mathrm{Zr}-$ V-Ti-containing intermetallics..

2. Alloy solidus temperature was determined to be approximately $507^{\circ} \mathrm{C}$ and was used to select the solution treatment temperature at $485,510^{\circ} \mathrm{C}$ for the 1 -step and $510{ }^{\circ} \mathrm{C}+525$

${ }^{0} \mathrm{C}$ for the 2-step processes. The optimum solutionizing process for these alloys was 510 ${ }^{\circ} \mathrm{C}$ for $0.5 \mathrm{~h}+525{ }^{\circ} \mathrm{C}$ for $4.5 \mathrm{~h}$. To obtained higher strength $200{ }^{\circ} \mathrm{C}$ temperature for $1 \mathrm{~h}$ and for higher dimensional stability $250{ }^{\circ} \mathrm{C}$ temperature for $16 \mathrm{~h}$ considered as optimum artificial aging parameters for T6 and T7 heat treatment process, respectively..

3. The TEM and EDX analysis showed that the Al-Si-Cu-Mg base alloy formed typical phases $\mathrm{Al}_{2.1} \mathrm{Cu}, \mathrm{Al}_{8.5} \mathrm{Si}_{2.4} \mathrm{Cu}, \mathrm{Al}_{7.2} \mathrm{Si}_{8.3} \mathrm{Cu}_{2} \mathrm{Mg}_{6.9}$ and $\mathrm{Al}_{14} \mathrm{Si}_{7.1} \mathrm{FeMg}_{3.3}$. An additional phase of $\mathrm{Al}_{6.8} \mathrm{Si}_{1.4} \mathrm{Ti}$ was identified in the alloy MA1. Other Ti-Zr-rich phases $\mathrm{Al}_{6.7} \mathrm{Si}_{1.2} \mathrm{TiZr}_{1.8}$ and $\mathrm{Al}_{5.1} \mathrm{Si}_{35.4} \mathrm{Ti}_{1.6} \mathrm{Zr}_{5.7} \mathrm{Fe}$ were detected in the other three alloys of MA2, MA3 and MA4. At the same time, Ti-V-Zr-containing phases of $\mathrm{Al}_{2.8} \mathrm{Si}_{3.8} \mathrm{~V}_{1.6} \mathrm{Zr}$ and 
$\mathrm{Al}_{21.4} \mathrm{Si}_{4.1} \mathrm{Ti}_{3.5} \mathrm{VZr}_{3.9}$ with different morphologies (plate/bulk/needle) were seen only in the MA3 and MA4 alloys while only needle and bulk- shape morphologies were found in alloy MA3.

4. The combination of electron microscopy and high temperature X-ray diffraction and thermal analysis was used. $\mathrm{Cu}$ - and $\mathrm{Mg}$ - rich phases along with the eutectic Si dissolved in the temperature range from 300 to $500^{\circ} \mathrm{C}$. At the same time, the transition metals Ti$\mathrm{V}-\mathrm{Zr}$-containing phases were identified with a tetragonal crystal structure of $\mathrm{D}_{22} / \mathrm{DO}_{23}$ with different lattice parameters and were stable up to $696-705^{\circ} \mathrm{C}$.

5. The calculated flow stress from the semi-empirical model versus plastic strain curve was observed to be in agreement with the experimental compression test data. Thus, the model implemented allowed assessing the contribution of shearable and non-shearable precipitates to the dislocation-induced hardening during compression indicating the dominant role of non-shearable, coarser precipitates.

6. Another constitutive equation of the temperature-dependent dislocation slip distance, based on Mott's theory of strain hardening, was derived and validated using the experimental data of a newly-evaluated $\mathrm{Al}-\mathrm{Si}-\mathrm{Cu}-\mathrm{Mg}$ cast alloy with $\mathrm{Zr}, \mathrm{V}$ and $\mathrm{Ti}$ additions as well as other Al-based and low-melting point $\mathrm{Pb}-\mathrm{Sb}$ alloys with deformation data available in the literature. The proposed equation can be used to predict the dislocation slip distance of other alloys in a wide range of deformation temperatures.

7. The high temperature compression tests showed that the temperature in the range of 200$400^{\circ} \mathrm{C}$ and to a lesser extent the strain rate in the range of $10^{-3}-1 \mathrm{~s}^{-1}$ affected the flow stress during compression deformation of the studied alloys. The presence of microadditions of $\mathrm{V}$ and $\mathrm{Zr}$ in the base alloy increased the activation energy of its plastic 
deformation from $282.6 \mathrm{~kJ} / \mathrm{mol}$ to $315.2 \mathrm{~kJ} / \mathrm{mol}$, suggesting the beneficial role of transition elements in improving its high temperature performance.

8. The tensile tests at different temperatures showed that the additions of $\mathrm{Zr}$, $\mathrm{Ti}$ and $\mathrm{V}$ to the Al-Si-Cu-Mg alloy successfully improved the alloy strength, which had significantly higher UTS in comparison with the A356, 354 and existing Al-Si-Cu-Mg alloy.

9. The tensile tests at different temperatures showed that the additions of $\mathrm{Zr}$, Ti and $\mathrm{V}$ to the Al-Si-Cu-Mg alloy successfully improved the alloy strength, which had significantly higher UTS in comparison with the A356, 354 and Al-Si-Cu-Mg alloy with additions of Ti (MA1), Ti-Zr (MA2) and Ti-V-Zr (MA3) in lower amounts at the same condition. The tensile test results also showed that the newly modified alloy MA4 in the T6 temper condition had considerably higher ultimate strength and elongation of and $2.6 \%$ respectively, in comparison with the other studied alloys. This indicates that higher additions of $\mathrm{Zr}$, Ti and V positively affect the MA4 alloy strength.

10. The fatigue life of the alloy MA4 was considerably longer than that of the base alloy and other modified alloys with the same base but lower additions of $\mathrm{Ti}, \mathrm{V}$ and $\mathrm{Zr}$ in the $\mathrm{T} 6$ state. The cyclic stress amplitude and total strain energy density were almost stable at the lower total strain amplitude of $0.3-0.1 \%$ for all the studied alloys. Consistently, cyclic hardening occurred at higher strain amplitude with the extent of cyclic hardening and elastic energy density increasing with increasing total strain amplitudes from $0.3 \%$ to $0.6 \%$ for all three alloys. 


\subsection{Recommendations for Future Work}

From the above experimental results, it was found that the newly modified alloy could be a promising material in power train applications as high temperature materials. However, to be placed in service further analysis is important. Specifically:

1. Fatigue fracture of the materials is a crucial factor in the design of the product. In this study, low cycle fatigue testing was performed at room temperature. However, a detailed investigation of the influence of transition metals $\mathrm{Ti}-\mathrm{V}-\mathrm{Zr}$ in $\mathrm{Al}-\mathrm{Si}-\mathrm{Cu}-\mathrm{Mg}$ alloy on high temperature fatigue performance is necessary.

2. The strength of the Al-Si-Cu-Mg alloys drops dramatically with increasing temperature above $200{ }^{\circ} \mathrm{C}$ and the creep resistance is usually poor. In the present study, thermally stable precipitates were formed in the $\mathrm{Al}-\mathrm{Si}-\mathrm{Cu}-\mathrm{Mg}$ alloy by addition of $\mathrm{Ti}, \mathrm{V}, \mathrm{Zr}$ which have limited solid solubility and low diffusivity in Al. Thus, creep behavior of the alloy should be evaluated and compared with the base $\mathrm{Al}-\mathrm{Si}-\mathrm{Cu}-\mathrm{Mg}$ alloy.

3. Friction and wear of the materials are important properties of the Al-Si-Cu-Mg alloys in power train applications. Thus, the evaluation of friction and wear behavior of the modified alloys at room temperature and elevated temperature will be helpful to use this alloy.

4. The corrosion and oxidation properties of the alloys significantly influence the alloy performance. The alloy corrosion and oxidation performance should be measured and compared with the base alloy in severe corrosive environment at room and high temperatures. 


\subsection{Contribution of This Study}

The contribution of the proposed research lies in the development of a new Al-Si cast alloy with varying compositions of transition metals of $\mathrm{Ti}, \mathrm{V}$ and $\mathrm{Zr}$ for elevated temperature applications in the automotive industry. Also, the proposed study could have a significant contribution to the processing and post production of engine parts such as engine head and piston in automotive industries. The energy efficient heat treatment processes to identify could save significantly the energy during heat treatment. The rising energy costs should provide a positive stimulus to revise the existing heat treatment standards - particularly for cast components that solidified under high solidification rates - paying special attention to and taking great advantage of the thermal as-cast microstructure with its potential to leverage the metallurgical response of the component to subsequent heat treatment processing.

The present studied results should successfully promote the applications of lightweight Al-Si based alloy in the automotive industry for downsize the engine size which can effectively contribute to the reduction of greenhouse gas emissions.

\subsection{Publication Resulting from this Research}

\section{A. Journal Publications}

1. S. K. Shaha, W. Kasprzak, F. Czerwinski, J. Friedman and D.L Chen, Ageing characteristics and high-temperature tensile properties of $\mathrm{Al}-\mathrm{Si}-\mathrm{Cu}-\mathrm{Mg}$ alloys through micro-additions of $\mathrm{Cr}, \mathrm{Ti}, \mathrm{V}$ and $\mathrm{Zr}$, Materials Science and Engineering A, (Submitted).

2. S. K. Shaha, W. Kasprzak, F. Czerwinski, J. Friedman and D.L Chen, Effect of $\mathrm{Cr}, \mathrm{Ti}, \mathrm{V}$ and $\mathrm{Zr}$ micro-additions on microstructure and mechanical properties of 
the Al-Si-Cu-Mg cast alloy, Metallurgical and Materials Transactions A (Submitted).

3. S.K. Shaha, F. Czerwinski, W. Kasprzak, J. Friedman and D.L. Chen, Role of transition metals in absorption of energy during low cycle fatigue of $\mathrm{Al}-\mathrm{Si}-\mathrm{Cu}-\mathrm{Mg}$ alloy at different strain amplitudes, International Journal of Fatigue, 2015 (Submitted).

4. F. Czerwinski, S.K. Shaha, W. Kasprzak, J. Friedman and D.L Chen, Ageing characteristics of the $\mathrm{Al}-\mathrm{Si}-\mathrm{Cu}-\mathrm{Mg}$ alloy modified with transition metals $\mathrm{Zr}, \mathrm{V}$, and Ti, Journal of Physics: conference series, 2015 (In-press).

5. S.K. Shaha, F. Czerwinski, W. Kasprzak, J. Friedman and D.L. Chen, Microstructure and mechanical properties of Al-Si cast alloy with additions of $\mathrm{Zr}$, V and Ti, Materials and Design, Vol. 83, pp 801-812, 2015.

6. F. Czerwinski, S.K. Shaha, W. Kasprzak, J. Friedman and D.L Chen, Thermal stability of $\mathrm{Al}-\mathrm{Si}-\mathrm{Cu}-\mathrm{Mg}$ cast alloys modified with transition metals $\mathrm{Zr}, \mathrm{V}$ and $\mathrm{Ti}$, Materials Science Forum, Vols. 828-829, pp 29-34, 2015.

7. S.K. Shaha, F. Czerwinski, W. Kasprzak, J. Friedman and D.L. Chen, Improving high-temperature tensile and low-cycle fatigue behavior of $\mathrm{Al}-\mathrm{Si}-\mathrm{Cu}-\mathrm{Mg}$ alloys through micro-additions of Ti, V and Zr, Metallurgical and Materials Transactions A, Vol. 46A, pp 3063-3078, 2015.

8. S.K. Shaha, F. Czerwinski, W. Kasprzak, J. Friedman and D.L. Chen, Effect of solidification rate and loading mode on deformation behavior of cast $\mathrm{Al}-\mathrm{Si}-\mathrm{Cu}-\mathrm{Mg}$ alloy with additions of $\mathrm{Zr}, \mathrm{V}$ and $\mathrm{Ti}$, Materials Science and Engineering A, Vol. 636, pp 361-372, 2015. 
9. S.K. Shaha, F. Czerwinski, W. Kasprzak, J. Friedman and D.L. Chen, Effect of strain level on the behavior of intermetallics and texture of $\mathrm{Al}-\mathrm{Si}-\mathrm{Cu}-\mathrm{Mg}$ alloy modified with transition metals, SAE International Journal of Materials and Manufacturing, Vol. 8, pp 1-5, 2015.

10. S.K. Shaha, F. Czerwinski, W. Kasprzak, J. Friedman and D.L. Chen, Monotonic and cyclic deformation behavior of the Al-Si-Cu-Mg cast alloy with microadditions of Ti, V and Zr, International Journal of Fatigue, Vol. 70, pp 383-394, 2015.

11. S.K. Shaha, F. Czerwinski, W. Kasprzak and D.L. Chen, Dislocation slip distance during compression of $\mathrm{Al}-\mathrm{Si}-\mathrm{Cu}-\mathrm{Mg}$ alloy with additions of $\mathrm{Ti}-\mathrm{Zr}-\mathrm{V}$, Materials Science and Technology, Vol. 31, pp 63-72, 2015.

12. S.K. Shaha, F. Czerwinski, W. Kasprzak, J. Friedman and D.L. Chen, Thermal stability of (AlSi)x(ZrVTi) intermetallic phases in the Al-Si-Cu-Mg cast alloy with additions of Ti, V and Zr, Thermochimica Acta, Vol. 595, pp 11-16, 2014.

13. S.K. Shaha, F. Czerwinski, W. Kasprzak, J. Friedman and D.L. Chen, Effect of $\mathrm{Zr}, \mathrm{V}$ and $\mathrm{Ti}$ on hot compression behavior of the Al-Si cast alloy for power-train applications, Journal of Alloys and Compounds, Vol. 615, pp 1019-1031, 2014.

14. S.K. Shaha, F. Czerwinski, W. Kasprzak and D.L. Chen, Tensile and compressive deformation behavior of the Al-Si-Cu-Mg cast alloy with additions of $\mathrm{Zr}, \mathrm{V}$ and Ti, Materials and Design, Vol. 59, pp 352-358, 2014.

15. S.K. Shaha, F. Czerwinski, W. Kasprzak and D.L. Chen, Work hardening and texture during compression deformation of the $\mathrm{Al}-\mathrm{Si}-\mathrm{Cu}-\mathrm{Mg}$ alloy modified with V, Zr and Ti, Journal of Alloys and Compounds, Vol. 593, pp 290-299, 2014. 
16. W. Kasprzak, D.L. Chen, and S.K. Shaha, Heat treatment development for rapidly solidified heat resistant cast Al-Si alloy, Journal of Materials and Engineering Performance, Vol. 22(7), pp 1839-1847, 2013.

\section{B. Conference Papers}

1. S.K. Shaha, F. Czerwinski, W. Kasprzak, J. Friedman and D.L Chen, Effect of heat treatment on microstructure and mechanical properties of cast $\mathrm{Al}-\mathrm{Si}-\mathrm{Cu}-\mathrm{Mg}$ alloy with micro additions of Zr-Ti-V, COM 2015, August 23-26, 2015, Toronto, ON, Canada.

2. S.K. Shaha, F. Czerwinski, W. Kasprzak, J. Friedman and D.L Chen, Low cycle fatigue of Aluminum-Silicon alloys for power-train applications, TMS 2015, March 15-19, 2015, Orlando, FL, USA.

3. S.K. Shaha, W. Kasprzak, F. Czerwinski, J. Friedman and D.L Chen, Effect of temperature and strain rate on hot compression behavior of an $\mathrm{Al}-\mathrm{Si}-\mathrm{Cu}-\mathrm{Mg}$ cast alloy with additions of Ti, V and Zr, CSME International Congress 2014, June 1-4, 2014, University of Toronto, Ontario, Canada.

\section{Manuscripts Under Preparation}

1. S. K. Shaha, W. Kasprzak, F. Czerwinski, J. Friedman and D.L Chen, Effect of thermomechanical treatment on the precipitation behavior in $\mathrm{Al}-\mathrm{Si}-\mathrm{Cu}-\mathrm{Mg}$ alloy modified with addition of $\mathrm{Ti}, \mathrm{V}$ and $\mathrm{Zr}$ (Writing in progress).

2. S. K. Shaha, W. Kasprzak, F. Czerwinski, J. Friedman and D.L Chen, Role of thermomechanical on microstructure and texture evolution of $\mathrm{Al}-\mathrm{Si}-\mathrm{Cu}-\mathrm{Mg}$ alloy modified with addition of $\mathrm{Ti}-\mathrm{V}-\mathrm{Zr}$ (Writing in progress). 
3. S. K. Shaha, W. Kasprzak, F. Czerwinski, J. Friedman and D.L Chen, Effect ageing parameters on compressive properties of $\mathrm{Al}-\mathrm{Si}-\mathrm{Cu}-\mathrm{Mg}$ alloy modified with addition of Ti, $\mathrm{V}$ and $\mathrm{Zr}$. (work has been done and the manuscript in preparation).

4. S. K. Shaha, W. Kasprzak, F. Czerwinski, J. Friedman and D.L Chen, Effect Cr and heat treatment on microstructure and tensile properties of Al-Si alloy modified with addition of $\mathrm{Ti}, \mathrm{V}$ and $\mathrm{Zr}$. (work has been done and the manuscript in preparation)

5. S. K. Shaha, W. Kasprzak, F. Czerwinski, J. Friedman and D.L Chen, Role of Cr on the high temperature properties of cast $\mathrm{Al}-\mathrm{Si}-\mathrm{Cu}-\mathrm{Mg}$ alloy modified with addition of $\mathrm{Ti}, \mathrm{V}$ and $\mathrm{Zr}$ for power train application. (work has been done and the manuscript in preparation)

6. S. K. Shaha, W. Kasprzak, F. Czerwinski, J. Friedman and D.L Chen, Influence of $\mathrm{Ti}, \mathrm{V}$ and $\mathrm{Zr}$ on the corrosion behavior of cast $\mathrm{Al}-\mathrm{Si}-\mathrm{Cu}-\mathrm{Mg}$ alloy for power train application. (work has been done and the manuscript in preparation)

7. S. K. Shaha, W. Kasprzak, F. Czerwinski, J. Friedman and D.L Chen, A details TEM analysis of Al-Si-Cu-Mg alloy modified with addition of $\mathrm{Ti}, \mathrm{V}$ and $\mathrm{Zr}$ for the recrystallization and precipitation during compression. (work has been done and the manuscript in preparation)

\section{Book Chapter}

1. Czerwinski, S.K. Shaha, W. Kasprzak, J. Friedman and D.L Chen, Effect of transition metals on thermal stability of Al-Si cast alloys, Light Metals 2015, Springerlink Publisher (Will be published). 


\section{E. Posters and Presentations}

1. S. K. Shaha, F. Czerwinski,W. Kasprzak, J. Friedman and D.L Chen, Effect of strain level on the behavior of intermetallics and texture of $\mathrm{Al}-\mathrm{Si}-\mathrm{Cu}-\mathrm{Mg}$ alloy modified with transition metals, SAE International 2015, Detroit, Mihigan, USA.

2. S. K. Shaha, D.L. Chen and W. Kasprzak, Compression deformation behavior of a modified 356 aluminum-silicon alloy, 24th Canadian Materials Science Conference (CMSC-24), University of Western Ontario, Ontario, Canada, June 5$8,2012$.

3. S. K. Shaha, D.L. Chen and W. Kasprzak, Effect of spheroidization of eutectic silicon phase on the properties of an $\mathrm{Al}-\mathrm{Si}-\mathrm{Cu}-\mathrm{Mg}$ cast aluminum alloy with additions of $\mathrm{Zr}, \mathrm{V}$ and $\mathrm{Ti}, 24$ th Canadian Materials Science Conference (CMSC24), University of Western Ontario, Ontario, Canada, June 5-8, 2012. 


\section{APPENDIX}

\section{Appendix: A Microstructure of Master Alloys}
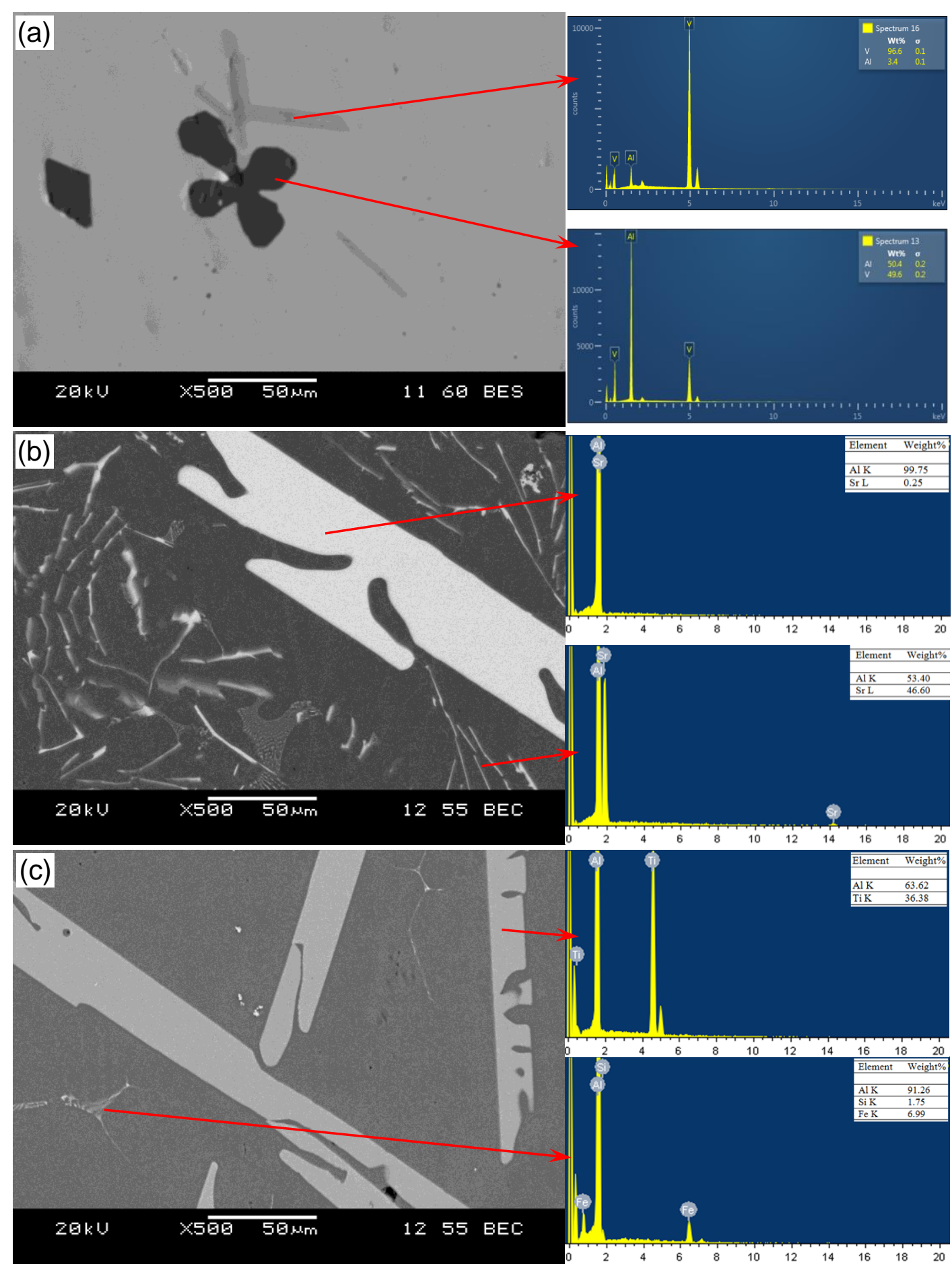

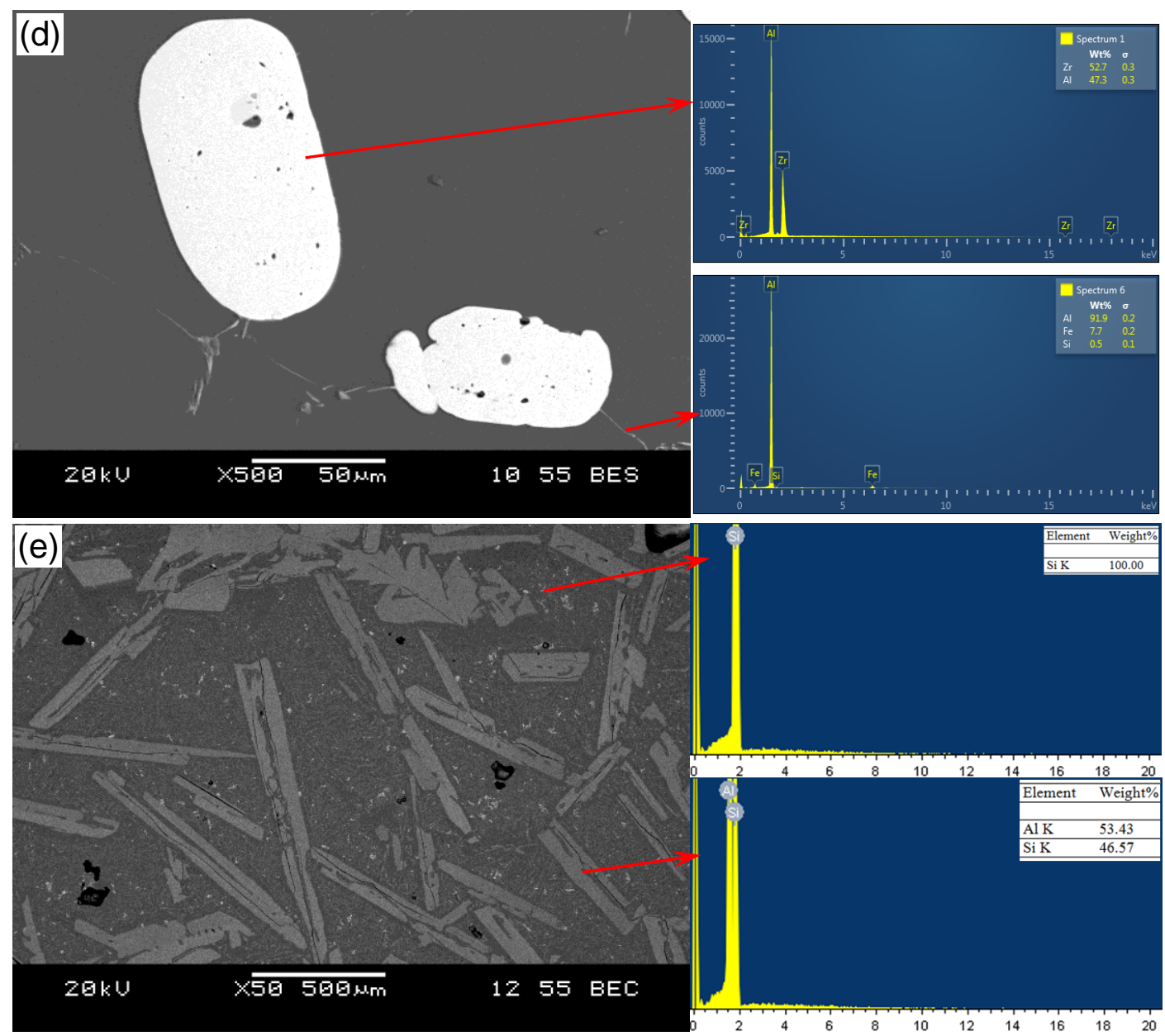

Fig. A1.Typical SEM microstructures with EDX spectrums of major phases of the master alloys used as a source of alloying elements; (a) Al-85\% V, (b) Al-10\% Sr, (c) Al-6.1\% Ti, (d) Al$10 \% \mathrm{Zr}$ and (e) Al-35\% Si in wt\%. 


\section{Appendix: B Additional SEM Microstructures of the Studied Alloys}
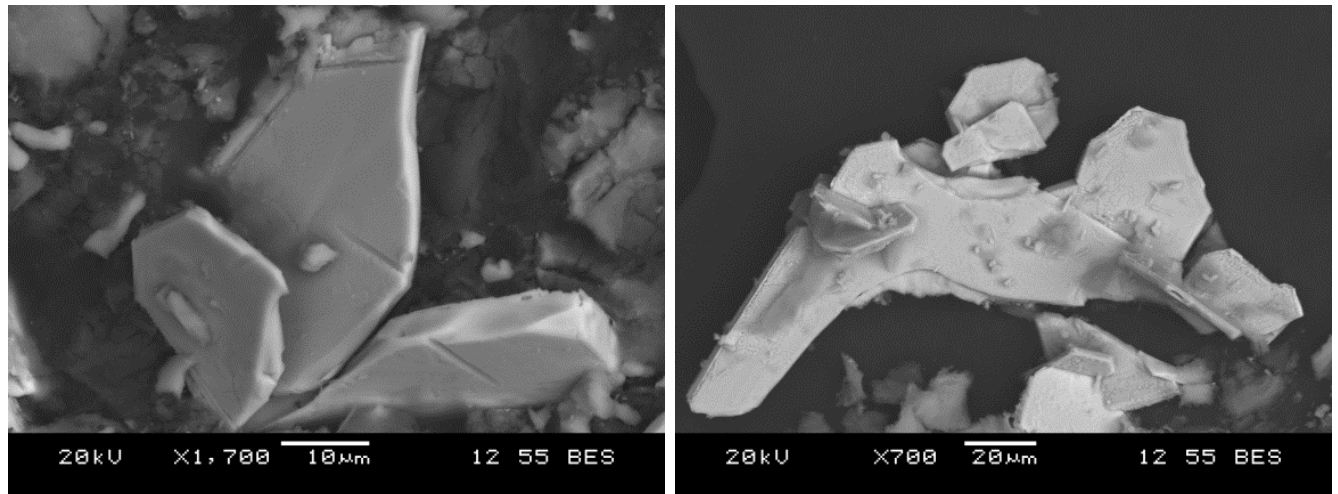

Fig. B1. Typical SEM images showing morphology of extracted intermetallics in the cast Al-Si$\mathrm{Cu}-\mathrm{Mg}$ modified alloy MA4. The above intermetallics composition is corresponding to the \#7 in Table B1.

Table B1: The main phases and their chemistry in wt. \% identified using SEM/EDX in the cast Al-Si-Cu-Mg modified alloy MA4.

\begin{tabular}{|c|c|c|c|c|c|c|c|c|c|}
\hline No. & Calculated phase & $\mathrm{Al}$ & $\mathrm{Si}$ & $\mathrm{Cu}$ & $\mathrm{Mg}$ & $\mathrm{Fe}$ & $\mathrm{Zr}$ & $\mathrm{Ti}$ & $\mathrm{V}$ \\
\hline$\# 1$ & $\alpha$-aluminum & & & & & & & & \\
\hline \multirow{2}{*}{$\# 2$} & \multirow{2}{*}{ Eutectic silicon } & 35.28 & 64.72 & & & & & & \\
\hline & & \pm 2.31 & \pm 2.31 & & & & & & \\
\hline \multirow{2}{*}{ \#3 } & \multirow{2}{*}{$\mathrm{Al}_{2.1} \mathrm{Cu}$} & 47.15 & & 52.85 & & & & & \\
\hline & & \pm 4.89 & & \pm 4.89 & & & & & \\
\hline \multirow{2}{*}{ \#4 } & \multirow{2}{*}{$\mathrm{Al}_{8.5} \mathrm{Si}_{2.4} \mathrm{Cu}$} & 63.55 & 18.77 & 17.68 & & & & & \\
\hline & & \pm 6.54 & \pm 4.54 & \pm 1.96 & & & & & \\
\hline \multirow{2}{*}{ \#5 } & \multirow{2}{*}{$\mathrm{Al}_{7.2} \mathrm{Si}_{8.3} \mathrm{Cu}_{2} \mathrm{Mg}_{6.9}$} & 26.81 & 32.33 & 17.61 & 23.26 & & & & \\
\hline & & \pm 2.97 & \pm 0.29 & \pm 2.35 & \pm 0.34 & & & & \\
\hline \multirow{2}{*}{ \#6 } & \multirow{2}{*}{$\mathrm{Al}_{14} \mathrm{Si}_{7.1} \mathrm{FeMg}_{3.3}$} & 52.84 & 28.03 & & 11.28 & 7.85 & & & \\
\hline & & \pm 2.06 & \pm 1.43 & & \pm 1.39 & \pm 1.58 & & & \\
\hline \multirow{2}{*}{$\# 7$} & \multirow{2}{*}{$\mathrm{Al}_{21.4} \mathrm{Si}_{4.1} \mathrm{Ti}_{3.5} \mathrm{VZr}_{3.9}$} & 45.46 & 9.11 & & & & 28.15 & 13.25 & 4.03 \\
\hline & & \pm 2.28 & \pm 0.73 & & & & \pm 3.25 & \pm 1.57 & \pm 1.15 \\
\hline \multirow{2}{*}{ \#8 } & \multirow{2}{*}{$\mathrm{Al}_{6.7} \mathrm{Si}_{1.2} \mathrm{TiZr}_{1.8}$} & 42.26 & 7.92 & & & & 38.58 & 11.25 & \\
\hline & & \pm 0.83 & \pm 0.17 & & & & \pm 0.65 & \pm 0.34 & \\
\hline \multirow{2}{*}{ \#9 } & \multirow{2}{*}{$\mathrm{Al}_{2.8} \mathrm{Si}_{3.8} \mathrm{~V}_{1.6} \mathrm{Zr}$} & 21.20 & 30.09 & & & & 25.73 & & 22.98 \\
\hline & & \pm 2.99 & \pm 1.97 & & & & \pm 1.39 & & \pm 0.41 \\
\hline \multirow{2}{*}{ \#10 } & \multirow{2}{*}{$\mathrm{Al}_{5.1} \mathrm{Si}_{35.4} \mathrm{Ti}_{1.6} \mathrm{Zr}_{5.7} \mathrm{Fe}$} & 7.68 & 55.74 & & & 3.13 & 29.15 & 4.29 & \\
\hline & & \pm 1.14 & \pm 1.52 & & & \pm 0.81 & \pm 1.96 & \pm 0.38 & \\
\hline
\end{tabular}



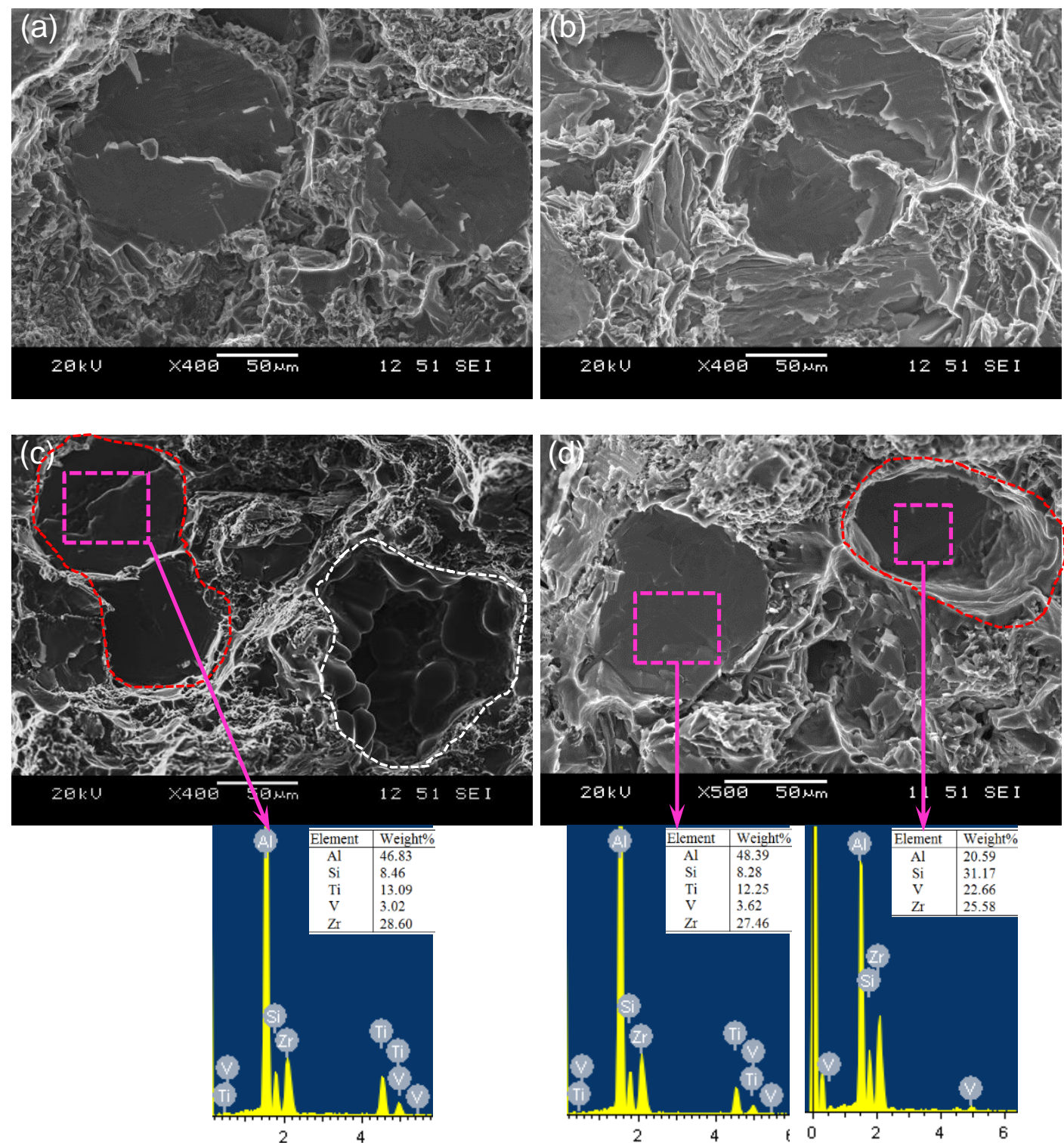

Fig. B2. SEM micrographs with EDX spectrums in a magnified views correspondingly showing the tensile fracture surface of studied alloy MA4 in as-cast states obtained at different temperatures of (a) $25^{\circ} \mathrm{C}$, (b) $200^{\circ} \mathrm{C}$, (c) $300^{\circ} \mathrm{C}$ and (d) $400^{\circ} \mathrm{C}$. Note: the areas enclose by white and red lines show the surface pores and pullout of the precipitates, respectively. 

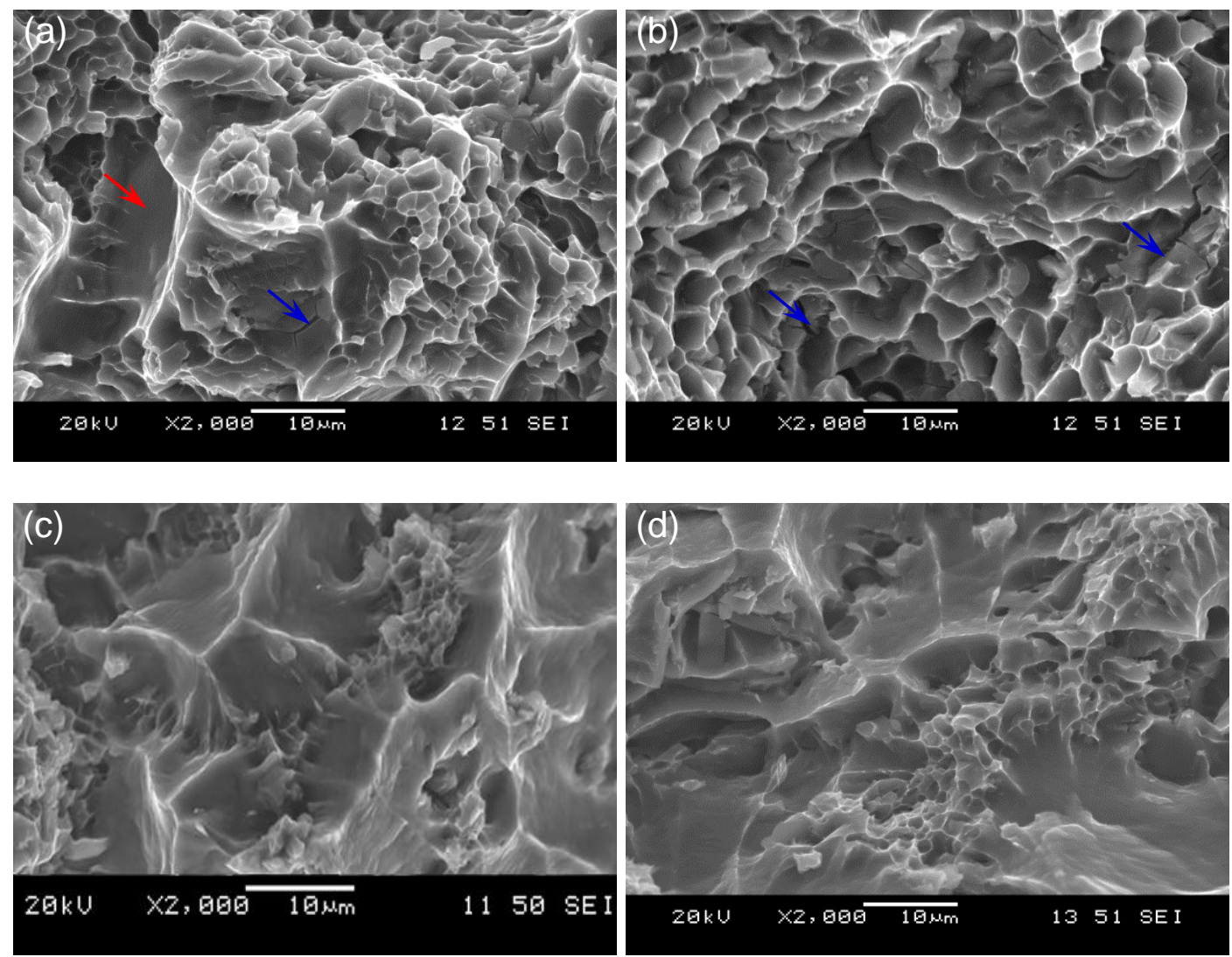

Fig. B3. The corresponding SEM micrographs showing the matrix morphology of the tensile fracture surface of studied alloy MA4 in as-cast states obtained at different temperatures of (a) $25^{\circ} \mathrm{C}$, (b) $200^{\circ} \mathrm{C}$, (c) $300^{\circ} \mathrm{C}$ and (d) $400^{\circ} \mathrm{C}$. 

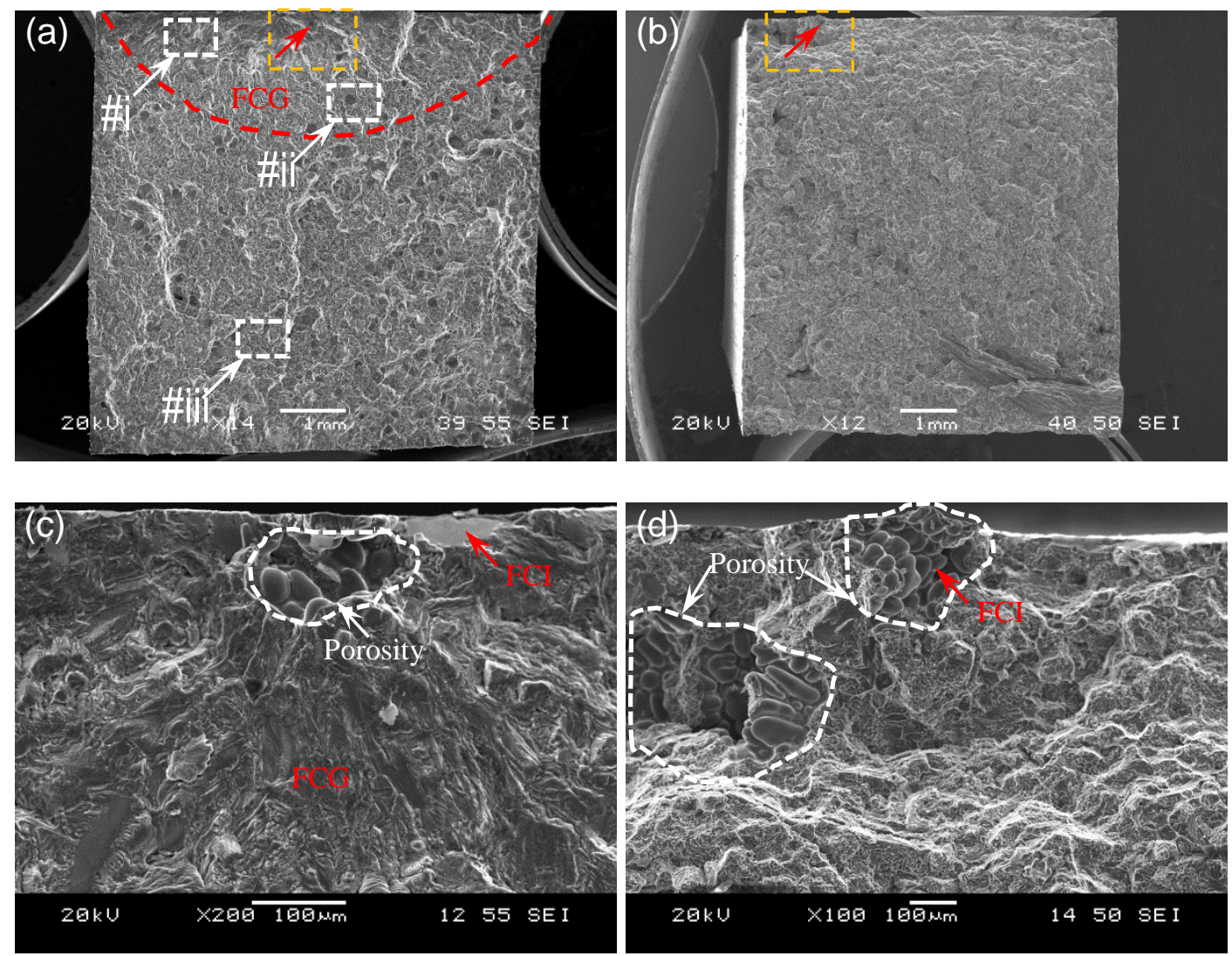

Fig. B4. SEM images of fatigue fracture surfaces of the samples tested at a total strain amplitude of (a) $0.2 \%$ and (b) $0.6 \%$ showing an overall view for as-cast Al-Si-Cu-Mg modified alloy MA4 and the corresponding fatigue crack initiation sites at higher magnifications, where fatigue cracks initiate at a large surface pore and slip bands (c); clusters of near-surface pores and large surface inclusion (d). Here, yellow box and red arrows indicate the position of crack initiation sites while red dashed line separated the crack propagation area. The areas enclose by white line shows the surface pores. Note that increasing the strain amplitude crack propagation zone decreases. FCI-fatigue crack initiation, FCG-fatigue crack growth/propagation zone. 

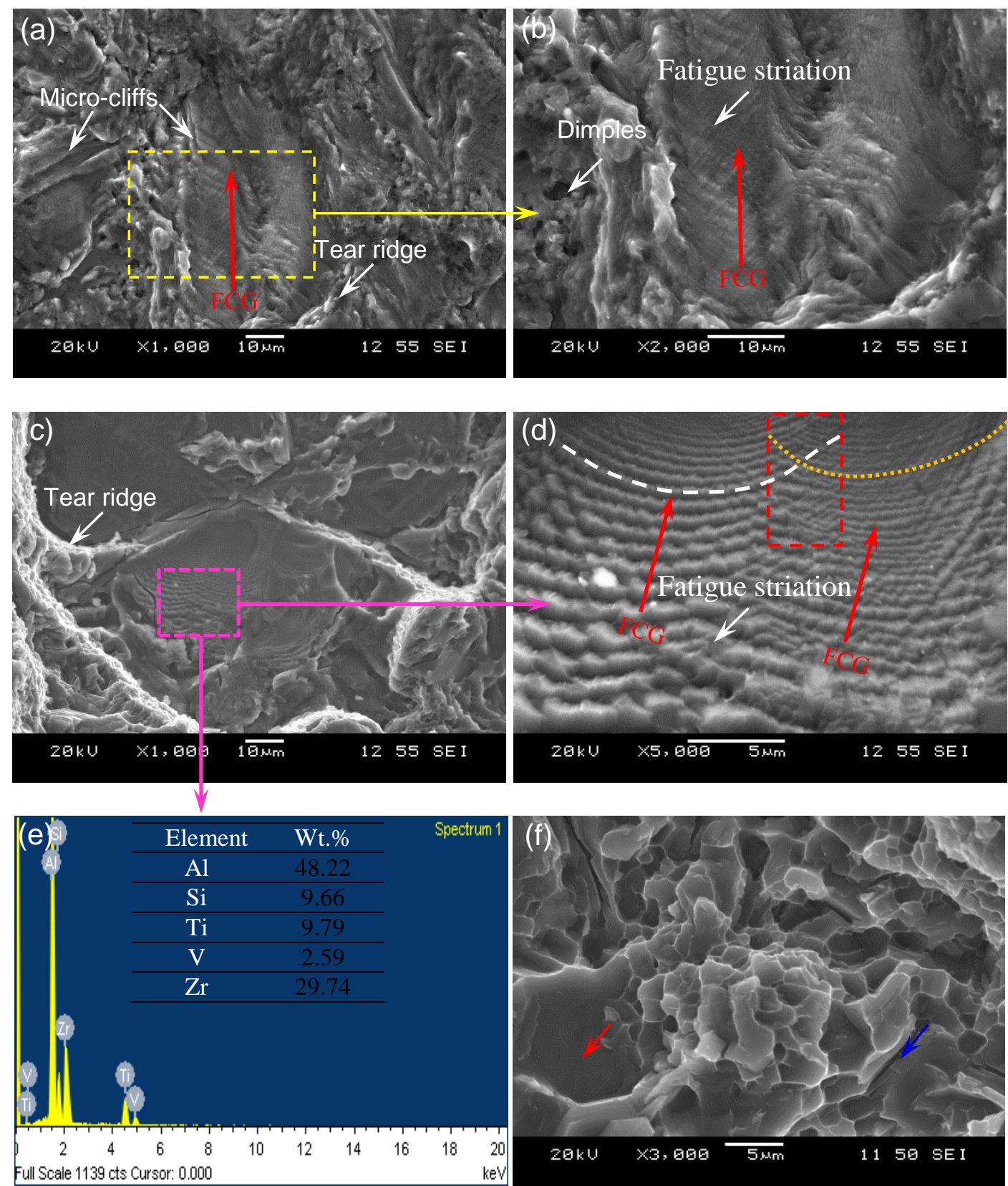

Fig. B5. SEM images of fatigue fracture surfaces for as-cast Al-Si-Cu-Mg modified alloy MA4 samples tested at total strain amplitude of $0.2 \%$ showing fatigue striation in matrix (a and b) (as indicated in Fig. 11a with i) and precipitates (c and d), (as pointed out in Fig. 14a with ii), (e) EDX analysis of intermetallic (typical \#7 as listed in Table 2) on the fracture surface and (f) final fracture of the alloy (as marked in Fig. 11a with iii).

Note: the dotted lines in (e) show two sets of fatigue striations along the crack propagation direction which overlapped with each other as indicated by enclosed red box. 


\section{REFERENCES}

[1] "The Past, Present and Future of Aluminum in North American, Ducker Worldwide, 2012. Weblink:http://www.aluminum.org/Content/ContentFolders/Miscellaneous/AW_ 2012_Schultz_Aluminum_in_N.A._Light_Vehicles.pdf (visit: March 21,2013)," 21 March 2013. [Online].

[2] "Developing a technology roadmap for automotive light weighting metals recycling, Final report of workshop," United States Council for Automotive Research LLC (USCAR) Offices Detroit, Michigan, 24 September 2008. [Online]. [Accessed 09 March 2014].

[3] W. Kasprzak, H. Kurita, J. H. Sokolowski and H. Yamagata, "Energy-efficient tempers for aluminum motorcycle cylinder blocks," Advanced Materials and Processes, vol. 168, pp. 24-27, 2010.

[4] D. Sarker and D. L. Chen, "Detwinning and strain hardening of an extruded magnesium alloy during compression," Scripta Materialia, vol. 67, pp. 165-168, 2012.

[5] C. Gu, J. Lian, J. He, Z. Jiang and Q. Jiang, "High corrosion-resistance nano-crystalline Ni coating on AZ91D magnesium alloy," Surface and Coatings Technology, vol. 200, pp. 5413-5418, 2006.

[6] H. Toda, T. Nishimura, K. Uesugi, Y. Suzuki and M. Kobayashi, "Influence of hightemperature solution treatments on mechanical properties of an $\mathrm{Al}-\mathrm{Si}-\mathrm{Cu}$ aluminum alloy," Acta Materialia, vol. 58, pp. 2014-2025, 2010. 
[7] G. Wang, X. Bian, W. Wang and J. Zhang, "Influence of $\mathrm{Cu}$ and minor elements on solution treatment of Al-Si-Cu-Mg cast alloys," Materials Letters, vol. 57, pp. 40834087, 2003.

[8] S. K. Das, P. S. Gilman and D. Raybould, "Application of rapidly solidified high temperature aluminium alloys," Key Engineering Materials, Vols. 38-39, pp. 367-392, 1989.

[9] H. Jones, Materials in Aerospace: vol. 1, London: The Royal Aeronautical Society, 1986.

[10] D. Apelian, S. Shivkumar and G. Sigwortlv, "Fundamental aspects-of-heat treatment of cast Al-Si-Mg alloys," AFS Transactions, vol. 97, pp. 727-742, 1989.

[11] S. G. Shabestari and F. Shahri, "Influence of modification, solidification conditions and heat treatment on the microstructure and mechanical properties of A356 aluminum alloy," Journal of Materials Science, vol. 39, pp. 2023-2032, 2004.

[12] S. Shankar, Y. W. Riddle and M. M. Makhlouf, "Nucleation mechanism of the eutectic phases in Aluminum-Silicon hypoeutectic alloys," Acta Materialia, vol. 52, pp. 44474460, 2004.

[13] M. Timpel, N. Wanderka, R. Schlesiger, T. Yamamoto, N. Lazarev, D. Isheim, G. Schmitz, S. Matsumura and J. Banhart, "The role of strontium in modifying aluminiumsilicon alloys," Acta Materialia, vol. 60, pp. 3920-3928, 2012.

[14] L. Wang, M. Makhlouf and D. Apelian, "Aluminium die casting alloys: alloy composition, microstructure, and properties-performance relationships," International Materials Reviews, vol. 40, pp. 221-238, 1995.

[15] A. L. Dons, G. Heiberg, J. Voje, J. S. Mæland, J. O. Løland and A. Prestmo, "On the effect of additions of $\mathrm{Cu}$ and $\mathrm{Mg}$ on the ductility of $\mathrm{Al}-\mathrm{Si}$ foundry alloys cast with a 
cooling rate of approximately $3 \mathrm{~K} / \mathrm{s}$," Materials Science and Engineering: A, Vols. 413414, pp. 561-566, 2005.

[16] F. H. Samuel, A. M. Samuel and H. W. Doty, "Factors controlling the type and morphology of $\mathrm{Cu}$ containing phases in $319 \mathrm{Al}$ alloy," AFS Transactions, vol. 30, pp. 893-903, 1996.

[17] H. de la Sablonniere and F. H. Samuel, "Solution heat treatment of 319 aluminum alloy containing $\sim 0.5 \mathrm{wt} \% \mathrm{Mg}$ : Part 1- Solidification and tensile properties," International Journal of Cast Metals Research, vol. 9, pp. 195-211, 1996.

[18] A. Taylor, D. H. St John, J. Barresi and M. J. Couper, "Influence of Mg content on the microstructure and solid solution chemistry of $\mathrm{Al}-7 \% \mathrm{Si}-\mathrm{Mg}$ casting alloys during solution treatment," Materials Science Forum, Vols. 331-337, pp. 277-282, 2000.

[19] G. Sha, H. Möller, W. E. Stumpf, J. H. Xia and G. Goven, "Solute nanostructures and their strengthening effects in Al-7Si-0.6Mg alloy F357," Acta Materialia, vol. 60, pp. 692-701, 2012.

[20] M. F. Ibrahim, E. Samuel, A. M. Samuel, A. M. Al-Ahmari and F. H. Samuel, "Impact toughness and fractography of Al-Si-Cu-Mg base alloys," Materials and Design, vol. 32, pp. 3900-3910, 2011.

[21] O. Elsebaie, A. M. Mohamed, A. M. Samuel and F. H. Samuel, "The role of alloying additives and aging treatment on the impact behavior of 319 cast alloy," Materials and Design, vol. 32, pp. 3205-3220, 2011.

[22] J. Hernandez-Sandoval, G. H. Garza-Elizondo, A. M. Samuel, S. Valtiierra and F. H. Samuel, "The ambient and high temperature deformation behavior of Al-Si-Cu-Mg alloy with minor Ti, Zr, Ni additions," Materials and Design, vol. 58, pp. 89-101, 2014. 
[23] P. Sepehband, R. Mahmudi and F. Khomamizadeh, "Effect of $\mathrm{Zr}$ addition on the aging behavior of A319 aluminum cast alloy," Scripta Materialia, vol. 52, pp. 253-257, 2005.

[24] R. Mahmudi, P. Sepehrband and H. M. Ghasemi, "Improved properties of A319 aluminum casting alloy modified with Zr," Materials Letters, vol. 60, pp. 2606-2610, 2006.

[25] T. Sato, A. Kamio and G. W. Lormier, "Effects of Si and Ti additions on the nucleation and phase stability of the $\mathrm{L}_{2}$-Type $\mathrm{Al}_{3} \mathrm{Zr}$ phase in $\mathrm{Al}-\mathrm{Zr}$ alloys," Materials Science Forum, Vols. 217-222, pp. 895-900, 1996.

[26] R. Tucker, "Trends in automotive lightweighting," Metal Finishing, vol. 111, pp. 23-25, 2013.

[27] "Aluminum promises greater fuel-efficiency: Metallurgy," Materials Today, vol. 5, pp. 12-16, 2002.

[28] R. Tucker, "Alternative materials advance," Metal Finishing, vol. 111, pp. 31-33, 2013.

[29] G. Hébert, D. Dubé and R. Tremblay, "Tensile and fatigue behavior of thin-walled cast A383.0 components," Materials Science and Engineering: A, vol. 552, pp. 89-96, 2012.

[30] M. Warmuzek, Aluminum-silicon casting alloys, Ohio, USA: ASM International, 2004.

[31] A. Sverdlin, "Introduction to aluminum," in Handbook of aluminum, vol. 1: Physical Metallurgy and Processes, G. E. Totten and D. S. MacKenzie, Eds., New York, USA, Marcel Dekker, Inc., 2003, pp. 1-30.

[32] J. Campbell, The new metallurgy of cast metals: castings, London, UK: ButterworthHeinemann, 2003.

[33] P. Beeley, Foundry technology, Madras, India: Butterworth-Heinemann, 2001. 
[34] A. M. Mohamed and F. H. Samuel, "A review on the heat treatment of Al-Si-Cu/Mg casting alloys," in Heat Treatment - Conventional and Novel Applications, F. Czerwinski, Ed., Intech, 2012, pp. 54-72.

[35] S. Lin, M. Pekguleryuz, C. Aliravci, "Hot-tear sensitivity of aluminum wrought alloys and the effect of grain refining," Metallurgical and Materials Transaction A, vol. 38A, pp. 1056-1068, 2007.

[36] L. Arnberg, L. Bäckerud and G. Chai, Solidification characteristics of aluminum alloys vol 2: foundry alloys, American Foundreymen's Society, 1996, 1996.

[37] P. S. Mohanty and J. E. Gruzleski, "Grain refinement mechanisms of hypoeutectic Al-Si alloys," Acta Materialia, vol. 44, pp. 3749-3760, 1996.

[38] C. Limmaneevichitr and W. Eidhed, "Fading mechanism of grain refinement of aluminum-silicon alloy with Al-Ti-B grain refiners," Materials Science and Engineering A, vol. 349, pp. 197-206, 2003.

[39] J. A. Garcia-Hinojosaa, C. González, J. A. Juárez and M. K. Surrapa, "Effect of grain refinement treatment on the microstructure of cast $\mathrm{Al}-7 \mathrm{Si}-\mathrm{SiCp}$ composites," Materials Science and Engineering: A, vol. 386, pp. 54-60, 2004.

[40] M. Andrzejczuk, M. Lewandowska, J. Latuch and K. J. Kurzydłowski, "Multiscale characterization of nanostructured $\mathrm{Al}-\mathrm{Si}-\mathrm{Zr}$ alloys obtained by rapid solidification method," Journal of Materials Science, vol. 46, pp. 5454-5459, 2011.

[41] Z. Chen, T. Wang, L. Gao, H. Fu and T. Li, "Grain refinement and tensile properties improvement of aluminum foundry alloys," Materials Science and Engineering: A, vol. 553, pp. 32-36, 2012. 
[42] Y. Chen, Y. Pan, T. Lu, S. Tao and J. Wu, "Effects of combinative addition of lanthanum and boron on grain refinement of Al-Si casting alloys," Materials and Design, vol. 64, pp. 423-426, 2014.

[43] F. Ernst, "Precipitation hardening of Al-Si-Mg alloys," EMSE-290, EMSE-290 Materials Laboratory III, 2004.

[44] S. -Z. Lu and A. Hellawell, "The mechanism of silicon modification in aluminumsilicon alloys: Impurity induced twinning," Metallurgical Transactions A, vol. 18, pp. 1721-1733, 1987.

[45] M. Haghhenas, A. Zarei-Hanzaki and S. M. Fatemi-Varzaneh, "A study of the Si-phase growth mechanism in thixocast (A356) alloy during hot deformation," International Journal of Materials Research, vol. 99, pp. 208-211, 2008.

[46] X. G. Chen and M. Fortier, "TiAlSi intermetallic formation and its impact on the casting processing in Al-Si alloys," Journal of Materials Processing Technology, vol. 210, pp. 1780-1786, 2010.

[47] S. K. Chaudhury and D. Apelian, "Effects of rapid heating on solutionizing characteristics of $\mathrm{Al}-\mathrm{Si}-\mathrm{Mg}$ alloys using a fluidized bed," Metallurgical and Materials Transactions A, vol. 37A, pp. 763-778, 2006.

[48] S. Farahany, A. Ourdjini, T. A. Abu-Bakar and M. H. Idris, "On the refinement mechanism of silicon in Al-Si-Cu-Zn alloy with addition of bismuth," Metallurgical and Materials Transactions: A, vol. 45, pp. 1085-1088, 2014.

[49] J. H. Li, J. Barrirero, M. Engstler, H. Aboulfadl, F. Mücklich and P. Schumacher, "Nucleation and growth of eutectic Si in Al-Si alloys with Na addition," Metallurgical and Materials Transactions: A, vol. 46, pp. 1300-1311, 2015. 
[50] M. D. Hanna, S. -Z. Lu and A. Hellawell, "Modification in the aluminum silicon system," Metallurgical Transactions A, vol. 15, pp. 459-469, 1984.

[51] S. Farahany, A. Ourdjini, M. H. Idrsi and S. G. Shabestari, "Evaluation of the effect of $\mathrm{Bi}, \mathrm{Sb}, \mathrm{Sr}$ and cooling condition on eutectic phases in an Al-Si-Cu alloy (ADC12)by in situ thermal analysis," Thermochimia Acta, vol. 559, pp. 59-68, 2013.

[52] J. Barresi, M. J. Kerr, H. Wang and M. J. Couper, "Effect of magnesium, iron, and cooling rate on mechanical properties of Al-7Si-Mg foundry alloys," AFS Transactions, vol. 108, pp. 563-570., 2000.

[53] E. Sjölander and S. Seifeddine, " The heat treatment of Al-Si-Cu-Mg casting alloys," Journal of Materials Processing Technology, vol. 210, pp. 1249-1259, 2010.

[54] E. Sjölander and S. Seifeddine, "Artificial ageing of Al-Si-Cu-Mg casting alloys," Materials Science and Engineering: A, vol. 528, pp. 7402-7409, 2011.

[55] A. M. Mohamed, F. h. Samuel and S. Al-kahtani, "Influence of Mg and solution heat treatment on the occurrence of incipient melting in $\mathrm{Al}-\mathrm{Si}-\mathrm{Cu}-\mathrm{Mg}$ cast alloys," Materials Science and Engineering: A, vol. 543, pp. 22-34, 2012.

[56] A. M. Samuel, H. W. Doty, S. Valtierra and F. H. Samuel, "Defects related to incipient melting in Al-Si-Cu-Mg alloys," Materials and Design, vol. 52, pp. 947-956, 2013.

[57] J. H. Sokolowski, X. -C. Sun, G. Byczynski, D. O. Northwood, D. E. Penrod, R. Thomas and A. Esseltine, "The removal of copper-phase segregation and the subsequent improvement in mechanical properties of cast 319 aluminium alloys by a two-stage solution heat treatment," Journal of Materials Processing Technology, vol. 53, pp. 385$392,1995$. 
[58] J. H. Sokolowski, M. B. Djurdjevic, C. A. Kierkus and D. O. Northwood, "Improvement of 319 aluminum alloy casting durability by high temperature solution treatment," Journal of Materials Processing Technology, vol. 109, pp. 174-180, 2001.

[59] Y. Han, A. M. Samuel, H. W. Doty, S. Valtierra and F. H. Samuel, "Optimizing the tensile properties of $\mathrm{Al}-\mathrm{Si}-\mathrm{Cu}-\mathrm{Mg}$ 319-type alloys: Role of solution heat treatment," Materials and Design, vol. 58, pp. 426-438, 2014.

[60] M. Tiryakioğlu and J. T. Staley, "Physical metallurgy and the effect of alloying additions in aluminum alloys," in Handbook of Aluminum Volume 7: Physical Metallurgy and Processes, G. E. Totten and D. S. MacKenzie, Eds., New York, Marcel Dekker Inc., 2003, pp. 888-905.

[61] J. W. Martin, Concise encyclopedia of the structure of materials, Oxford, UK: Elsevier, 2007.

[62] W. F. Smith, Structure and properties of engineering alloys, New York: McGraw-Hill, 1981.

[63] W. Kasprzak, D. L. Chen and S. K. Shaha, "Heat treatment development for a rapidly solidified heat resistant cast Al-Si alloy," Journal of Materials Engineering and Performance, vol. 22, pp. 1838-1847, 2013.

[64] S. Shivkumar, C. Keller, M. Trazzera and D. Apelian, "Precipitation hardening in A356 alloys," Production, Refining, Fabrication and Recycling of Light Metals, pp. 264-278, 1990.

[65] L. Lasa and J. M. Rodriguez-Ibabe, "Evolution of the main intermetallic phases in Al-Si$\mathrm{Cu}-\mathrm{Mg}$ casting alloys during solution treatment," Journal of Materials Science, vol. 39, pp. 1343-1355, 2004. 
[66] S. K. Chaudhury and D. Apelian, "Fluidized bed heat treatment of cast Al-Si-Cu-Mg alloys," Metallurgical and Materials Transactions: A, vol. 37A, pp. 2295-2311, 2006.

[67] X. Pan, J. E. Morral and H. D. Brody, "Predicting the Q-phase in Al-Cu-Mg-Si alloys," Journal of Phase Equilibria and Diffusion, vol. 31, pp. 144-148, 2010.

[68] C. Wolverton, " Crystal structure and stability of complex precipitate phases in $\mathrm{Al}-\mathrm{Cu}-$ Mg-(Si) and Al-Zn-Mg alloys," Acta Materialia, vol. 49, pp. 3129-3142, 2001.

[69] J. Schäfer and K. Albe, "Influence of solutes on the competition between mesoscopic grain boundary sliding and coupled grain boundary motion," Scripta Materialia, vol. 66, pp. 315-317, 2012.

[70] W. D. Callister, Jr. and D. G. Rethwisch, Materials Science and Engineering: An Introduction, New York, USA: John Wiley \& Sons, Inc., 2010.

[71] S. K. Shaha, F. Czerwinski, W. Kasprzak and D. L. Chen, "Work hardening and texture during compression deformation of the Al-Si-Cu-Mg alloy modified with $\mathrm{V}, \mathrm{Zr}$ and $\mathrm{Ti}$," Journal of Alloys and Compounds, vol. 593, pp. 290-299, 2014.

[72] W. Kasprzak, D. Emadi, M. Sahoo and M. Aniolek, "Development of aluminium alloys for high temperature applications in diesel engines," Materials Science Forum, Vols. 618-619, pp. 595-600, 2009.

[73] T. Gao, X. Zhu, Q. Sun and X. Liu, "Morphological evolution of ZrAlSi phase and its impact on the elevated-temperature properties of Al-Si piston alloy," Journal of Alloys and Compounds, vol. 567, pp. 82-88, 2013.

[74] K. L. Sahoo and B. N. Pathak, "Solidification behaviour, microstructure and mechanical properties of high Fe-containing Al-Si-V alloys," Journal of Materials Processing Technology, vol. 209, pp. 798-804, 2009. 
[75] S. K. Shaha, F. Czerwinski, W. Kasprzak, J. Friedman and D. L. Chen, "Effect of Zr, V and $\mathrm{Ti}$ on hot compression behavior of the Al-Si cast alloy for powertrain applications," Journal of Alloys and Compounds, vol. 615, pp. 1019-1031, 2014.

[76] S. K. Shaha, F. Czerwinski, W. Kasprzak and D. L. Chen, "Tensile and compressive deformation behavior of the Al-Si-Cu-Mg cast alloy with additions of $\mathrm{Zr}, \mathrm{V}$ and $\mathrm{Ti}$," Materials and Design, vol. 59, pp. 352-358, 2014.

[77] K. E. Knipling, "Development of a nanoscale precipitation-strengthened creep-resistant aluminum alloy containing trialuminide precipitates," Northwestern University, Evanston, IL, 2006.

[78] I. M. Lifshitz and V. V. Slyozov, "The kinetics of precipitation from supersaturated solid solutions," Journal of Physics and Chemistry of Solids, vol. 19, pp. 35-50, 1961.

[79] C. Wagner, "Theory of aging of precipitates by Ostwald ripening," Periodical of Electrochemistry, vol. 65, pp. 581-591, 1961.

[80] H. A. Calderon, P. W. Voorhees, J. L. Murray and G. Kostorz, "Ostwald ripening in concentrated alloys," Acta Metallurgica et Materialia, vol. 42, pp. 991-1000, 1994.

[81] M. E. Fine, "Stability and coarsening of dispersoids in aluminum alloys in dispersion strengthened aluminum alloys (Y-W Kim and W.M Griffith, Eds)," in Light Metals 1988, TMS, Warrendale, 1988.

[82] N. A. Belov, D. G. Eskin and N. N. Avxentieva, " Constituent phase diagrams of the Al$\mathrm{Cu}-\mathrm{Fe}-\mathrm{Mg}-\mathrm{Ni}-\mathrm{Si}$ system and their application to the analysis of aluminium piston alloys," Acta Materialia, vol. 53, pp. 4709-4722, 2005.

[83] V. Raghavan, "Al-Ti-V-Zr (Aluminum-Titanium-Vanadium-Zirconium)," Journal of Phase Equilibria and Diffusion, vol. 26, pp. 639-640, 2005. 
[84] M. Bulanova, L. Tretyachenko, M. Golovkova and K. Meleshevich, "Phase Equilibria in the $\alpha$-Ti-Al-Si Region of the Ti-Si-Al System," Journal of Phase Equilibria and Diffusion, vol. 25, pp. 209-229, 2004.

[85] C. Booth-Morrison, Z. Mao, M. Diaz, D. C. Dunand, C. Wolverton and D. N. Seidman, "Role of silicon in accelerating the nucleation of $\mathrm{Al}_{3}(\mathrm{Sc}, \mathrm{Zr})$ precipitates in dilute $\mathrm{Al}-\mathrm{Sc}$ Zr alloys," Acta Materialia, vol. 60, pp. 4740-4752, 2012.

[86] Y. Li, Y. Yang, Y. Wu, L. Wang and X. Liu, "Quantitative comparison of three Nicontaining phases to the elevated-temperature properties of $\mathrm{Al}-\mathrm{Si}$ piston alloys," Materials Science and Engineering: A, vol. 527, pp. 7132-7137, 2010.

[87] Y. Li, Y. Yang, Y. Wu, Z. Wei and X. Liu, "Supportive strengthening role of Cr-rich phase on Al-Si multicomponent piston alloy at elevated temperature," Materials Science and Engineering: A, vol. 528, pp. 4427-4430, 2011.

[88] J. H. Hollomon, "Tensile deformation," Transactions of the Metallurgical Society of AIME, vol. 162, pp. 268-290, 1945.

[89] Y. Meng, J. Cui, Z. Zhao and Y. Zuo, "Effect of vanadium on the microstructures and mechanical properties of an Al-Mg-Si-Cu-Cr-Ti alloy of 6XXX series," Journal of Alloys and Compounds, vol. 573, pp. 102-111, 2013.

[90] T. V. Atamanenko, D. G. Eskin, M. Sluiter and L. Katgerman, "On the mechanism of grain refinement in Al-Zr-Ti alloys," Journal of Alloys and Compounds, vol. 509, pp. $57-60,2011$.

[91] T. Gao and X. Liu, "Replacement with each other of Ti and Zr in the intermetallics of Al-(Si-)Ti-Zr alloys," Journal of Materials Science and Technology, vol. 29, pp. 291296, 2013. 
[92] N. Q. Vo, D. C. Dunand and D. N. Seidman, "Improving aging and creep resistance in a dilute Al-Sc alloy by micro-alloying with $\mathrm{Si}, \mathrm{Zr}$ and Er," Acta Materialia, vol. 63, pp. 73-85, 2014.

[93] C. L. Chen, A. Richter and R. C. Thomson, "Investigation of mechanical properties of intermetallic phases in multi-component Al-Si alloys using hot-stage nano-indentation," Intermetallics, vol. 18, pp. 499-508, 2010.

[94] S. Ferraro, A. Fabrizi and G. Timelli, "Evolution of sludge particles in secondary diecast aluminum alloys as function of $\mathrm{Fe}, \mathrm{Mn}$ and $\mathrm{Cr}$ contents," Materials Chemistry and Physics, vol. 153, pp. 168-179, 2015.

[95] X. Cao, N. Saunders and J. Campbell, "Effect of iron and manganese contents on convection-free precipitation and sedimentation of primary $\alpha-\mathrm{Al}(\mathrm{FeMn}) \mathrm{Si}$ phase in liquid Al-11.5Si-0.4Mg alloy," Journal of Materials Science, vol. 39, pp. 2303-2314, 2004.

[96] A. M. Mohamed, F. H. Samuel and S. Al-kahtani, "Microstructure, tensile properties and fracture behavior of high temperature Al-Si-Mg-Cu cast alloys," Materials Science and Engineering: A, vol. 577, pp. 64-72, 2013.

[97] H. Westengen, L. Auran and O. Reiso, "Effect of minor additions of transition elements on the recrystallization of some commercial aluminium alloys," Aluminium, vol. 57, pp. 797-821, 1981.

[98] G. H. Deaf, M. H. N. Beshai, A. A. M. El-Khalek, G. Graiss and M. A. Kenawy, "Stabilization effect of $\mathrm{Zr}$ and $\mathrm{Ti}$ additions on the ageing characteristics of $\mathrm{Al}-1 \mathrm{wt} \% \mathrm{Si}$ alloy through a creep study," Crystal Research and Technology, vol. 32, pp. 423-430, 1997. 
[99] S. K. Mukherjee, "Effect of $\mathrm{Zr}$ on 6111 Al-alloy produced by rapid solidification processing (RSP)," Journal of Materials Science Letters, vol. 19, pp. 1107-1110, 2000.

[100] T. Gao, Y. Zhang and X. Liu, "Complex modification effect by ZrAlSi intermetallic and element $\mathrm{Sr}$ on the microstructure and mechanical properties of hypereutectic $\mathrm{Al}-\mathrm{Si}$ alloys," Journal of Alloys and Compounds, vol. 589, pp. 25-28, 2014.

[101] H. A. Elhadari, H. A. Patel, D. L. Chen and W. Kasprzak, "Tensile and fatigue properties of a cast aluminum alloy with $\mathrm{Ti}, \mathrm{Zr}$ and $\mathrm{V}$ additions," Materials Science and Engineering: A, vol. 528, pp. 8128-8138, 2011.

[102] W. Kasprzak, B. S. Amirkhiz and M. Niewczas, "Structure and properties of cast Al-Si based alloy with Zr-V-Ti additions and its evaluation of high temperature performance," Journal of Alloys and Compound, vol. 595, pp. 67-79, 2014.

[103] H. Ye, "An overview of the development of Al-Si-Alloy based material for engine applications," Journal of Materials Engineering and Performance, vol. 12, pp. 288-297, 2003.

[104] M. Krupiński, K. Labisz, Z. Rdzawski and M. Pawlyta, "Cooling rate and chemical composition influence on structure of Al-Si-Cu alloys," Journal of Achievements in Materials and Manufacturing Engineering, vol. 45, pp. 13-22, 2011.

[105] W. Kasprzak, J. H. Sokolowski, H. Yamagata, M. Aniolek and H. Kurita, "Energy efficient heat treatment for liner-less hypereutectic Al-Si engine blocks made using vacuum HPDC process," Journal of Materials Engineering and Performance, vol. 20, pp. 120-132, 2011.

[106] L. He, J. Kang, T. Huang and Y. Rong, "The integrated technique for the heat treatment of aluminium-alloy castings: A review," Heat Treatment of Metals, vol. 31, pp. 69-72, 2004. 
[107] D. L. Zhang, L. H. Zheng and D. H. StJohn, "Effect of a short solution treatment time on microstructure and mechanical properties of modified Al-7wt.\%Si-0.3wt.\%Mg alloy," Journal of Light Metals, vol. 2, pp. 27-36, 2002.

[108] S. Haro, J. Ramirez, D. K. Dwivedi and E. Martinez, "Influence of solutionizing and aging temperatures on microstructure and mechanical properties of cast Al-Si-Cu alloy," Journal of Materials Science and Technology, vol. 25, pp. 886-891, 2009.

[109] M. Tash, F. H. Samuel, F. Mucciardi and H. W. Doty, "Effect of metallurgical parameters on the hardness and microstructural characterization of as-cast and heattreated 356 and 319 aluminum alloys," Materials Science and Engineering: A, vol. 443, pp. 185-201, 2007.

[110] R. N. Lumley, I. J. Polmear and P. R. Curtis, "Rapid heat treatment of aluminum highpressure diecastings," Metallurgical and Materials Transactions: A, vol. 40, pp. 17161726, 2009.

[111] K. L. Fan, G. Q. He, X. S. Liu, B. Liu, M. She, Y. L. Yuan, Y. Yang and Q. Lu, "Tensile and fatigue properties of gravity casting aluminum alloys for engine cylinder heads," Materials Science and Engineering: A, Vols. 78-85, p. 586, 2013.

[112] W. Kasprzak, M. Sahoo, J. Sokolowski, H. Yamagata and H. Kurita, "The effect of the melt temperature and the cooling rate on the microstructure of the Al-20\% Si alloy used for monolithic engine blocks," International Journal of Metal casting, vol. 3, pp. 55-71, 2009.

[113] M. Haghshenas, A. Zarei-Hanzaki and J. Jahazi, "An investigation to the effect of deformation-heat treatment cycle on the eutectic morphology and mechanical properties of a Thixocast A356 alloy," Materials Characterization, vol. 60, pp. 817-823, 2009. 
[114] V. Páramo, R. Colás, E. Velasco and S. Valtierra, "Spheroidization of the Al-Si eutectic in a cast aluminum alloy," Journal of Materials Engineering and Performance, vol. 9, pp. 616-622, 2000.

[115] A. R. Farkoosh, M. Javidani, M. Hoseini, D. Larouch and M. Pekguleryuz, "Phase formation in as-solidified and heat-treated Al-Si-Cu-Mg-Ni alloys: Thermodynamic assessment and experimental investigation for alloy design," Journal of Alloys and Compounds, vol. 551, pp. 596-606, 2013.

[116] S. K. Shaha, F. Czerwinski, W. Kasprzak, J. Friedman and D. L. Chen, "Effect of solidification rate and loading mode on deformation behavior of cast $\mathrm{Al}-\mathrm{Si}-\mathrm{Cu}-\mathrm{Mg}$ alloy with additions of $\mathrm{Zr}, \mathrm{V}$ and Ti," Materials Science and Engineering: A, vol. 636, pp. 361-372, 2015.

[117] G. E. Dieter, Mechanical metallurgy, London, UK: McGraw-Hill Book Company, 1988, pp. 283-284.

[118] M. Garat and G. Laslaz, "Improved aluminum alloys for common rail disel cylinder heads," in AFS Transection 2007, American Foundry society, Schaumburg, IL, USA, 2007.

[119] A. A. Canales, J. Talamantes-Silva, D. Gloria, S. Valtierra and R. Colás, "Thermal analysis during solidification of cast Al-Si alloys," Thermochimica Acta, vol. 510, pp. 82-87, 2010.

[120] S. Farahany, A. Ourdjini, T. A. Abu-Bakar and M. H. Idris, "A new approach to assess the effects of Sr and Bi interaction in ADC12 Al-Si die casting alloy," Thermochimica Acta, vol. 575, pp. 179-187, 2014. 
[121] S. Farahany, M. H. Idris and A. Ourdjini, "Evaluations of antimony and strontium interaction in an Al-Si-Cu-Zn die cast alloy," Thermochimica Acta, vol. 584, pp. 72-78, 2014.

[122] S. G. Shabestaria, M. H. Ghonchehb and H. Momenic, "Evaluation of formation of intermetallic compounds in A12024 alloy using thermal analysis technique," Thermochimica Acta, vol. 589, pp. 174-182, 2014.

[123] E. Ogris, A. Wahlen, H. Lüchinger and P. J. Uggowitzer, "On the silicon spheroidization in Al-Si alloys," Journal of Light Metals, vol. 2, pp. 263-269, 2002.

[124] J. L. Jorstad and D. Apelian, "Hypereutectic Al-Si alloys: practical processing techniques," Die Casting Engineer, vol. 48, pp. 50-55, 2004.

[125] C. H. Cáceres, M. M. Djurdjevic, T. J. Stockwell and J. H. Sokolowski, "The effect of cu content on the level of microporosity in Al-Si-Cu-Mg casting alloys," Scripta Materialia, vol. 40, pp. 631-637, 1999.

[126] M. F. Ibrahim, E. Samuel, A. M. Samuel, A. M. Al-Ahmari and F. H. Samuel, "Metallurgical parameters controlling the microstructure and hardness of $\mathrm{Al}-\mathrm{Si}-\mathrm{Cu}-\mathrm{Mg}$ base alloys," Materials and Design, vol. 32, pp. 2130-2142, 2011.

[127] A. R. Farkoosh, X. Grant-Chen and M. Pekguleryuz, "Dispersoid strengthening of a high temperature Al-Si-Cu-Mg alloy via Mo addition," Materials Science and Engineering: A, vol. 620, pp. 181-189, 2015.

[128] L. Hurtalová, E. Tillová and M. Chalupová, "Identification and analysis of intermetallic phases in age-hardened recycled AlSi9Cu3 cast alloy," The Archive of Mechanical Engineering, vol. 59, pp. 385-396, 2012. 
[129] S. K. Shaha, F. Czerwinski, W. Kasprzak, J. Friedman and D. L. Chen, "Monotonic and cyclic deformation behavior of the Al-Si-Cu-Mg cast alloy with micro-additions of $\mathrm{Ti}, \mathrm{V}$ and Zr," International Journal of Fatigue, vol. 70, pp. 383-394, 2015.

[130] S. K. Shaha, F. Czerwinski, W. Kasprzak, J. Friedman and D. L. Chen, "Thermal stability of (AlSi)x(ZrVTi) intermetallic phases in the Al-Si-Cu-Mg cast alloy with additions of Ti, V, and Zr," Thermochimica Acta, vol. 595, pp. 11-16, 2014.

[131] C. -L. Chen and R. C. Thomson, "The combined use of EBSD and EDX analyses for the identification of complex intermetallic phases in multicomponent Al-Si piston alloys," Journal of Alloys and Compounds, vol. 490, pp. 293-300, 2010.

[132] M. Fiawoo, X. Gao, L. Bourgeois, N. Parson, X. Q. Zhang, J. F. Nie and M. Couper, "Formation of multiple orientation relationships of $\mathrm{Q}$ precipitates in $\mathrm{Al}-\mathrm{Mg}-\mathrm{Si}-\mathrm{Cu}$ alloys," Scripta Materialia, vol. 88, pp. 53-56, 2014.

[133] Y. Yang, K. Yu, Y. Li, D. Zhao and X. Liu, "Evolution of nickel-rich phases in Al-Si$\mathrm{Cu}-\mathrm{Ni}-\mathrm{Mg}$ piston alloys with different $\mathrm{Cu}$ additions," Materials and Design, vol. 33, pp. 220-225, 2012.

[134] O. Reiso, H. Westengen and L. Auran, "Effect of Si additions on precipitation and recrystallization in $\mathrm{Al}-0.18 \mathrm{wt} \% \mathrm{Zr}$ alloys," in Internationale Leichtmetalltagung, Montanuniv Leoben, Austria, 1981.

[135] Y. Himuro, K. Koyama and Y. Bekki, "Precipitation behaviour of zirconium compounds in Zr-bearing Al-Mg-Si alloy," Materials Science Forum, Vols. 519-521, pp. 501-506, 2006.

[136] H. Yamagata, W. Kasprzak, M. Aniolek, H. Kurita and J. H. Sokolowski, "The effect of average cooling rates on the microstructure of the Al-20\% Si high pressure die casting 
alloy used for monolithic cylinder blocks," Journal of Materials Processing Technology, vol. 203, pp. 333-341, 2008.

[137] K. Sukumaran, B. C. Pai and M. Chakraborty, "The effect of isothermal mechanical stirring on an Al-Si alloy in the semisolid condition," Materials Science and Engineering: A, vol. 369, p. 275-283, 2004.

[138] T. N. Blanton, S. Zdzieszynski, M. Nicholas and S. Misture, "An in situ hightemperature X-ray diffraction study of phase transformations in silver behenate," Advances in X-ray Analysis, vol. 48, pp. 27-32, 2005.

[139] H. Möller, G. Govender and W. E. Stumpf, "Application of shortened heat treatment cycles on A356 automotive brake calipers with respective globular and dendritic microstructures," Transactions of Nonferrous Metals Society of China, vol. 20, pp. 1780$1785,2010$.

[140] M. Tiryakioğlu, "The effect of solution treatment and artificial aging on the work hardening characteristics of a cast $\mathrm{Al}-7 \% \mathrm{Si}-0.6 \% \mathrm{Mg}$ alloy," Materials Science and Engineering: A, vol. 427, p. 154-159, 2006.

[141] G. Timelli, O. Lohne, L. Arnberg and H. I. Laukli, "Effect of solution heat treatments on the microstructure and mechanical properties of a die-cast AlSi7MgMn alloy," Metallurgical and Materials Transactions: A, vol. 39, pp. 1747-1758, 2008.

[142] W. Kasprzak, J. H. Sokolowski, H. Yamagata, M. Aniolek and H. Kurita, "Energy efficient heat treatments for hypereutectic Al-Si engine blocks made using vacuum high pressure die-casting," Journal of Materials Engineering and Performance, vol. 20, pp. 120-132, 2011. 
[143] M. A. Hanim, S. C. Chung and O. K. Chuan, "Effect of a two-step solution heat treatment on the microstructure and mechanical properties of 332 aluminium silicon cast alloy," Material and Design, vol. 31, pp. 69-72., 2004.

[144] J. Campbell, "An overview of the effects of bifilms on the structure and properties of cast alloys," Metallurgical and Materials Transactions: B, vol. 37, pp. 857-863, 2006.

[145] Q. G. Wang, "Plastic deformation behavior of aluminum casting alloys A356/357," Metallurgical and Materials Transactions: A, vol. 35, pp. 2707-2718, 2004.

[146] O. R. Myhr, Ø. Grong and K. O. Pedersen, "A combined precipitation, yield strength, and work hardening model for Al-Mg-Si alloys," Metallurgical and Materials Transactions: A, vol. 41A, pp. 2276-2289, 2010.

[147] V. M. J. Sharma, K. S. Kumar, B. N. Rao and S. D. Pathak, "Studies on the workhardening behavior of AA2219 under different aging treatments," Metallurgical and Materials Transactions: A, vol. 40, pp. 3186-3195, 2009.

[148] L. M. Cheng, W. J. Poole, J. D. Embury and D. J. Lloyd, "The influence of precipitation on the work-hardening behavior of the aluminum alloys AA6111 and AA7030," Metallurgical and Materials Transactions: A, vol. 34, pp. 2473-2481, 2003.

[149] S. Esmaeili, X. Wang, D. J. Lloyd and W. J. Poole, "On the precipitation-hardening behavior of the $\mathrm{Al}-\mathrm{Mg}-\mathrm{Si}-\mathrm{Cu}$ alloy AA6111," Metallurgical and Materials Transactions: A, vol. 34A, pp. 751-763, 2003.

[150] J. Røyset, N. Ryum, D. Bettella, A. Tocco, Z. Jia, J. K. Solberg and O. Reiso, "On the addition of precipitation- and work-hardening in an Al-Sc alloy," Materials Science and Engineering: A, vol. 483-484, p. 175-178, 2008.

[151] W. A. Curtin, "New interpretation of the Haasen plot for solute-strengthened alloys," Scripta Materialia, vol. 63, pp. 917-920, 2010. 
[152] C. V. Singh, A. J. Mateos and D. H. Warner, "Atomistic simulations of dislocationprecipitate interactions emphasize importance of cross-slip," Scripta Materialia, vol. 64, pp. 398-401, 2011.

[153] N. F. Mott, "Dislocation, work-hardening and creep," Nature, vol. 175, pp. 365-367, 1955.

[154] B. Devincre, T. Hoc and L. Kubin, "Dislocation mean free paths and strain hardening of crystals," Science, vol. 320, pp. 1745-1748, 2008.

[155] H. Conrad, S. Feuerstein and L. Rice, "Effects of grain size on the dislocation density and flow stress of niobium," Materials Science and Engineering, vol. 2, p. 157-168, 1967.

[156] N. F. Mott, "The 1960 institute of metals lecture: the work hardening of metals," Transactions of the Metallurgical Society of AIME, vol. 218, pp. 961-968, 1960.

[157] A. J. Bushby and D. J. Dunstan, "Size effects in yield and plasticity under uniaxial and non-uniform loading: experiment and theory," Philosophical Magazine: A, vol. 91, pp. 1037-1049, 2011.

[158] Q. G. Wang, "Microstructural effects on the tensile and fracture behavior of aluminum casting alloys A356/357," Metallurgical and Materials Transaction: A, vol. 34, pp. 2887$2899,2003$.

[159] X. Hou and N. M. Jennett, "Application of a modified slip-distance theory to the indentation of single-crystal and polycrystalline copper to model the interactions between indentation size and structure size effects," Acta Materialia, vol. 60, pp. 41284135, 2012.

[160] S. Saimoto and D. J. Lloyd, "A new analysis of yielding and work hardening in AA1100 and AA5754 at low temperatures," Acta Materialia, vol. 60, pp. 6352-6361, 2012. 
[161] H. Agarwal, A. M. Gokhale FASM, S. Graham and M. F. Horstemeyer, "Quantitative characterization of three-dimensional damage evolution in a wrought Al-alloy under tension and compression," Metallurgical and Materials Transactions: A, vol. 33, pp. 2599-2606, 2002.

[162] H. Agarwal, A. M. Gokhale, S. Graham and M. F. Horstemeyer, "Anisotropy of intermetallic particle cracking damage evolution in an Al-Mg-Si base wrought aluminum alloy under uniaxial compression," Metallurgical and Materials Transactions: A, vol. 33, pp. 3443-3448, 2002.

[163] M. D. Dighe, A. M. Gokhale and M. F. Horstemeyer, "Effect of loading condition and stress state on damage evolution of silicon particles in an Al-Si-Mg-base cast alloy," Metallurgical and Materials Transactions: A, vol. 33, pp. 555-565, 2002.

[164] W. J. Poole and E. J. Dowdle, "Experimental measurements of damage evolution in AlSi eutectic alloys," Scripta Materialia, vol. 39, pp. 1281-1287, 1998.

[165] M. R. Daymond, C. Hartig and H. Mecking, "Interphase and intergranular stress generation in composites exhibiting plasticity in both phases," Acta Materialia, vol. 53, pp. 2805-2813, 2005.

[166] U. F. Kocks and H. Mecking, "Physics and phenomenology of strain hardening: the FCC case," Progress in Materials Science, vol. 48, pp. 171-273, 2003.

[167] A. D. Rollett and U. F. Kocks, "A review of the Stages of work hardening," Solid State Phenomena, Vols. 35-36, pp. 1-18, 1993.

[168] L. Lecarme, C. Tekoglu and T. Pardoen, "Void growth and coalescence in ductile solids with stage III and stage IV strain hardening," International Journal of Plasticity, vol. 27, pp. 1203-1223, 2011. 
[169] A. Deschamps, S. Esmaeili, W. J. Poole and M. Militzer, "Strain hardening rate in relation to microstructure in precipitation hardening materials," Journal of Physics IV France, vol. 10, pp. 151-56, 2000.

[170] H. Mecking and U. F. Kocks, "Kinetics of flow and strain-hardening," Acta Metallurgica, vol. 29, pp. 1865-1875, 1981.

[171] Y. Estrin, "Dislocation density-related constitutive modeling," in Unified Constitutive Law of Plastic Deformation, New York, NY: Academic Press, pp. 69-106, 1996.

[172] G. I. Taylor, "Plastic strain in metals," Journal of the Institute of Metals, vol. 62, pp. 307-324, 1938.

[173] C. Cui, A. Schulz, J. Epp and H. W. Zoch, "Deformation behavior of spray-formed hypereutectic Al-Si alloys," Journal of Materials Science, vol. 45, pp. 2798-2807, 2010.

[174] J. Zhang, B. Chen and B. Zhang, "Effect of initial microstructure on the hot compression deformation behavior of a 2219 aluminum alloy," Materials and Design, vol. 34, pp. 15$21,2012$.

[175] L. D. Nguyen and D. H. Warner, "Improbability of void growth in aluminum via dislocation nucleation under typical laboratory conditions," Physical Review Letter, vol. 108, pp. 035501-1-5, 2012.

[176] A. N. Stroh, "A theoretical calculation of the stored energy in a work-hardened material," Proceedings of the Royal Society of London. Series A, Mathematical and Physical, vol. 218, pp. 391-400, 1953.

[177] P. Feltham and J. D. Meakin, "On the mechanism of work hardening in face-centred cubic metals, with special reference to polycrystalline copper," Philosophical Magazine, vol. 2, pp. 10-112, 1957. 
[178] L. B. Brown, "A brief response to Intermittent plastic flow of single crystals: central problems in plasticity: a review, by M. Niewczas," Materials Science and Technology, vol. 30, pp. 758-758, 2014.

[179] M. Niewczas, "Intermittent plastic flow of single crystals: central problems in plasticity: a review," Materials Science and Technology, vol. 30, pp. 739-757, 2014.

[180] M. Huang, P. E. Rivera-Díaz-del-Castillo, O. Bouaziz and S. Van-der-Zwaag, "Modelling strength and ductility of ultrafine grained BCC and FCC alloys using irreversible thermodynamics," Materials Science and Technology, vol. 25, pp. 833-839, 2009.

[181] M. Huang, P. E. Rivera-Díaz-del-Castillo, O. Bouaziz and S. Van-der-Zwaag, "Irreversible thermodynamics modelling of plastic deformation of metals," Materials Science and Technology, vol. 24, pp. 495-500, 2008.

[182] M. Huang, P. E. Rivera-Díaz-del-Castillo, O. Bouaziz and S. van-der-Zwaag, "Modelling plastic deformation of metals over a wide range of strain rates using irreversible thermodynamics," IOP Conf. Series: Materials Science and Engineering, vol. 3, pp. 012006-11, 2009.

[183] E. I. Galindo-Nava and P. E. Rivera-Díaz-del-Castillo, "A thermostatistical theory of low and high temperature deformation in metals," Materials Science and Engineering: A, vol. 543, pp. 110- 116, 2012.

[184] C. Shi, J. Lai and X. -G. Chen, "Microstructural evolution and dynamic softening mechanisms of Al-Zn-Mg-Cu alloy during hot compressive deformation," Materials, vol. 7, pp. 244-264, 2014. 
[185] M. Haghshenas, A. Z. Hanzaki and S. M. Varzaneh, "Hot deformation behavior of thixocast A356 aluminum alloy during compression at elevated temperature," International Journal of Material Forming, vol. 1, pp. 1001-1005, 2008.

[186] N. F. Mott, "CXVII. A theory of work-hardening of metal crystals," Philosophical Magazine, vol. 43, pp. 1151-1178, 1952.

[187] H. Dong and A. W. Thompson, "The effect of grain size and plastic strain on slip length in 70-30 brass," Metallurgical Transactions: A, vol. 16, pp. 1025-1030, 1985.

[188] L. W. Meyer, "Constitutive equations at high strain rates," in Shock Waves and High Strain-Rate Phenomena in Materials, M. A. Meyers, L. E. Murr and K. P. Staudhammer, Eds., New York, Marcel Dekker, 1992, pp. 49-67.

[189] H. Kobayashi and B. Dodd, "A numerical analysis for the formation of adiabatic shear bands including void nucleation and growth," International Journal of Impact Engineering, vol. 8, pp. 1-13, 1989.

[190] A. Fawzy, A. S. Awadallah, M. Sobhy and G. Saad, "Precipitation kinetics in quenched and slowly cooled Pb-1.5 wt\% Sb alloy specimens," Physica B: Condensed Matter, vol. 355, pp. 286-294, 2005.

[191] E. M. Sakr, M. R. Nagy and A. S. Mahmoud, "Effect of microstructural variations developed by heat treatment on the mechanical and electrical properties of ( $\mathrm{Pb}-1.5 \mathrm{wt} \%$ Sb)," Egyptian Journal of Solids, vol. 29, pp. 81-99, 2006.

[192] M. M. El-Sayed, F. Abd El-Salam and R. Abd El-Haseeb, "Effect of structure transformation on the work hardening characteristics of lead-based bearing alloys," Physica Status Solidi (a), vol. 147, pp. 401-407, 1995. 
[193] B. P. Kashyap and G. S. Murty, "Experimental constitutive relations for the high temperature deformation of a Pb-Sn eutectic alloy," Materials Science and Engineering, vol. 50, pp. 205-213, 1981.

[194] F. Abd El-Salam, A. M. Abd El-Khalek, R. H. Nada, L. A. Wahab and H. Y. Zahran, "Thermally induced structural and mechanical variations in ternary Al-Si based alloys," Materials Science and Engineering: A, vol. 527, pp. 281-286, 2009.

[195] M. A. Mahmoud, M. Sobhy, A. F. Abd El-Rehim, and R. M. Abdel Rahman, "The variation of work hardening characteristics of $\mathrm{Al}-5 \mathrm{wt} \% \mathrm{Mg}$ alloy during phase transition," Physica B: Condensed Matter, vol. 405, pp. 3616-3623, 2010.

[196] E. M. Taleff and P. J. Nevland, "The high-temperature deformation and tensile ductility of Al alloys," JOM, vol. 51, pp. 34-36, 1999.

[197] N. Anjabin and A. K. Taheri, "Microstructure based modelling of flow behaviour of AlMg-Si alloy at different temper conditions," Materials Science and Technology, vol. 29, pp. 968-974, 2013.

[198] Q. Luo, Q. Li, J. -Y. Zhang, S. -L. Chen and K. -C. Chou, "Experimental investigation and thermodynamic calculation of the Al-Si-Ti system in Al-rich corner," Journal of Alloys and Compounds, vol. 602, pp. 58-65, 2014.

[199] M. Warmuzek, "Chemical composition of the Ni-containing intermetallic phases in the multicomponent Al alloys," Journal of Alloys and Compounds, vol. 604, pp. 245-252, 2014.

[200] A. Gorny, J. Manickaraj, Z. Cai and S. Shankar, "Evolution of Fe based intermetallic phases in Al-Si hypoeutectic casting alloys: influence of the $\mathrm{Si}$ and $\mathrm{Fe}$ concentrations, and solidification rate," Journal of Alloys and Compounds, vol. 577, p. 103-124, 2013. 
[201] Y. -D. Jia, F. -Y. Cao, Z. -L. Ning, X. -B. Sun and J. -F. Sun, "Hot deformation behavior of spray formed Al-22Si-5Fe-3Cu-1Mg alloy," Transaction of Nonferrous Metal Society of China, vol. 21, pp. s299-s303, 2011.

[202] Y. C. Lin and X. -M. Chen, "Effects of deformation temperatures on stress/strain distribution and microstructure evolution of deformed 42CrMo steel," Materials and Design, vol. 32, pp. 1733-1759, 2011.

[203] M. R. Rokni, A. Zarei-Hanzaki, A. A. Roostaei and A. Abolhasani, "Constitutive base analysis of a 7075 aluminum alloy during hot compression testing," Materials and Design, vol. 32, pp. 4955-4960, 2011.

[204] J. Li, F. Li, J. Cai, R. Wang, Z. Yuan and X. Xue, "Flow behavior modeling of the 7050 aluminum alloy at elevated temperatures considering the compensation of strain," Materials and Design, vol. 42, pp. 369-377, 2012.

[205] S. Spigarelli, E. Evangelista and H. J. McQueen, "Study of hot workability of a heat treated AA6082 aluminum alloy," Scripta Materialia, vol. 49, pp. 179-183, 2003.

[206] N. Jin, H. Zhang, Y. Han, W. Wu and J. Chen, "Hot deformation behavior of 7150 aluminum alloy during compression at elevated temperature," Materials Characterization, vol. 60, pp. 530-536, 2009.

[207] L. M. Dougherty, I. M. Robertson and J. S. Vetrano, "Direct observation of the behavior of grain boundaries during continuous dynamic recrystallization in an $\mathrm{Al}-4 \mathrm{Mg}-0.3 \mathrm{Sc}$ alloy," Acta Materialia, vol. 51, pp. 4367-4378, 2003.

[208] H. Agarwal, A. M. Gokhale, S. Graham, M. F. Horstemeyer and D. J. Bamman, "Rotations of brittle particles during plastic deformation of ductile alloys," Materials Science and Engineering: A, vol. 328, pp. 310-316, 2002. 
[209] Y. C. Lin, M. -S. Chen and J. Zhong, "Effects of deformation temperatures on stress/strain distribution and microstructural evolution of deformed 42CrMo steel," Matererials and Design, vol. 30, pp. 908-913, 2009.

[210] H. R. R. Ashtiani, H. Bisadi and M. H. Parsa, "Influence of thermomechanical parameters on the hot deformation behavior of AA1070," Journal of Engineering Materials and Technology, vol. 136, pp. 011004:1-5, 2014.

[211] . H. J. McQueen, S. Spigarelli, M. Kassner and E. Evangelista, Hot deformation and processing of aluminum alloys, Boca Raton, FL, USA: CRC Press, 2011.

[212] F. J. Humphreys and M. Hatherly, in Recrystallization and related annealing phenomena, Oxford, UK, Elsevier Ltd., 2004, pp. 11-450.

[213] S. Gourdet and F. Montheillet, "An experimental study of the recrystallization mechanism during hot deformation of aluminium," Materials Science and Engineering: A, vol. 283, pp. 274-288, 2000.

[214] H. Ahamed and V. Senthilkumar, "Prediction of flow stress during hot deformation of MA'ed hybrid aluminium nanocomposite employing artificial neural network and Arrhenius constitutive model," Multidiscipline Modeling in Materials and Structures, vol. 8, pp. 136-158, 2012.

[215] C. Wang, F. Yu, D. Zhao, X. Zhao and L. Zuo, "Hot deformation and processing maps of DC cast Al-15\%Si alloy," Materials Science and Engineering: A, vol. 577, pp. 73-80, 2013.

[216] R. D. Doherty, H. A. Hughes, F. J. Humphreys, J. J. Jonas, D. J. Jensen, M. E. Kassner, W. E. King, T. R. McNelley, H. J. McQueen and A. D. Rollett, "Current issues in recrystallization: a review," Materials Science and Engineering: A, vol. 238, pp. 219274, 1997. 
[217] H. Yang, Z. -H. Li and Z. -L. Zhang, "Investigation on Zener-Hollomon parameter in the warm-hot deformation behavior of 20CrMnTi," Journal of Zhejiang University Science: A, vol. 7, pp. 1453-1460, 2006.

[218] F. Jiang, H. Zhang, X. Ji, X. Meng and L. Li, "Comparative hot deformation characters of Al-Mn-Mg-RE alloy and Al-Mn-Mg-RE-Ti alloy," Materials Science and Engineering: A, vol. 595, p. 10-17, 2014.

[219] M. F. Horstemeyer, J. Lathrop, A. M. Gokhale and M. Dighe, "Modeling stress state dependent damage evolution in a cast Al-Si-Mg aluminum alloy," Theoretical and Applied Fracture Mechanics, vol. 33, pp. 31-47, 2000.

[220] A. Balasundaram, Z. Shan, A. M. Gokhale, S. Graham and M. F. Horstemeyer, "Particle rotations during plastic deformation of 5086 aluminum alloy," Materials Characterizations, vol. 48, pp. 363-69, 2002.

[221] A. R. Farkoosh, X. G. Chen and M. Pekguleryuz, "Interaction between molybdenum and manganese to form effective dispersoids in an Al-Si-Cu-Mg alloy and their influence on creep resistance," Materials Science and Engineering: A, vol. 627, pp. 127-138, 2015.

[222] A. R. Emami, S. Begum, D. L. Chen, T. Skszek, X. P. Niu, Y. Zhang and F. Gabbianelli, "Cyclic deformation behavior of a cast aluminum alloy," Materials Science and Engineering: A, vol. 516, pp. 31-41, 2009.

[223] E.-S. Y. El-Kady, ,. T. S. Mahmoud and M. A.-A. Sayed, "Elevated temperatures tensile characteristics of cast A356/A12O3 nanocomposites fabricated using a combination of rheo-casting and squeeze casting techniques," Materials Sciences and Applications, vol. 2, pp. 390-398, 2011. 
[224] A. M. Samuel, J. Gauthier and F. H. Samuel, "Microstructural aspects of the dissolution and melting of $\mathrm{Al} 2 \mathrm{Cu}$ phase in $\mathrm{Al}-\mathrm{Si}$ alloys during solution heat treatment," Metallurgical and Materials Transactions: A, vol. 27, pp. 1785-1798, 1996.

[225] M. Tiryakioğlu, J. Campbell and N. D. Alexopoulos, "Quality indices for aluminum alloy castings: a critical review," Metallurgical and Materials Transactions: B, vol. 40, pp. 802-811, 2009.

[226] P. Cavaliere and P. P. De Marco, "Friction stir processing of a Zr-modified 2014 aluminium alloy," Materials Science and Engineering: A, vol. 462, pp. 206-210, 2007.

[227] S. Spigarelli, M. Cabibbo, E. Evangelista and J. Bidulská, "A study of the hot formability of an Al-Cu-Mg-Zr alloy," Journal of Materials Science, vol. 38, pp. 81-88, 2003.

[228] N. Afrin, D. L. Chen, X. Cao and M. Jahazi, "Strain hardening behavior of a friction stir welded magnesium alloy," Scripta Materialia, vol. 57, pp. 1004-1007, 2007.

[229] X. Chen, F. Pan, J. Mao, J. Wang and D. Zhang, "Effect of heat treatment on strain hardening of ZK60 Mg alloy," Materials and Design, vol. 32, pp. 1526-1530, 2011.

[230] S. K. Shaha, F. Czerwinski, D. L. Chen and W. Kasprzak, "Dislocation slip distance during compression of Al-Si-Cu-Mg alloy with additions of Ti-Zr-V," Materials Science and Technology, vol. 31, pp. 63-72, 2015.

[231] P. A. Rometsch and G. B. Schaffer, "An age hardening model for Al-7Si-Mg casting alloys," Materials Science and Engineering: A, vol. 325, pp. 424-434, 2002.

[232] Q. G. Wang, C. H. Caceres and J. R. Griffiths, "Damage by eutectic particle cracking in aluminum casting alloys A356/357," Metallurgical and Materials Transactions: A, vol. 34A, pp. 2901-2912, 2003. 
[233] Q. G. Wang, D. Apelian and D. A. Lados, "Fatigue behavior of A356/357 aluminum cast alloys. Part II - Effect of microstructural constituents," Journal of Light Metals, vol. 1, pp. 85-97, 2001.

[234] W. F. Hosford, "Fatigue," in Mechanical Behavior of Materials, New York, Cambridge University Press, 2005, pp. 279-307.

[235] M. S. Song, Y. Y. Kong, M. W. Ran and Y. C. She, "Cyclic stress-strain behavior and low cycle fatigue life of cast A356 alloys," International Journal of Fatigue, vol. 33, pp. 1600-1607, 013.

[236] Q. G. Wang, D. Apelian and D. A. Lados, "Fatigue behavior of A356-T6 aluminum cast alloys. Part I. Effect of casting defects," Journal of Light Metals, vol. 1, pp. 73-84, 2001.

[237] H. R. Ammar, A. M. Samuel and F. H. Samuel, "Porosity and the fatigue behavior of hypoeutectic and hypereutectic aluminum-silicon casting alloys," International Journal of Fatigue, vol. 30, pp. 1024-1035, 2008.

[238] Q. G. Wang, P. N. Crepeau, C. J. Davidson and J. R. Griffiths, "Oxide films, pores and the fatigue lives of cast aluminum alloys," Metallurgical and Materials Transactions: B, vol. 37, pp. 887-895, 2006.

[239] J. B. Jordon, M. F. Horstemeyer, N. Yang, J. F. Major, K. A. Gall, J. Fan and D. L. McDowell, "Microstructural inclusion influence on fatigue of a cast A356 aluminum alloy," Metallurgical and Materials Transactions: A, vol. 41, pp. 356-363, 2010.

[240] M. Okayasu, R. Sato, S. Takasu, A. Niikura and T. Shiraishi, "Mechanical properties of $\mathrm{Al}-\mathrm{Si}-\mathrm{Cu}$ alloys produced by the twin rolled continuous casting process," Materials Science and Engineering: A, vol. 534, pp. 614-623, 2012. 
[241] L. Wei, Q. Pan, H. F. Huang, L. Feng and Y. Wang, "Influence of grain structure and crystallographic orientation on fatigue crack propagation behavior of 7050 alloy thick plate," International Journal of Fatigue, vol. 66, pp. 55-64, 2014.

[242] S. Kobayashi, T. Maruyama, S. Tsurekawa and T. Watanabe, "Grain boundary engineering based on fractal analysis for control of segregation-induced intergranular brittle fracture in polycrystalline nickel," Acta Materialia, vol. 60, pp. 6200-6212, 2012.

[243] T. O. Mbuya, I. Sinclair, A. J. Moffat and P. A. Reed, "Micro-mechanisms of fatigue crack growth in cast aluminium piston alloys," International Journal of Fatigue, vol. 42, pp. 227-237, 2012. 